\title{
Design of Highwall Mining Equipment Electronic Guidance Package
}

\author{
B. B. Brenden \\ G. P. Morgen \\ J. R. Skorpik
}

November 1981

Prepared for the U.S. Department of Energy

under Contract DE-AC06-76RLO 1830

Pacific Northwest Laboratory

Operated for the U.S. Department of Energy

by Battelle Memorial Institute 


\title{
NOTICE
}

This report was prepared as an account of work sponsored by the United States Government. Neither the United States nor the Department of Energy, nor any of their employees, nor any of their contractors, subcontractors, or their employees, makes any warranty, express or implied, or assumes any legal liability or responsibility for the accuracy. completeness or usefulness of any information, apparatus. product or process disclosed, or represents that its use would not infringe privately owned rights.

The views. opinions and conclusions contained in this report are those of the contractor and do not necessarily represent those of the United States Government or the United States Department of Energy.

PACIFIC NORTHWEST LABORATORY

operated by

BATTELLE

for the

UNITED STATES DEPARTMENT OF ENERGY

Under Contract DE-AC06-76RLO 1830

\author{
Printed in the United States of America \\ Available from \\ National Technical Information Service \\ United States Department of Commerce \\ 5285 Port Royal Road \\ Springfield, Virginia 22151
}

Price: Printed Copy $\mathbf{s}$

$\because$ Microfiche $\$ 3.00$

NTIS

-Pages Selling Price

$\begin{array}{ll}001-025 & \$ 4.00 \\ 026-050 & \$ 4.50 \\ 051-075 & \$ 5.25 \\ 076-100 & \$ 6.00 \\ 101-125 & \$ 6.50 \\ 126-150 & \$ 7.25 \\ 151-175 & \$ 8.00 \\ 176-200 & \$ 9.00 \\ 201-225 & \$ 9.25 \\ 226-250 & \$ 9.50 \\ 251-275 & \$ 10.75 \\ 276-300 & \$ 11.00\end{array}$


B.B. Brenden

G.P. Morgen

J.R. Skorpik

Richard Farrar(a)

November 1981

Prepared for

the Division of Fossil Fuel Extraction of

the U.S. Department of Energy

under Contract DE-AC06-76RLO 1830

Pacific Northwest Laboratory

Richland, Washington 99352

(a) Technical contact with Carbondale Mining Research Center, Carbondale, IL 


\section{ABSTRACT}

This report provides design specifics and guidance software for a guidance system intended for use in guiding an auger type highwall mining head through thin coal seams to depths of up to $600 \mathrm{ft}$. A small desk top computer is used at the operator's station to send and receive signals in serialized bit streams to a downhole microprocessor. The guidance system accepts signals from a variety of sensors, and uses these signals to plot and control the course of the auger head automatically using computer algorithms designed to keep the auger head in the coal seam and maintain a specified stump thickness

Key Words: Highwall Mining, Auger Machine, Radar Sensors, Steerable Cutterhead, Coal Thickness Measurement, Coal/Rock Interface Detector, Extended Depth Auger, Thin Seam Coal, Auger Tools, Guidance and Controls, Natural Gamma Coal Thickness Sensor 

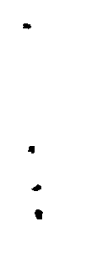


\section{EXECUTIVE SUMMARY}

The work reported in this document was undertaken with the purpose of making the mining of coal from thin seams economically feasible. Efficient mining of this coal using an auger type machine depends upon accurate guidance of the auger head to maintain its course within the coal seam. Sensors for detecting the roof and the floor of the coal seam are essential to achieve remote guidance. Two types of sensors had been identified prior to the work reported here. One was based upon radar techniques. The other was based upon measuring the natural gamma activity of the host rock. It was not the purpose of our work to specify the type of roof or floor sensor to be used. The purpose of our effort was to design an automatic electronic guidance control system. The scope of the work included the identification of specific devices to sense pitch, roll, torque, thrust and horizontal heading. It included the design of an electronic system to gather the sensor data and to transmit the data in a single serialized digital bit stream to a surface electronic controller. It included specifying a computer which would use the data to calculate guidance instructions and create displays to keep an operator informed. Algorithms and software for accomplishing the guidance task have also been developed.

The starting point for the work reported here was the report (June 13, 1977) of work carried out by R.A. Hansen Co., Spokane, HA 99206 for the Bureau of Mines under contract HO 262033.

The system breaks naturally into two subsystems, the surface electronic controller (SEC) and the remote electronic package (REP). An HP9825T desk top computer is recommended as the main element of the SEC. Peripheral equipment including a multiprogrammer, a video monitor, an extra tape memory and meters are identified which fulfill all the requirements of the SEC.

A microprocessor (Intel 8748 ) is used together with a DAS-952R (Datel) data aquisition system as the basis for the REP. Design drawings of the system circuitry are included in this report. 
The next step in implementing the program to achieve an extended depth auger mining system is to purchase the equipment and components herein identified, assemble them into an integrated system, test and fully validate the system operation. The guidance system would then be ready for installation on a suitably designed auger head and for testing and refinement under operating conditions. The computer equipment for the SEC including meters and console would currently cost about $\$ 45 \mathrm{~K}$. The cost of the REP lies primarily in the sensors which including radar for rib thickness measurement, two natural gamma sensors and a gyro system would cost approximately $\$ 165 \mathrm{~K}$. 


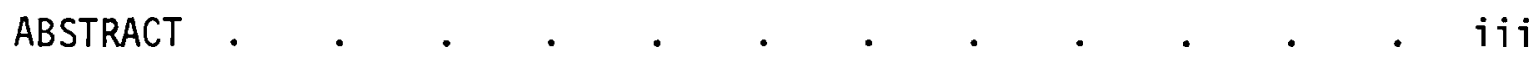

EXECUTIVE SUMMARY

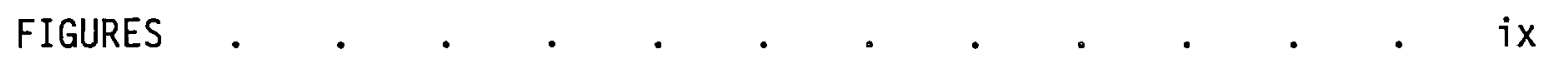

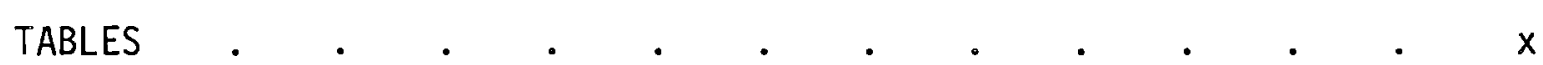

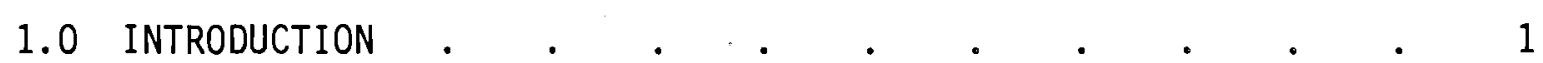

2.0 GUIDANCE SYSTEM DESIGN

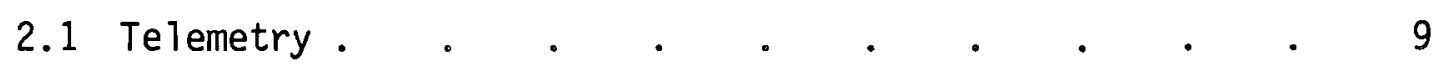

2.2 Guidance Displays . . . . . . . . . . . . 10

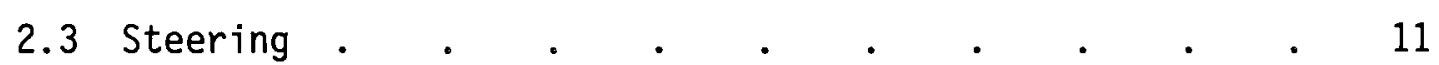

2.4 Electrical $\quad . \quad$. $\quad . \quad$.

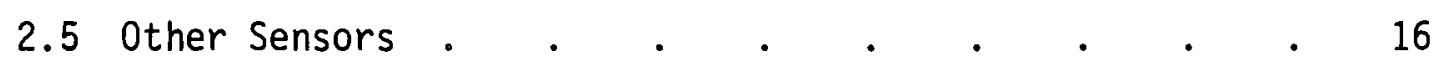

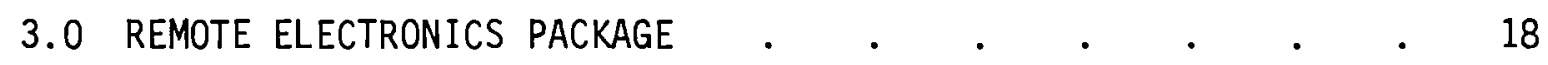

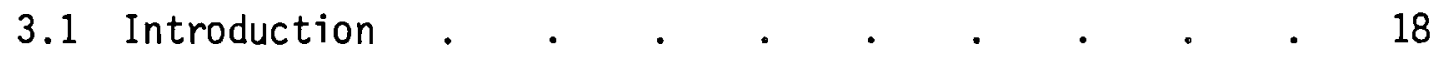

3.2 Data Acquisition/Control Circuitry . . . . . 20

3.3 Instruments and Signal Conditioning . . . . . 20

3.3.1 Torque/Thrust Measurement . . . . . 20

3.3.2 Pitch/Rol1 Measurement. . . . . . 20

3.3.3 Cylinder Displacement Measurement _ . . $\quad$. 22

3.3.4 Roof, Floor, and Rib Measurement . . . . 22

3.3.5 Signal Conditioning . . . . . . . . 23

3.3.6 Intrinsically Safe Power . . . . . 23

4.0 SURFACE ELECTRONIC CONTROLLER (SEC) . • • • • • • • 26

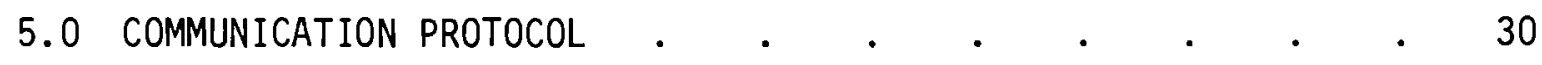

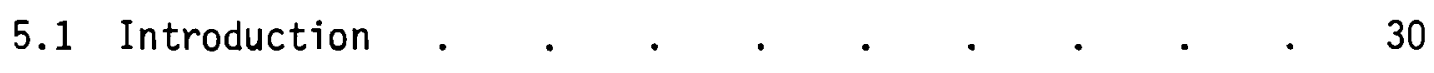

5.2 General Information . . . . . . . . . 30 
CONTENTS (contd)

5.3 Messages from SEC to REP . . . . . . . . 30

5.4 Messages from REP to SEC . . . . . . . . . . 31

5.5 Control Messages . . . . . . . . . . 31

5.6 Microprocessor Flow Chart . . . . . . 31

6.0 GUIDANCE PHILOSOPHY . . . . . . . . . . . 33

6.1 Introduction . . . . . . . . . . . . 33

6.2 Vertical Guidance . . . . . . . . . . 33

6.3 Horizontal Guidance. . . . . . . . . 36

6.4 Rol1 Correction . . . . . . . . . 40

6.5 Guidance Commands . . . . . . . . . . 42

6.6 MUX Channel Assignments . . . . . . . . . . 42

7.0 SUMMARY AND CONCLUSIONS . . . . . . . . . . . . 47

APPENDIX A - DATA SHEETS FOR THE REMOTE ELECTRONICS PROCESSOR (REP)

APPENDIX B - DATA SHEETS FOR SURFACE ELECTRONICS PROCESSOR (SEC)

APPENDIX C - GUIDANCE PROGRAM FOR HP9825T

APPENDIX D - PROGRAM FOR SIMULATED RUNS-VERTICAL PLOT

APPENDIX E - PROGRAM FOR SIMULATED FUNS-HORIZONTAL PLOT

APPENDIX $F$ - LIST OF SYMBOLS USED IN THE GUIDANCE SOFTWARE

APPENDIX G - FLOW CHART FOR GUIDANCE PROGRAM (APPENDIX C) 


\section{FIGURES}

1. Impulse Radar Measuring Rib Thickness Between Adjacent Holes 3

2. High Wall Auger Mining Machine . . . . . . 6

3. Diagram of Telemetry System . . . . . . . . 7

4. Anticipation Target Geometry . . . . . . . . 12

5. Diagram of Guidance Display . . . . . . . 13

6. Cutterhead and Guidance Assembly Showing Steering Mechanism . 14

7. Steering Mechanism's Hydraulic Cylinder and Electromechanical Position Indicator . . . . . . . . . . 15

8. Typical Steering Hydraulic Circuit . . . . . . 17

9. Block Diagram of the Remote Electronics Package . . . 19

10. Schematic Diagram of the Data Acquisition and Control Circuitry. . . . . . . . . . . 21

11. Details of the Signal Conditioning Circuits . . . . 24

12. Schematic of Power Unit . . . . . . . . 25

13. Current Specification of Telementry System . . . . 27

14. Internal Configuration of the Guidance Console . . . 28

15. Layout of Operator's Control Panel . . . . . . 29

16. Downhole Microprocessor Flow Chart for Controlling the
A/D Acquisition Chip (Datel DAS-952R) . . 32

17. A Schematic Representation of the Cutterhead Course with
Exaggerated Angular Deflections . . . . . 35

18. Diagram Illustrating the Relationship of the LVDT Reading S[9] to the Radius of Curvature R of the Course of the Auger . 38

19. Plan View of Cutterhead . . . . . . . . . 39

20. Diagram Illustrating the Recursion Formula for Calculating the Horizontal Coordinate $\mathrm{X}[2, \mathrm{~K}]$. . . . . . . 41

21. Schematic Drawing Labeling the Six Thrust Pads Used for
Steering the Cutterhead. Viewed from SEC location. . 43

22. Multiplex Channel Assignments . . . . . . . 47 


\section{FIGURES (contd)}

D.1 Simulation Run-First Hole-Vertical .

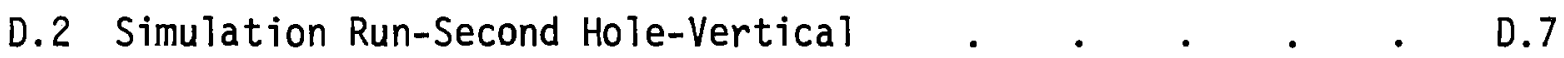

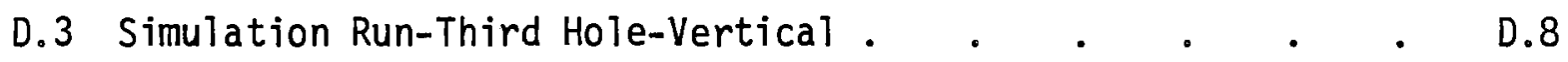

E.1 Simulation Run-1st and 2nd Hole-Horizontal . . . . E.5

\section{TABLES}

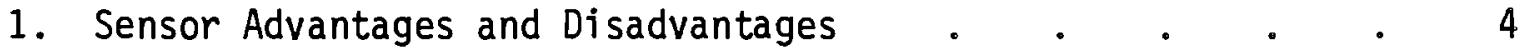

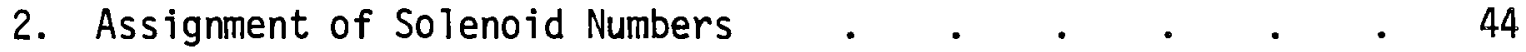

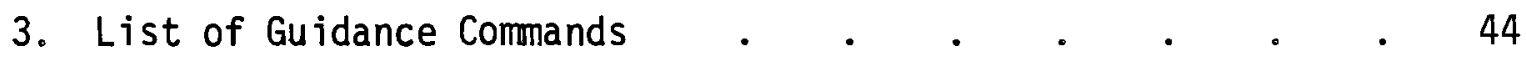

4. Solenoids Activated for Each Command Word . . . . $\quad$. 45 
DESIGN OF HIGHWALL MINING EQUIPMENT ELECTRONIC GUIDANCE PACKAGE 


\section{DESIGN OF HIGHWALL MINING EQUIPMENT}

\section{ELECTRONIC GUIDANCE PACKAGE}

\subsection{INTRODUCTION}

A substantial portion of the U.S. coal reserve lies in seams less than 36 inches thick. In order to mine this coal it will be necessary to develop machines and systems which expand coal recovery beyond the highwall limits of contour and open pit mines. One current technique, with potential to recover coal beyond the highwall, uses the auger machine. Historically, auger mining has accounted for a very small percentage of coal mined. The reasons for its limited use vary, but the two primary limitations of the mining method are the inability to keep the cutter in the coal seam, and the difficulty of maintaining a heading so holes can be kept close together with a minimum rib support. All of the auger mining techniques advantages are offset by these limitations.

The design of an auger machine which overcomes these limitations was addressed by R.A. Hanson, Inc. under Contract H0262033 from the Bureau of Mines. A summary of their work was given in a two volume report dated June 1977. Some idea of the contents of this report can be gained from the abstract taken from the report documentation page and repeated below.

"[The] report describes the work done to develop a coal mining machine to increase productivity and recovery from thin seams beyond the highwall, in addition to decreasing the miner's susceptibility to highwall hazards. First, radar transducers were adapted to measure coal thickness and detect rock and coal interfaces; then, the radar was incorporated into a cutterhead with steering controls. Next, visual displays were designed to show cutter position in the coal seam, and anticipated change in coal seam inclination. Finally, development of a telemetry system made remote control of the cutterhead possible.

Simultaneously, a high-performance extended depth (HPXD) auger machine was designed with an automatic system to handle $600 \mathrm{ft}$ of $36-i n$. diameter dual spiral flight conveyor sections. A two man crew controls all operations from a weather conditioned cap outside the VDZ, either at night or day time. 
As a primary mining tool, working $400 \mathrm{hr} / \mathrm{yr}$ (2 shifts/day) recovering $60 \%$ of the coal $600 \mathrm{ft}$ beyond the highwall, production to 500,000 ton/yr can be achieved."

It is apparent from the above quoted abstract that radar was chosen as the sensor method all three sensor tasks, namely sensing the roof and the floor of the coal seam and sensing the distance to the previously augered hole. Figure 1 illustrates the stump thickness (distance to the previous hole) measurement operation and partially illustrates the interpretation task which the operator must perform. Correlation techniques were proposed to automate the interpretation task. To automatically locate the interface, the reflected radar signal is compared to a stored reflection signal in a microprocessor. The time of maximum correlation is a measure of the distance to the interface. Actually two correlation times would be expected as illustrated in Figure 1 . The first correlation time $t_{1}$ indicates the location of the first coal-air interface and the second correlation time indicates the location of the second coal-air interface. The difference represents the stump thickness.

Coal-air interfaces provide well defined discontinuities from which clean reflection signals may be expected. Roof and floor interfaces can be expected to be less well defined. In addition, the change in dielectric constant from coal to host rock is much less than from coal to air so the reflection amplitude is less.

In the intervening period from 1977 until the present several other methods for sensing roof and floor positions have been investigated. At least four different techniques may be identified. These may be briefly described as follows. A somewhat expanded description is given in Appendix A.

1. Penetrometer Method - A rod with a hardened tip is driven against a surface. An accelerometer attached to the rod gives an output which differs for coal and host rock so that the nature of the surface can be identified.

2. Reflectometer - Relies upon the difference in reflectivity of coal and host rock for identification.

Note: The above two methods do not provide any information beyond the surface in view. 


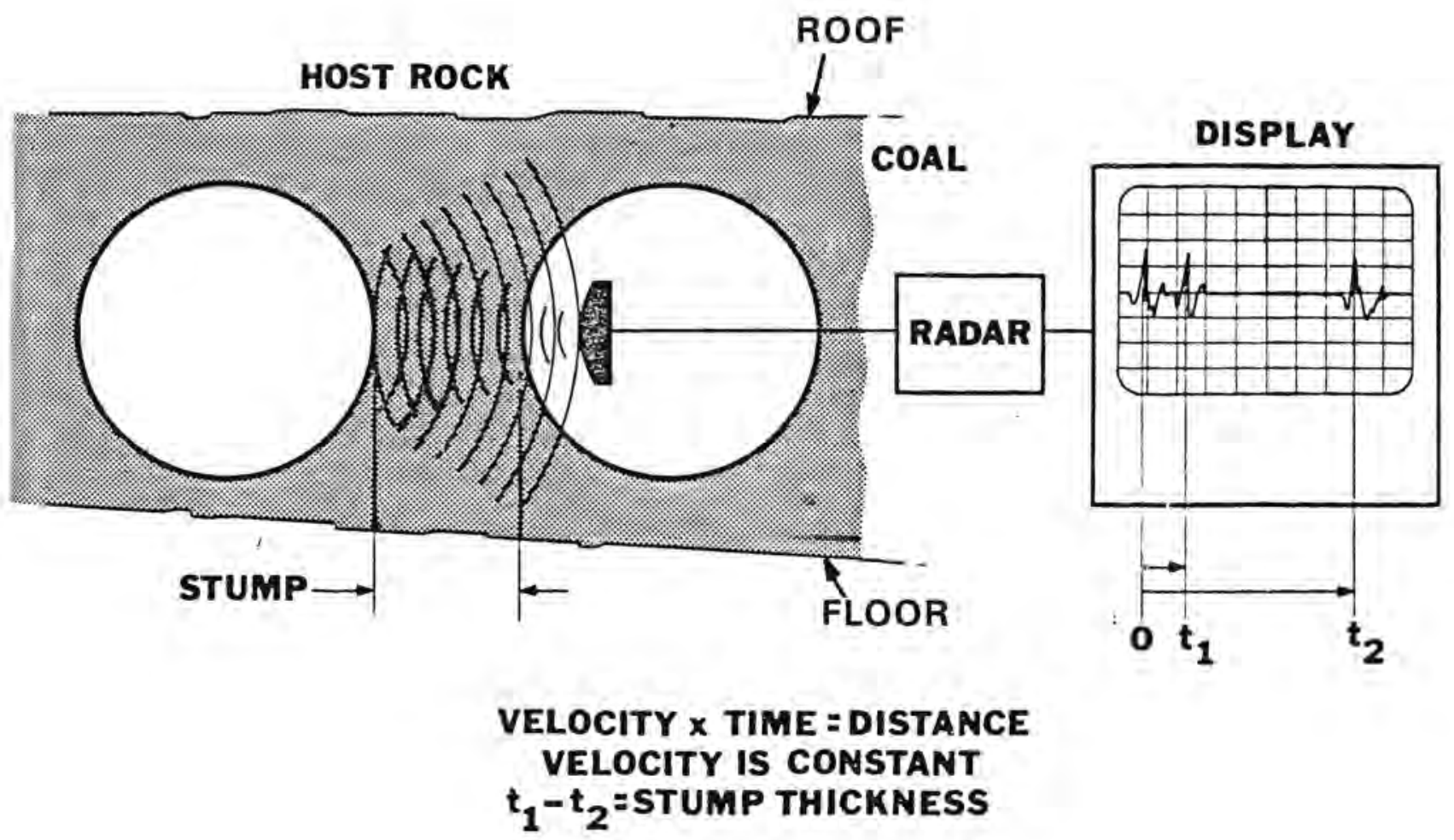

FIGURE 1. Impulse Radar Measuring Rib Thickness Between Adjacent Holes 
3. Chirped Radar - A 2- to 4-GHz oscillator is frequency modulated at a $100 \mathrm{~Hz}$ rate causing reflections from near surfaces to be higher in frequency than those from surfaces beyond. The difference in frequency detected by a mixer diode is a direct measure of the distance of the coal-host rock interface from the nearer coal-air interface.

4. Natural Gamma Sensor - In many areas the natural gamma activity of the host rock is as much as $10 x$ higher than the natural gamma activity of the intervening coal. An instrument designed to measure gamma activity and shielded to count only those gamma photons incident from one direction can be calibrated to provide a dc voltage proportional to the distance to the coal-host rock interface.

In the remainder of this report it is assumed that the pulsed radar sensor will be used to measure stump thickness and that the natural gamma probe will be used for roof and floor sensing. The choice of sensor does not critically affect the design aspects of this report if it is assumed that whatever sensor is used provides a dc voltage level proportional to the roof, floor or stump interface distance. The tradeoffs between the pulsed radar system shown in Figure 1 and the natural gamma probe may be judged from Table 1 which also includes comments about the known alternative methods which have been suggested.

\section{TABLE 1. Sensor Advantages and Disadvantages}

\begin{tabular}{|c|c|}
\hline Sensor & Advantages \\
\hline $\begin{array}{l}\text { Pulsed Radar } \\
\text { (nonchirped) }\end{array}$ & $\begin{array}{l}\text { Smal1 sensor package } \\
9 \times 12 \times 3 \text { inches. }\end{array}$ \\
\hline $\begin{array}{l}\text { Chirped } \\
\text { Radar }\end{array}$ & $\begin{array}{l}\text { Simple signal } \\
\text { processing. }\end{array}$ \\
\hline Natural Gamma & $\begin{array}{l}\text { Passive detection. } \\
\text { Simple, direct signal } \\
\text { processing. }\end{array}$ \\
\hline
\end{tabular}

Penetrometer

Reflectrometer

\section{Disadvantages}

Complex signal processing. Requires active source.

Requires somewhat more complex active source.

Some sites do not have sufficiently high host rock gamma activity. Sensor package large $7 \times 9 \times 25.5$ inches.

Cannot 'see' beyond first coal-air interface. Must contact the surface.

Cannot 'see' beyond first coal-air interface. May go blind because of accumulated dust. 
Figure 2 provides a graphic illustration of the overall system concept. The largest component of the system is the auger flight handling and storage rack which is mounted on a track so that it can advance to come into position for each new hole to be augered. Each time the auger drive system has advanced the cutterhead by one flight length the drive system is retracted to its start position and a new pair of auger flights are inserted into the string. Near the cutterhead at the far end of the auger string, two enclosures are provided for mounting sensors and steering components.

Three of these sensors have already been discussed, namely, the natural gamma probes for sensing the roof and floor and the radar unit for sensing stump thickness. The other sensors are two inclinometers, two torque sensors, two thrust sensors and three LVDT's to measure the extension of the thrust pads. In addition it is recomended that a north seeking gyroscope be included for determination of horizontal heading (yaw).

Course correction is accomplished by means of a set of three double acting solenoid values which control the flow of hydraulic fluid to three double acting cylinders which act upon thrust pads to push the cutting head up, down, left or right as required to stay within the coal seam and at the desired distance from the previous hole. Two hydraulic cylinders are used for up and down movement. Selective activation of the two up-down cylinders permits correction of any tendency for the double auger system to twist (ro11).

These sensors and relays to operate the solenoid activated valves together with a multiplexor and microprocessor based controller are the major elements of the Remote Electronic Package (REP) which is housed in the cutterhead unit of the auger system. The microprocessor based controller responds to the instructions of the Surface Electronic Control (SEC) by sending bit serialized data from the sensors or receiving bit serialized instructions for the valve relays. A schematic diagram of the electronic guidance system is given in Figure 3. 


\section{HIGH WALL AUGER MINING MACHINE}

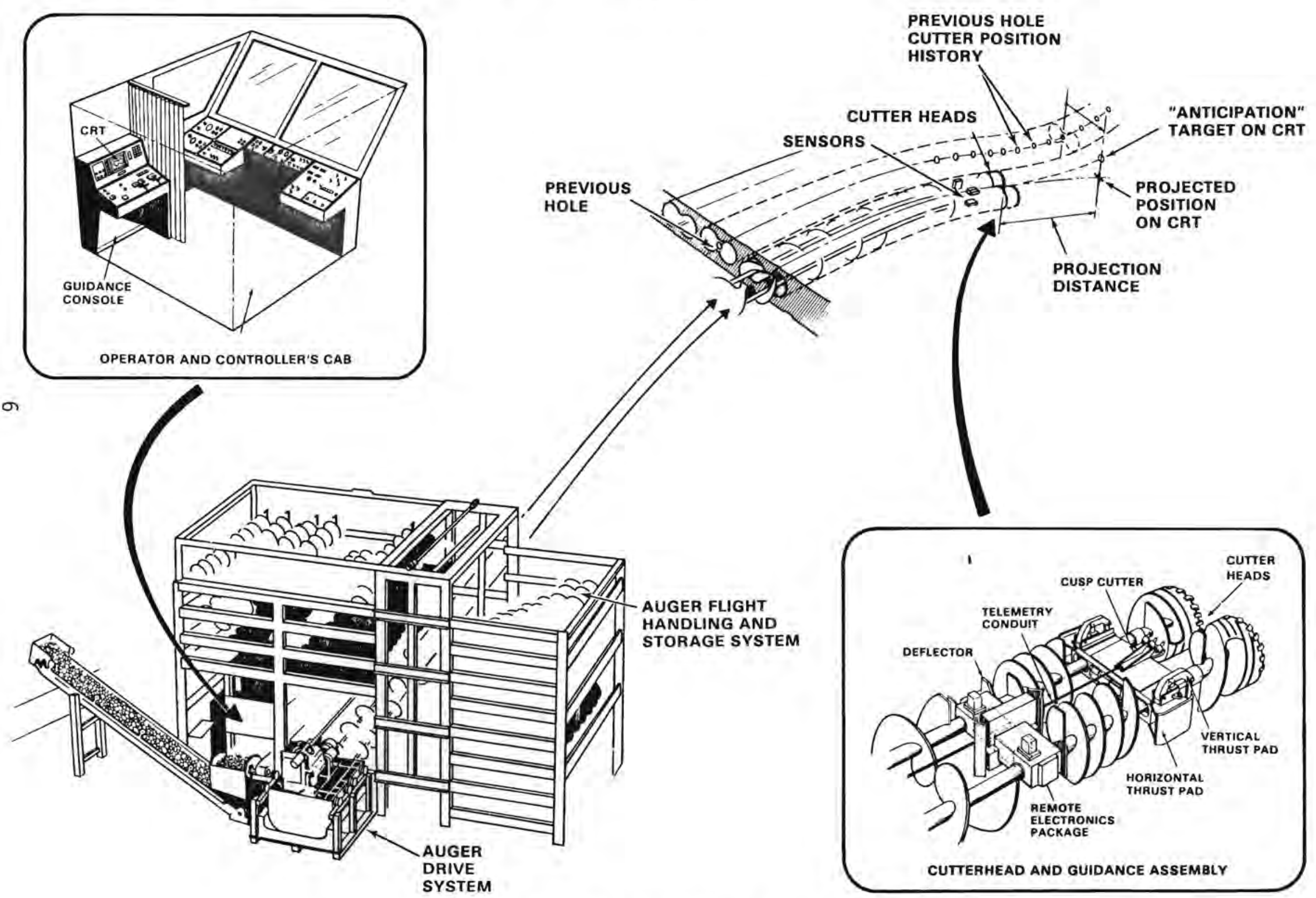

FIGURE 2. High Wall Auger Mining Machine 


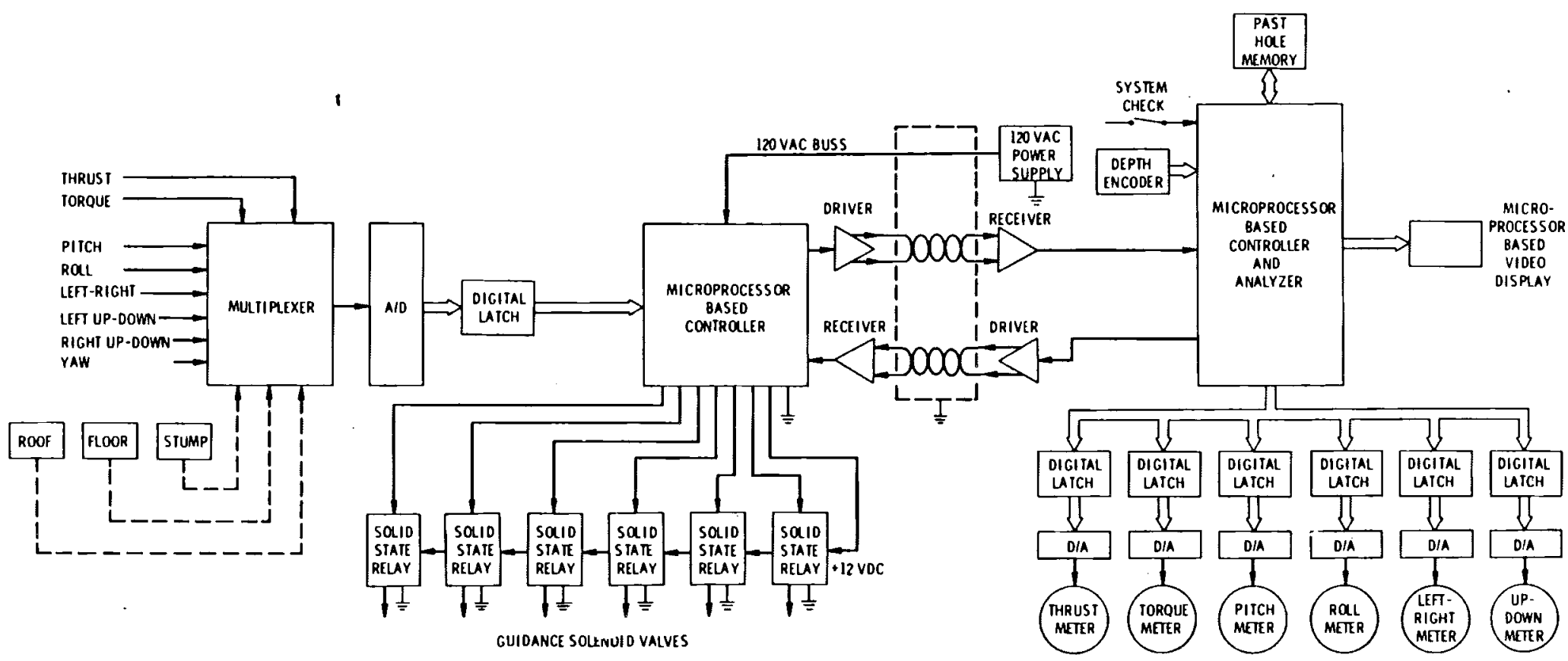

FIGURE 3. Diagram of Telemetry System 
The operator is primarily involved in monitoring sensor levels and cutterhead location. The electronic controller acts automatically to keep the cutterhead on an optimum course. The operator judges whether sufficient thrust and torque forces are being applied and acts to end the run when he observes that the cutter can no longer remain within the coal seam or other undesirable conditions develop such as intersection of a previous hole, low auger advance rate, loss of sensor data, etc.

\subsection{GUIDANCE SYSTEM DESIGN}

To advance the state-of-the-art for mining coal from exposed seam edges without removing overburden or putting men in the coal seam, it will be necessary to develop a system for remotely guiding a coal cutter in the coal seam. Without a guidance system, the development of a highperformance, extended-depth mining machine would be a fruitless effort.

To be effective and practical, the guidance system must be:

- Environmentally rugged

- Compact

- Able to maintain the cutterhead in the coal seam

- Controllable to allow changing course

- Able to respond to changes in the deposit

- Able to function without impeding efficient excavation of coal.

The guidance system as presently designed consists of noncontact, continuously monitoring sensors to identify the interface between the coal seam and the rock. It has the ability to measure the thickness of the coal and remotely display to the controller the position of the cutting tool in the coal seam. The system provides the controller with information on roof and floor distances, rib thickness and cutterhead heading necessary to make steering decisions. Control is accomplished remotely as the cutter is digging coal 600 to $800 \mathrm{ft}$ inside the coal seam.

The in-seam guidance equipment incorporates a self-contained, steering system for moving the cutting tools. The controller is programmed to automatically direct the movement of the steering devices. 


\subsection{Telemetry}

Information from sensors and position indicators downhole will be telemetered to the control panel and displays, and the return control signals from the controller telemetered to downhole steering devices, on a cable that is reeled out or in as spiral flights are added or retracted. To provide support and mechanical protection, the cable will be laid in a semi-closed trough between the twin spiral flights of each section.

Alternative transmission methods were considered but the technical hazards and few successfully documented applications precluded the use of less mechanical systems.

The telemetry system will transmit the following information signals from "downhole" to the surface (REP to SEC):

Roof position

Floor position

Stump thickness

Cutterhead thrust

Cutterhead torque

Pitch angle

Roll angle

Yaw angle

Right Vertical thrust cylinder displacement

Left vertical thrust cylinder displacement

Horizontal thrust cylinder displacement

It is assumed here that the natural gamma sensor will be used for sensing roof and floor position. The natural gamma sensor is of no use in sensing rib thickness. The rib surfaces are relatively strong radar reflectors as compared to the coal host-rock interfaces of the roof and floor so a radar sensor should be successful and effective for this task.

The telemetry system is designed to transmit six control signals from the controller-operator at the surface to "downhole" devices. The six signals are to hydraulic valve solenoids and are: 


$\begin{array}{ll}\text { Right vertical thrust cylinder - up } & \text { RVU } \\ \text { Right vertical thrust cylinder - down } & \text { RVD } \\ \text { Left vertical thrust cylinder - up } & \text { LVU } \\ \text { Left vertical thrust cylinder - down } & \text { LVD } \\ \text { Horizontal thrust cylinder - right } & \text { HR } \\ \text { Horizontal thrust cylinder - left } & \text { HL }\end{array}$

The data and signals are time multiplexed and digitized to a single serialized bit stream for transmission via hard wire to the receivers. At the receiving end the data is demultiplexed and synchronized with the correct output, as illustrated on the telemetry block diagram in Figure 3.

\subsection{Guidance Displays}

As a first approximation it may be assumed that the coal seam profile for two adjacent holes is the same. Guidance in cutting the first hole is solely dependent upon a prior knowledge of the orientation of the coal seam and the sensor data coming in as the hole is being cut. The computer in the Surface Electronic Controller uses the sensor data to generate vertical coordinates of the center of the coal seam as a function of depth. Horizontal coordinates of the augered hole are also calculated. Ideally the horizontal coordinates will not deviate from a linear path, the direction of which is determined by the heading as the hole is initiated. Random wanderings about this ideal linear path can be expected. More severe deviations from linearity may develop because of accumulated navigational errors. Allowance is made in the guidance program for recognizing the maximum excursion from a straight horizontal path and compensating for this excursion by starting the next hole far enough away from the previous hole to permit navigation along a straight horizontal course without going below the minimum desired stump (rib) thickness or intercepting the previous hole.

The vertical coordinates of the center of the coal seam are stored in the previous hole memory so that in progressing through any hole after the first, the electronic controller can look ahead ten feet to see where the coal seam is expected to be. This expected location is called 
the anticipation target (Figure 4). The controller also projects the current heading of the auger to determine if the cutting head will intercept the anticipation target. If not, the electronic controller sends instructions to the Remote Electronic Package to apply hydraulic pressure to correct the heading.

A11 of this is displayed on a video monitor (CRT) in the guidance console (Figure 5) where the operator has a pictorial presentation of the location of the anticipation target relative to the auger hole. In addition, the roof and floor interfaces are imaged and the distance to the previous hole ( $r$ ib thickness) is indicated. Rib thickness is displayed on only one side, left or right depending upon the relative location of the previous hole.

\subsection{Steering}

The cutter is steered by changing the position of the thrust pads relative to the cutter centerline; the steering cylinders hold the position set by the controller. Extending the vertical thrust pads a fractional distance starts the cutter on a very large radius turn, up or down, which continues until the thrust pads are returned to neutral. The longer the time the thrust pads are extended, the larger the arc, and the greater the thrust pad extension, the tighter the turn. The smallest turning radius is $330 \mathrm{ft}$. Smaller turning radii will cause the following spiral flights to bind, or seriously reduce the mechanical efficiency of the auger.

The guidance mechanism (Figure 6) incorporates six thrust shoes, with one horizontal pair causing the cutter to move left or right (yaw) and two vertical pairs contolling the up or down movement (pitch). In addition, the two vertical thrust pads can be moved in opposite directions to correct the orientation (ro11) of the cutterhead level. Each pair of thruster pads are moved by double-acting, double-rod hydraulic cylinders controlled by operator signals to the hydraulic control valves. Each hydraulic cylinder incorporates linear voltage differential transducer (LVDT) devices to electronically indicate the location of the hydraulic cylinder piston (Figure 7). The cylinder position is remotely displayed on the operator's console to aid in guiding the cutterhead. 


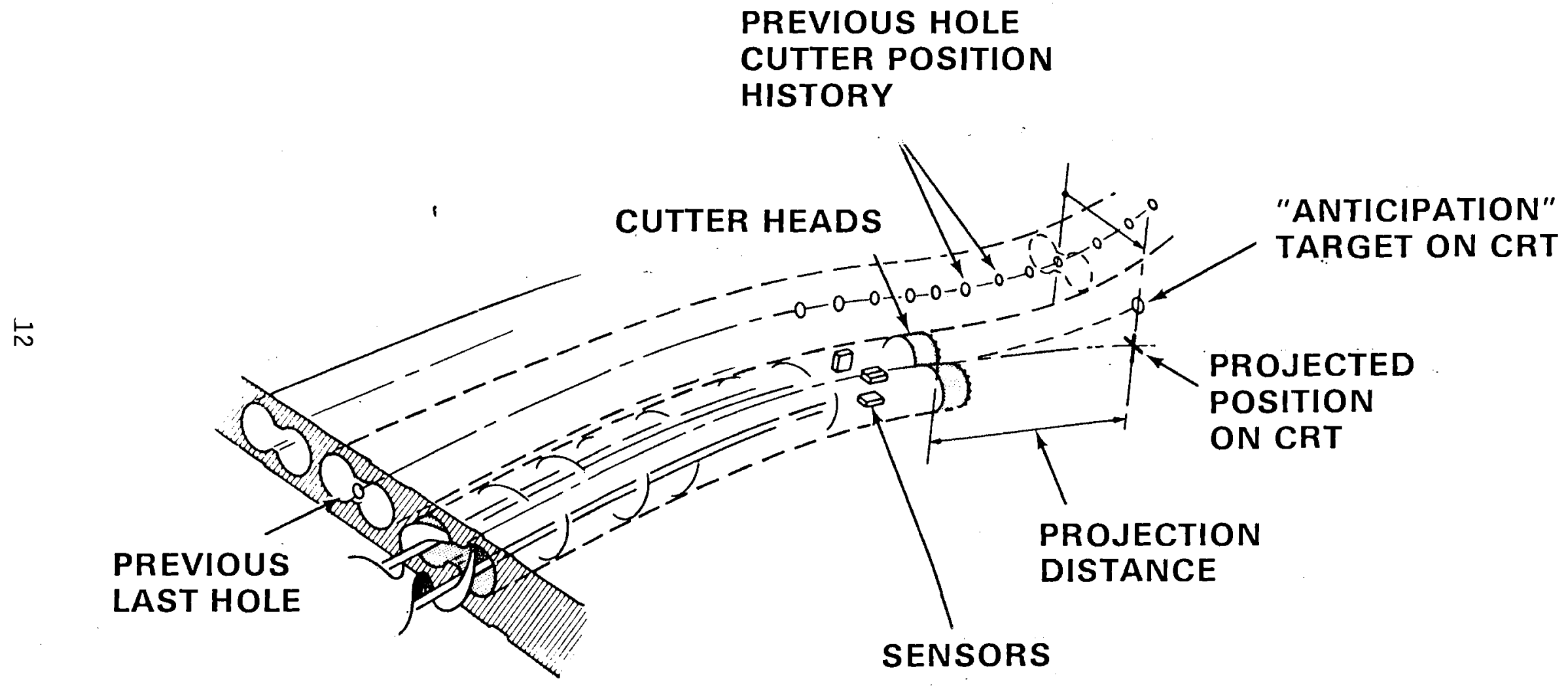

FIGURE 4. Anticipation Target Geometry 


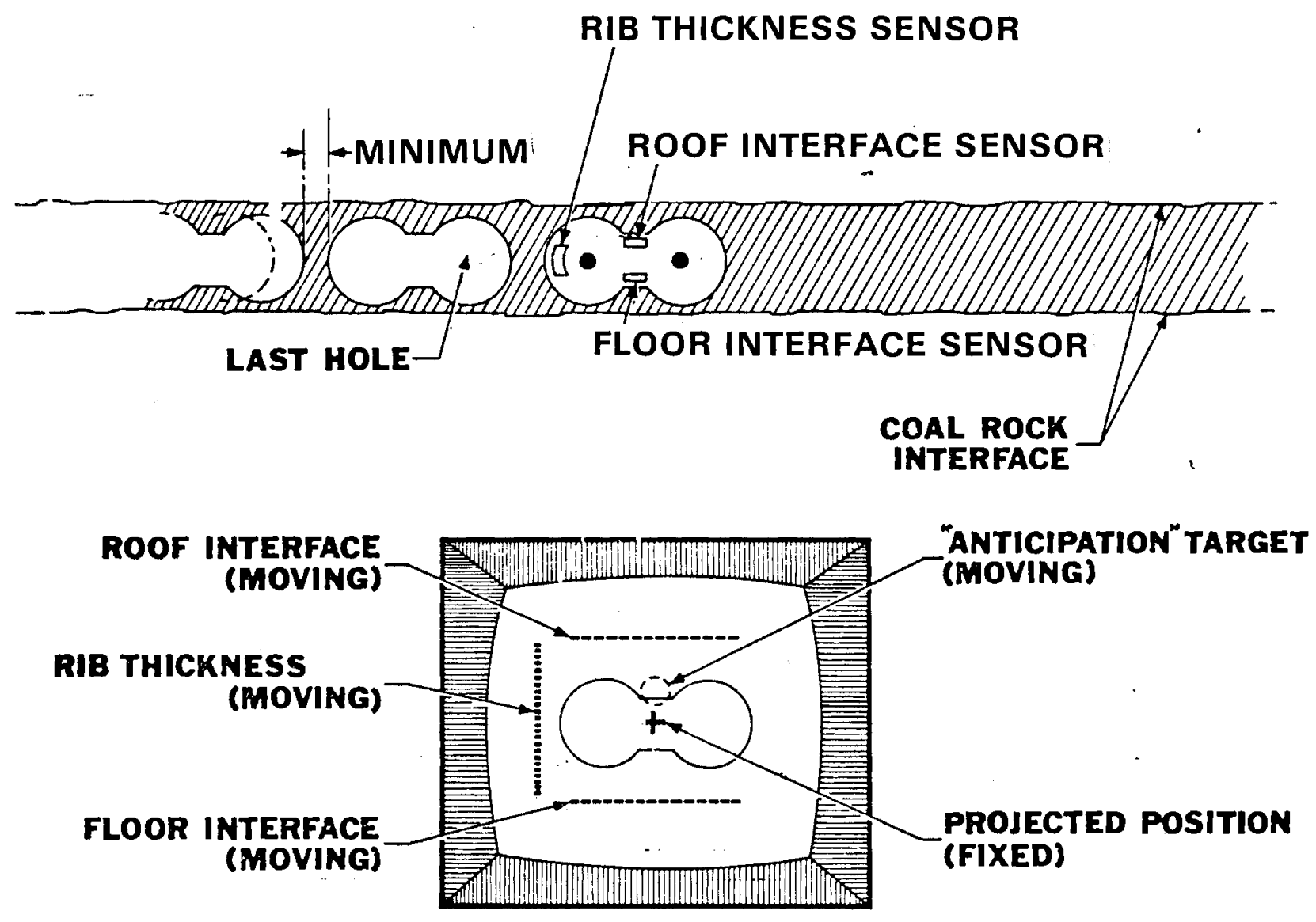

FIGURE 5. Diagram of Guidance Display 


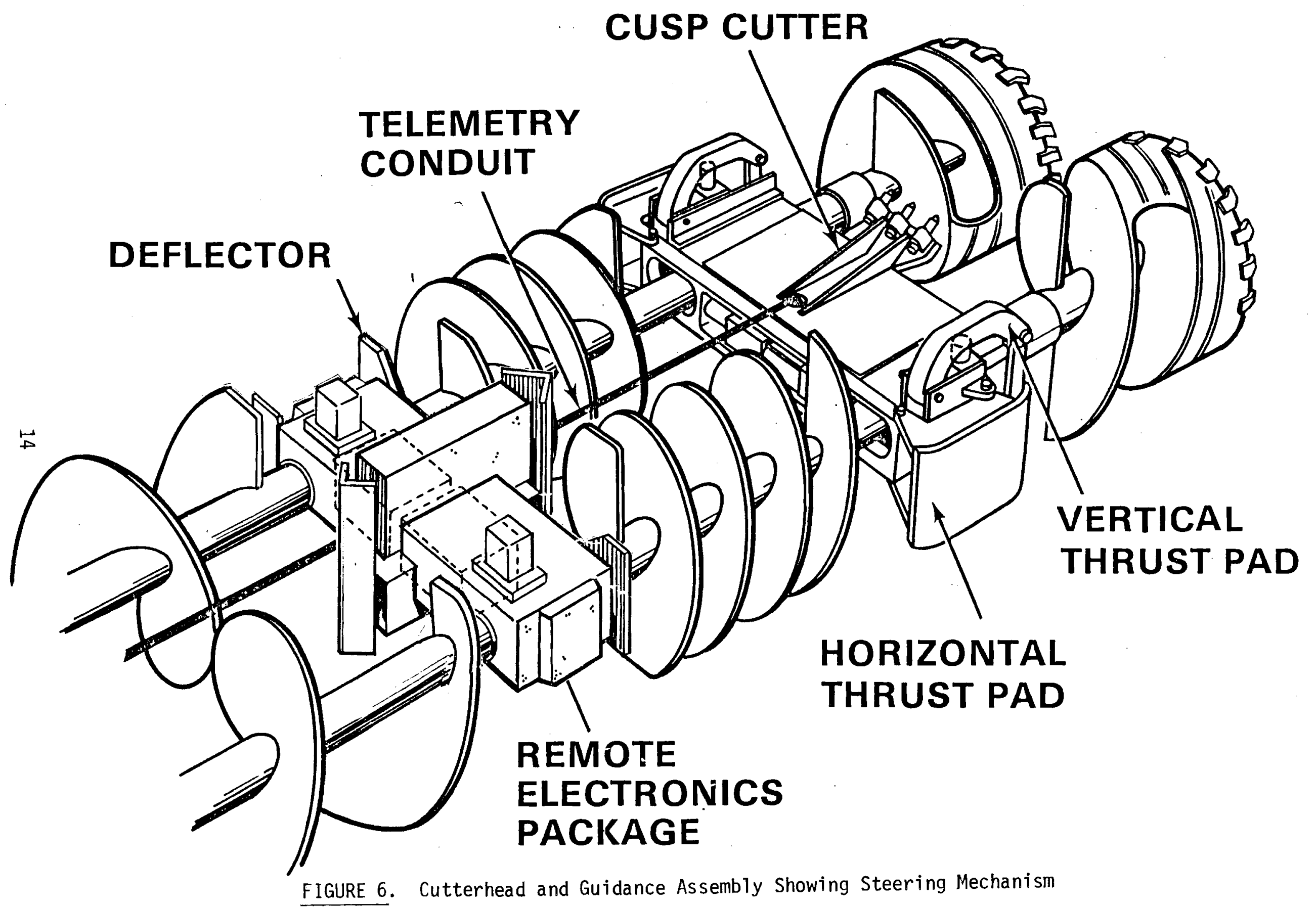




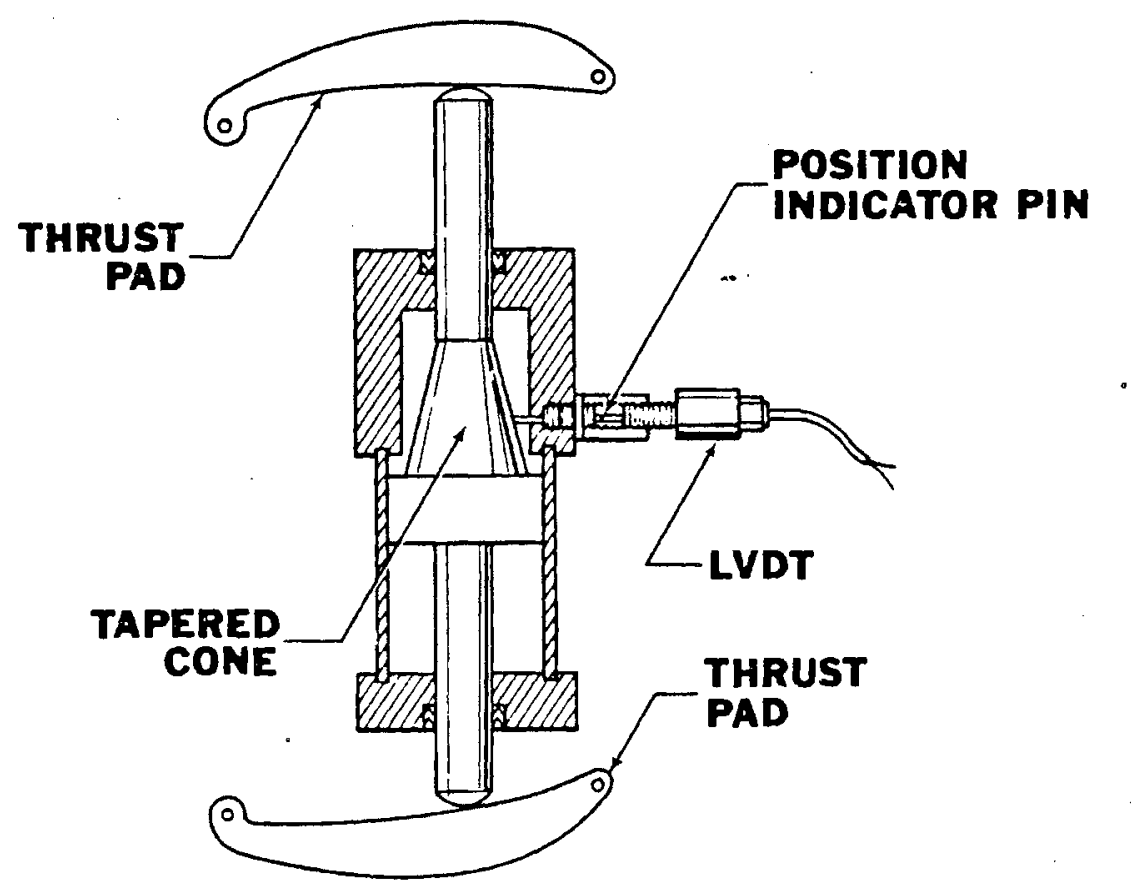

FIGURE 7. Steering Mechanism's Hydraulic Cylinder and Electromechanical Position Indicator 
Hydraulic power is provided by a six-piston, ball-check type pump, which can operate at $10 \mathrm{rpm}$. The rotating cutterhead shaft drives the pump, so no external power is required. The pump's pistons are isolated into pairs to supply oil independently to the three cylinder circuits so the three pairs may operate simultaneously. Each hydraulic circuit consists of a relief valve, directional control valve, dual pilot operatedcheck valve, and hydraulic cylinder (Figure 8).

At the end of a run, when the auger is to be withdrawn, an operatorcontrolled solenoid-operated bypass valve is opened to allow the thrust pads to move freely. This prevents the thrust pads from creating additional drag while the auger is being withdrawn.

\subsection{Electrical}

Electric power supplied from the auxiliary ac generator will be provided for the guidance and control systems. Downhole power to the hydraulic-valve solenoids, radar transducers, and telemetry will be transmitted at 120 VAC by a wire parallel to the telemetry cable.

\subsection{Other Sensors}

The cutterhead pitch and roll are measured by inclinometers, which are gravity-referenced, servo-accelerometers. The inclinometers produce output voltages proportional to angular displacement from true vertical in a single plane. The voltage signal is generated when a pendulum attached to a torque motor shaft moves from the zero reference point.

The voltage signal generated by the "pitch" inclinometer is transmitted by the telemetry system to the control console. The controller may monitor the pitch, but the information is also stored in the microprocessor memory to develop the "anticipation" target display for the next hole.

The inclinometer oriented perpendicular to the auger's center1 ine provides a reference signal which maintains the horizontal position of the cutterhead. If the cutterhead begins to roll, the voltage output signal from the inclinometer activates relays to operate hydraulic valves to move the vertical thrust cylinders in opposite directions to correct the roll. When the seam slope perpendicular to the auger 


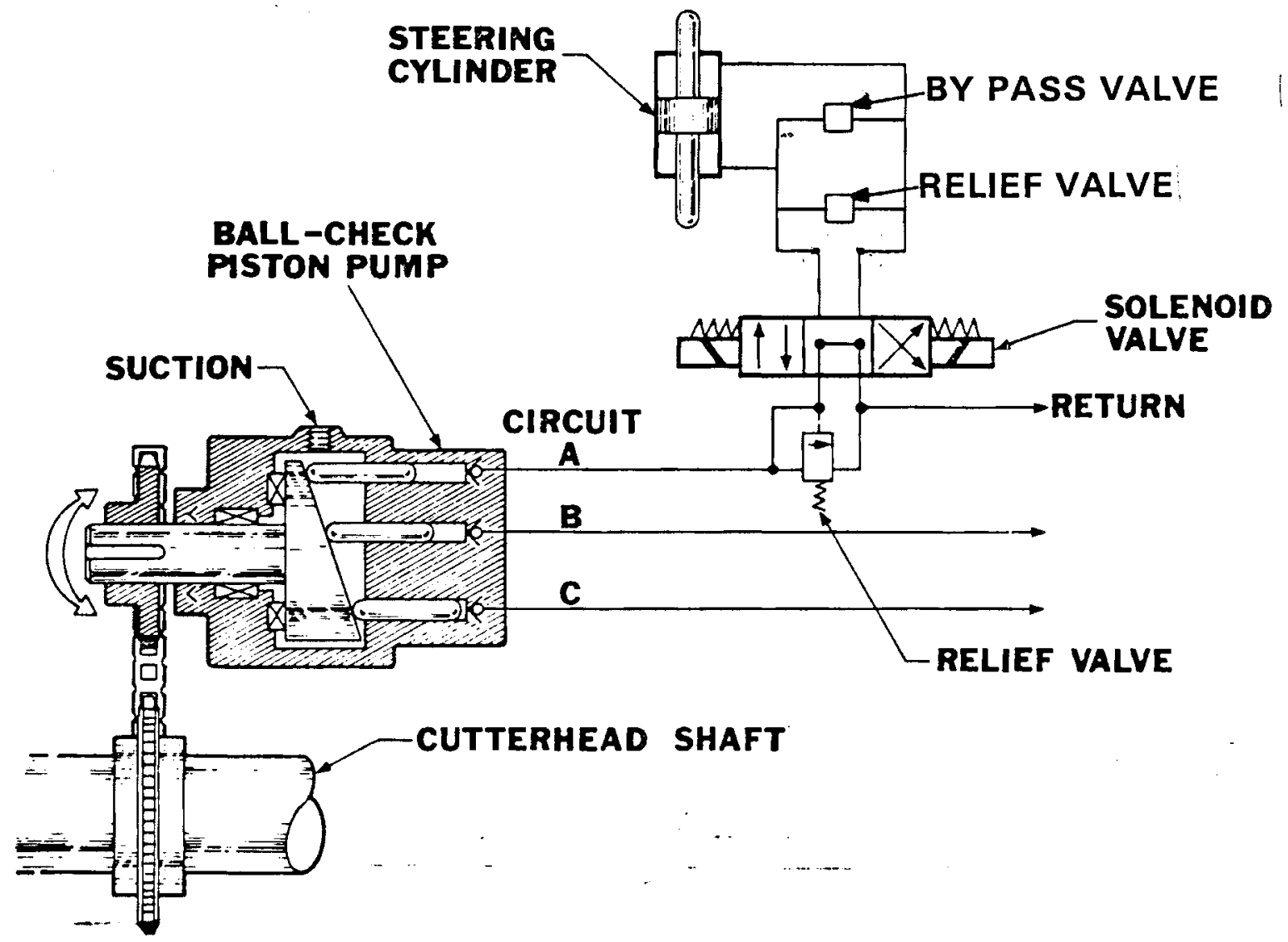

FIGURE 8. Typical Steering Hydraulic Circuit 
centerline is extreme, the zero reference point may be matched to the seam slope to optimize cutter performance. The roll inclinometer output is also displayed on the control console for monitoring by the controller.

\subsection{REMOTE ELECTRONICS PACKAGE}

\subsection{Introduction}

The Remote Electronics Package (REP) is that portion of the guidance system that is mounted on the cutterhead of the auger highwall miner. The REP consists of: 1) a communication link with the operator control station, 2) roof, floor, and rib coal interface sensors, 3) instruments for measuring pitch, rol1, displacement, thrust, and torque, and 4) data acquisition and control to guide the auger.

Figure 9 is a block diagram of the REP. The main power feed is 120 VAC at $60 \mathrm{~Hz}$. This power is conditioned by an isolation transformer that will "clean up" and remove line voltage transients that are typically present in mining environments. The isolated 120 VAC powers a Power Mate $(18 \mathrm{~V} / 8 \mathrm{~A}) \mathrm{dc}$ power supply that is the main power unit for the instruments and electronics. A second Power Mate $(24 \mathrm{~V} / 10 \mathrm{~A})$ dc power supply is used to provide power to the solenoid valves that control the hydraulic guidance elements. Also powered from the isolated $120 \mathrm{VAC}$ is the Acurex $1201 \mathrm{~A}$ torque/thrust mea surment system.

The +18 VDC supply powers three $+5 \mathrm{~V} / 3 \mathrm{~A}$ power modules that are designed to be intrinsically safe for coal mining (methane) applications. The design is basically the same as that used on a previous MSHA-approved project for use on a shaft sinking demonstration machine. The sensor power and signal conditioning circuits provide power for the instruments, usually \pm 15 VDC at approximate $1 y=15 \mathrm{~mA}$, and condition the output from the instrument so that it is compatible with the data acquisition and control electronics. It should be noted that the gamma probe type coal interface sensors have been submitted by the manufacturer to MSHA for approva 1 . 


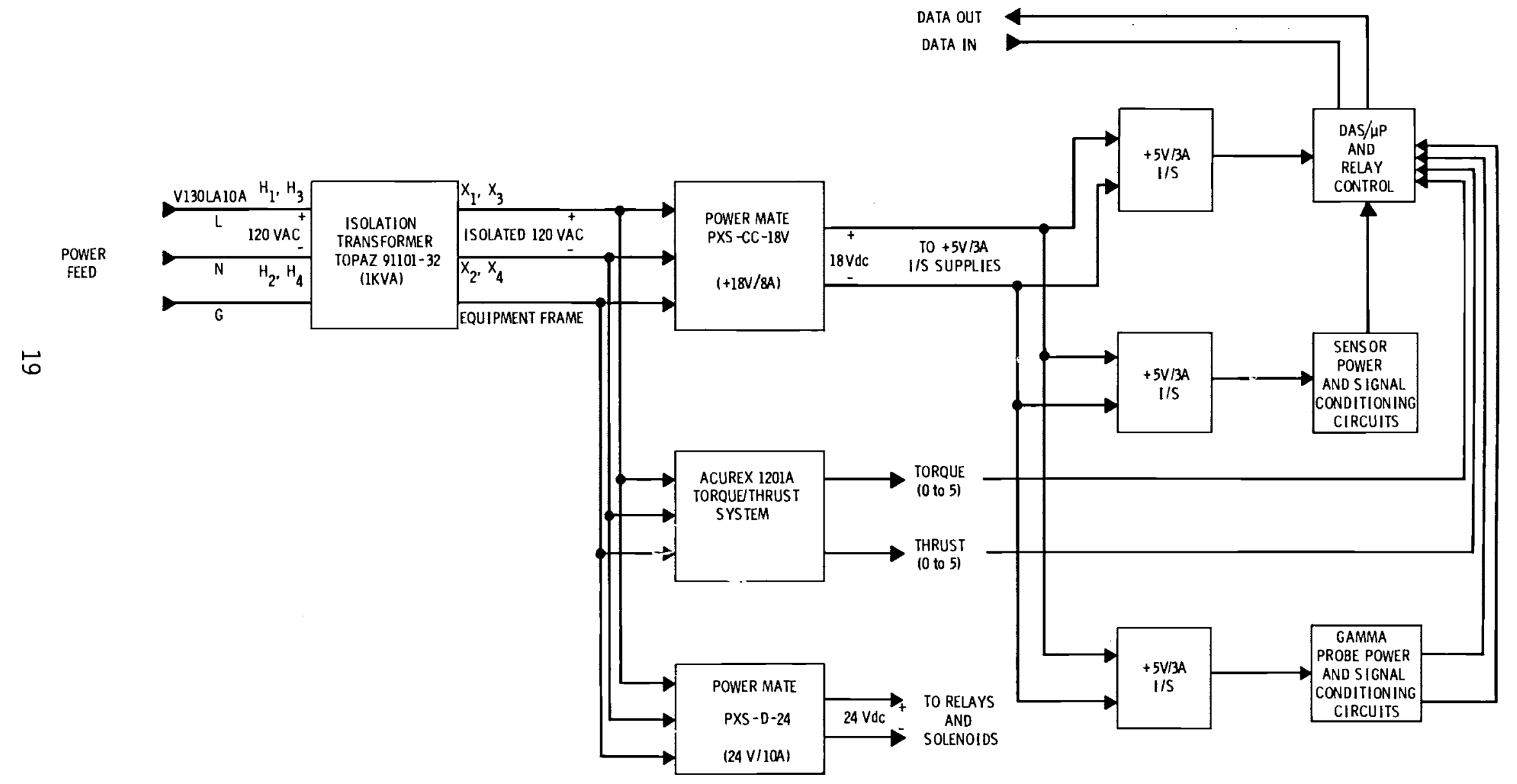

FIGURE 9. Block Diagram of the Remote Electronics Package 


\subsection{Data Acquisition/Control Circuitry}

Figure 10 is a detailed schematic of the data acquisition and control circuitry. The data acquisition and control function is based on an Intel 8748 programmable single chip microprocessor. The microprocessor communicates with the control computer in the operator's station over optically isolated twisted pair serial data lines at a 9600 baud rate. Guidance commands are sent from the control computer to the microprocessor, which in turn outputs the appropriate control bits through an 1/0 expander to the solenoid valves. The solenoid valves are interfaced to the $I / 0$ expander through optically isolated dc solid state relays. Data from the sensing instruments is input to the microprocessor through a Datel DAS-952R data acquisition chip. This DAS chip has a 16-channel 0 - to 5-VDC analog multiplexer, and an 8-bit analog to digital converter. The microprocessor selects one of the 16 analog channels. The DAS chip converts the analog value to 8 bits of digital data which are latched so that the microprocessor can input the data and store it until it is time for the data to be transmitted to the control computer.

\subsection{Instruments and Signal Conditioning}

\subsubsection{Torque/Thrust Measurement}

The instrument recommended to make the torque and thrust measurements is the Acurex Model 1201A dual channel system. This unit has the capability of simultaneously making two distinct measurements (such as torque and thrust) on a rotating shaft. Strain gauges, typically $350 \Omega$ type, placed on the shaft in a full bridge configuration are required in addition to the Model $1201 \mathrm{~A}$ instrument. The unit is powered from $120 \mathrm{VAC} / 60 \mathrm{~Hz}$ at approximately $1 \mathrm{~A}$. The standard output is -10 to $+10 \mathrm{VDC}$, but can be supplied with a non-standard output, such as 0 to 5 VDC, which is compatible with the input of the analog input of the DAS-952R data acquisition chip. It also comes with a digital readout that can be deleted to reduce the size and cost of the unit.

\subsubsection{Pitch/Roll Measurement}

The instrument selected to make the pitch and roll measurements is a gravity-referenced inclinometer, such as the Schaevitz Engineering 


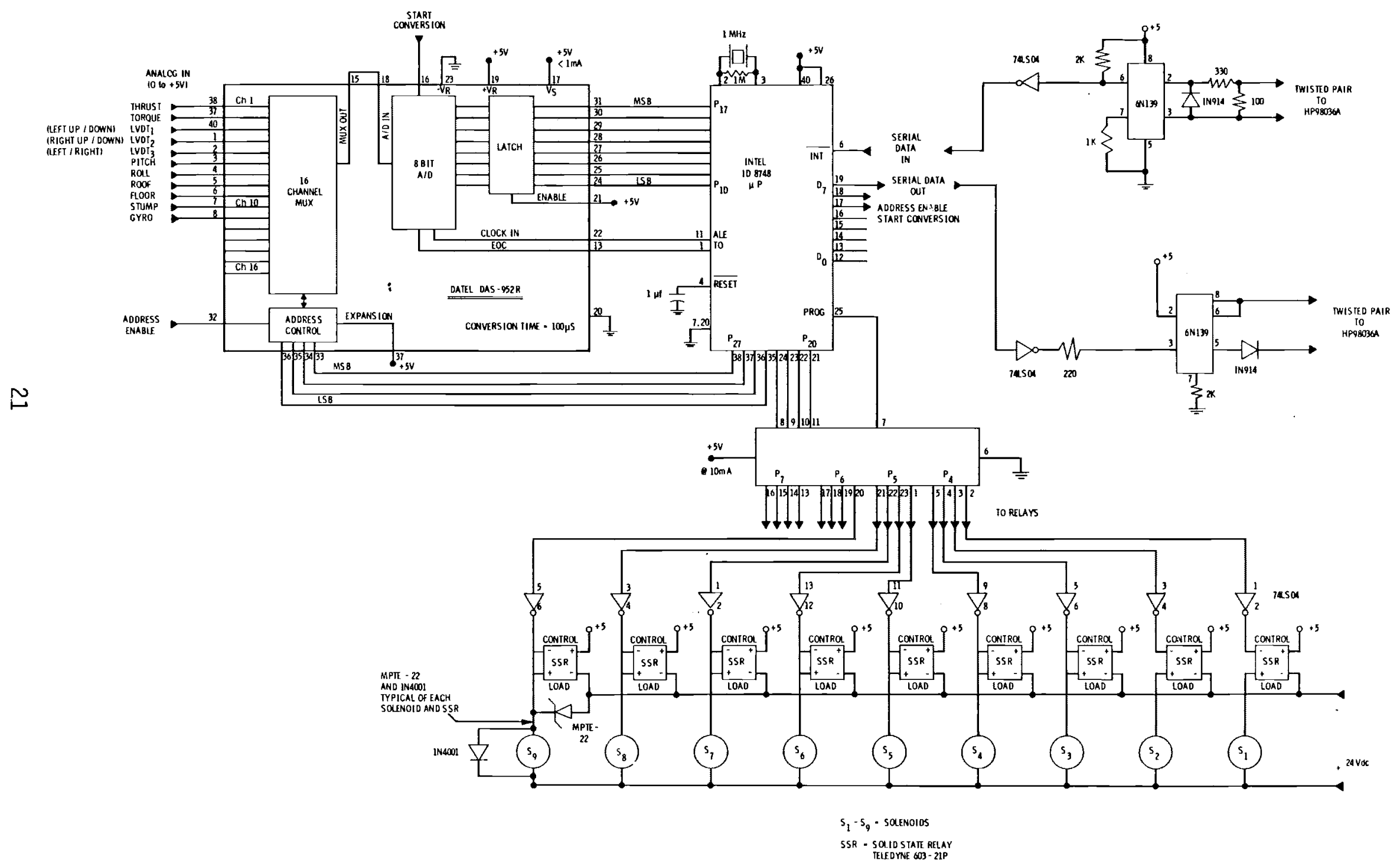

FIGURE 10. Schematic Diagram of the Data Acquisition and Control Circuitry 
Model LSOC inclinometer. This unit is dc operated, nominally requiring \pm 15 VDC (a \pm 9 to \pm 18 VDC range is acceptable) at approximately $15 \mathrm{~mA}$. There are various tilt ranges available, and it is presently specified as $\pm 30^{\circ}$. The output voltage range is 0 to $5 \mathrm{VDC}\left(0^{\circ}\right.$ tilt will be $\left.+2.5 \mathrm{VDC}\right)$. This tilt range versus the output voltage range results in $83 \mathrm{mV}$ per degree of tilt. The 0 to 5 VDC output voltage range is compatible with the data acquisition chip.

\subsubsection{Cylinder Displacement Measurement}

Calculations for the cylinder displacement measurement indicates that to achieve the minimum turning radius (specified as 330 feet), a cylinder displacement from nominal of approximately 0.020 inches (20 mils) is required. In order to steer a prescribed course, accuracies of a few mils are needed for the cylinder displacement measurement. Therefore, the instrument selected is a Schaevitz Engineering Model GCD-121-050 LVDT gauge head that has a measurement range of $50 \mathrm{mils}$. This is a dcoperated LVDT requiring \pm 15 VDC at $25 \mathrm{mZ}$. It has a standard full range output of -10 to +10 VDC. This is not compatible with the data acquisition chip and will require signa 1 conditioning to obtain a 0 to 5 VDC signal range. This range corresponds to an output to LVDT displacement relationship of $50 \mathrm{mV}$ per $0.001 \mathrm{inch}$. The original design document indicated that the LVDT would be in contact with a cone-shaped cylinder rod as illustrated in Figure 7.

The displacement of the LVDT is related to the displacement of the cylinder by the angle of the cone, $\emptyset$.

$$
\text { Displacement LVDT }=\frac{\text { Displacement Cylinder }}{\operatorname{Tan} \emptyset}
$$

\subsubsection{Roof, Floor, and Rib Measurement}

For the present, it is anticipated that the roof and floor coal interface measurements will be made using a natural gamma probe such as the Type 801 built by Salford Electrical Instruments (SEI). This probe requires +15 VDC at $150 \mathrm{~mA}$ to operate, and outputs an analog signal of 0.4 to 2 VDC which represents a coal thickness of 0 to 20 inches. This 
output range is compatible with the data acquisition chip, but signal conditioning is provided so that all signals input to the data acquisition chip are 0 to 5 VDC for full scale ranges. Data sheets on all instruments are provided in Appendix $A$.

\subsubsection{Signal Conditioning}

Figure 11 shows details of the signal conditioning circuits. The basic design concept is for the circuits to be similar enough so that a single pc board layout could be used. By changing a resistor and/or a couple of jumpers, or by adding a DC-DC converter, the standard pc board can be tailored to the individual instruments. This would reduce spare parts and allow quick replacement if necessary. Power for the instruments is obtained by converting the +5 intrinsically safe output to \pm 15 volts with an Analog Devices 949 DC-DC converter. The 949 also supplies the power for the signal conditioning amplifiers. An additional power module, Power General 816 DC-DC converter, is required only for the SEI Type 801 gamma probe circuits. The signal conditioning electronics is based on using the 725A instrumentation amplifier. The $725 \mathrm{~A}$ provides accurate closed loop gain, low noise, low voltage drift, low voltage offset, and provides buffering between the instrument output and input the data acquisition chip. For the 0 to 5 VDC sensor signals (torque, thrust, pitch, and roll), the instrumentation amplifiers are merely buffers and connected as voltage followers. For the non-0 to 5 VDC sensor signals (displacements and coal interface), the instrumentation amplifiers adjust the gain and level shift the signals to obtain a 0 to 5 VDC range.

\subsubsection{Intrinsically Safe Power}

Figure 12 is a detailed schematic of the $+5 \mathrm{~V} / 3 \mathrm{~A}$ intrinsically safe power unit. Main power is derived from the +18 VDC supply, and then dual voltage and current regulated by the $123 \mathrm{~K}$ modules which are connected in series. A crowbar type overvoltage protection circuit set at 5.5 volts (10\% overvoltage) will cause an SCR to trigger shorting the +18 VDC to ground through a 4 amp fuse in the event of an overvoltage condition. This causes the fuse to blow, removing all power to the supply. 


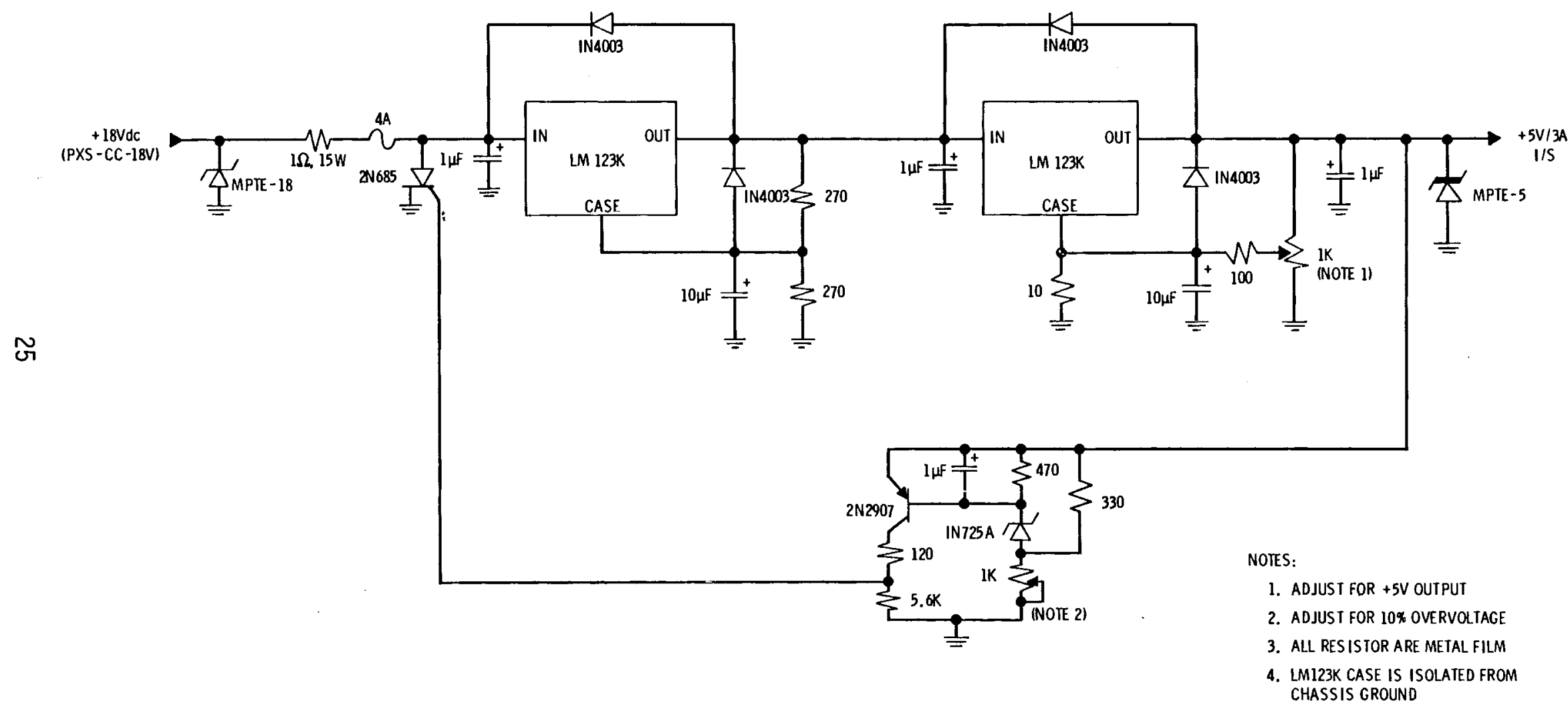

FIGURE 12. Schematic of Power Unit 


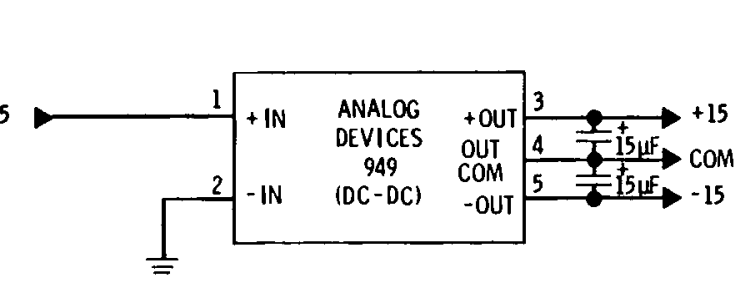

TO PITCH/ROLL/DIS PLACEMENT
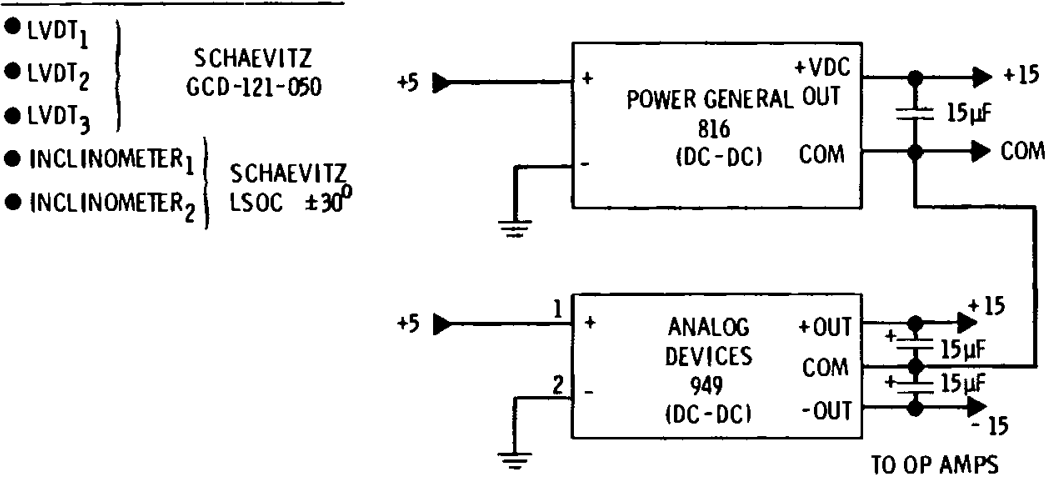

TO SEI TYPE 801 GAMMA PROBE

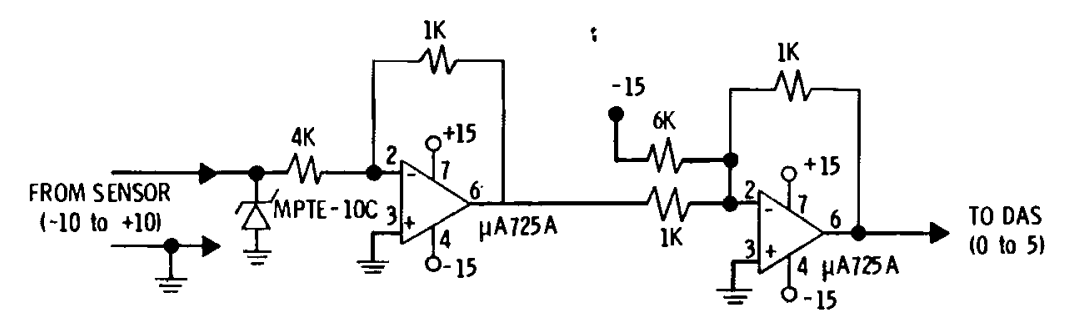

- LVDT ${ }_{\text {l }}$ (LEFT UP/DOWN)

- LVDT $_{2}$ (RIGHT UP/DOWNI

- LVDT $_{3}$ (LEFT/RIGHT)
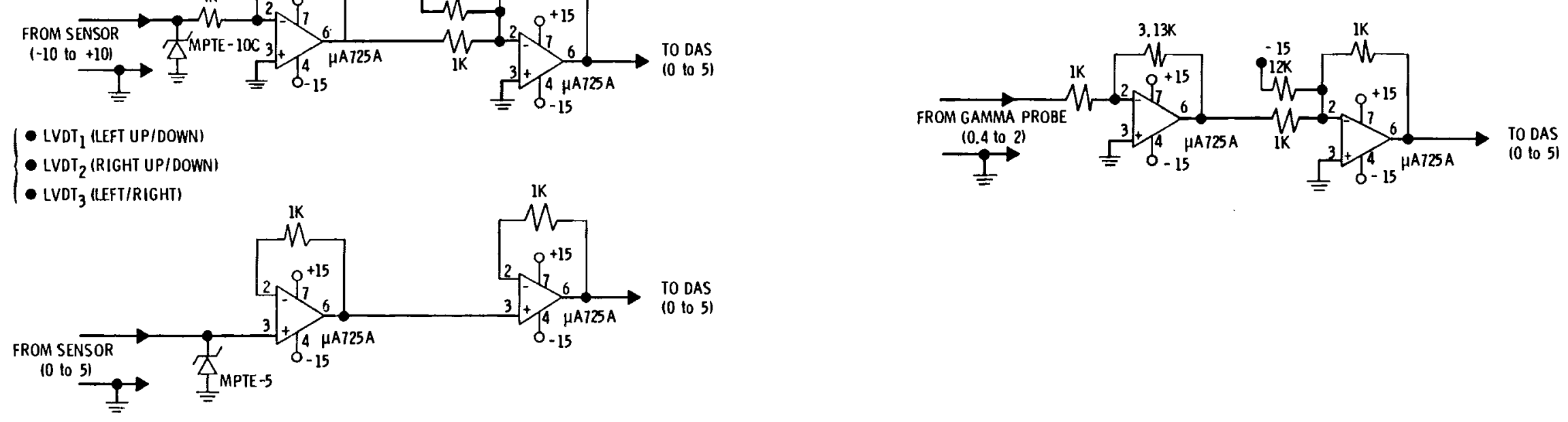

FIGURE 11. Details of the Signal Conditioning Circuits

- THRUST

- INCLINOMETER (PITCH)

- INCLINOMETER ${ }_{2}$ (ROLL) 


\subsection{SURFACE ELECTRONIC CONTROLLER (SEC)}

Another representation of the block diagram of the telemetry system is given in Figure 13. This block diagram is to be compared with Figure 3 which is less specific. Note that the SEC is fully implemented using standard commercial components. An HP9825T desk top computer and peripheral equipment provides all the features needed to instruct the REP to send data, to use the data to drive display meters and to use the data to calculate guidance instructions.

The HP9825T will use an internal protected tape cartridge to store programming instructions. The HP9875 cartridge tape unit is an additional tape unit external to the HP9825T and is used for the previous hole memory.

The HP9825T, equipped with an extended I/0 ROM, automatically loads the guidance program from the internal protected tape cartridge when the power to the computer is turned on. The computer is then automatically in run condition. The autostart routine is also performed after a power failure, enabling the computer to automatically reload and restart a program.

That the equipment designated for the SEC in Figure 13 readily fits into a smal1 sized console is illustrated in Figure 14. Meters to directly display thrust, torque, depth, pitch, roll and thrust pad extension would be mounted in the sloping face of the console (see also Figures 2 and 15). The keyboard of the HP9825T would not be directly accessible. The operator interaction with the computer requires only the functions of Power On-0ff, Stop and Continue. These controls located on the operator's control pane1 provide the only access to the computer needed on a routine basis. The console will be fully enclosed and sealed to provide protection for the SEC from the rugged environments in which it must operate.

Other features of the HP9825T and the associated equipment are given in the data sheets included in Appendix B. 
REMOTE ELECTRONIC PACKAGE (REP)

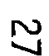

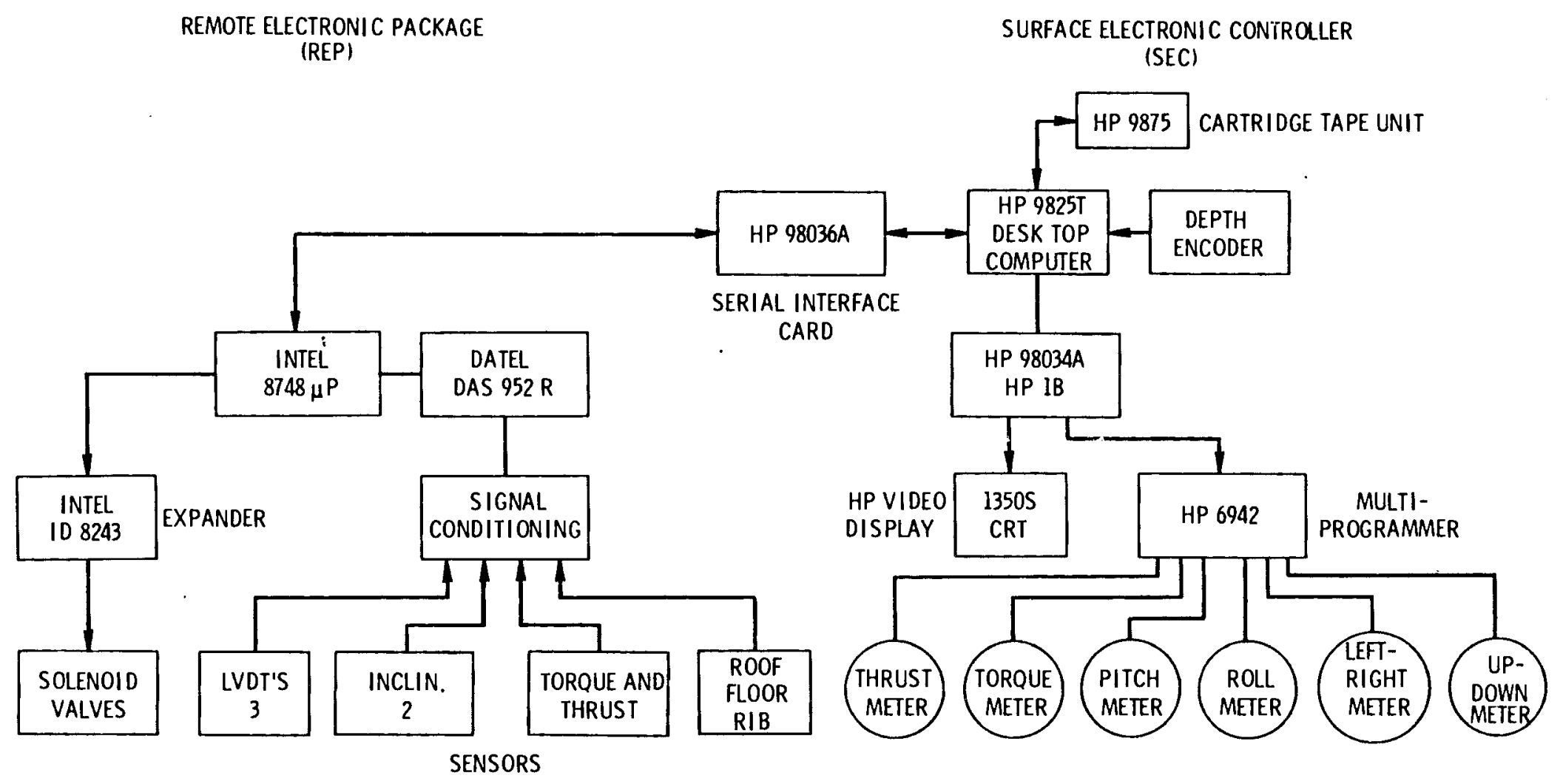

FIGURE 13. Current Specification of Telementry System 


\section{GUIDANCE CONSOLE INTERNAL CONFIGURATION}

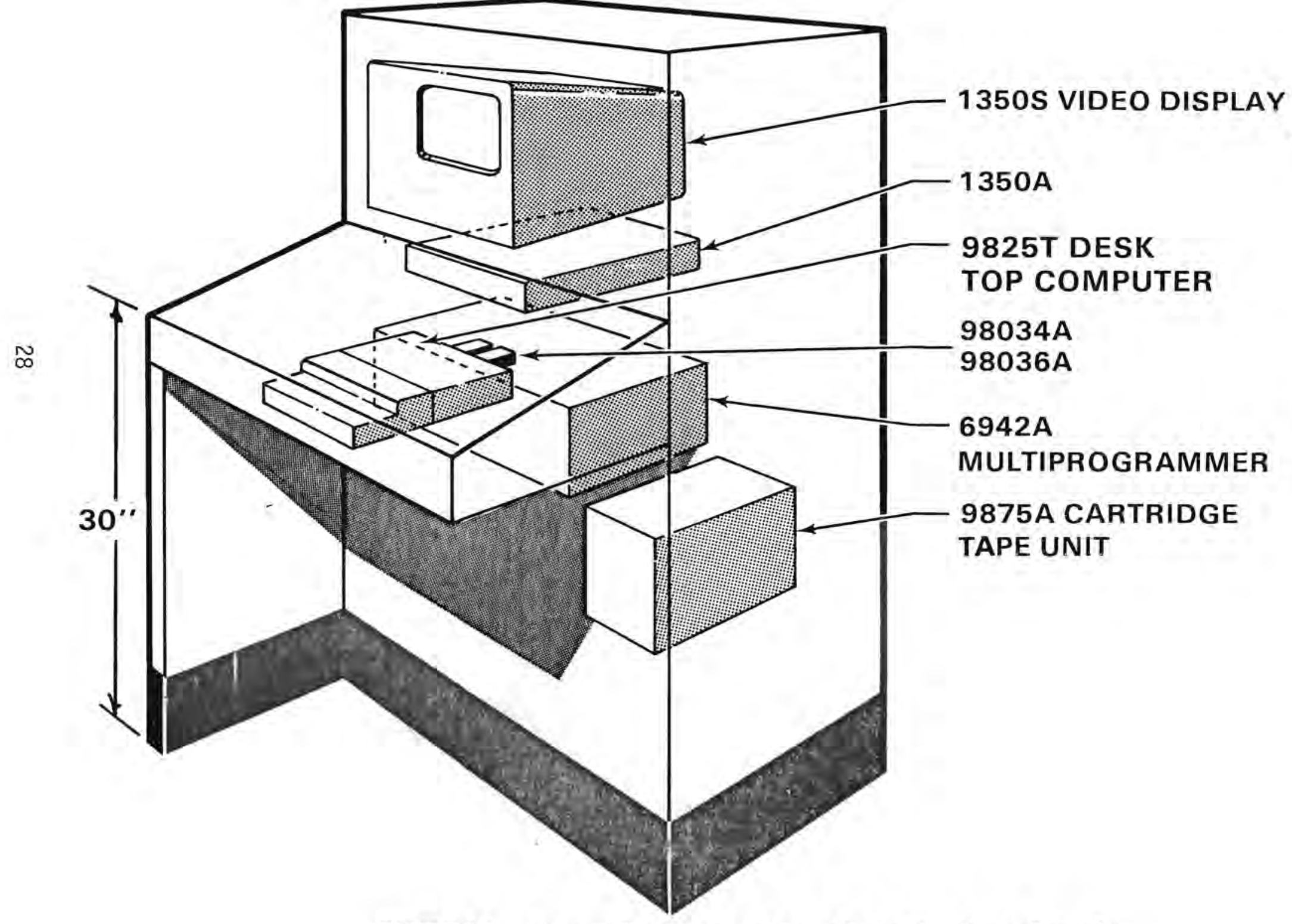

FIGURE 14. Internal Configuration of the Guidance Console 


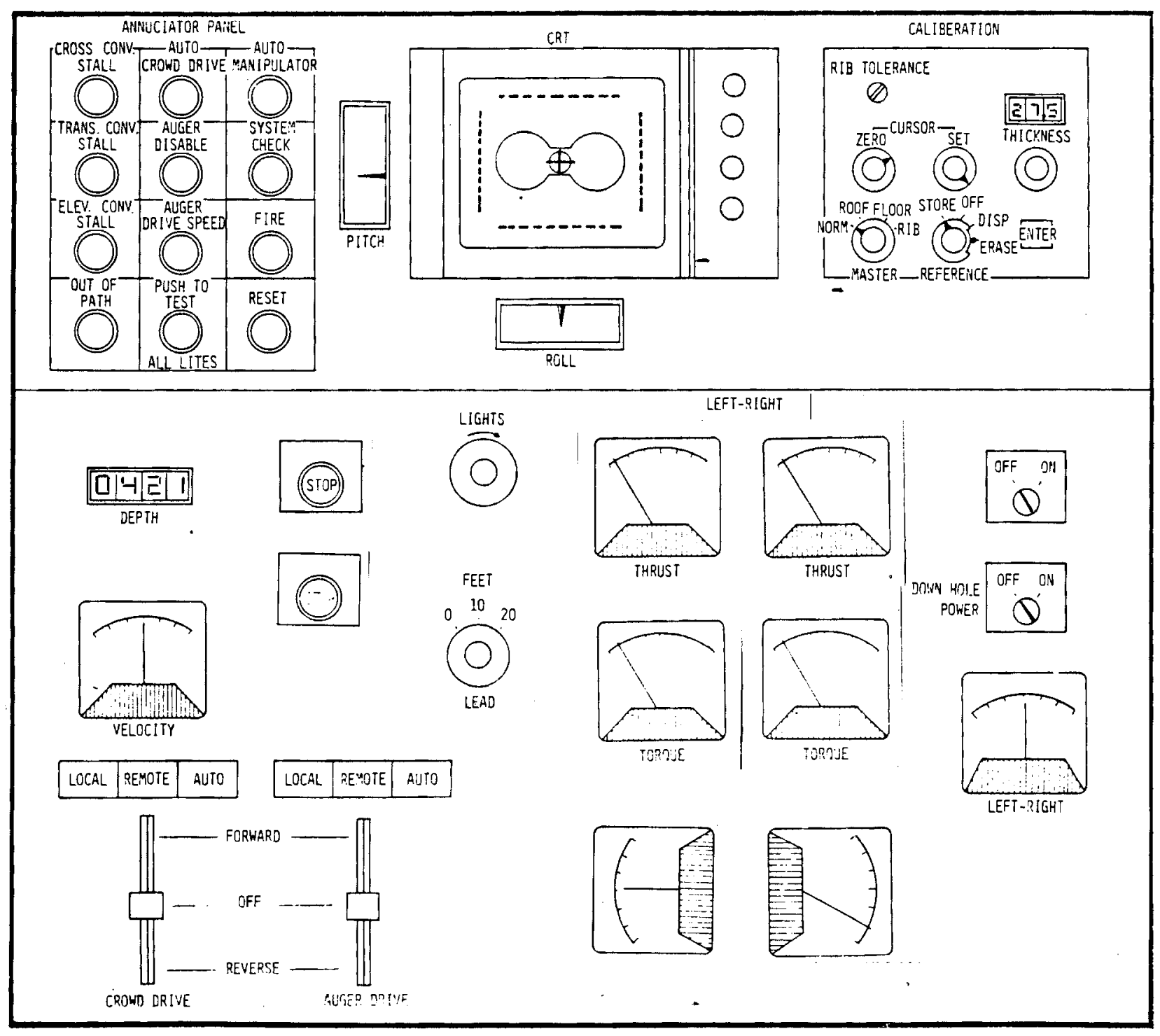

FIGURE 15. Layout of Operator's Control Panel 


\subsection{COMMUNICATION PROTOCOL}

\subsection{Introduction}

The interface between the remote electronics package (REP) which is downhole and the surface electronics controller (SEC) will be serial with a formalized protocol. The SEC will always be the master and will command the slave REP.

The SEC will require the REP to peform two functions:

1. Downhole guidance control

2. Downhole analog parametric acquisition

\subsection{General Information}

1. All information will be sent in ASCII strings

2. 8-bit fields are sent in hex as two alphanumeric characters

3. All characters will be ignored except those following a record mark until the end of record mark (a line feed after a carriage return is ignored)

4. Transmission speed is 9600 Baud

\subsection{Messages from SEC to REP}

$: \mathrm{FD}_{1} \mathrm{D}_{2} \mathrm{CCt}$

where

: colon signifying a record mark

$F \quad$ function code signifying action REP is to perform $A \rightarrow$ data acquisition, $F \rightarrow$ guidance control

DD guidance steering parameter - command word selected from Table 3

CC modulo 100 sum of all digits in F and $D-2$ digits

$\downarrow \quad$ carriage return signifying an end of record mark 


\subsection{Messages from REP to SEC}

$: F D_{1} D_{1} D_{2} D_{2} D_{3} D_{3}---C C t$

where

: colon signifying a record mark

$F \quad$ function code

$D_{1} D_{1} D_{2--} \quad$ Digitized parametrics, low channels sent first with the most significant nibble of the 8-bit byte followed by the lower significant nibble

CC modulo 100 sum of all digits in $F D_{1} D_{1} D_{2} D_{2}-\cdots$

$\downarrow$ carriage return signifying an end of record mark

\subsection{Control Messages}

1. SEC Poll: When the SEC is ready to start a test, it will send a message with FDCC set to ASCII 0; i.e., :0000t. The message repeats at regular intervals until the REP responds with a "ready" message.

2. REP Ready: When the REP is ready to perform guidance/acquisition cycles, it responds to the SEC poll by returning a message with the $F_{1} D_{1} D_{2} D_{2}---$ and $C C$ fields set to ASCII 0 ; i.e., :00000----00ł.

3. REP Negative Acknowledgement: If the REP receives a message from the SEC in error (e.g., bad checksum) it responds with a message with the $D_{1} D_{1} D_{2} D_{2}--$ field set to ASCII $N^{\prime} s$; i.e., :FNNNN---CCl.

4. SEC Negative Acknowledgement: If the SEC receives a message in error, it will repeat the last transmission.

5. REP Self-Diagnostic Error: Upon power-up the REP will undergo initialization and then perform a self-diagnostic routine. If the diagnostics fail, it will respond to the SEC poll with a designated function code $F$ and all data, $D_{1} D_{1}--C C$, set to ASCII Q's, i.e., : FQQ----QQL.

\subsection{Microprocessor Flow Chart}

Figure 16 is a flow chart showing the manner in which the microprocessor will control the Datel DAS-952R A/D data acquisition chip. 


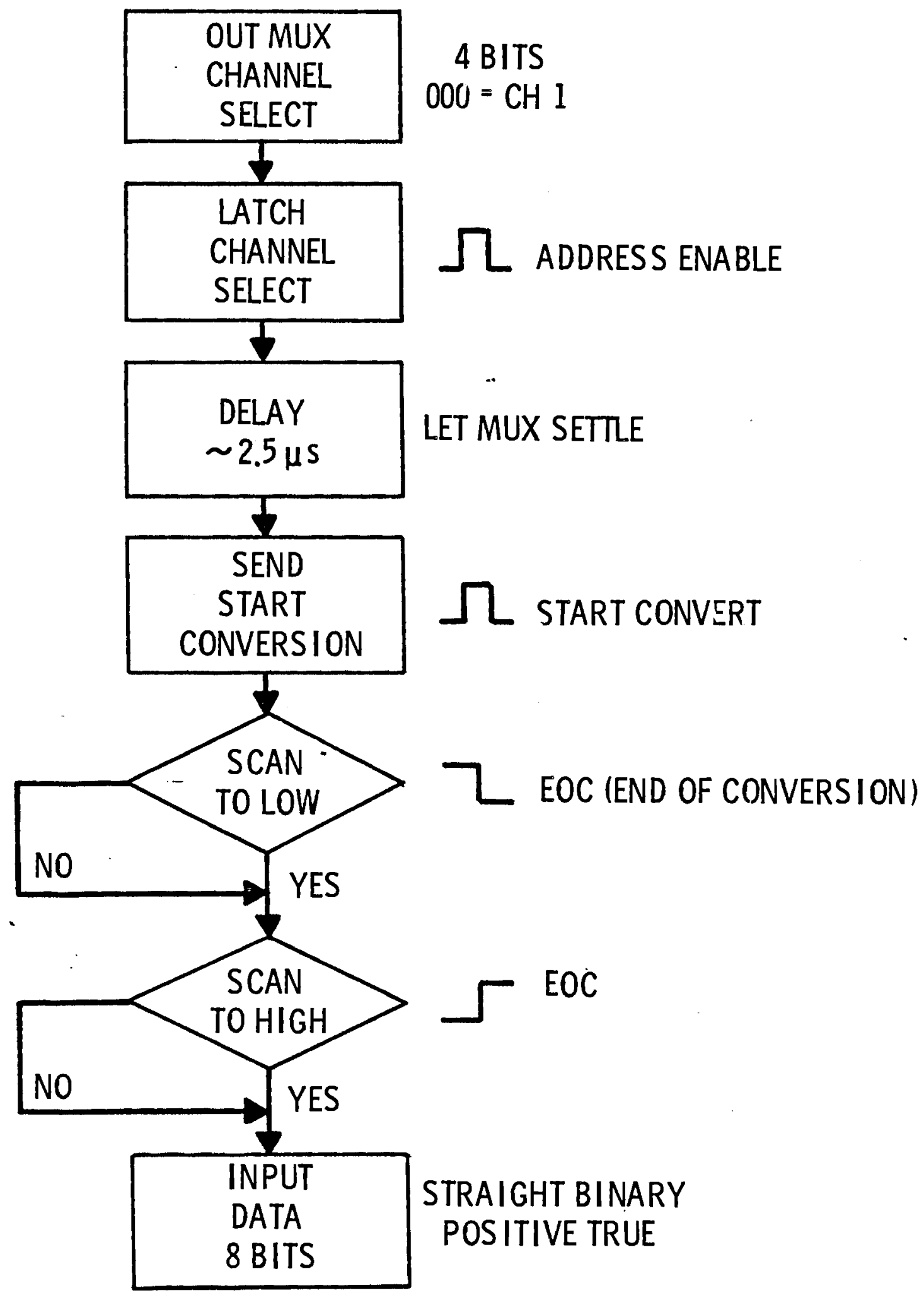

FIGURE 16. Downhole Microprocessor Flow Chart for Controlling the A/D Acquisition Chip (Date1 DAS-952R) 


\subsection{GUIDANCE PHILOSOPHY}

\subsection{Introduction}

Guiding the cutterhead vertically and guiding it horizontally involve different sensors and different algorithms. The inclinometers used as sensors for vertical guidance cannot be used for horizontal guidance since they are gravity referenced. It appears that in many instances the natural gamma probe will be the preferred roof and floor sensor. On the other hand, this sensor is not appropriate for horizontal mode guidance as a stump thickness sensor. There are choices of sensors and guidance mode algorithms for the horizontal guidance operation which differ from those for vertical operation. Since vertical and horizontal guidance modes are significantly different they are discussed separately below.

\subsection{Vertical Guidance}

The objective of the vertical guidance operation is to keep the auger within the coal seam on a path having a minimum of curvature. Guidance by means of sensing roof and floor locations only is not optimum. Improved coal recovery can be realized if the roof and floor contours observed in the previous hole are used in developing guidance instructions for the hole being augered. The roof and floor contours of a hole can be determined from the succession of inclinometer readings measuring the pitch of the cutterhead. A direct and simple past hole memory would be achieved by storing pitch inclinometer readings for equally spaced depth position. The corresponding roof and floor positions relative to the augerhead position could also be stored. This would involve the storage of four measured values (depth, pitch, roof and floor) for each data entry and it would not provide any easily interpretable absolute contour information about the roof or the floor. What we have chosen to do is integrate the pitch inclinometer readings to develop an absolute contour map of the centerline of the coal seam. Past hole memory is loaded with only one vertical coordinate for each depth position. Guidance instructions are generated on the basis of this previous hole centerline contour unless overridden by out-of-bounds signals from the roof or the floor sensor. Specifically, the guidance instruction is concerned with aiming the cutterhead to 
intercept the previous hole vertical position 10 feet ahead of its current depth unless overridden by out-of-bounds signals from the roof or the floor sensor. Interception of either the roof or the floor will cause an abort light to flash at the control station allowing the operator to terminate the run.

Consider the greatly exaggerated cutterhead course illustrated in Figure 17. Each straight line segment of the course is of length $L$ equal to the length of the cutterhead. The pitch inclinometer measures the angle $\theta$ from which the slope

$$
\mathrm{m}=\tan \theta
$$

can be determined. The vertical and depth coordinates ( $V, D)$ for each point on the course are determined as follows. For $D=0, V$ is given an arbitrary value, $v_{0}$, convenient for the operation. It may be that $v_{0}=0$. $v_{1}$ is determined from

$$
V_{1}=V_{0}+L \sin \theta_{1}
$$

and $V_{2}$ from

$$
\begin{aligned}
V_{2} & =V_{1}+L \sin \theta_{2} \\
& =V_{0}+L\left(\sin \theta_{1}+\theta_{2}\right) .
\end{aligned}
$$

It follows that $v_{m}$ is given by

$$
V_{m}=V_{n-1}+L \sin \theta_{n-1}
$$

or, al ternatively,

$$
V_{m}=V_{0}+L \sum_{i=1}^{n} \sin \theta_{i}
$$




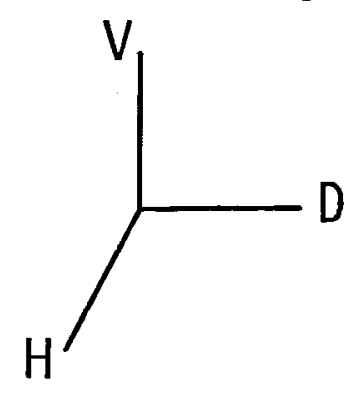

$\omega$

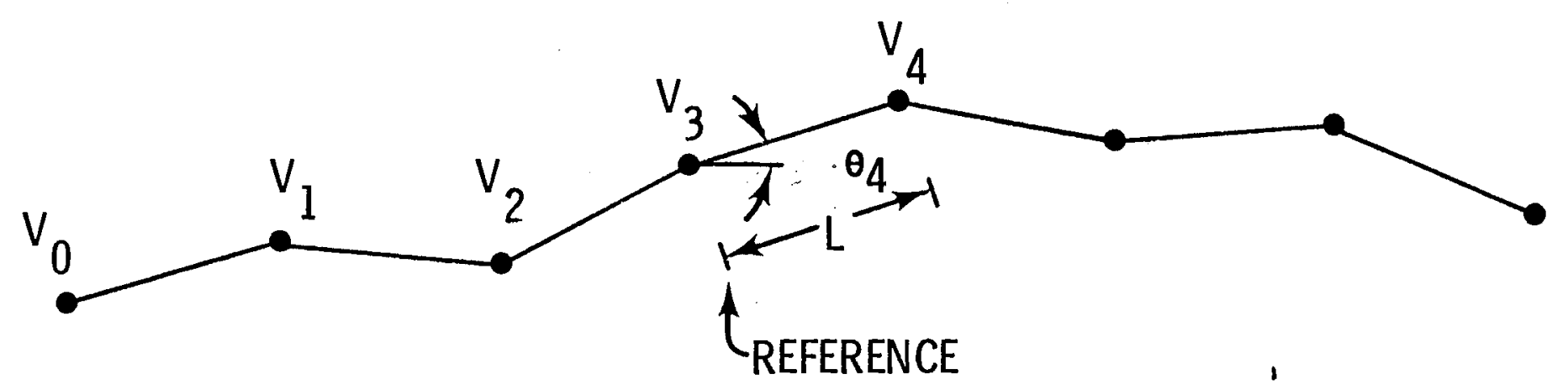

FIGURE 17. A Schematic Representation of the Cutterhead Course with Exaggerated Angular Deflections 
The depth is given by

$$
\begin{aligned}
D_{m} & =D_{n-1}+L \cos \theta_{n-1} \\
& =L \sum_{i=1}^{n} \cos \theta_{i}
\end{aligned}
$$

since $D_{0}$ is taken to be zero.

\subsection{Horizontal Guidance}

Horizontal guidance is based upon the idea that the horizontal course should be straight, i.e., that it should have a constant horizontal heading. Guidance instructions will be generated to attain this end unless the stump thickness sensor indicates that the course must be changed to preserve adequate stump thickness. The only feasible stump thickness sensor appears to be a radar type sensor. Sensing the absolute heading is possible only through the use of a north seeking gyroscope. It is possible however to obtain a measure of the horizontal radius of curvature from a measurement of the horizontal thrust pad extension. This extension is measured by means of an LVDT as i1lustrated in Figure 7.

The horizontal position is denoted by the coordinate $x[2, K] . \quad X[2, K]$ must be derived from the measurement $S[9]$ of a thrust pad position sensed by an LVDT. Most standard books on elementary calculus demonstrate that radius of curvature $R$, of any curve described by the equation $y=f(z)$ is given by

$$
\frac{1}{R}=\frac{y^{\prime \prime}}{\left(1+\left(y^{\prime}\right)^{2}\right)^{3 / 2}}
$$

where

$$
y^{\prime \prime}=d^{2} y / d z^{2}
$$

and

$$
y^{\prime}=d y / d z
$$


The slope $y^{\prime}$ at any position $P$ (Figure 18) along the trajectory is given by

$$
y^{\prime}=L \sum y^{\prime \prime}+M_{0} \equiv M
$$

where $L$ is the distance moved between measurements. This distance should ideally be the distance between the support shoe at the trailing part of the cutterhead section and the leading edge of the cutterhead as illustrated in Figure 19. $M_{0}$ is the initial entry slope. It follows from these equations that

$$
y^{\prime \prime}=\left(1+M^{2}\right)^{3 / 2} / R
$$

We will calculate new value of M using Eq. 12 by substituting Eq. 13 (using the previous value of $M$ ) into Eq. 12. On this basis

$$
M=\sum_{p=1}^{K}\left(1+M_{p}^{2}\right)^{3 / 2} / R+\text { Mo. }
$$

It is apparent from Figure 18 that

$$
C[5]=R-\sqrt{R^{2}-r^{2}}
$$

and since $r \simeq 2 \mathrm{ft}$ while the minimum value of $R$ is $330 \mathrm{ft}$, we can approximate this equation by

$$
C[5]=\frac{r^{2}}{2}\left(\frac{1}{R}\right) \text {. }
$$

Equation 6 becomes

$$
C[5] L\left(1+M^{2}\right)^{3 / 2} / r^{2}+M \rightarrow M
$$

in which the previous value of $M$ is used on the left hand side of the arrow to generate the new value of $M$ on the right hand side. Since $r \equiv L[7]$

$$
C[5] L\left(1+M^{2}\right)^{3 / 2} / L[7]^{2}+M \rightarrow M .
$$




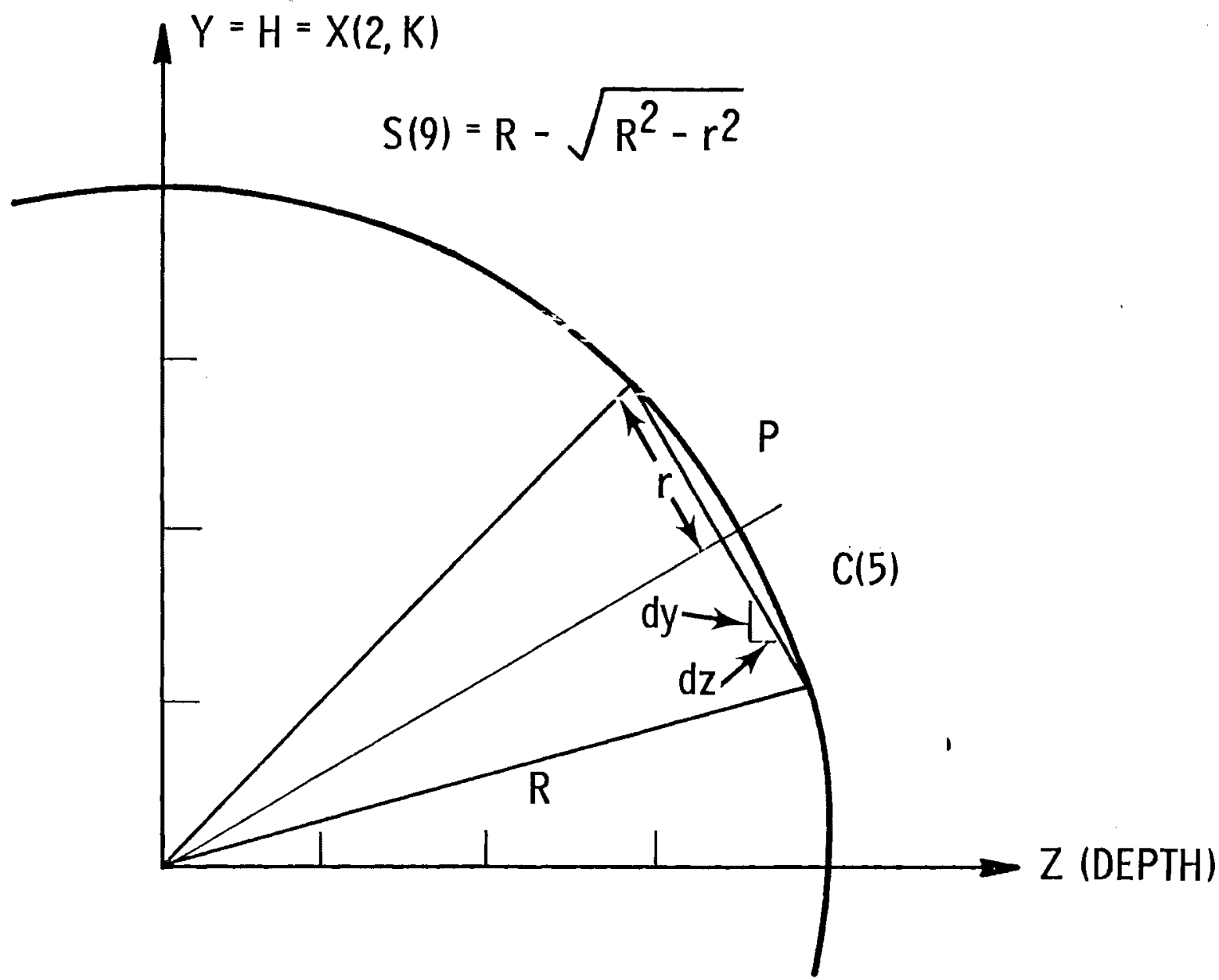

FIGURE 18. Diagram Illustrating the Relationship of the LVDT Reading S[9] to the Radius of Curvature $R$ of the Course of the Auger 


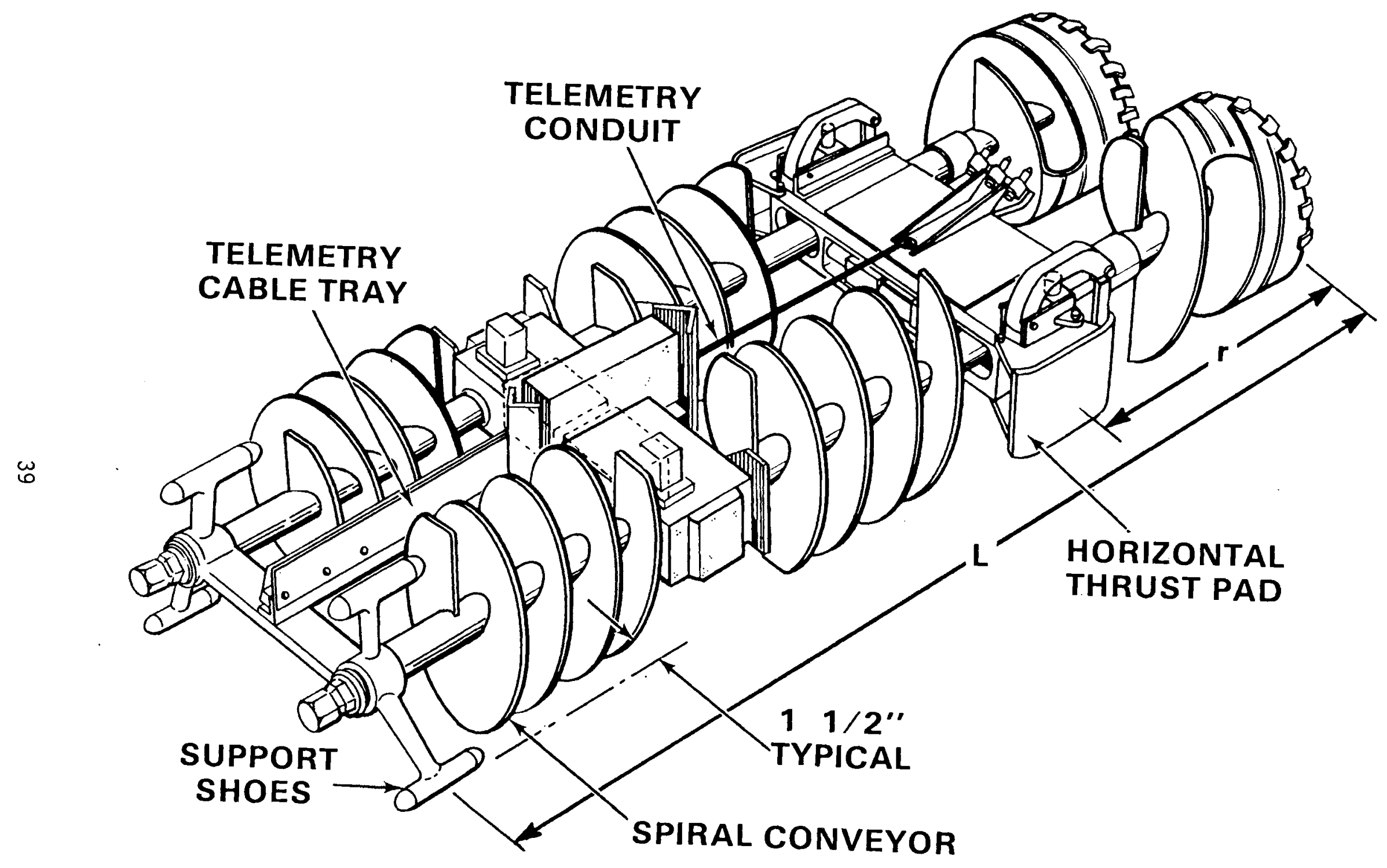

CUTTERHEAD AND GUIDANCE ASSEMBLY

FIGURE 19. Plan View of Cutterhead 
The value of $X[2, K]$ is calculated from the previous value of $X[2, K-1]$ using the recursion formula

$$
X[2, K-1]+L \sin (\operatorname{atn} M)+X[2, K]
$$

as illustrated in Figure 20.

A north seeking gyro would provide a better solution to the task of defining the horizontal coordinate. It would provide a measure of the horizontal heading $\theta$ at any point along the course. Readings would be taken at increments, $L$, equal to the length of the cutterhead (see Figure 19). Calculation of the horizontal coordinate $X[2, K]$ follows precisely the pattern in which the vertical coordinate $V_{k}=X[1, K]$ was calculated, namely

$$
x[2, K]=x[2, K-1]+L \sin \theta_{K-1}
$$

or, al ternatively,

$$
x[2, K]=x[2,0]+L \sum_{i=1}^{K} \sin \theta_{i-1}
$$

where the $\theta_{K}$ are gyroscope readings at positions $K$ at depths $D_{K}$ given by Eq. 7. A more precise formulation of Eq. 7 would include the effects of the horizontal component of $\theta$ but this component will be negligable due to the horizontal guidance method which seeks to maintain a constant horizontal heading.

\subsection{Roll Correction}

It is assumed that a dual auger should always maintain the same roll position throughout a run. Normally it is expected that the roll orientation should be zero degrees, i.e., the two auger axes should be in the same horizontal plane. If the coal seam dips out of the horizontal plane in a direction other than the direction of drilling it is possible to set the equipment to be operated at a constant non-zero roll position. Roll correction is accomplished by means of two pairs of vertical thrust pads, either of which may be activated to push down while the other is pushing up. 


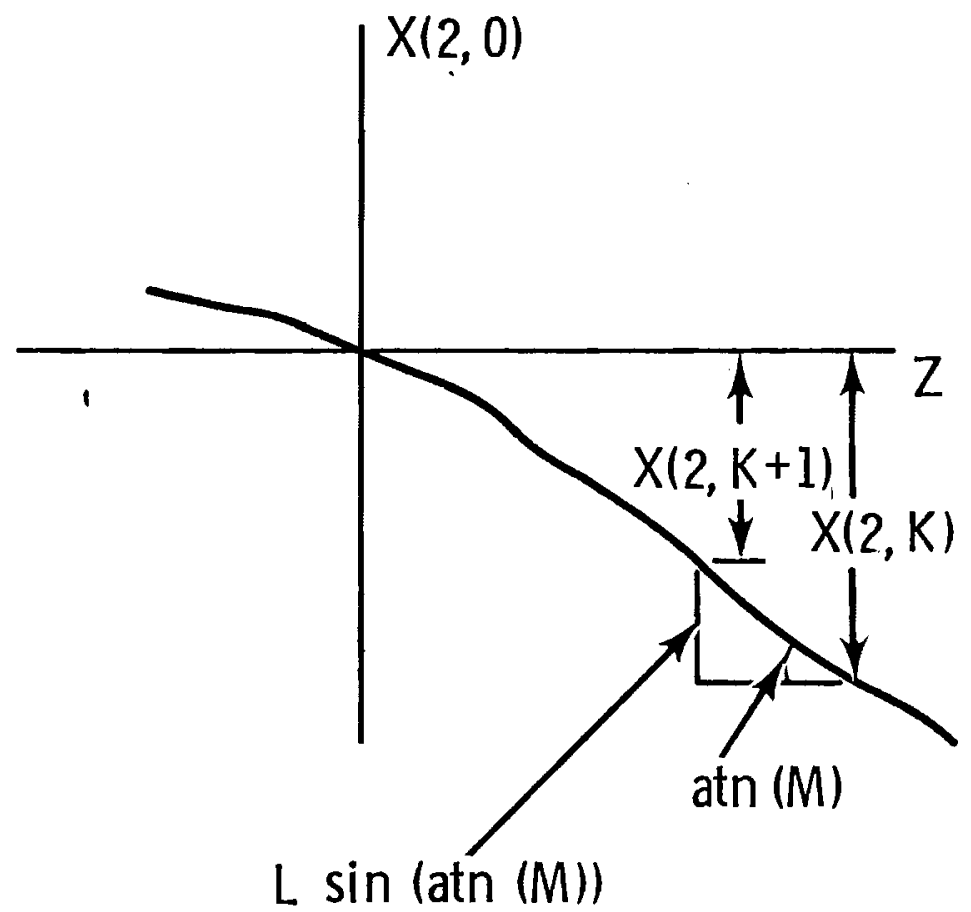

$X(2, K-1)+L \sin ($ atn $(M)) \rightarrow X(2, K)$

FIGURE 20. Diagram Illustrating the Recursion Formula for Calculating the Horizontal Coordinate $\mathrm{X}[2, \mathrm{~K}]$ 


\subsection{Guidance Commands}

All the possible auger course corrections are performed through the use of six thrust pads. Nomenclature for identifying these six thrust pads is given in Figure 21. Only three double acting hydraulic cylinders are used to move the thrust pads. Thrust pads VLT and VLB are coupled to one hydraulic cylinder, pads VRT and VRB to another and pads HL and HR to the third. The three hydraulic cylinders are designated as VL, VR and LR. There are two solenoids on each of these cylinders and associated with each cylinder there is also a solenoid operated relief valve as illustrated in Figure 8 . Thus there are a total of nine solenoids used to perform the guidance instructons. Table 2 assigns a number to each of the nine solenoids. This number will be used in the protocol for specifying commands. Guidance commands will be transmitted from the SEC to the REP in two letter ASCII code. Table 3 gives the letters chosen to identify each command. Table 4 identifies the combination of solenoids that are activated to execute each guidance command.

\subsection{MUX Channel Assignments}

For programming purposes specific channels of the DAS-952R multiplexer must be assigned to each sensor. Information regarding these assignments is given in Figure 22. 


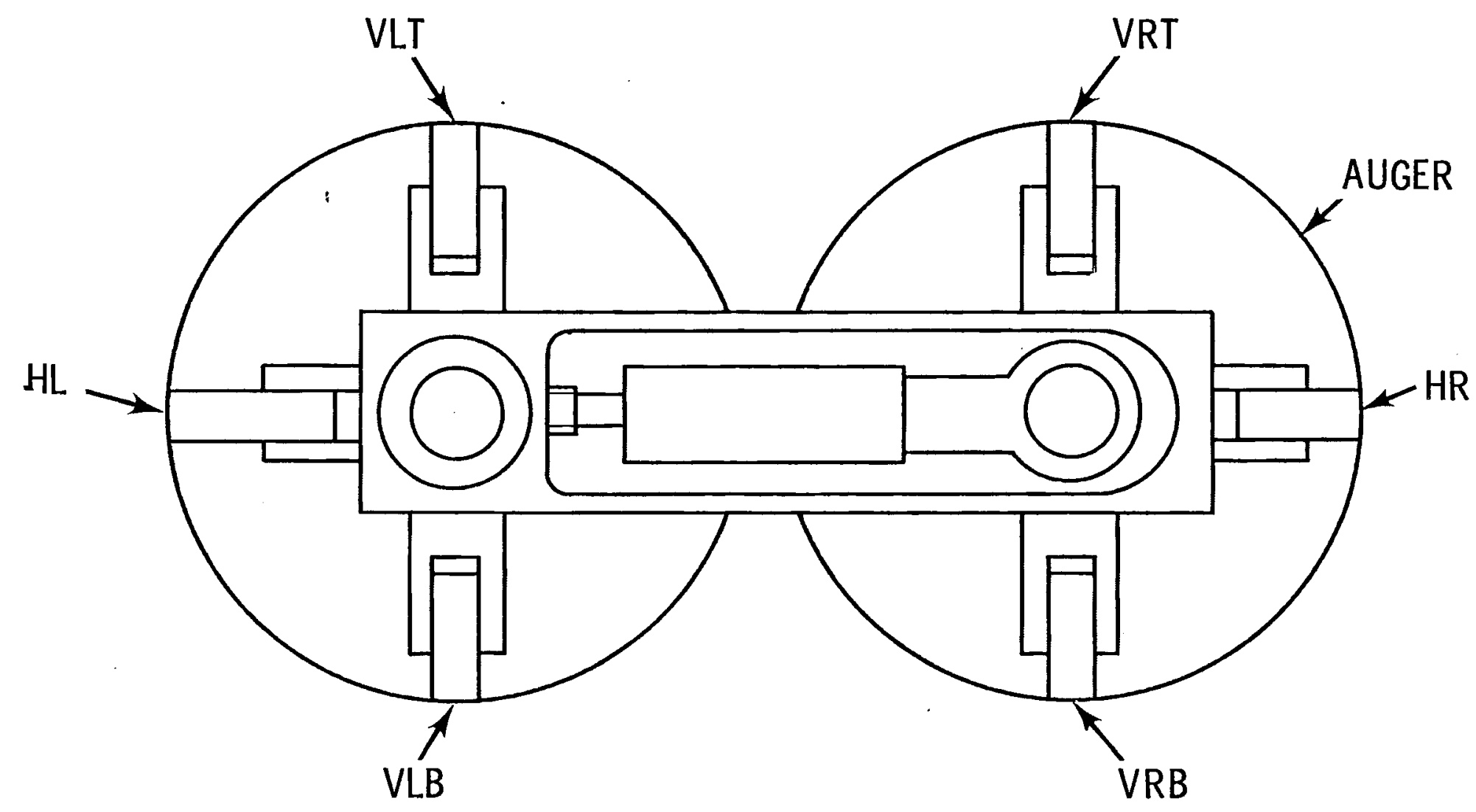

FIGURE 21. Schematic Drawing Labeling the Six Thrust Pads Used for Steering the Cutterhead. Viewed from SEC location. 
TABLE 2. Assignment of Solenoid Numbers

\begin{tabular}{|c|c|c|}
\hline $\begin{array}{l}\text { Solenoid } \\
\text { Identification } \\
\end{array}$ & $\begin{array}{c}\text { Solenoid } \\
\text { Number } \\
\end{array}$ & $\begin{array}{l}\text { Bypass } \\
\text { Valve }\end{array}$ \\
\hline VLT/B & $1 / 2$ & 7 \\
\hline VRT/B & $3 / 4$ & 8 \\
\hline$L / R$ & $5 / 6$ & 9 \\
\hline
\end{tabular}

TABLE 3. List of Guidance Commands

\begin{tabular}{|c|c|}
\hline Vertical and Roll & Command \\
\hline Drift Up & A \\
\hline Drift Down & B \\
\hline Twist CW \& Drift Up & C \\
\hline Twist CCW \& Drift Up & D \\
\hline Twist CW \& Drift Down & $E$ \\
\hline Twist CCW \& Drift Down & $F$ \\
\hline Twist CW & G \\
\hline Twist CCW & H \\
\hline Neutral & I \\
\hline
\end{tabular}

The horizontal commands are $L, R$ and $N$ for Left, Right and Neutral. The series of commands are therefore

$$
\begin{aligned}
& A L, A R, A N \\
& B L, B R, B N \\
& \text { etc. } \ldots \\
& \text { IL, IR, IN }
\end{aligned}
$$


TABLE 4. Solenoids Activated for Each Command Word

\begin{tabular}{|c|c|c|c|c|c|c|c|c|c|}
\hline Command & 1 & $\begin{array}{l}\text { So } \\
2 \\
\end{array}$ & $\begin{array}{c}\text { Teno } \\
3 \\
\end{array}$ & $\begin{array}{c}\text { oids } \\
4 \\
\end{array}$ & $5 \mathrm{Ac}$ & 5 & $\begin{array}{l}\text { lat } \\
7 \\
\end{array}$ & $\begin{array}{r}e d \\
8 \\
\end{array}$ & 9 \\
\hline$A L$ & 1 & & 3 & & 5 & & & & \\
\hline$A R$ & 1 & & 3 & & 6 & 6 & & & \\
\hline AN & 1 & & 3 & & & & & & 9 \\
\hline$B L$ & & 2 & & 4 & 5 & & & & \\
\hline BR & & 2 & & 4 & 6 & 6 & & & \\
\hline BN & & 2 & & 4 & & & & & 9 \\
\hline$C L$ & 1 & & & & 5 & & & 8 & \\
\hline CR & 1 & & & & 6 & 6 & & 8 & \\
\hline $\mathrm{CN}$ & 1 & & & & & & & 8 & 9 \\
\hline DL & & & 3 & & 5 & & 7 & & \\
\hline DR & & & 3 & & 6 & 6 & 7 & & \\
\hline DN & & & 3 & & & & 7 & & 9 \\
\hline$E L$ & & & & 4 & 5 & & 7 & & \\
\hline ER & & & & 4 & 6 & 6 & 7 & & \\
\hline EN & & & & 4 & & & 7 & & 9 \\
\hline $\mathrm{FL}$ & 1 & & & & 5 & & & 8 & \\
\hline FR & 1 & & & & 6 & 6 & & 8 & \\
\hline FN & 1 & & & & & & & 8 & 9 \\
\hline GL & 1 & & & 4 & 5 & & & & \\
\hline GR & 1 & & & 4 & 6 & 6 & & & \\
\hline GN & 1 & & & 4 & & & & & 9 \\
\hline$H L$ & & 2 & 3 & & 5 & & & & \\
\hline HR & & 2 & 3 & & 6 & 6 & & & \\
\hline $\mathrm{HN}$ & & 2 & 3 & & & & & & g \\
\hline IL & & & & & 5 & & 7 & 8 & \\
\hline IR & & & & & 6 & 0 & 7 & 8 & \\
\hline IN & & & & & & & 7 & 8 & 9 \\
\hline
\end{tabular}




\section{QUANTITY MEASURED}

STUMP THICKNESS

ROOF

FLOOR

ROLL

VL POSITION

VR POSITION

PITCH

YAW

LR POSITION

के THRUST

TORQUE

THRUST

TORQUE

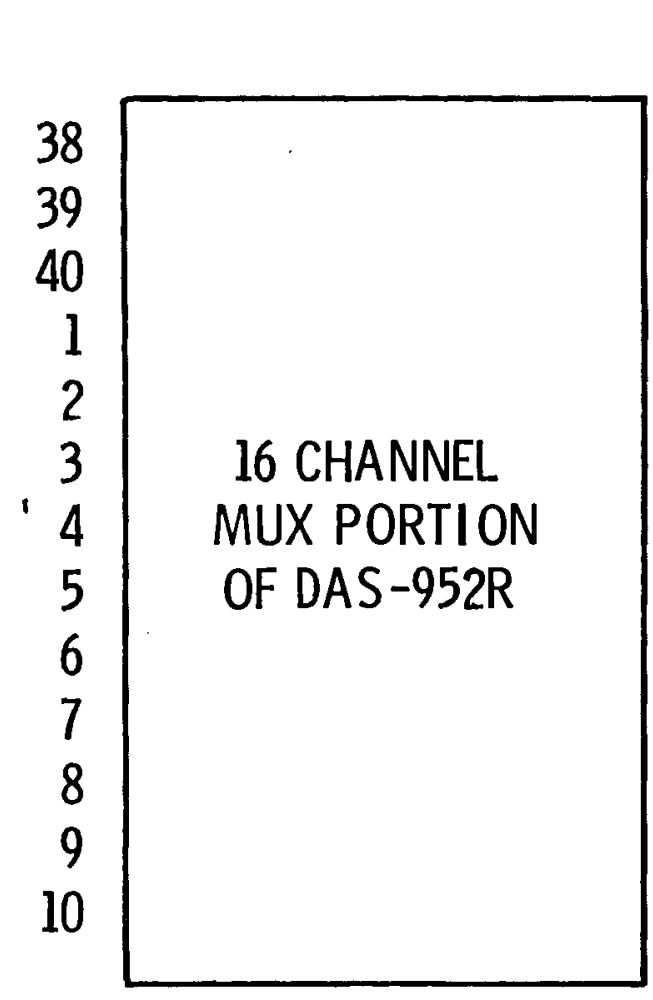

$\frac{\text { SENSOR }}{\text { RADAR }}$

NATURAL $\gamma$

NATURAL $\gamma$

INCLINOMETER

$\mathrm{LVDT}_{1}$

$\mathrm{LVDT}_{2}$

INCLI NOMETER

GYRO

$\mathrm{LVDT}_{3}$

STRAIN GAUGE

STRAIN GAUGE

STRAIN GAUGE

STRAIN GAUGE
PROGRAM DESIGNATION

$S(1)$

$S(2)$

$S(3)$

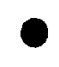

0

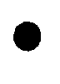

$S(9)$

$S(10)$

$S(11)$

$S(12)$

$S(13)$

FIGURE 22. Multiplex Channel Assignments 


\subsection{SUMMARY AND CONCLUSIONS}

Stating with the general system description given in the previously referenced R.A. Hanson, Inc. report we have identified a specific computer for use in the surface electronic controller. Peripheral equipment suitable for use with this computer has also been identified. Similarly a suitable microprocessor and data aquisition system have been identified for use downhole in the remote electronics package. Algorithms for guidance control based upon sensor data have been worked out and translated into a program for the computer. Detailed programing of the microprocessor has not been carried out since that step would be more appropriately done with the electronic hardware in hand and assembled into a system. Programs for simulating auger runs in thin coal seams have been included in this report to assist in the understanding of the results which can be achieved in using an automatic guidance system.

Providing that sensors for roof, floor and rib thickness have been adequately qualified, progress toward an effective extended depth auger miner for thin coal seams can best be served by purchasing the hardware identified in this study and assembling it into an integrated system. 



\section{APPENDIX A}

DATA SHEETS FOR THE

REMOTE ELECTRONICS PROCESSOR (REP) 


\section{APPENDIX A \\ DATA SHEETS FOR THE REMOTE ELECTRONICS PROCESSOR (REP)}

The data sheets included here are representative of products and devices which could be used in the REP portion of the guidance system. No endorsement of the specific manufacturers product is intended. In most cases severa 1 al ternate manufacturers products could be used.

No flyer is included covering the radar system which was recommended for stump thickness measurement. A da.ta sheet is included on a gyro which was discussed as an alternate system for sensing heading in the horizontal plane. The electronic package associated with this north seeking gyro would occupy only a small amount of the otherwise unused space in the REP enclosure.

See the text and Figure 13 for other comments relating to the sensors and effectors described by these data sheets.

Data sheets reprinted by permission of the respective companies. 


\title{
I8048/8748/8035L
}

\section{INDUSTRIAL TEMPERATURE RANGE SINGLE COMPONENT 8-BIT MICROCOMPUTER}

\author{
- 8048 Mask Programmable ROM \\ - 8648 One-Time Factory Programmable EPROM \\ - 8748 User Programmable/Erasable EPROM \\ - 8035/8035L External ROM or EPROM \\ - $-40^{\circ} \mathrm{C}$ to $+85^{\circ} \mathrm{C}$ Operation
}

\author{
- 8-Bit CPU, ROM, RAM, I/O in Single \\ Package \\ - Interchangeable ROM and EPROM \\ Versions \\ - Single 5V Supply \\ - $2.5 \mu \mathrm{sec}$ and $5.0 \mu \mathrm{sec}$ Cycle Versions: \\ All instructions 1 or 2 Cycles \\ - Over 90 Instructions: $\mathbf{7 0 \%}$ Single Byte
}
- $1 \mathrm{~K} \times 8 \mathrm{ROM} / \mathrm{EPROM}$ $64 \times 8$ RAM 27 IIO LINES
- Interval Timer/Event Counter
- Easily Expandable Memory and $1 / 0$
- Compatible with 8080/8085 Series Peripherals
- Single Level Interrupt

The intel $8048 / 8648 / 8748 / 8035$ is a totalty self-sufflcient 8 -bit parallel computer fabricated on a single silicon chip using Intel's $\mathrm{N}$-channel silicon gate MOS process.

The 8048 contains a $1 \mathrm{~K} \times 8$ program memory, a $64 \times 8$ RAM data memory, 27 WO lines, and an 8-bit timer/counter in addition to on-board oscillator and clock circuits. For systems that require extra capability, the 8048 can be expanded using standard memories and MCS $-80^{\mathrm{TM}} / \mathrm{MCS}^{-85^{\mathrm{TM}}}$ peripherals. The 8035 is the equivalent of an 8048 without program memory. The $8035 \mathrm{~L}$ has the RAM power-down mode of the 8048 while the 8035 does not. The 8648 is a one-time programmable (at the factory) 8748 which can be ordered as the first 25 pieces of a new 8048 ROM order. The substitution of 8648 's for 8048 's allows for very fast turnaround for initial code verification and evaluation units.

To reduce development problems to a minimum and provide maximum flexibility, three interchangeable pin.compatible versions of this single component microcomputer exist: the 8748 with user-programmable and erasable EPROM program memory for prototype and preproduction systems, the 8048 with factory-programmed mask ROM program memory for low cost, high volume production, and the 8035 without program memory for use with external program memories.

This microprocessor is designed to be an efficient controller as well as an arithmetic processor. The 8048 has extensive bit handling capability as well as facilities for both binary and BCD arithmetic. Efficient use of program memory results from an instruction set consisting mostly of single byte instructions and no instructions over 2 bytes in length.

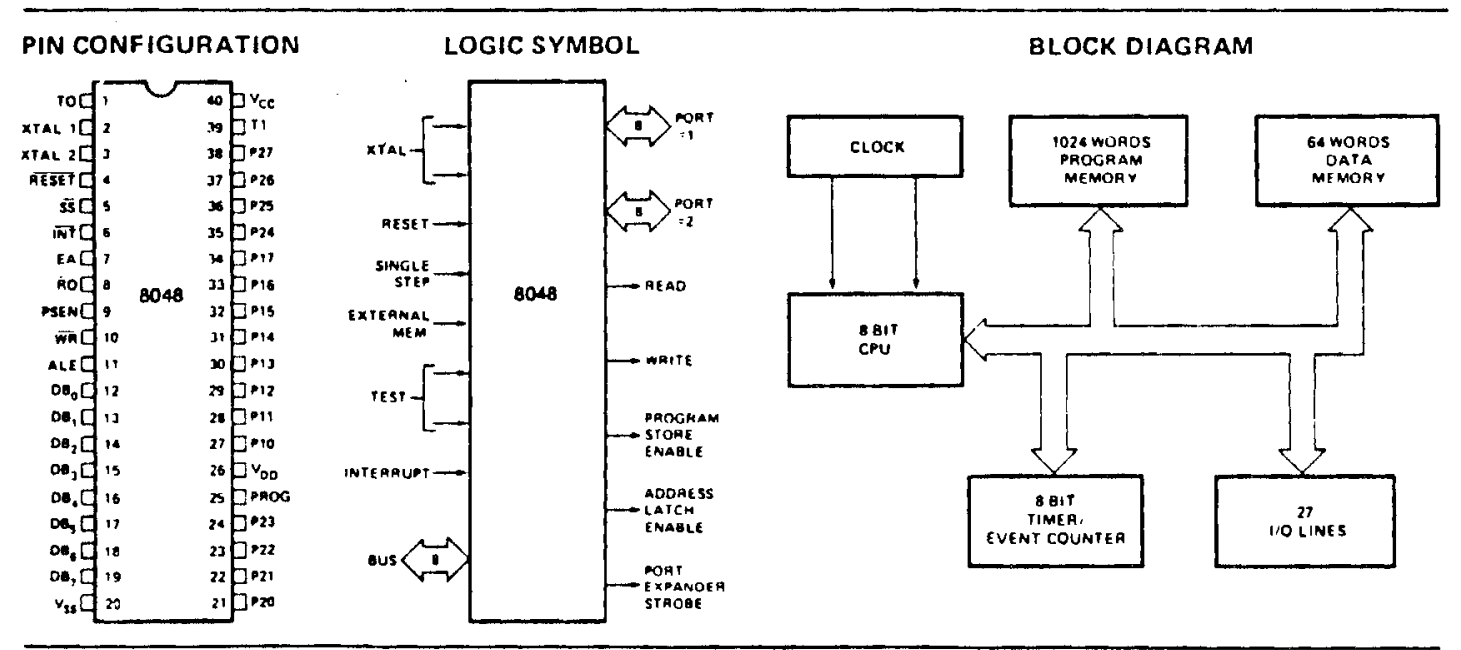

Reprinted by permission of Intel Corporation, Cooyright 1980. 


\section{3 \\ MCS-48 ${ }^{\circledR}$ INPUT/OUTPUT EXPANDER}

\author{
Low Cost \\ Simple Interface to MCS $-48^{\circ}$ \\ Microcomputers \\ a Four 4-Bit l/O Ports \\ AND and OR Directly to Ports
}

\author{
24-PIn DIP \\ Single 5V Supply \\ High Output Drive \\ Direct Extension of Resident 8048 1/O \\ Ports
}

The Intel 8243 is an input/output expander designed specifically to provide a low cost means of $1 / 0$ expansion for the MCS-48 ${ }^{\circ}$ family of single chip microcomputers. Fabricated in 5 volts NiMOS, the 8243 combines low cost, single supply voltage and high drive current capability.

The 8243 consists of four 4-bit bidirectional static $1 / O$ ports and one 4-bit port which serve_ as an interface to the MCS-48 microcomputers. The 4-bit interface requires that only 4 I/O lines of the 8048 be used for $1 / 0$ expansion, and also allows multiple 8243 's to be added to the same bus.

The 1/O ports of the 8243 serve as a direct extension of the resident $1 / O$ fa-ilities of the MCS-48 microcomputers and are accessed by their own MOV. ANL, and ORL instructions.
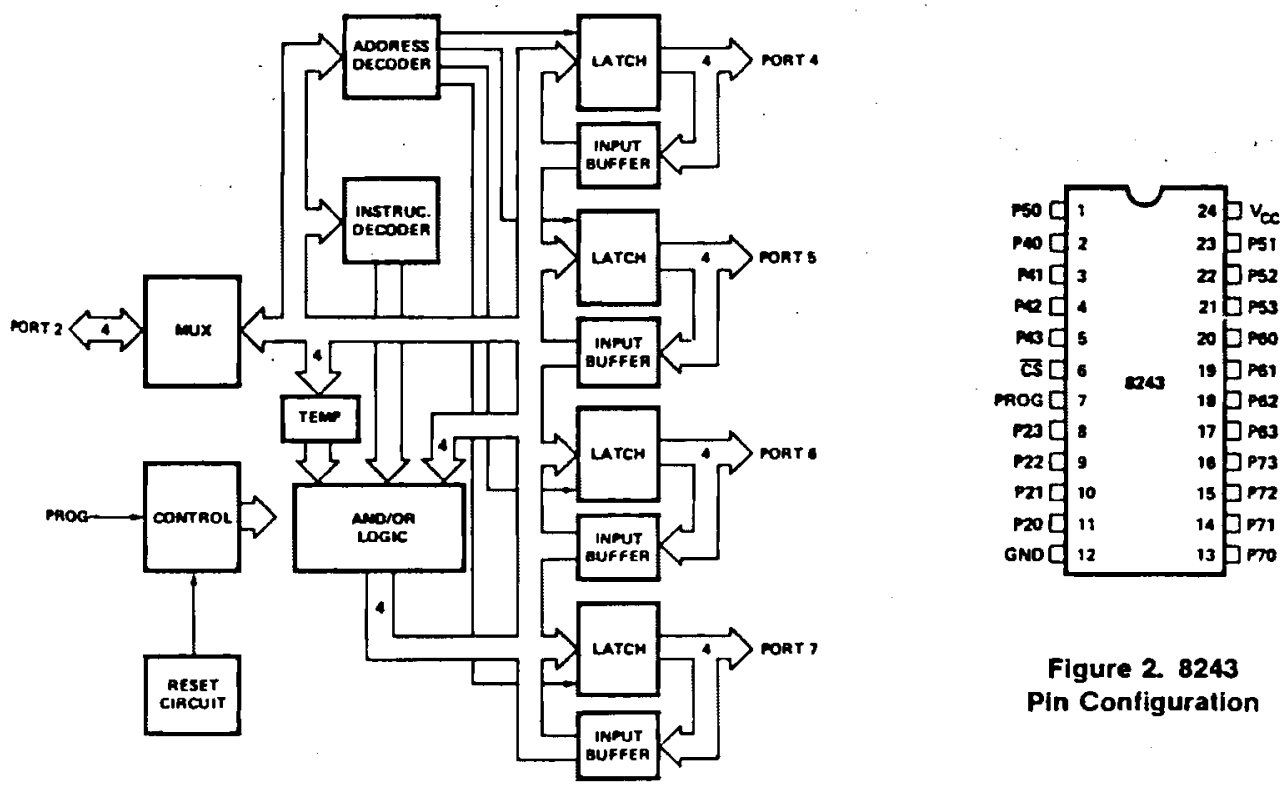

Figure 1. 8243

Block Diagram

Figure 2. 8243

Pin Configuration 
FEATURES

- 16 Single Ended Channels

- 8 Bits Resolution

- Monolithic CMOS Construction

- Three-State Outputs

- Ratiometric Operation

- Low Cost

\section{GENERAL DESCRIPTION}

The DAS-952R is a single-chip, 16 channel, 8 bit data acquisition system. Monolithic CMOS technology allows a 16 channel multiplexer, 8 bit successive approximation $A / D$ converter, and microprocessorcompatible control logic to be fabricated on a single chip and contained in a compact Dual-In-Line package.

The design of this system emphasizes high accuracy, excellent repealability. low power consumption, and a minimum of adjustments (no full scale or zero adjustment required). Latched and decoded address inputs and latched TTL three-state outputs allow easy interfacing to microprocessors.

The input multiplexer allows random access to any one of 16 single ended analog input channels and provides necessary logic for additional channel expansion. Connection of the multiplexer output to the converter input is by external pin connection, thus permitting easy signal conditioning such as amplification, linearization, or the use of a sample and hold.

The 8 bit A/D converter uses a 256R ladder network, successive approximation register. and a chopper-stabilized comparator to implement the successive approximation conversion technique with a switching tree. Use of 256R ladder network ensures monotonicity while the chopper-stabilizer comparator makes the converter highly resistant to thermal effects and long term drift. In ratiometric conversion, the converter expresses the analog value being measured as a percentage of reference input. Full scale range may be selected within limits, to adjust the sensitivity of the converter to the desired application or to refer the output to a secondary standard.

Accuracy, speed, flexibility, excellent performance over a wide temperature range $\left(-25^{\circ} \mathrm{C}\right.$ to $\left.+85^{\circ} \mathrm{C}\right)$ and low cost make the DAS-952R an easy and practical answer to many data acquisition needs.

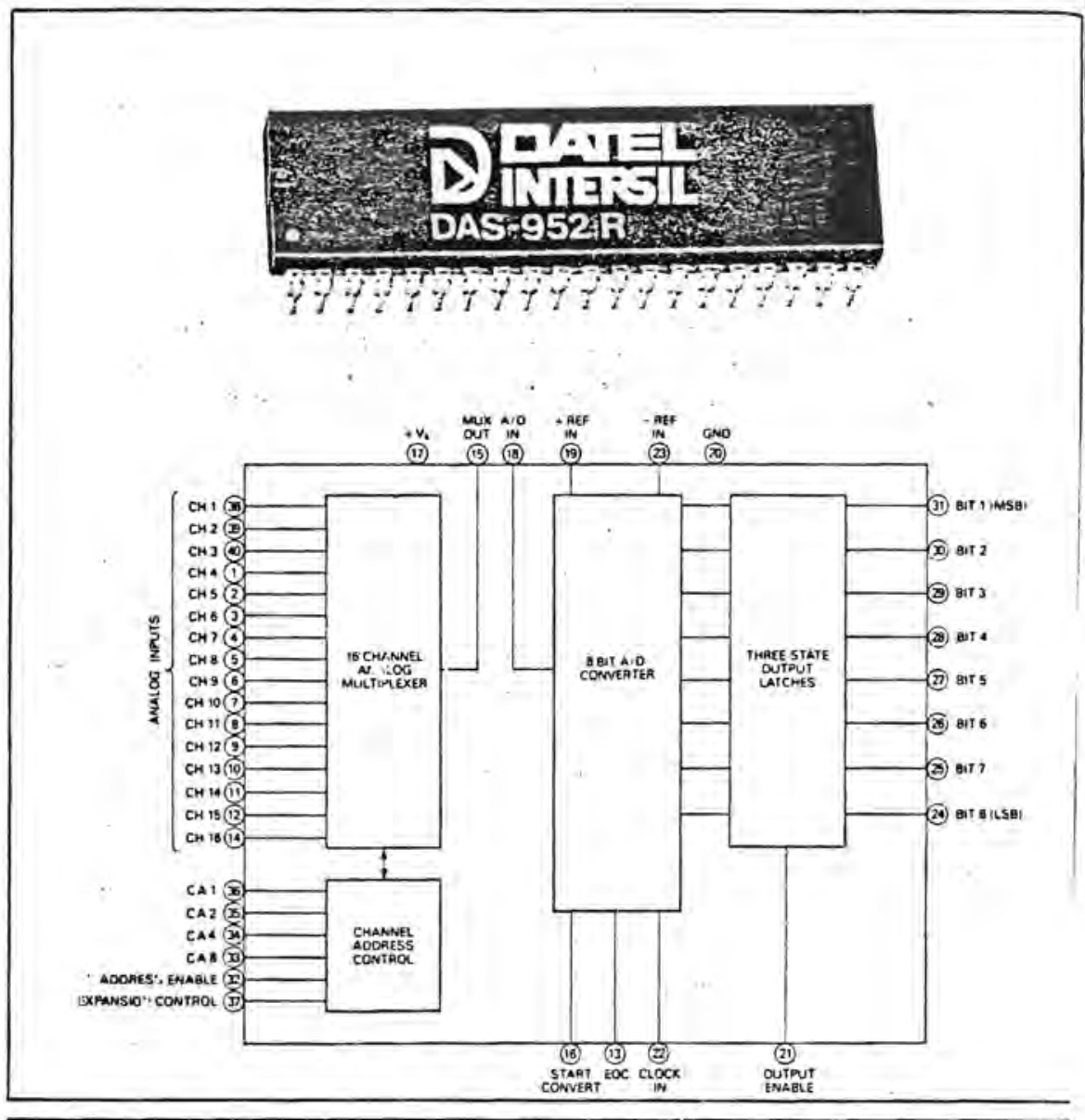

MECHANICAL DIMENSIONS INCHES (MM)

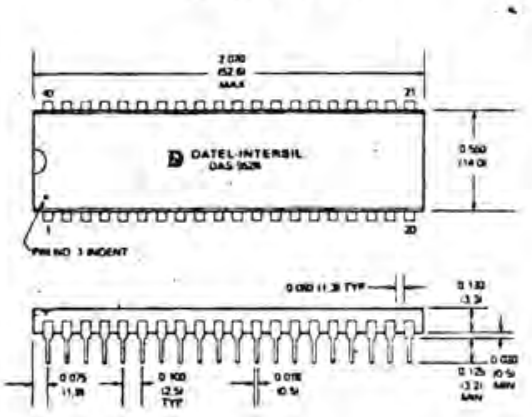

INPUT/OUTPUT CONNECTIONS

\begin{tabular}{|c|c|c|c|}
\hline PIN & FUNCTION & $P$ PIN: & FLNCTION \\
\hline t & $\mathrm{CH} 4 \mathrm{NW}$ & 21 & OUTPUT ENAELE \\
\hline 2 & CHSIN & 22 & CLOCA INPUT \\
\hline 3 & $\mathrm{CH} 6 \mathrm{WN}$ & 23 & -AEF IN \\
\hline 4 & $\mathrm{CH} T \mathbb{N}$ & 24 & BIT Q OUT ILSEI \\
\hline 5 & $\mathrm{CH} 8 \mathrm{CN}$ & 25 & $81770 \mathrm{NT}$ \\
\hline 5 & $\mathrm{CH} 9 \mathrm{IN}$ & 26 & GISOOUT \\
\hline 7 & $\mathrm{CH} 10 \mathrm{IN}$ & 27 & BIT SOUT \\
\hline B & $\mathrm{CH} \| \mathbb{N}$ & 28 & 817 4007 \\
\hline 9 & $\mathrm{CH} 12 \mathrm{IN}$ & 29 & BIT 3 OUT \\
\hline 10 & $\mathrm{CH} / 3 \mathrm{IN}$ & 30 & B.T 2OUT \\
\hline 19 & $\mathrm{CH} / 4 \mathrm{IN}$ & 31 & BIT I OUT, MSB, \\
\hline 12 & CH 15 IN & 32 & ADDAESS ENABLE \\
\hline 33 & $E O C$ & 33 & CA B NNPUT \\
\hline in & $\mathrm{CH} 16 \mathrm{IN}$ & 34 & CA AIMPUT \\
\hline 15 & MURTPLEXER OUTPUT & 35 & CA 2 SNPUT \\
\hline 16 & STAAT CONVEAT & 36 & CA, WNOUT \\
\hline 17 & $-4 s$ & 37 & EXPA:4SCONCONTAC: \\
\hline 18 & ADSN & 湿 & CH INPGT \\
\hline 19 & -AEF IN & 39 & CH 2 सQR \\
\hline 20 & GROUNOD & 26 & Cin $310-y^{4}$ \\
\hline
\end{tabular}




\section{INCLINOMETERS}
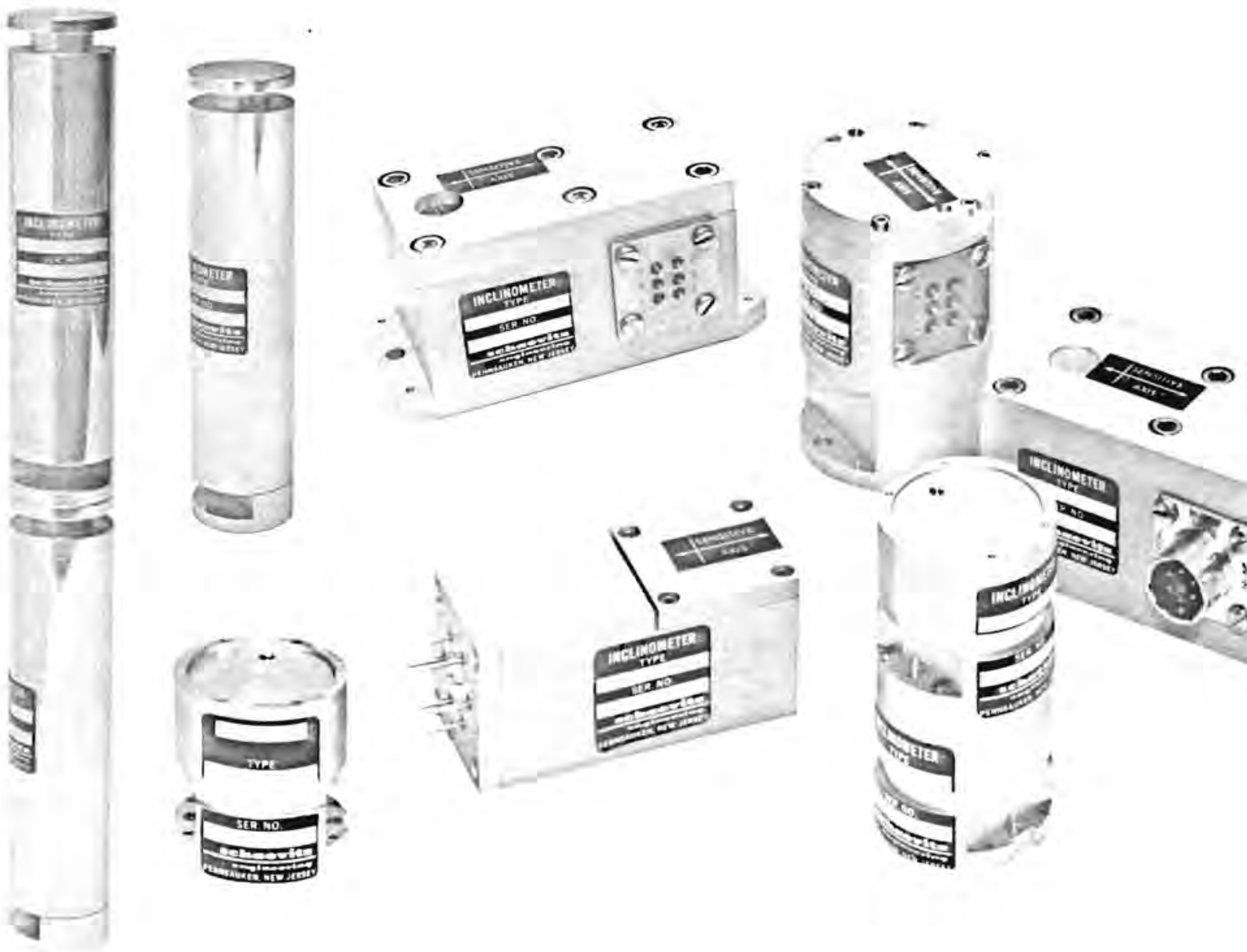

西

(ब)

(2)

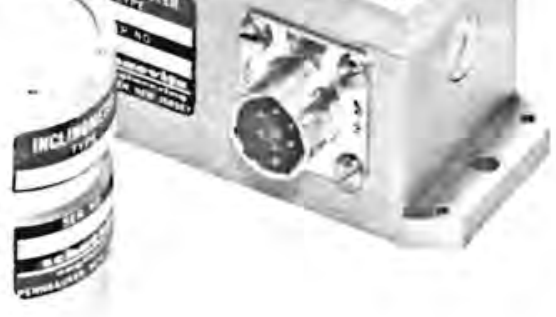

\section{APPLICATIONS}

- Borehole mapping, dam and rock shifts, and other geophysical, seismic, and civil engineering studies

- Ballast transfer systems for offshore barges, ships, and other marine applications.

- Gunsight level control and calibration, weapons platforms, missile launchers

- Pipeline leveling, setting tilt of grading machines, crane overturning-moment alarms, and other heavy construction control requirements

- Large machinery installation, and other electronic level applications

\section{FEATURES}

- Units are fully self-contained. Connect to a DC power source and a readout or control device for a complete operating system

- High-level DC output signal proportional to sine of the angle of tilt from as little as $\pm 1^{\circ}$ full scale to $\pm 90^{\circ}$ full scale

- Responds to changes of slope as small as $0.000006 " / \mathrm{ft}$, and changes in angle as small as 0.1 second of arc

- Hysteresis less than $0.0005 \%$ of full scale

- Vibration rectification less than $0.00005 \mathrm{~g} / \mathrm{g}^{2}$ 
The Schaevitz inclinometer is an extremely sensitive transducer that measures horizontal angle or verticle deviation with virtually infinite resolution. Rugged enough to withstand severe shock and vibration, its "all weather" construction makes it ideally suited for use in the construction industry for setting tilt of road grading and paving machines; in the geophysics field for tilt and strong motion studies; in the civil engineering field for evaluation of tilt of supporting walls in dams and other structures; and other applications where high-accuracy measurement of tilt is required.

The Schaevitz inclinometer is fully self-contained and designed to operate from a standard DC power source. Its output is an analog DC signal directly proportional to the sine of the angle of tilt. In level (horizontal) position, the DC output is zero. When tilted in one direction, the inclinometer output is 0 to $+5 V$ DC. When tilted in the opposite direction, the output is 0 to $-5 \mathrm{~V} D C$.

The heart of this closed-loop, gravity-referenced sensor is a flexure-supported torque-balance system, rugged enough to withstand severe shock and vibration and still maintain excellent accuracy. The solid-state electronics and sensor are enclosed within the sealed housing, permitting opera* tion in high moisture and salt-laden atmospheres with absolutely no degradation of performance.
As the inclinometer tilts through angle " $\forall$ ", pendulous mass " $A$ " tries to move in the direction of tilt (due to force of gravity). The resultant change in relative position between the pendulous mass and position sensor " $B$ " produces an error signal input to the servo amplifier, which drives torque motor " $C$ ", The motor instantaneously drives mass " $A$ " back until transducer " $B$ " detects that pendulous mass " $A$ " has returned to its original position, less a minute displacement to generate and error signal. In order to return mass " $A$ " to its original position a current is required; this current is supplied by the servo amplifier and is proportional to the sine of the angle of tilt. By permitting the current to pass through a stable resistor, Ro, a directly proportional voltage output is developed. Stops are provided on both sides of the pendulous mass to limit its travel when not powered. When powered, the pendulous mass automatically moves to its zero position.

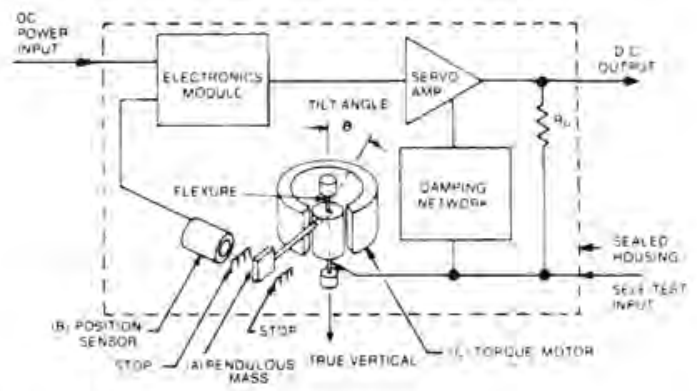

FIGURE 1

\section{SPECIFICATIONS @ $20^{\circ} \mathrm{C}$}

Input Voltage (Note 1).

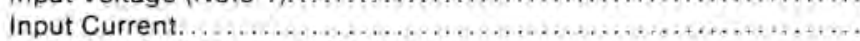

Full Scale Output, Volts DC (Note 2)

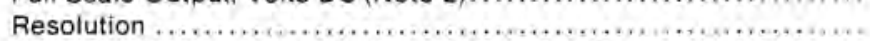

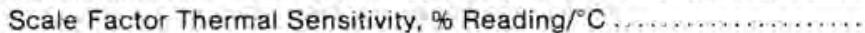

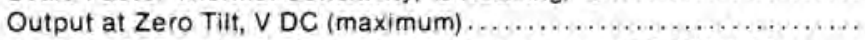

Zero Tilt Thermal Sensitivity, \% Full Scale Output $/{ }^{\circ} \mathrm{C}$ (Note 2) ........

Output Noise, V RMS .......................................

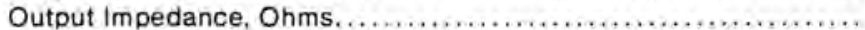

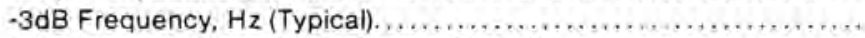

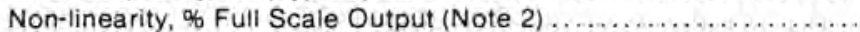

Non-repeatability and Hysteresis, \% of Full Scale Output (Note 2)...

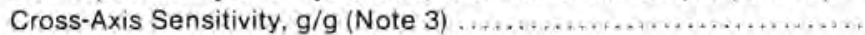

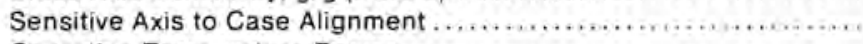

Operating Temperature Range..................................

Survival Temperature Range............., .......................

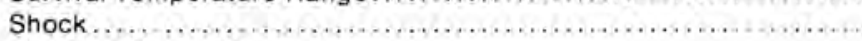

Vibration-Sinusoidal. ........................................

Vibration-Random.

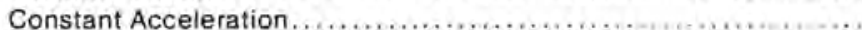

Vibration Rectification

Sealing.

\section{RANGE}

\begin{tabular}{|c|c|c|c|c|}
\hline $\pm 1^{\circ}$ & $\pm 3^{\circ}$ & $\pm 14.5^{a}$ & $\pm 30^{\circ}$ & $\pm 90^{\circ}$ \\
\hline $\begin{array}{l} \pm 9 \mathrm{~V} \text { to } \\
0.015 \\
\pm 5 \mathrm{~V} D \\
0.1 \text { aro }\end{array}$ & $D C( \pm 1$ & minal) & & \\
\hline 0.05 & 0.03 & 0.01 & 0.006 & 0.006 \\
\hline 0.10 & 0.04 & 0.02 & 0.02 & 0.02 \\
\hline 0.05 & 0.03 & 0.01 & 0.005 & 0.005 \\
\hline 0.002 & 0.002 & 0.002 & 0.002 & 0.002 \\
\hline $5 K$ & $5 K$ & $15 \mathrm{~K}$ & $7.5 \mathrm{~K}$ & $4 K$ \\
\hline 0.5 & 1 & 15 & 20 & 40 \\
\hline 0.05 & 0.02 & 0.02 & 0.02 & 0.05 \\
\hline \multicolumn{5}{|c|}{ Less than 0.0005} \\
\hline 0.001 & 0.001 & 0.001 & 0.001 & 0.001 \\
\hline $\pm 0.1^{\circ}$ & $\pm 0.15^{\circ}$ & $\pm 0.25^{\circ}$ & $\pm 0.5^{\circ}$ & $\pm 1^{\circ}$ \\
\hline \multicolumn{5}{|c|}{$-18^{\circ}$ to $+71^{\circ} \mathrm{C}$} \\
\hline \multicolumn{5}{|c|}{$-40^{\circ}$ to $+75^{\circ} \mathrm{C}$} \\
\hline \multicolumn{5}{|c|}{$1500 \mathrm{~g}$} \\
\hline \multicolumn{5}{|c|}{$50 \mathrm{~g}$ peak } \\
\hline \multicolumn{5}{|c|}{$35 \mathrm{~g} \mathrm{RMS}, 20 \mathrm{~Hz}$ to $2000 \mathrm{~Hz}$} \\
\hline \multicolumn{5}{|c|}{$50 \mathrm{~g}$} \\
\hline \multicolumn{5}{|c|}{ Less than $0.00005 \mathrm{~g} / \mathrm{g}^{2}$} \\
\hline
\end{tabular}

\section{OPTIONS}

\section{NOTES}

1) Units can be easily adapted to operate with single ended power supplies from 18 to 36 Voits.

2) Full Scale is defined as "from negative full input to positive full input"

3) Cross-axis sensitivity, defined as inclinometer output with $1 . \mathrm{g}$ acceleration perpendicular to the sensitive axis, independent of alignment errors.
1) 1.9 bias (available on LSO $\pm 30^{\circ}$ and $\pm 90^{\circ}$ only)

2) Low output impedance (LSO only)

3) Non-standard damping or frequency response

4) Non-standard output voltage

5) Extended temperature range

Consult factory for availability of other options. 


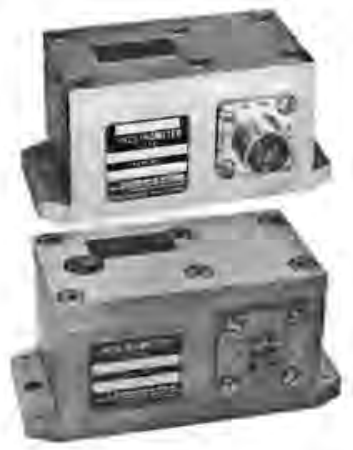

\section{MODEL LSOP AND LSOC}

For ship ballast control, setting tilt of paving machines, and other tilt measurement applications. Has a wide mounting base to minimize any error caused by rough mounting surtaces. Choice of connector-type or solder-pin terminations.

MODEL LSOP - Solder-pin-type MODEL LSOC - Connector-type

\section{MODEL LSVP}

LSVP is designed for those applications which require smaller height, width and length than the model LSOP or LSOC above. Its small cross-section permits use in horizontal bore holes to 1.9" diameter. Available only with solder-pin type terminations.

\section{MODEL LSRP}

Model LSRP is a compact, stackable unit designed for downhole logging or for use where overall space is limited. It measures only 1.60 inch high and less than 1.50 inch diameter. Can be stacked for simultaneous measurement of titt angles. Solderpin terminations are standard.

\section{MODEL LSFPA}

Model LSFPA is contigured for use where minimum profile and/or simultaneous 2-axis measurements are required, such as in $X \cdot Y$ probes for use in small diameter boreholes. Units are designed with mating holes in end flanges to permit biaxial stacking.
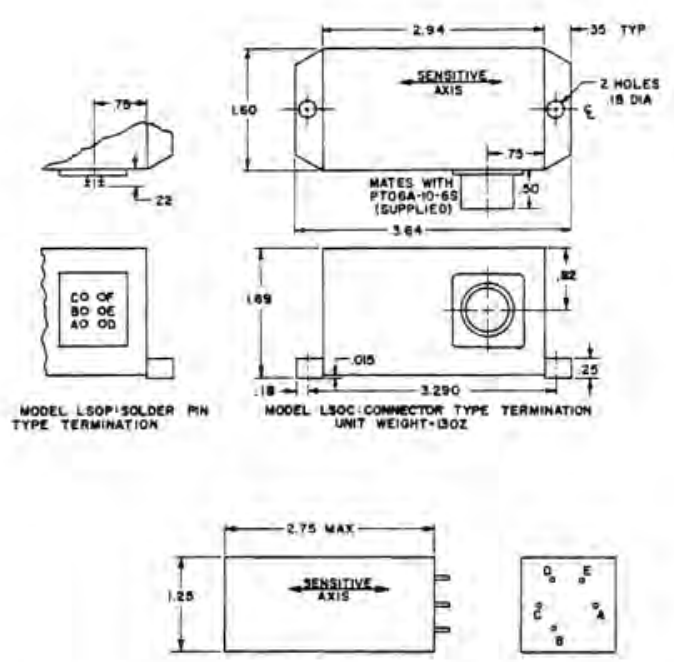

Ywit WEIGAT. 6 az

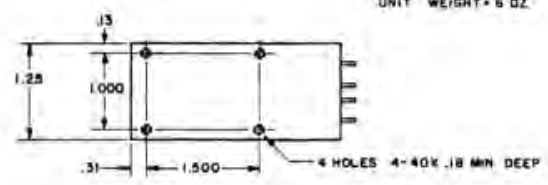

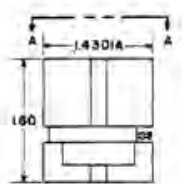
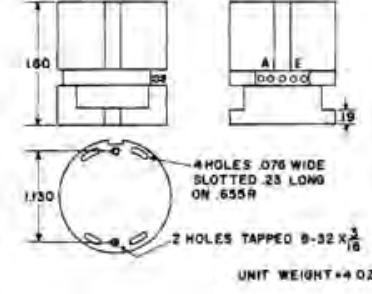

vice A-A

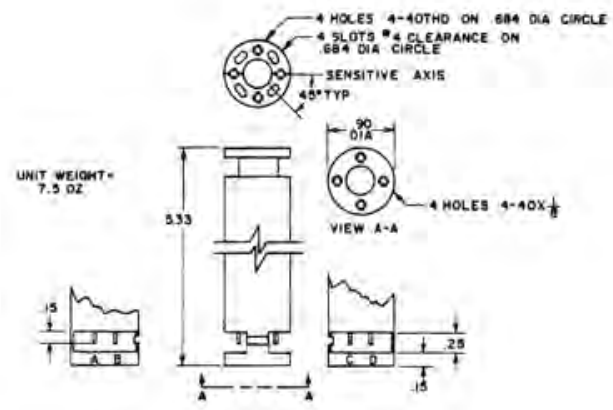

\section{ORDERING INFORMATION}

\section{STANDARDMODELS}

To order inclinometers listed in this catalog, specify model, range, and options desired.

Example: LSOC-14.5 designates a model LSO inclinometer with connector termination and a full scale range of $\pm 14.5^{2}$.

\section{SPECIAL MODELS}

Schaevitz designs and manufactures many special inclinometers for OEM requirements and other quantity users. Consult the factory with specific requirements including such pertinent information as input power, range, frequency response and damping ratio, bias, environmental considerations, and mechanical packaging. 


\section{TYPICAL APPLICATIONS}

\section{HEAVY CONSTRUCTION}

For setting and controlling the angle of the moldboard on road graders by providing fine and coarse control signals to the grader's servo system. Tolerance well within code requirements can be met with ease. Schaevitz inclinometers can measure changes in slope as small as \pm 0.00005 inches per foot.

\section{SHIP AND BARGE LEVELING}

Signals from an inclinometer installed on a ship or barge are sent to a ballast transfer hydraulic system. The infinite resolution and high sensitivity of the inclinometer provides very high accuracy level control. The inclinometer is also employed for closed-loop leveling of equipment in use underwater in drilling and mining operations.

\section{DEVIATION SURVEYS}

Used extensively for borehole mapping and deviation surveys. Schaevitz inclinometers respond to borehole deviations as small as 0.1 second of arc. The inclinometer provides a signal for analog recording or input to a computer, or can easily be read out on a digital display.

\section{HEAVY MACHINERY}

This giant mill, 150 feet long, bores a single hole into a multi-ton block of steel simultaneously from both sides. The boring equipment meets within the block with less than a $0.005^{\prime \prime}$ error; a Schaevitz inclinometer system makes this possible.

\section{WEAPONS PLATFORM LEVELING}

A gravity referenced inclinometer can compensate for slope and tilt and thereby eliminates the need for a level weapon or target acquisition system. In a typical field application, inclinometers at both the target acquisition system and the weapon feed data into the fire-control computer, which automatically compensates for offlevel conditions. Manual leveling becomes unnecessary, although electronic level readouts can also be incorporated for manual jacking or leveling if desired. Inherent ruggedness permits the inclinometer to withstand large shock loads and vibration inputs.
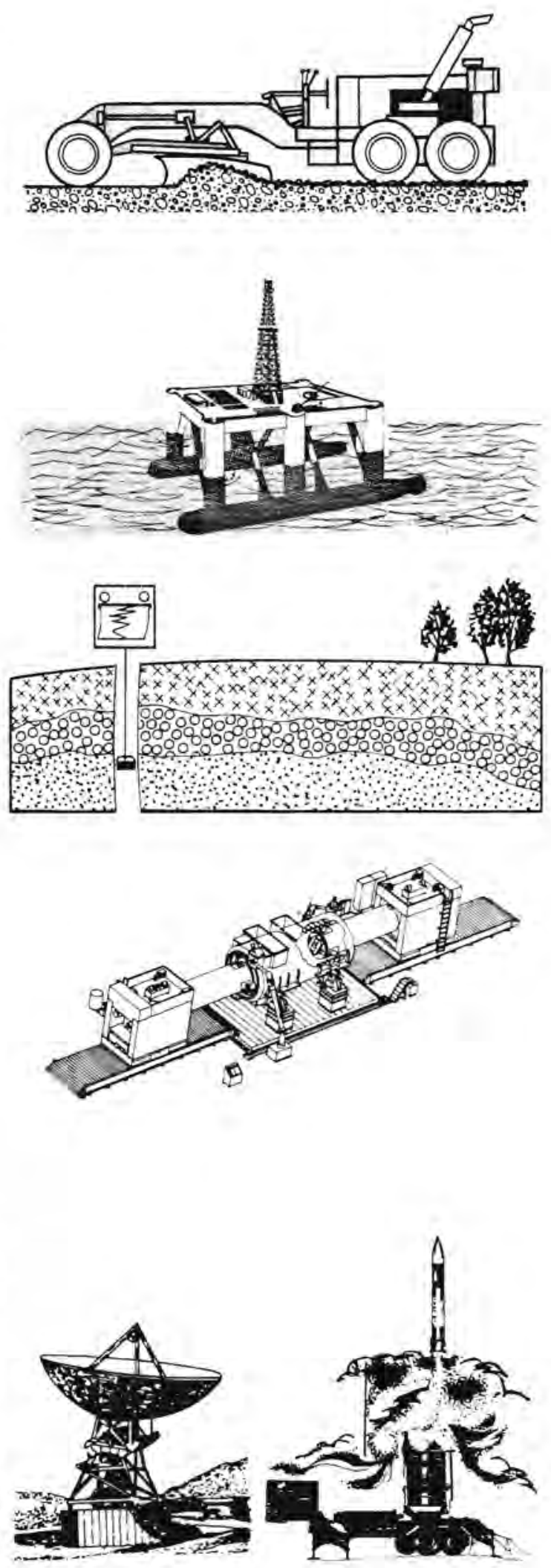

SCHAEVITZ ENGINEERING
U.S. Route 130 \& Union Ave., Pennsauken, New Jersey •

P.O. Box 505, Camden, N.J. 08101 •
(609) $662-8000$

Pennsauken, N.J. (710) 892-0714 


\section{FEATURES:}

- Excellent system accuracy - better than $1 \%$ of full scale

- Clamps onto shaft without shaft modification - shaft disassembly or redesign is not required

- Maintenance free - no brushes to change or clean; no bearings to oil

- Operates in harsh environments high $G$ loading, vibrations and wide temperature ranges
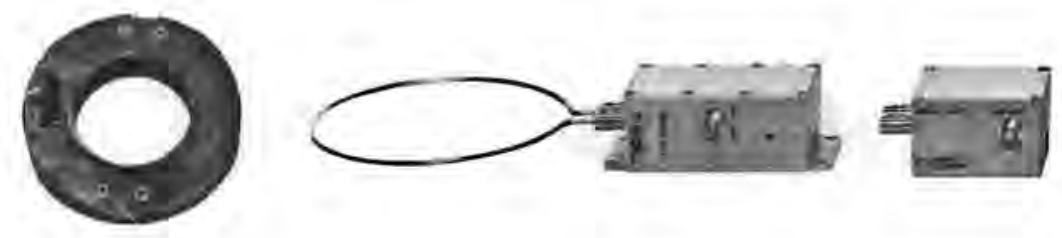

conditioned signal is also available in analog form at the rear panel.

\section{System Description}

The 1200A System consists of four components: a Readout Unit (1206D), Rotary Module (1216A), Power Separation Unit (1211A), and a rotating High Speed Collar (1226A). Operationally, the split collar is bolted around the shaft. The Rotary Module, located in the collar, is wired to customer applied strain gages placed on the shaft and generates a signal when the strain gages sense a torsional load. This signal is coupled from the rotating collar to a stationary loop held by the Power Separation Unit, and is routed via cable to the Readout Unit for signal conditioning. The conditioned signal is then displayed by the Readout Unit in torque engineering units (i.e., ft.-lbs., in.lbs., kg.-m, micro-strain, etc.). The

\section{System Operation}

The torque sensor consists of a four arm strain gage bridge on the shaft to detect torsional strain. As a twisting load is applied to the shaft, a signal is created by the unbalancing of the strain gage bridge. This signal is presented as a voltage to the input of the Rotary Module located in the rotating collar, and is used to pulse width modulate a constant amplitude $5 \mathrm{kHz}$ square wave. The duty cycle of the square wave (i.e., pulse width) is directly proportional to the torsional load. A voltage controlled oscillator, having a nominal frequency of $10.7 \mathrm{MHz}$, is modulated by the square wave. Its output is fed to a coupling loop imbedded in the rotating

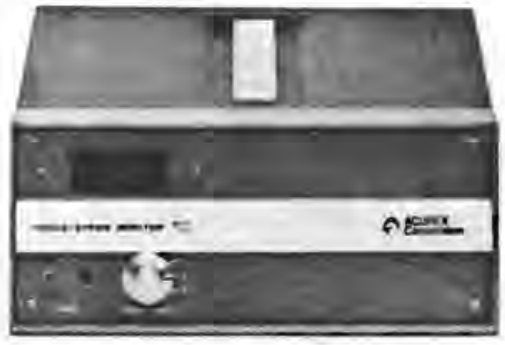

1200A System Block Diagram

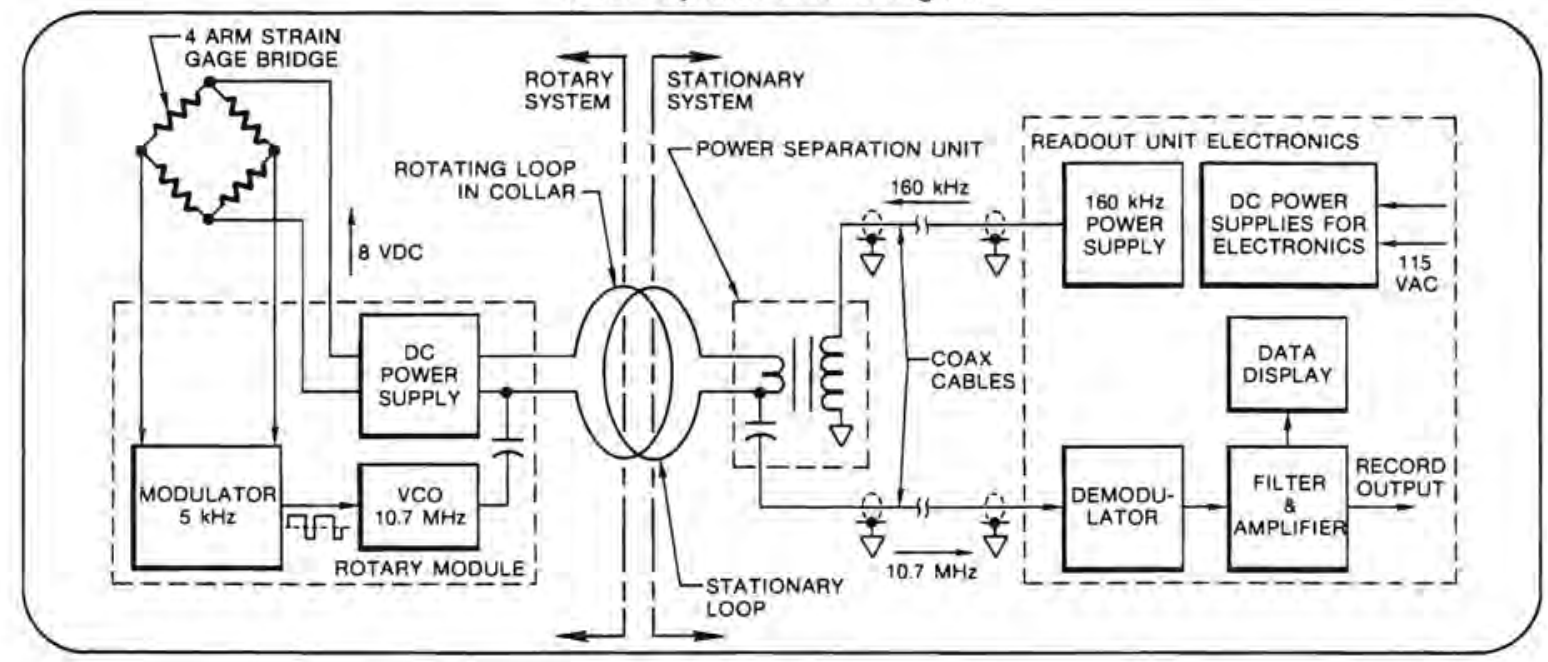

collar and is capacitively coupled to a nearby stationary loop. The signal is carried via coaxial cable from the stationary coupling loop base (Power Separation Unit) to the Readout Unit where it is demodulated, scaled, and displayed as torque in engineering units such as in.-lbs., ft.-lbs., kg.-m, etc.

The rotating equipment is completely self-contained and is powered by an induction power system. The system does not require the use of batteries. A $160 \mathrm{kHz}$ power oscillator is located within the Readout Unit which sends power through a coaxial cable to the power separation unit (PSU). This unit performs two tasks. First, it couples the $160 \mathrm{kHz}$ power into the stationary loop. Second, it decouples the $10.7 \mathrm{MHz}$ torque signal from the same stationary 


\section{System Components}

loop and sends it to the Readout Unit for conditioning. After the $160 \mathrm{kHz}$ power signal has been transferred to the stationary loop, it is inductively coupled to the rotating loop imbedded in the collar. There it is fed into the Rotary Module where it is rectified and regulated to supply the stable DC voltage source required by the strain gages and Rotary Module.

\section{Calibration}

Two techniques are available to calibrate the 1200A System. The first is accomplished through the use of a static torsional load applied to the shaft. An adjustment in the Readout Unit and/or the Rotary Module permits setting a zero indication with no load applied to the shaft. A second reading is taken with the static load applied, and a span adjustment is made to equate the display's indication with that of the torsional load.

A second method allows calibration through the use of a shunt calibration resistor. The resistor is placed in parallel with one of the strain gages, and simulates a torsional strain by unbalancing the strain gage bridge. If the shaft dimensions and its shear modulus are known, the theoretical equivalent torque can be determined and the equipment calibrated accordingly.

\section{Static vs. Dynamic Measurement}

The standard DC to $900 \mathrm{~Hz}$ bandwidth permits both the measurement of static and most dynamic torsional strains. If it is desirable to limit the extent of dynamic variation present on a shaft, special low pass filters are available.

\section{Strain Gage Placement}

Neither the strain gages nor their installation is included with the $1200 \mathrm{~A}$ System.

\section{Other Measurements}

Although the principal application of the 1200 A System is for measuring torque. it is also well suited for making other types of measurement. For instance. by laying the strain gage bridge to measure elongation and Poisson strains, the thrust present on a rotating shaft could also be determined. Another bridge configuration would detect shaft bending.

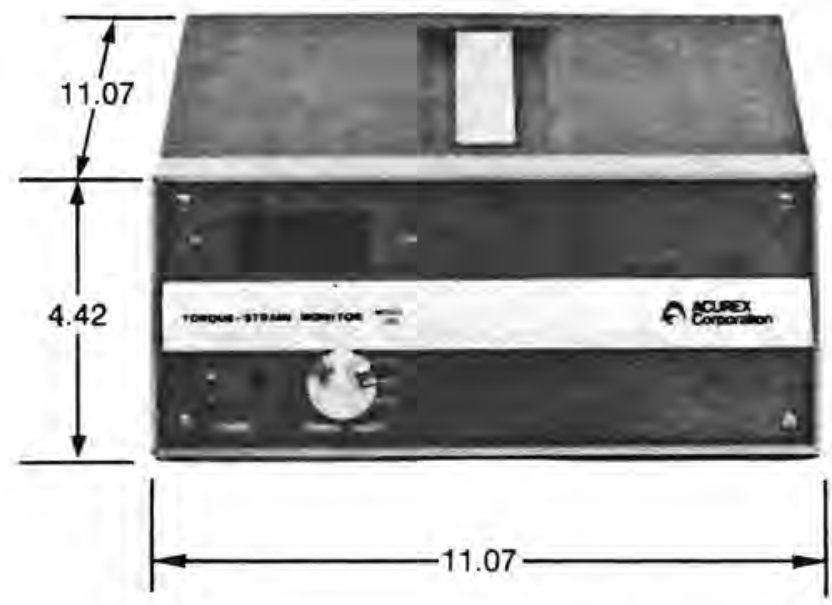

\section{D Readout Unit}

The Readout Unit contains signal conditioning circuitry, $160 \mathrm{kHz}$ induction power supply, and a $3 \frac{1}{2}$ digit bipolar display. Gain and zero controls are conveniently located behind the front panel trim strip allowing the user to easily adjust the display to indicate the desired engineering units. An analog DC voltage output is also provided for use with magnetic or oscillographic recorders and computers. The unit is portable, or rack mounting may be ordered as an option.

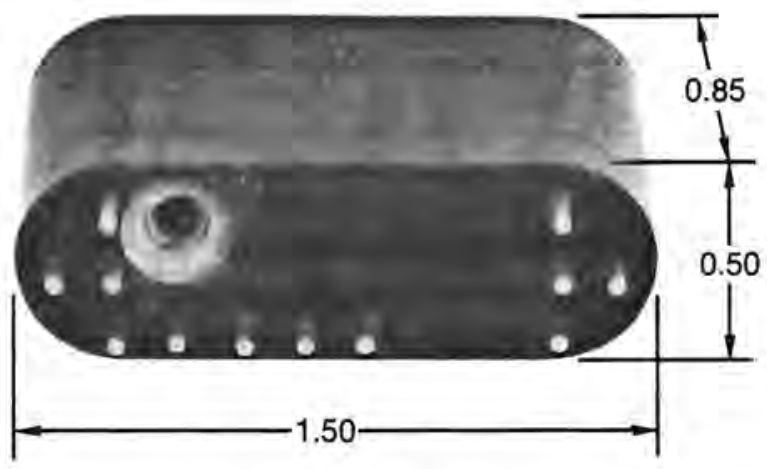

\section{A Rotary Module}

The Rotary Module contains the rotating electronics consisting of two specially designed hybrid microcircuits employing the most recent techniques in solid state technology, It is encapsulated in tough epoxy making it impervious to moisture, oil, or dirt, and is capable of withstanding a maximum static $\mathrm{g}$ force of $15,000 \mathrm{~g}$. The module is pretuned to the $10.7 \mathrm{MHz}$ carrier frequency and the $160 \mathrm{kHz}$ induction power system frequency. Its voltage regulating circuitry maintains a constant DC voltage which is required by the microcircuits and for strain gage excitation. 

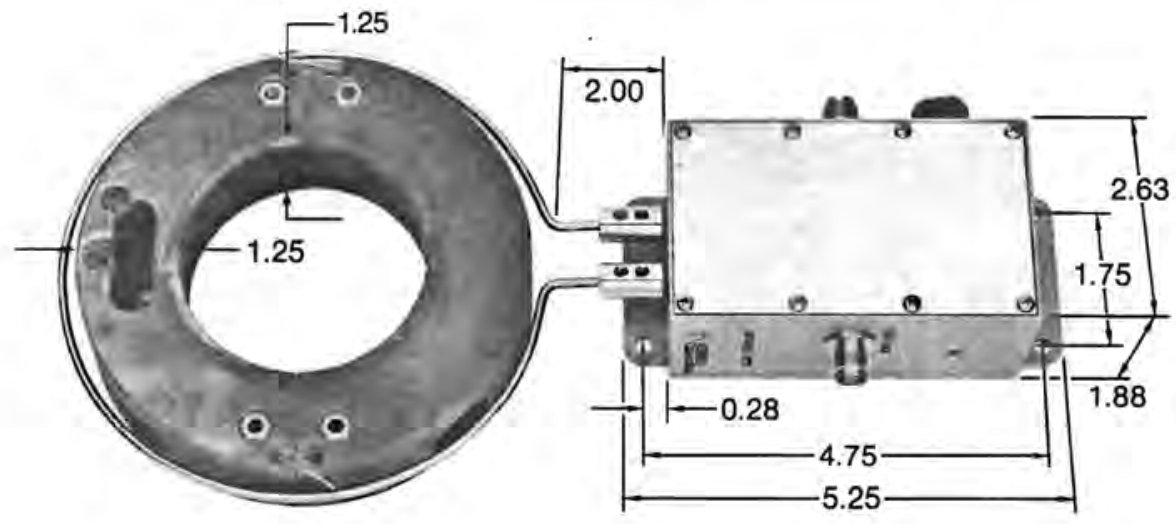

\section{A High Speed Collar}

The 1226A collar is designed to hold the Rotary Module and a coupling loop which is imbedded within it. The collar material is G-11 glass laminate, custom machined to individual shaft specifications, and delivered in two halves which clamp around the shaft and are held in place by high tensile strength bolts. The collar and Rotary Module can be dynamically balanced as an option. In order to assure adequate power is supplied to the transmitter, the outside diameter of the collar is always greater than 6.0 inches. Typical clearance between antenna and collar is $1 / 2$ inch.

\section{A Power Separation Unit}

The $1211 \mathrm{~A}$ acts as a mount for the stationary coupling loop and separates the $10.7 \mathrm{MHz}$ torque signal from the $160 \mathrm{kHz}$ induction power. It has a built-in tuning system which permits peaking the induction power system efficiency.

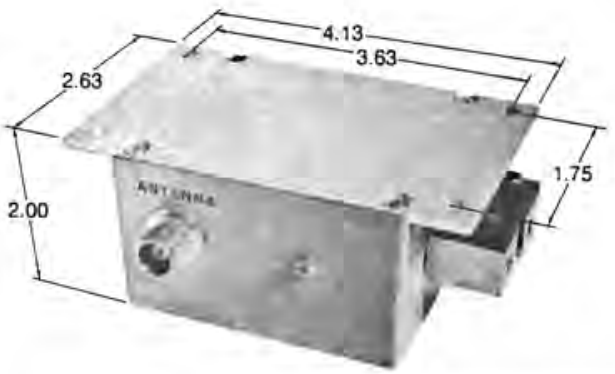

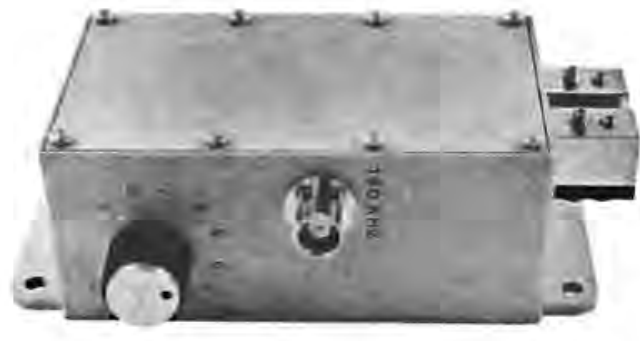

\section{System Option 1207A Power Separation Unit}

The 1207A is filled with epoxy and recommended for use in harsh environments where the tuning system of the $1211 \mathrm{~A}$ is undesirable. Peaking the induction power efficiency is still possible; however, it must be accomplished at the Readout Unit.
This is how the 1200A Torsion Measurement System goes together.

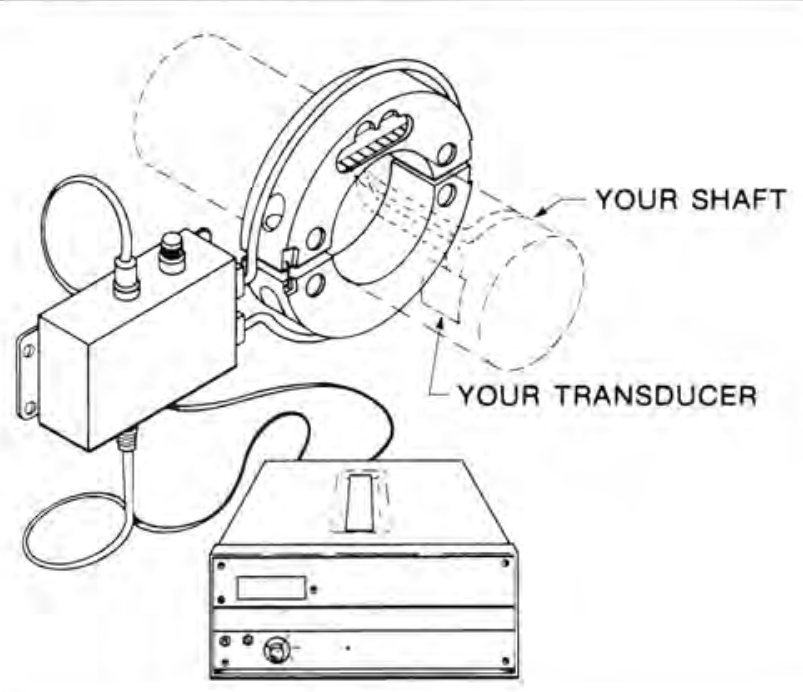




\section{System ${ }^{(r)}$}

Frequency Response:(2) DC to $900 \mathrm{~Hz}$ (3 dB limit)

Linearity: ${ }^{(3)} 0.1 \%$ of full scale

Repeatability: ${ }^{(3)} 0.05 \%$ of full scale

Zero Drift: $\quad \pm 0.02 \%$ of full scale $/{ }^{\circ} \mathrm{C}$

max, typically $\pm 0.01 \%$

Gain Drift: $\quad \pm 0.02 \%$ of full scale $/{ }^{\circ} \mathrm{C}$ max; typically $\pm 0.01 \%$

Torque Accuracy: (3) $1 \%$ of full scale

Minimum Torsional Strain for Full

Scale Reading: $350 \Omega$ gage, $175 \mu \mathrm{in}$./ in.

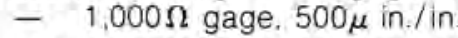

Typical Received Signal: $-40 \mathrm{dBm}$

Average Shipping Weight: $20 \mathrm{lbs} .(44 \mathrm{~kg}$.)

Rotary Module

Power Source: $160 \mathrm{kHz}$ induction power supplied

Carrier Frequency: $10.7 \mathrm{MHz}$

Adjustments: Zeroing pot for strain

gage bridge

Modulation: Pulse width FM

Inputs: 4 arm strain gage bridge.

$350 \Omega$ to $1,000 \Omega$

Operating Temperature Range: $0-75^{\circ} \mathrm{C}$

Bridge Excitation: 8 VDC

Vibration (any axis): $100 \mathrm{~g}, 0$ to $1 \mathrm{kHz}$

Maximum Static Acceleration: $15,000 \mathrm{~g}$

Rotary Module Weight (1216A):

$0.96 \mathrm{oz}$. (27.2 gm.) average

Collar Density (1226A): $0.067 \mathrm{lbs} / \mathrm{in}^{3}$

\section{Readout Unit}

Carrier Frequency: $10.7 \mathrm{MHz}$

Sensitivity (full specification): $-70 \mathrm{dBm}$ Quieting: $20 \mathrm{~dB}$ at $-80 \mathrm{dBm}$

Input Impedance: $75 \Omega$

Analog Output Voltage: \pm 10 volts maximum

Analog Output Impedance: $10 \Omega(10$ mA maximum)

AM Rejection: $45 \mathrm{~dB}$ at $-40 \mathrm{dBm}$ Power Requirements: 115 VAC, 50 $400 \mathrm{~Hz} .100 \mathrm{VA} ; 100$ or $230 \mathrm{VAC}$ Optional

Weight: 14 lbs. (31 kg.)

Operating Temperature Range:

$0.50^{\circ} \mathrm{C}$

\section{Notes:}

(1) System specifications assume that the receiver is held to $\pm 5^{\circ} \mathrm{C}$ within the operational range of the Readout Unit, $0-50^{\circ} \mathrm{C}$.

(2) Available at several reduced bandwidths, consult factory.

(3)Accuracy, linearity, and repeatability are affected by temperature. strain level, and calibration technique Values shown are typical with proper consideration of these parameters Values shown apply to systems using a four-armed bridge. Gage induced errors are not included.

\section{Required Ordering Information}

1. Shaft diameter to the closest \pm 0.005 inch or $\pm 0.13 \mathrm{~mm}$.

2. Maximum shaft RPM

3. Cable lengths.

\section{Technical Considerations}

The graph below indicates allowable combinations of shaft diameter and RPM for standard system plus dynamic balanc. ing System will operate properly without dynamic balancing below 2000 RPM for shaft sizes, 2.0 inches to 20.0 inches. For operation with shaft sizes above 20.0 inches consult factory.
Specifying a 1200A System

\section{Equipment}

The 1200A Torsion Measurement Sys-

tem comes with the following

equipment:

- 1206D, Readout Unit with 3/2 digit bipolar display

- 1216A, Rotary Module

- 1226A, High Speed Collar

- 1211A, Power Separation Unit

- Two 15-foot interconnecting cables with connectors

In addition, various options are available.

Model 1200A Torsion Measurement System Options.

- 1201A, Two channels of data

- 1202A. System Horsepower and R.P.M. (refer to Tech Note No. 2).

- $1206 \mathrm{D}-03,19 \times 5 \frac{1}{4}$ inch rack mounting for Readout Unit.

- 1221A-04, Dynamic balancing of collar and rotary module

- 1207A. Fixed Tuned Power Separation Unit (1207A substituted for 1211A)

- Operation from 100V, $50-400 \mathrm{~Hz}$

- Operation from 230V, $50-400 \mathrm{~Hz}$

- Cable lengths other than 15 feet (up to 200 feet maximum)

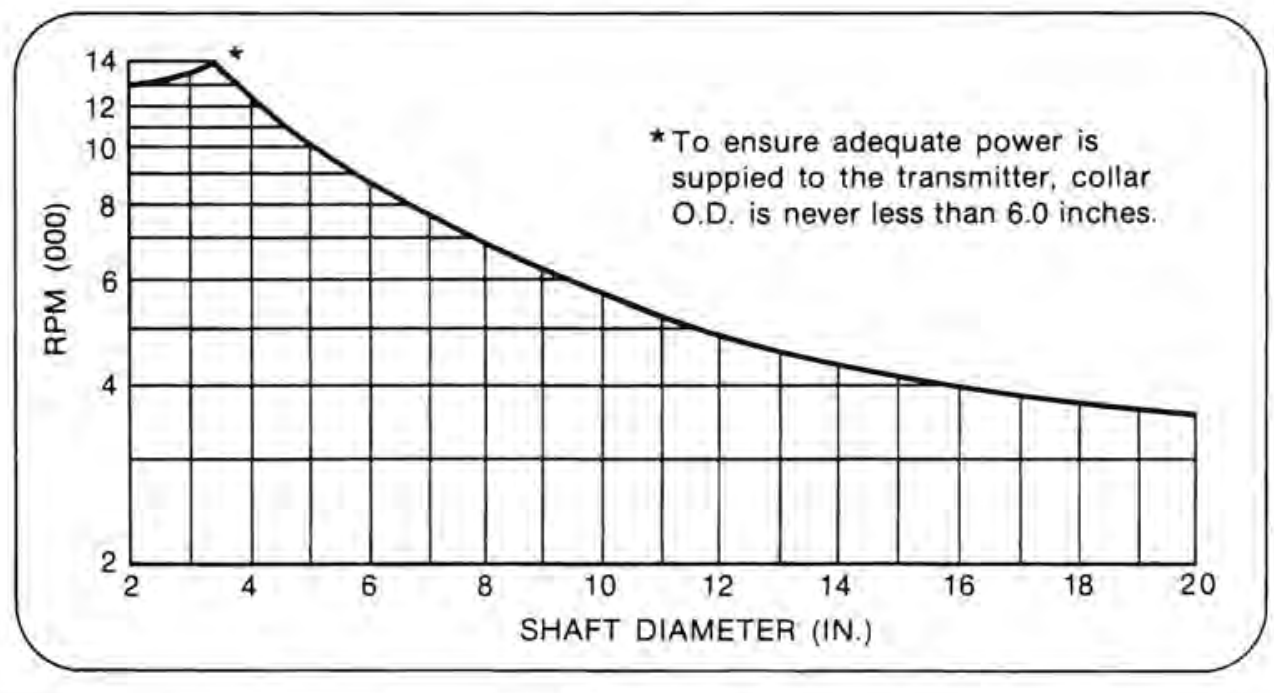

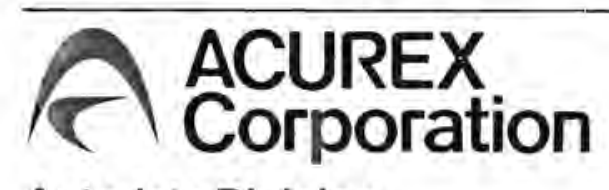

\section{Autodata Division}

485 Clyde Ave, Mt View CA 94042

(415) 964-3200 Telex: 34-6391
Acurex Corporation, Europe

Esplanade 6

2000 Hamburg 36

West Germany

(040) 34-15-25

Telex $841-214448$
Acurex Far East, Inc.

Kyodo Building Suite 47

2-2, 4-Chome Hatchobori

Chuo-ku. Tokyo 104. Japan

03-552-2017

Telex: $781-28719$ 


$$
\begin{array}{r}
z=\Xi-\equiv:-\square \\
\therefore--\therefore-\equiv-1
\end{array}
$$

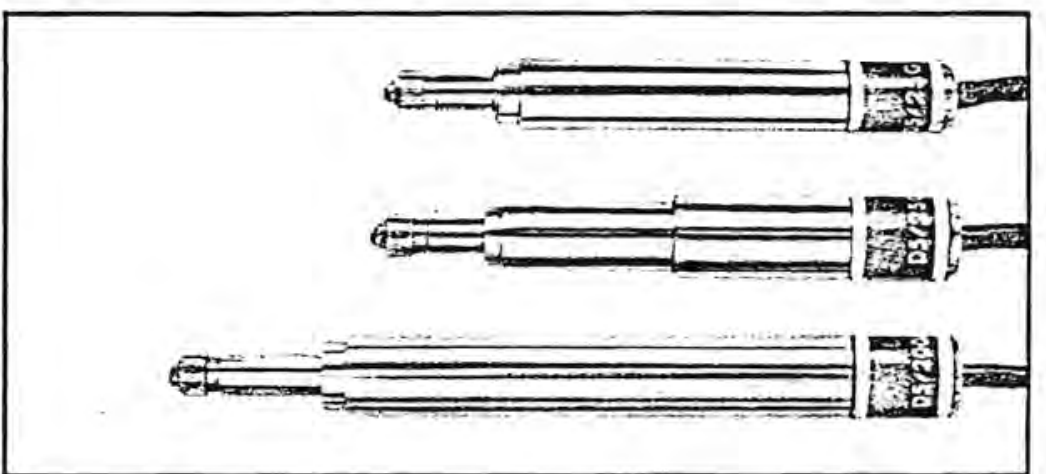

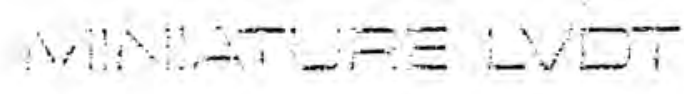

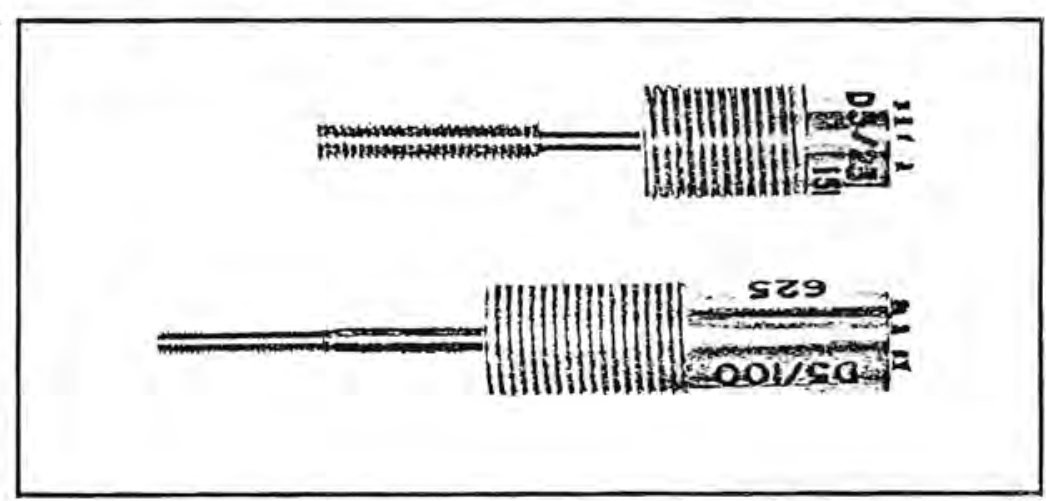

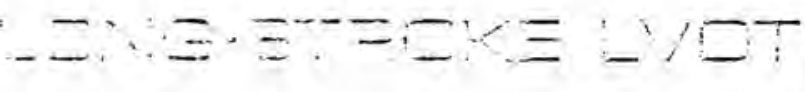
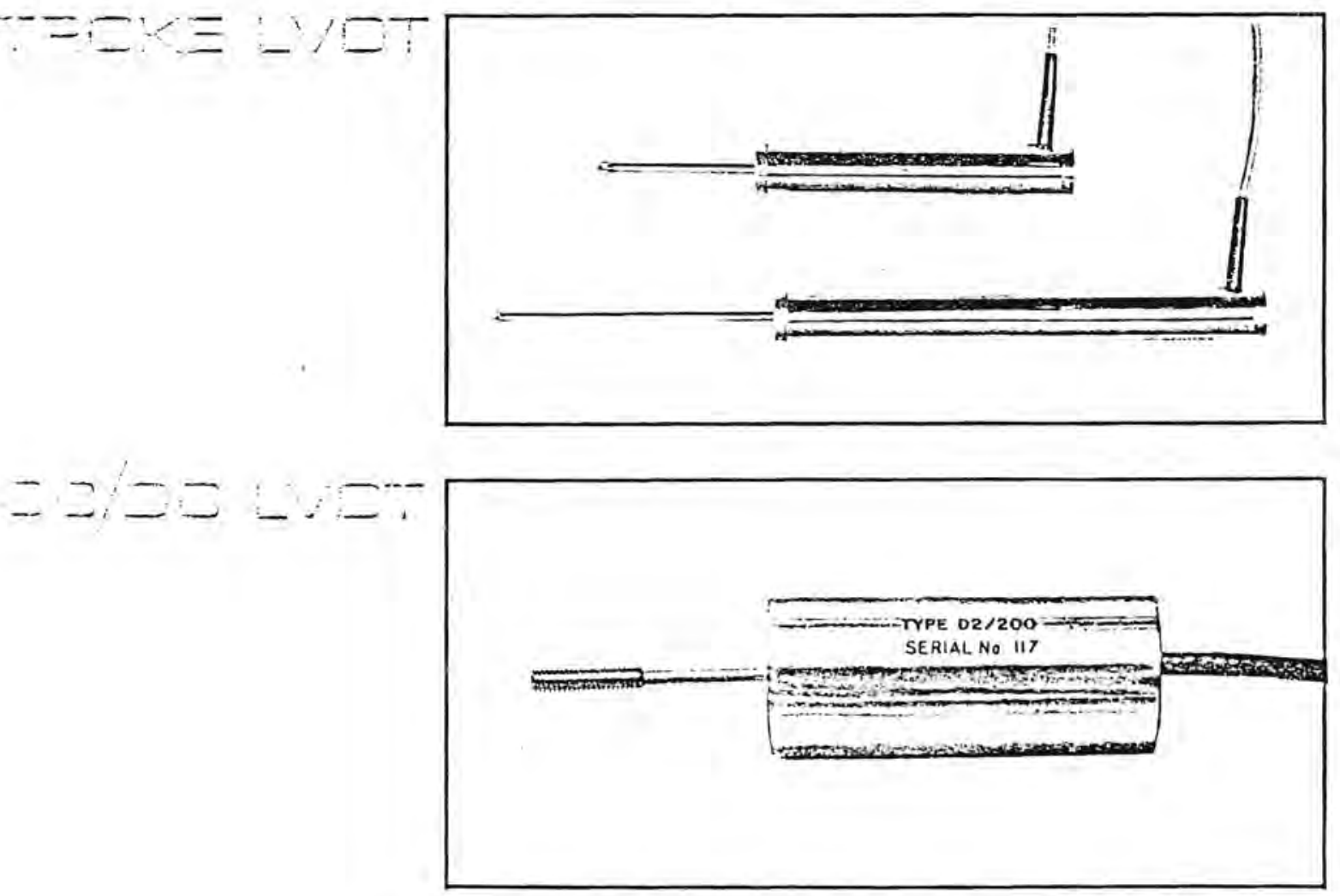

Manufactured inU.K.

ROBINSON-HALPERN COMPANY

One Apollo Rd Plymouth Meeting Pa. 19462
TWX \#510-660-8637 (ROBHALCOPMTG) 


\section{FOUR MODELS COVER \\ THE REQUIREMENTS OF MOST SINGLE AND MULTI- POINT INDUSTRIAL GAUGING APPLICATIONS AND MICRO-DISPLACEMENT MEASURES IN RESEARCH AND SCIENTIFIC STUDIES.}

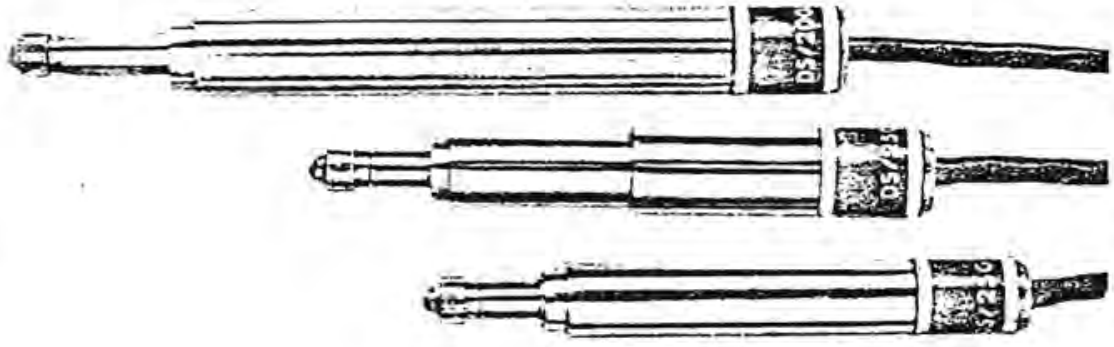

They represent a new departure in precision gauging-head construction. The use of a new bearing technique provides not only virtually friction-free action of the probes over a much wider temperature range but the high mechanical strength and reliability which is required in industrial applications. The non-rotating probes will withstand the high side loads to which gaugina heads are sometimes subjected in multi-point gauging jigs and fixtures, without damage or loss of performance. When used with suitable readout equipment these transducers will provide repeatibility within a few microinches.

The bodies and probes are of stainless steel and the windings are magnetically screened. They can be mounted in any position and are unaffected by being clamped into the steel housings of gauging fixtures.

They are normally supplied with LVDT windings for use with RHC or other carrier amplifier equipment. The optimum carrier frequency is $5 \mathrm{kHz}$, but they will operate satisfactorily at carrier frequencies between 2 and $10 \mathrm{kHz}$. They can be supplied to order with differential-inductance windings for use with equipment having half bridge input circuitry.

MECHANICAL SPECIFICATION

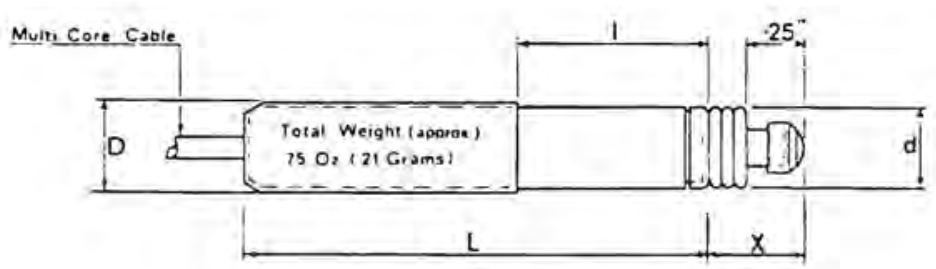

Outline Diagram D5/40G.

\begin{tabular}{|c|c|c|c|c|c|c|c|}
\hline Type & $\begin{array}{l}\text { working } \\
\text { range }\end{array}$ & L & 1 & D & d & $x^{*}$ & $\begin{array}{l}\text { maximum } \\
\text { spring force }\end{array}$ \\
\hline$D 5 / 40 G$ & $\begin{array}{l} \pm 0.040^{\prime \prime} \\
\pm 1 \mathrm{~mm}\end{array}$ & $\begin{array}{l}2.1^{\prime \prime} \\
53 \mathrm{~mm}\end{array}$ & $\begin{array}{l}0.75^{\prime \prime} \\
19 \mathrm{~mm}\end{array}$ & $9.5 \mathrm{~mm}$ & $8 \mathrm{~mm}$ & $\begin{array}{l}0.45^{\prime \prime} \\
11.5 \mathrm{~mm}\end{array}$ & $\begin{array}{l}0.75 \mathrm{oz} \\
21.4 \mathrm{gms}\end{array}$ \\
\hline D5/40G8 & $\begin{array}{l} \pm 0.040^{\prime \prime} \\
\pm 1 \mathrm{~mm}\end{array}$ & $\begin{array}{l}2^{\prime \prime} \\
51 \mathrm{~mm}\end{array}$ & - & $8 \mathrm{~mm}$ & $8 \mathrm{~mm}$ & $\begin{array}{l}0.45^{\prime \prime} \\
11.5 \mathrm{~mm}\end{array}$ & $\begin{array}{l}0.75 \mathrm{oz} \\
21.4 \mathrm{gms}\end{array}$ \\
\hline $\mathrm{D} 5 / 100 \mathrm{AG}$ & $\begin{array}{l} \pm 0.1^{\prime \prime} \\
\pm 2.5 \mathrm{~mm}\end{array}$ & $\begin{array}{l}2.425^{\prime \prime} \\
62 \mathrm{~mm}\end{array}$ & - & $9.5 \mathrm{~mm}$ & $9.5 \mathrm{~mm}$ & $\begin{array}{l}0.45^{\prime \prime} \\
11.5 \mathrm{~mm}\end{array}$ & $\begin{array}{l}0.5 \mathrm{oz} \\
14.3 \mathrm{gms}\end{array}$ \\
\hline D5/200AG & $\begin{array}{l} \pm 0.2^{\prime \prime} \\
\pm 5 \mathrm{~mm}\end{array}$ & $\begin{array}{l}2.675^{\prime \prime} \\
68 \mathrm{~mm}\end{array}$ & - & $9.5 \mathrm{~mm}$ & $9.5 \mathrm{~mm}$ & $\begin{array}{l}0.45^{\prime \prime} \\
11.5 \mathrm{~mm}\end{array}$ & $\begin{array}{l}0.5 \mathrm{oz} \\
14.3 \mathrm{gms}\end{array}$ \\
\hline
\end{tabular}

'dimension ' $X$ ' at nominal electrical zero point.

Body diameter tolerance; plus $0.000^{\prime \prime} ;$ minus $0.0015^{\prime \prime}$ All other dimensions nominal

\section{ELECTRICAL SPECIFICATIONS}

\section{ENERGIZING SUPPLY}

\section{LINEARITY}

TYPICAL SENSITIVITY

REPEATABILITY

TEMPERATURE COEFF. OF SENSITIVITY
Designed for $5 \mathrm{~V} . \mathrm{rms}$. @ $5 \mathrm{kHz}$. Will operate over the range

2. $10 \mathrm{kHz}$, and down to $2 \mathrm{~V}$. rms.

Primary current (at $5 \mathrm{~V} .5 \mathrm{kHz}$ ) : $05 / 40 \ldots 12 \mathrm{~mA}$.

$\mathrm{D} 5 / 100 \ldots 30 \mathrm{~mA}$.

D5/200...30mA.

$0.25 \%$ Standard

$0.1 \%$ Premium

$2 \mathrm{mV}$./V./0 001"

Within 10 microinches

Less than $0.01 \% / \mathrm{C}$. $(\%$ of $f .5$.)

$20^{\circ} \mathrm{C}$. to $+125^{\circ} \mathrm{C}$. (Teflon cable required above $85^{\circ} \mathrm{C}$. Please specify.) 


\section{PRECISION GAGE HEADS}

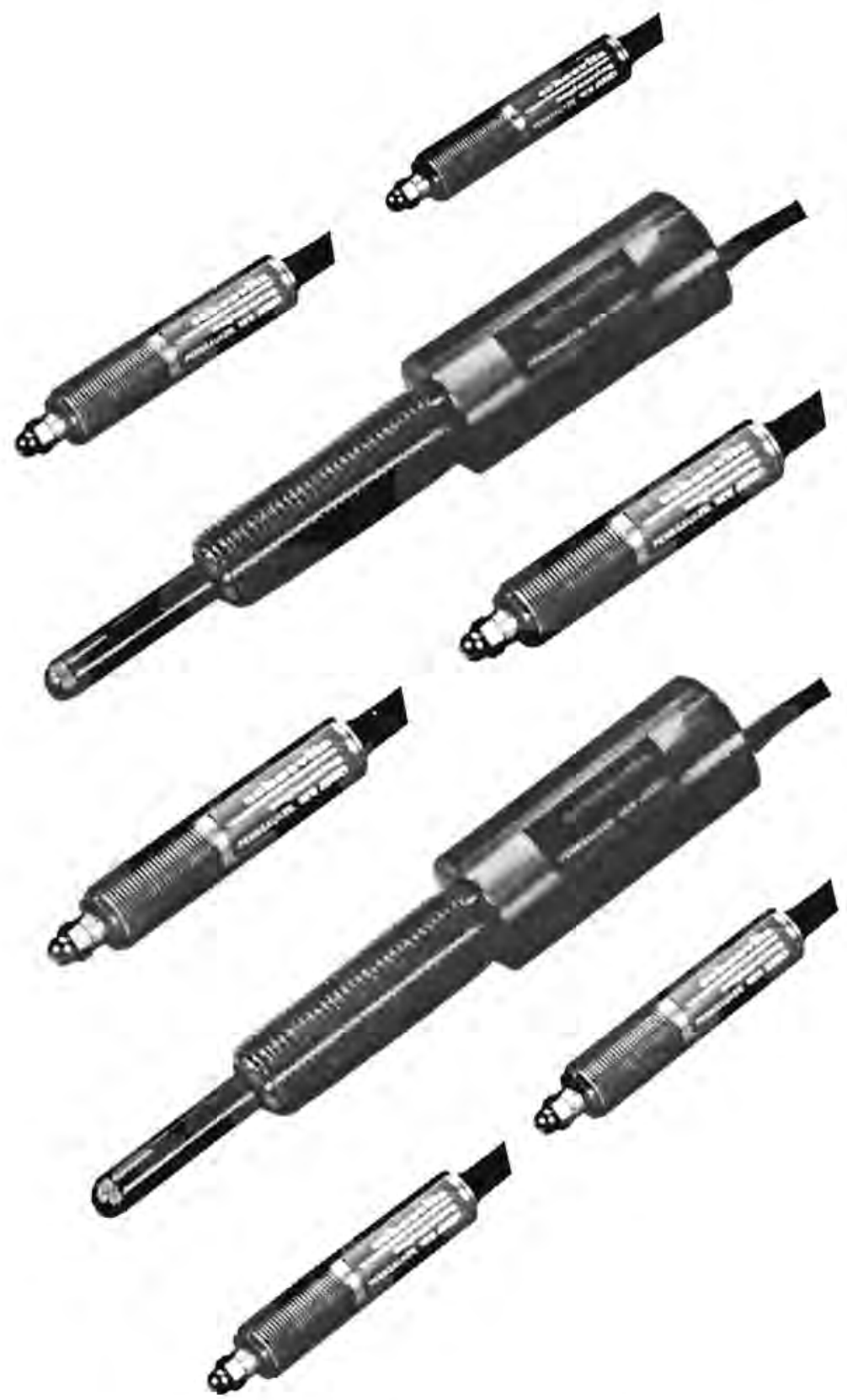

PERFORMANCE FEATURES

Repeatability to 4 millionths (0.000 $\left.004^{\prime \prime}\right)$ Resolution to 0.3 millionths ( $\left.0.0000003^{\prime \prime}\right)$ Linearity to $\pm 0.2 \%$ standard $\pm 0.05 \%$ special

\section{ELECTRICAL FEATURES}

Voltage output accurately proportional to probe displacement.

High sensitivity and high output level.

Stepless variation in output.

Electrically contactless, no wiping elements.

\section{MECHANICAL FEATURES}

Mechanical simplicity.

Ease of installation.

Extreme ruggedness, resistance to vibration and shock.

Operation in wide range of ambient temperatures.

Schaevitz gage heads and their readouts are precise substitutes for mechanical dial position indicators. They can make measurements that are otherwise difficult or impossible even with the most exact mechanical dial indicators or other mechanical measuring devices. These PC Series Gage Heads use the Linear Variable Differential Transformer (LVDT) as the mechanical-to-electrical signal transducer, which has significant advantages when used for precise position measurement. It has inherently infinite resolution limited only by the resolution of the readout equipment; and since the only moving part is a simple spring-biased probe supported on precision sleeve bearings, there are no linkages or gears to wear and cause inaccuracy. 
The LVDT is an electromechanical transducer that produces an electrical output proportional to the displacement of a separate movable core. In its simplest form three coils are equally spaced on a cylindrical coil form. A rod-shaped magnetic core positioned axially inside the coil assembly provides a path for magnetic flux linking the coils.

When the primary, or center coil, is energized with alternating current, voltages are induced in the two outer coils. When the core is in the center position the output is zero. This is referred to as the null position.

When the core is moved from the null position, the voltage induced increases in the coil toward which the core is moved while the voltage induced decreases in the opposite coil. This produces a differential voltage output which varies linearly with changes in core position.

Motion of the core in the opposite direction beyond the null position produces a similar linear voltage characteristic, but with the phase shifted 180 degrees.

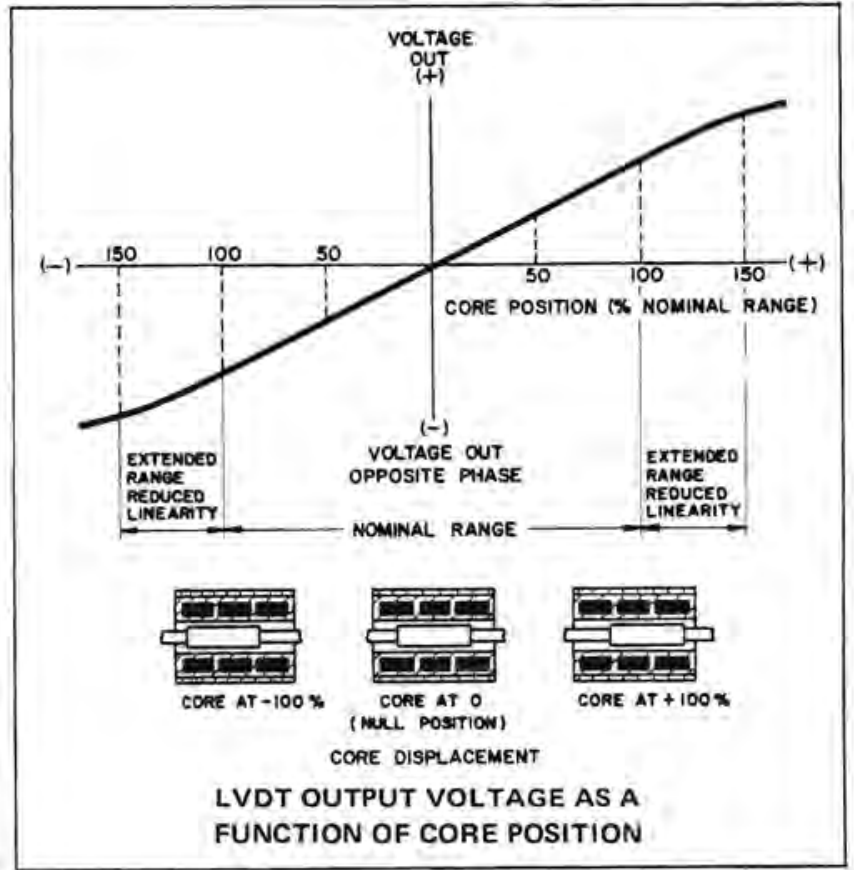

There are several possible ways to classify LVDT gage heads, but the most meaningful classification is according to performance capabilities. This leads to three general categories of LVDT gage heads; economy, precision, and ultra-precise. Considerations of bearing precision and linearity are the principal variables from one class to another.

\section{ECONOMY GAGE HEADS}

This series of gage heads is designed to give a good level of performance at moderate cost. Economy gage heads incorporate a lower cost LVDT having a linearity of bet. ter than $\pm 0.5 \%$ of full range. The shaft is fitted in a sleeve bearing and is free to rotate. Shaft loading is accomplished by an external helical compression spring. Economy gage heads are not threaded so they require an external mounting clamp.

The relatively large bearing clearance can contribute to longer gage head life in typical industrial environments. It also reduces the amount of environmental protection needed to keep out contamination that could jam the bearing or increase shaft friction. The typical life of economy gage heads exceeds 5 million cycles with no significant degradation in performance. Economy gage heads are not recommended for operation in severe environments, since special sealing and protection techniques are required.

\section{PRECISION GAGE HEADS}

Precision gage heads offer $\pm 0.25 \%$ linearity and good repeatability. They are especially suited for use by the original equipment manufacturer. Gage heads in this category are also available as AC or DC-operated with the LVDT hermetically sealed against corrosive liquids and gases.

\section{ULTRA.PRECISE GAGE HEADS - AIR OR SPRING ACTUATED}

Ultra-precise gage heads are characterized by excellent linearity and repeatability. They combine a special AC. LVDT with a honed and lapped, selectively fit sleevebearing or ball-bushing that has an extremely close fit to a non-rotating shaft. In spring-loaded units, the spring is located internally. Linearity is typically $\pm 0.2 \%$, and linearity to $\pm 0.05 \%$ is available on special order.

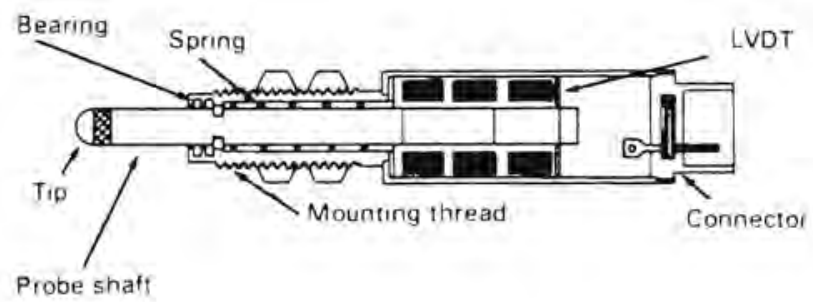

In an LVDT gage head, the core is connected to a springloaded probe shaft. The probe shaft is guided in a sleeve bearing that is retained in a case which also encloses the LVDT coil windings. The case is often threaded externalIV to simplify mounting. 
PCA-220 SERIES, SPRING ACTUATED

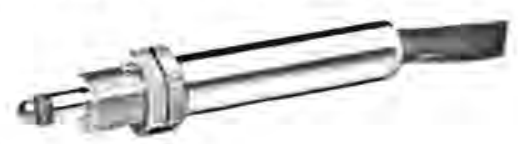

\section{SPECIFICATIONS}

Repeatability.... 0.000004 inch

Linearity . . . . $\pm 0.2 \%$ of full range $( \pm 0.05 \%$ on special order

Tip . . . . . . 0.156 inch diameter carbide ball

Housing. ....... Stainless steel

Electrical

Termination .... Amphenol 126-195 is standard.

Other connectors available on request.

Cable Length. . . . . Six feet
The PCA-220 Series are split-tenth accuracy cartridgetype gage heads which are ready to mount in your fixture for on-line gaging, and can work with virtually any gage amplifier. A non-rotating hard-chrome plated probe is guided by a precision sleeve-bearing and protected against over-travel. Probe contact is maintained by a helical spring. A spherical carbide contact tip is supplied and may be replaced by any tip threaded $4-48$. Units are magnetically shielded and are not affected by proximity of magnetic fields or ferromagnetic material. Units are generally mounted by the external 3/8-40 thread.

OUTLINE DRAWING

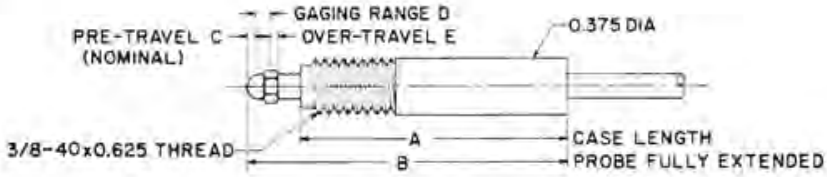

\section{ELECTRICAL CONNECTOR}

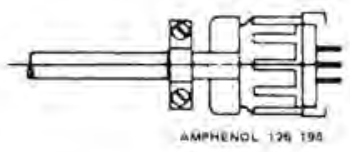

SPECIFICATIONS

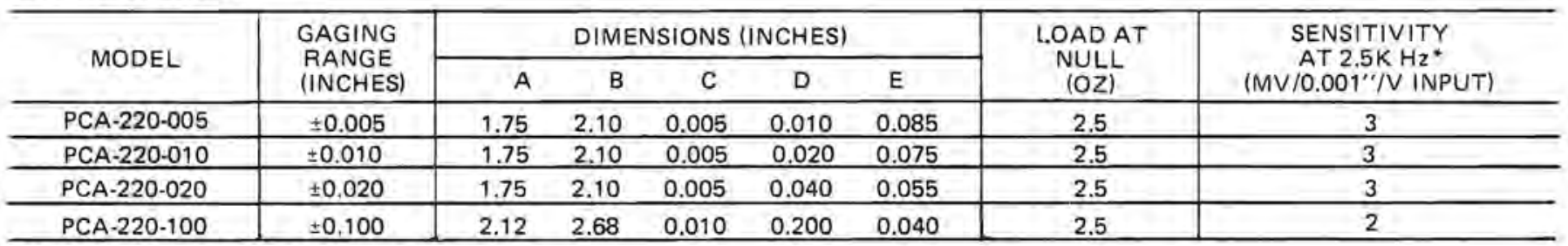

"MAXIMUM EXCITATION VOLTAGE: $3 \mathrm{~V}$ rms

PCA-230 AND PCA-240 SERIES, PNEUMATICALLY ACTUATED

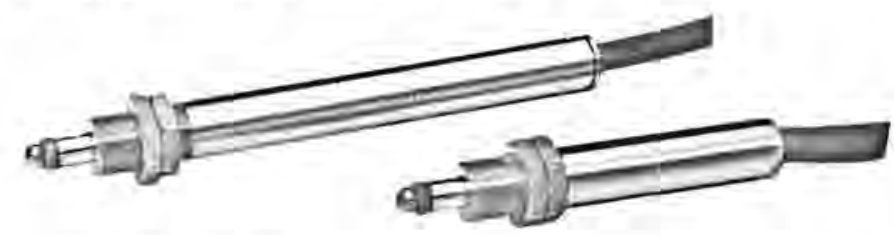

\section{SPECIFICATIONS}

Repeatability. ... 0.000004 inch

Linearity . , , $\pm 0.2 \%$ of full range $( \pm 0.05 \%$ on special order $)$

Tip. ........ 0.156 inch diameter carbide ball

Housing. ...... Stainless steel

Electrical

Termination . . . Amphenol 165-13 standard (modified with air fitting) Cable Length. . . Six feet

\section{OUTLINE DRAWING}

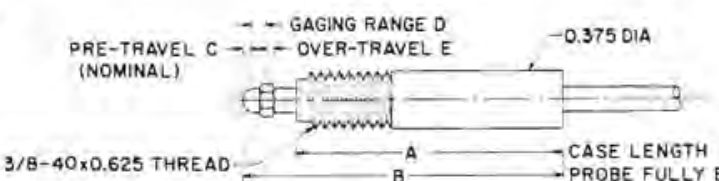

\section{SPECIFICATIONS}

\begin{tabular}{|c|c|c|c|c|c|c|c|c|}
\hline \multirow{2}{*}{ MODEL } & \multirow{2}{*}{$\begin{array}{l}\text { GAGING } \\
\text { RANGE } \\
\text { (INCHES) }\end{array}$} & \multicolumn{5}{|c|}{ DIMENSIONS (INCHES) } & \multirow{2}{*}{$\begin{array}{l}\text { GAGING } \\
\text { FORCE } \\
\text { (OZ/PS } \downarrow \text { ) }\end{array}$} & \multirow{2}{*}{$\begin{array}{c}\text { SENSITIVITY } \\
\text { AT } 2.5 \mathrm{~K} \mathrm{~Hz}{ }^{\circ} \\
\text { (MV } / 0.001^{\prime \prime} / \mathrm{V} \text { INPUT) }\end{array}$} \\
\hline & & A & $\mathrm{B}$ & C & $\mathrm{D}$ & $E$ & & \\
\hline PCA-230.005 & \pm 0.005 & 1.75 & 2.10 & 0.005 & 0.010 & 0.085 & 0.4 & 3 \\
\hline PCA-230-010 & \pm 0.010 & 1.75 & 2.10 & 0.005 & 0.020 & 0.075 & 0.4 & 3 \\
\hline PCA-230.020 & \pm 0.020 & 1.75 & 2.10 & 0.005 & 0.040 & 0.055 & 0.4 & 3 \\
\hline PCA-230-100 & \pm 0.100 & 2.12 & 2.68 & 0.010 & 0.200 & 0.040 & 0.4 & 2 \\
\hline PCA-240-020 & \pm 0.020 & 3.570 & 4.275 & 0.010 & 0.040 & 0.450 & 0.4 & 3 \\
\hline
\end{tabular}

"MAXIMUM EXCITATION VOLTAGE: $3 \mathrm{~V}$ rms

\section{A. 17}

Similar to PCA-220 Series except plunger is pneumatically driven (in both PCA-230 and PCA-240 Series). In the 230 Series, a low vacuum (5 to 10 inches of mercury) will retract the probe between gaging cycles. In the 240 Series, a spring retracts the gaging probe when actuating pressure is released. Gaging force may be varied over an extremely wide range by changing air pressure applied. As a result these gage heads can be adjusted not to distort the most delicate parts nor mar finely finished surfaces. Once the actuating pressure is set by means of an external pressure regulator, the probe contact force remains constant in the 230 Series, and nearly constant in the 240 Series (effect of the return spring is negligible). Note: The applied air must be entirely dry and oil-free. (Recommended maximum air pressure is $10 \mathrm{psig.)}$ It should also be filtered with a 10 -micron filter to prevent the introduction of contaminants into the bearing.

\section{ELECTRICAL CONNECTOR}

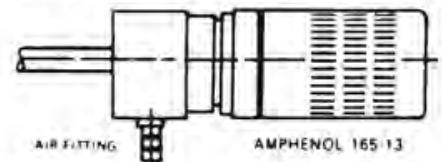


GCD-121

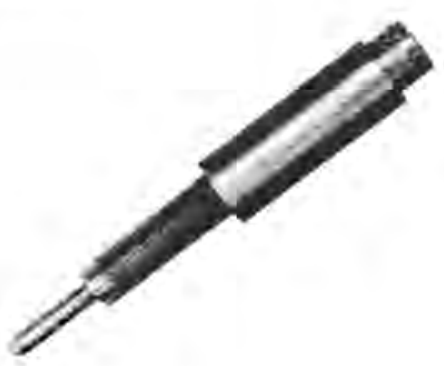

In this series, the entire assembly is housed in a stainless steel case with all joints TIG or EB-welded, thereby hermetically sealing against corrosive liquids and gases. Installation and adjustment is readily accomplished by an externally threaded $1 / 2-20$ bushing; locknuts are provided. A slotted shaft with a dog-point set screw prevents the core rod from rotating as it moves through the gage head.
DC-operated gage heads incorporate the core, LVDT, and all necessary electronics in one housing. Use of thick-film hybrid circuitry eliminates most of the volume, weight, and cost of conventional $A C$ excitation, amplification, and demodulation equipment. Requiring only $a \pm 15 \mathrm{~V}$ DC input (which produces an output of $\pm 10 \mathrm{~V}$ DC at full range), the unit can operate from a simple source such as batteries, and virtually any DC meter can be used for readout.

DC OPERATED UNITS

\begin{tabular}{|c|c|c|c|c|c|c|c|c|}
\hline \multirow{2}{*}{ MODEL } & \multirow{2}{*}{$\begin{array}{l}\text { GAGING } \\
\text { RANGE } \\
\text { (INCHES) } \\
\end{array}$} & \multicolumn{3}{|c|}{ DIMENSIONS (INCHES) } & \multirow{2}{*}{$\begin{array}{l}\text { PRE-TRAVEL } \\
\text { (NOMINAL, } \\
\text { INCHES) }\end{array}$} & \multirow{2}{*}{$\begin{array}{c}\text { MINIMUM } \\
\text { OVERTRAVEL } \\
\text { (INCHES) }\end{array}$} & \multirow{2}{*}{$\begin{array}{l}\text { SPRING LOAD } \\
\text { OVER GAGING } \\
\text { RANGE (OUNCES) }\end{array}$} & \multirow{2}{*}{$\begin{array}{l}\text { SENSITIVITY } \\
\text { (MV } / 0.001 \\
\text { INCH) }\end{array}$} \\
\hline & & $\begin{array}{l}\text { A }\left( \pm 0.01^{\circ}\right. \\
\text { INCHES })\end{array}$ & $\begin{array}{l}\text { B }( \pm 0.03 \\
\text { INCHES })\end{array}$ & $\begin{array}{l}C_{\text {(NCHES }}( \pm 0.02 \\
\text { INC }\end{array}$ & & & & \\
\hline $\begin{array}{l}\text { GCD-121-050 } \\
\text { GPD-121-050 }\end{array}$ & $\pm 0,050$ & 2.46 & 5.08 & 4.02 & 0.30 & 0.39 & 3.5 to 5.8 & 200 \\
\hline $\begin{array}{l}\text { GCD-121-125 } \\
\text { GPD-121-125 } \\
\end{array}$ & \pm 0.125 & 3.30 & 5.90 & 4.87 & 0.35 & 0.14 & 3.5 to 5.8 & 80 \\
\hline $\begin{array}{r}\text { GCD }-121-250 \\
\text { GPD-121-250 } \\
\end{array}$ & \pm 0.250 & 4.17 & 6.77 & 5.74 & 0.18 & 0,03 & 3.5 to 5.8 & 40 \\
\hline $\begin{array}{l}\text { GCD-121-500 } \\
\text { GPD-121-500 } \\
\end{array}$ & \pm 0.500 & 5.86 & 11.53 & 9.05 & 0.20 & 1.00 & 3.2 to 8.0 & 20 \\
\hline $\begin{array}{l}\text { GCD-121-1000 } \\
\text { GPD-121-1000 }\end{array}$ & \pm 1.000 & 8.11 & 13.76 & 11.29 & 0.10 & 0,10 & 3.2 to 8.0 & 10 \\
\hline \multicolumn{9}{|c|}{ AC OPERATED UNITS } \\
\hline \multirow[b]{2}{*}{ MODEL } & \multirow{2}{*}{$\begin{array}{l}\text { GAGING } \\
\text { RANGE } \\
\text { (INCHES) } \\
\end{array}$} & \multicolumn{3}{|c|}{ DIMENSIONS (INCHES) } & \multirow{2}{*}{$\begin{array}{l}\text { PRE-TRAVEL } \\
\text { (NOMINAL. } \\
\text { INCHES) } \\
\end{array}$} & \multirow{2}{*}{$\begin{array}{l}\text { MINIMUM } \\
\text { OVERTRAVEL } \\
\text { (INCHES) }\end{array}$} & \multirow{2}{*}{\begin{tabular}{|l|} 
SPRING LOAD \\
OVER GAGING \\
RANGE(OUNCES) \\
\end{tabular}} & \multirow{2}{*}{$\begin{array}{c}\text { SENSITIVITY } \\
\text { AT } 2.5 \mathrm{~K} \mathrm{HZ} \\
\text { (MV/0.001"/V INPUT) }\end{array}$} \\
\hline & & $\begin{array}{l}A( \pm 0.01 \\
\text { INCHES })\end{array}$ & $\begin{array}{l}\text { B }( \pm 0.03 \\
\text { INCHES }\end{array}$ & $\begin{array}{l}\text { C }( \pm 0.02 \\
\text { INCHES) }\end{array}$ & & & & \\
\hline $\begin{array}{l}\text { GCA-121-050 } \\
\text { GPA-121-050 }\end{array}$ & \pm 0.050 & 1.70 & 4.33 & 3.27 & 0.26 & 0.15 & 3.5 to 5.8 & 5.0 \\
\hline $\begin{array}{l}\text { GCA-121-125 } \\
\text { GPA-121-125 }\end{array}$ & \pm 0.125 & 2.55 & $5: 14$ & 4.12 & 0.30 & 0.15 & 3.5 to 5.8 & 2.4 \\
\hline $\begin{array}{r}\text { GCA-121.250 } \\
\text { GPA-121.250 } \\
\end{array}$ & \pm 0.250 & 3.41 & 6.10 & 4.99 & 0.06 & 0.15 & 3.5 to 5.8 & 1.7 \\
\hline $\begin{array}{l}\text { GCA-121-500 } \\
\text { GPA-121-500 }\end{array}$ & \pm 0.500 & 5.09 & 10.75 & 8.27 & 0.18 & 0.90 & 3.2 to 8.0 & 1.1 \\
\hline $\begin{array}{l}\text { GCA-121-1000 } \\
\text { GPA-121-1000 }\end{array}$ & \pm 1.000 & 7.35 & 13.01 & 10.53 & 0.01 & 0.10 & 3.2 to 8.0 & 0.9 \\
\hline
\end{tabular}

- MaXIMUM eXcitation VOLTAGe: $6 \mathrm{~V}$ rms

\section{SPECIFICATIONS}

Repeatability .......... 0.000025 "

Linearity . . . . . . $\pm 0.25 \%$ of full range

Housing. . . . . . . . . . Stainless steel

Electrical Termination. MS-type or solder-pin
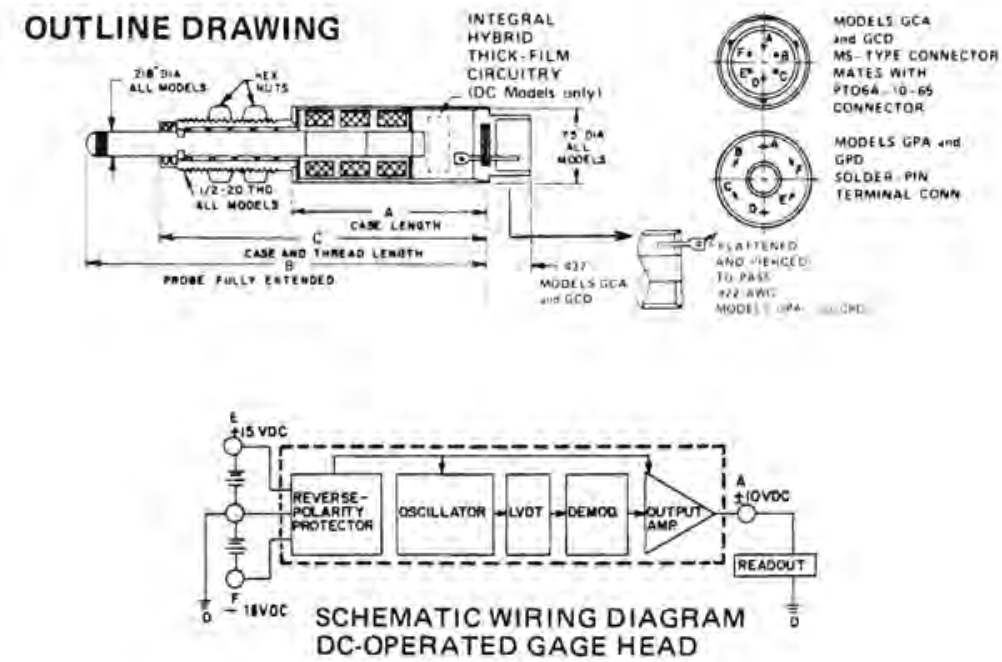
PCA-112 LOW COST PRECISION GAGE HEADS FOR PRODUCTION MEASUREMENTS
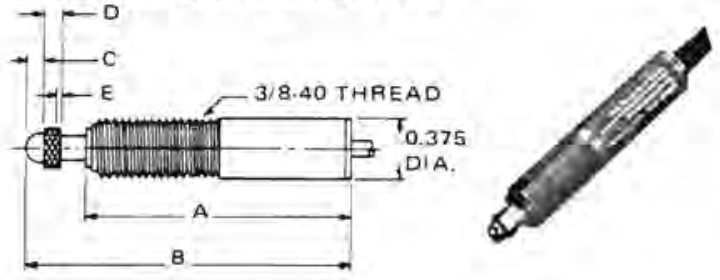

PCA-116 INEXPENSIVE SPRING-LOADED LVDT'S

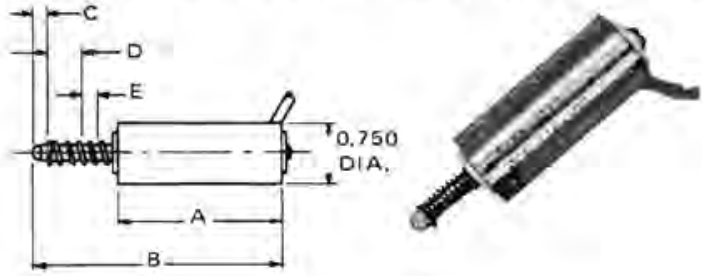

PCA-117 PRECISION GAGE HEADS ESPECIALLY DESIGNED FOR ORIGINAL EQUIPMENT MANUFACTURER
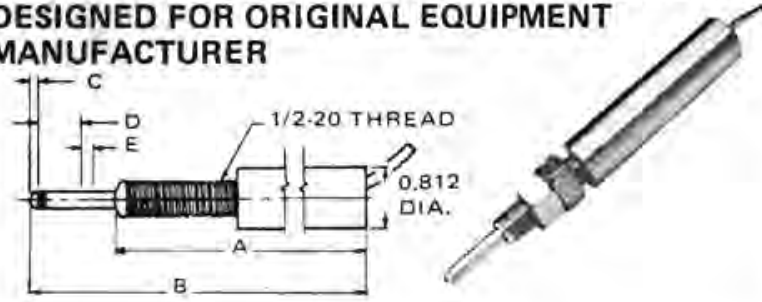

Slightly less precise bearing and considerably lower price makes the PCA-112 particularly attractive for applications where a number of dimensional measurements must be made simultaneously. Designed to accept optional protective boot.

Inexpensive externally-sprung LVDT position transducers. For applications where extreme linearity is not important and environment is not severe. The hardened-steel tipped probe is guided by low-friction nylon bearings.

Precision LVDT position transducers with DELRIN bearing. supported probe. Wide variety of ranges is available and all exhibit excellent linearity. Internally spring-loaded probe has a threaded mounting shank with locknut.
SPECIFICATIONS

Repeatability, .0 .000080 inch Linearity. $\pm 0.25 \%$ of full range

Tip . . . . 0.210 inch diameter hardened steel

Housing . . . . . Stainless steel Bearing . . . . . . Stainless steel Electrical

Termination .. Amphenol 126-195

Lead Length . . . . . . 6 feet

SPECIFICATIONS

Repeatability. .0.000 100 inch Linearity, $\pm 0.5 \%$ of full range Tip . . . . . . . Hardened Steel Housing .., , Stainless steel Bearing. .......... Nylon Electrical Termination. . Leads Lead Length . . . . . . 1 foot

\section{SPECIFICATIONS}

Repeatability .0 .000050 inch Linearity $, \pm 0,25 \%$ of full range Tip ... . . . . Hardened steel Housing ...... Stainless steel Bearing. ....... DELRIN Electrical Termination, Leads Lead Length , . . . . . 1 foot

\section{SPECIFICATIONS}

\begin{tabular}{|c|c|c|c|c|c|c|c|c|}
\hline \multirow{3}{*}{ MODEL } & \multirow{3}{*}{$\begin{array}{l}\text { GAGING } \\
\text { RANGE } \\
\text { (INCHES) }\end{array}$} & \multicolumn{5}{|c|}{ DIMENSIONS (INCHES) } & \multirow{3}{*}{$\begin{array}{l}\text { SPRING LOAD } \\
\text { AT NULL } \\
(O Z)\end{array}$} & \multirow{3}{*}{$\begin{array}{c}\text { SENSITIVITY } \\
\text { AT 2.5K Hz* } \\
\text { (MV/0.001"/V INPUT) }\end{array}$} \\
\hline & & \multicolumn{5}{|c|}{$\begin{array}{l}\text { A-CASE LENGTH } \\
\text { B-PROBE FULLY EXTENDED } \\
\text { C-PRE-TRAVEL (NOMINAL) } \\
\text { D-TOTAL GAGING RANGE } \\
\text { E-OVER-TRAVEL }\end{array}$} & & \\
\hline & & A & B & C & D & E & & \\
\hline PCA-112-020 & \pm 0.020 & 1.68 & 2.10 & 0.01 & 0.04 & 0.05 & 2.5 & 5,0 \\
\hline PCA-112-100 & \pm 0.100 & 2.13 & 2.89 & 0.01 & 0.20 & 0.04 & 2.5 & 2.0 \\
\hline PCA-116-100 & \pm 0.100 & 1.74 & 2.54 & 0.10 & 0.20 & 0.03 & 8.0 & 2.4 \\
\hline PCA-116-200 & \pm 0.200 & 2.25 & 3.30 & 0.09 & 0.40 & 0.11 & 8.0 & 2.1 \\
\hline PCA-116-300 & \pm 0.300 & 2.74 & 4.10 & 0.07 & 0.60 & 0.10 & 8.0 & 1.2 \\
\hline PCA-117-050 & \pm 0.050 & 1.14 & 3.75 & 0.06 & 0.10 & 0,60 & 3.0 & 6.3 \\
\hline PCA-117-100 & \pm 0.100 & 3.47 & 4.53 & 0.20 & 0.20 & 0.40 & 4.0 & 4.7 \\
\hline PCA-117-200 & \pm 0.200 & 4.15 & 5.23 & 0.15 & 0.40 & 0.28 & 4.0 & 2.7 \\
\hline PCA-117-300 & \pm 0.300 & 4.85 & 5.94 & 0.09 & 0.60 & 0.18 & 4.0 & 1.4 \\
\hline PCA-117.500 & \pm 0.500 & 8.76 & 11.20 & 0.29 & 1.00 & 0.83 & 5,0 & 0.8 \\
\hline PCA-117-1000 & \pm 1.000 & 9.83 & 12.28 & 0.03 & 2.00 & 0.09 & 5.0 & 0,4 \\
\hline
\end{tabular}

"MAXIMUM EXCITATION VOLTAGE: $3 \mathrm{~V}$ rms

\section{SCHAEVITZ SPECIAL CONTACT POINTS}

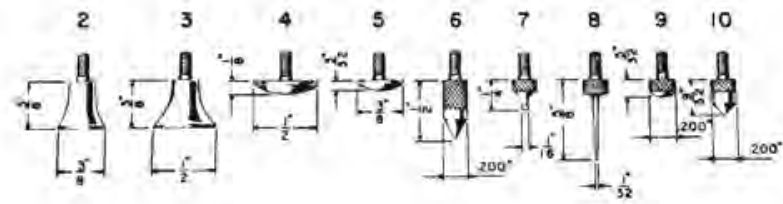

Schaevitz contact points are precision-made from high grade steel, hardened, ground, and chrome-plated. These points can be furnished in any of ten special shapes for use as a substitute for the tip supplied with the gage head. All Schaevitz contact points have a number $4-48$ thread.

Other special shapes, as well as contact points with tungsten carbide, sapphire, or diamond faces available on special order. 
PCA-115 HERMETICALLY SEALED

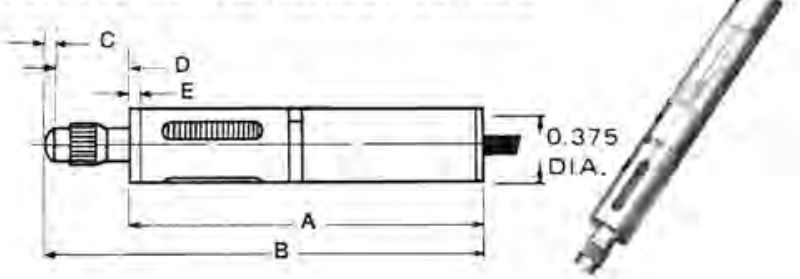

PCA-135 EXTRA SHORT GAGE HEAD
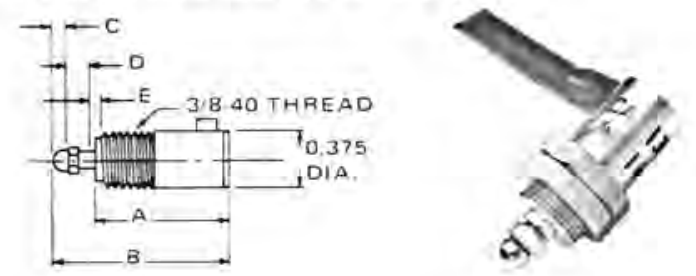

Metal bellows - Hermetic seal makes this unit ideal for applications in water, oil, or a dirty abrasive environment.
Extremely compact unit. Permits design of gaging systems without trade-offs between performance, number of gages, and space.

\section{SPECIFICATIONS}

Repeatability. 0.000080 inch Linearity $\pm 0,25 \%$ of full range Tip ........ Hardened stee Housing . . . . 303 Stainless Bearing. ..... 303 Stainless Electrical

Termination ... Amphenol 126-195

Lead Length . . . . . 6 feet

\section{SPECIFICATIONS}

Repeatability. 0.000060 inch Linearity . $\pm 0,25 \%$ of full range

Tip , , 0.156 inch carbide ball Housing ....... 17-4 PH Bearing. . . . . . 17-4 PH Spindle. ...... Stainless steel Electrical

Termination. . . Amphenol 126-195

Lead Length . . . . . . 6 feet

\section{SPECIFICATIONS}

\begin{tabular}{|c|c|c|c|c|c|c|c|c|}
\hline \multirow{3}{*}{ MODEL } & \multirow{3}{*}{$\begin{array}{l}\text { GAGING } \\
\text { RANGE } \\
\text { (INCHES) }\end{array}$} & \multicolumn{5}{|c|}{ DIMENSIONS (INCHES) } & \multirow{3}{*}{$\begin{array}{c}\text { SPRING LOAD } \\
\text { AT NULL } \\
\text { (OZ) }\end{array}$} & \multirow{3}{*}{$\begin{array}{c}\text { SENSITIVITY } \\
\text { AT } 2.5 \mathrm{~K} \mathrm{~Hz} \mathrm{H}^{*} \\
\text { (MV } / 0.001 \% / \mathrm{V} \text { INPUT) }\end{array}$} \\
\hline & & \multicolumn{5}{|c|}{$\begin{array}{l}\text { A-CASE LENGTH } \\
\text { B-PROBE FULLY EXTENDED } \\
\text { C-PRE-TRAVEL (NOMINAL) } \\
\text { D-TOTAL GAGING RANGE } \\
\text { E-OVER-TRAVEL }\end{array}$} & & \\
\hline & & A & B & c & D & $E$ & & \\
\hline PCA-115-050 & \pm 0.050 & 2.525 & 2,760 & 0.010 & 0.100 & 0.010 & 1.5 & 2 \\
\hline PCA-135-020 & \pm 0.020 & 0.88 & 1.21 & 0.01 & 0.04 & 0.05 & 2.5 & 2.5 \\
\hline
\end{tabular}

*MAXIMUM EXCITATION VOLTAGE: $3 \mathrm{~V}$ rms

An accurate non-contacting gage head for use where contact type gage heads will damage delicate material or affect measurement.

The Schaevitz non-contacting gage head consists of an LVDT and a pneumatic assembly which maintains a constant air gap between the work piece and a nozzle follower. By directly coupling the LVDT core to the nozzle follower, its movement as it tracks the profile of the part is converted to an electrical signal that is directly proportional to thickness.

\section{TYPICAL PERFORMANCE SPECIFICATIONS}

Gaging Force . . . . . 10 grams standard, 1 gram optional Gaging Range .......... \pm 0.050 inches to \pm 1.000 inches Repeatability , . . ., 0.0001 inches with 0.002 inch air gap 0.0002 inches with 0.015 inch air gap and booster cylinder Input Air Pressure . . . . . . . . . . . . 30 psi nominal

- PRECISE - Repeatability to $\pm 0.0001^{\prime \prime}$; linear over complete gaging range

- RUGGED CONSTRUCTION - Designed for production gaging

- CONNECTOR-TYPE TERMINATIONS - No external wires to be damaged

- NON-CONTACTING - Never contacts part being gaged. Will not mar or tear even the most fragile material

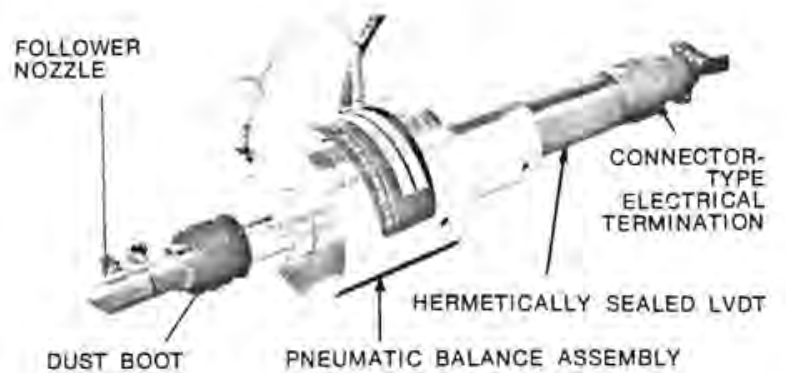

- WIDE STANDARD RANGES - Will follow displacements to $\pm 1.000^{\prime \prime}$

- MEASURES MANY MATERIALS - Measure variations in thickness of any non-porous material - metal, plastic, paper, film, etc., from smooth and flat to rough machined (even some materials like foam rubber and non-porous grinding wheels!)

Request Technical Bulletin for additional information 


\section{READY TO USE}

These ready-to-use units are available as fully self-contained single-channel conditioners. Just add an LVDT gage head and readout for a complete measurement system.

Line powered, bench or rack mount, single channel

- Perfect for the model shop or on the production line

- Complete signal conditioners-readouts aiso available, with or without BCD outputs

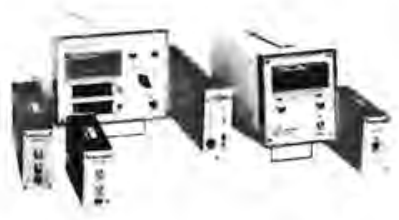

BASIC SIGNAL CONDITIONERS FOR ORIGINAL EQUIPMENT MANUFACTURERS

Ideal for the OEM who wants to adapt AC-operated LVDT gage heads for use with various controls and instrumentation. This approach enables OEM's to minimize cost by using only bare minimum modules, . e.g. modules available with only oscillator and demodulator/amplifier; others with DC power supply and circuits for zero and span adjustments, high-low limits, etc. OEM generally supplies and mounts adjustment potentiometers, etc.

From individual signal conditioning components to complete multiple channel assemblies

Cost less because there are fewer components... not less quality

\section{SINGLE AND MULTIPLE CHANNEL PLUG-IN SIGNAL CONDITIONING}

Only one power supply and one oscillator card needed to drive up to ten LVDT gage heads. Wide variety of cards makes it easy to satisfy almost any signal conditioning requirement without redun. dancy. Ideal for committed in-plant production or inspection equipment because PCB cards afford maximum flexibility,

- Provides same signal conditioning functions as multiple channel "ready-to-use" systems, but is more easily expanded.

- Components mounted on individual plug-in cards.

- "Design-it Yourself" concept for ready expansion from single into multiple channel systems.

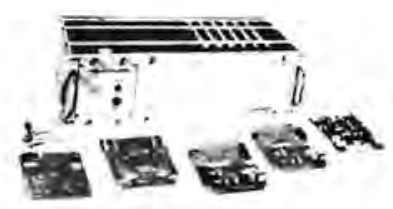

\section{Write for quotation to your special requirements}

\section{COMPUTING SUB-SYSTEMS}

Schaevitz sub-systems with plug-in modules are custom-engineered to meet specific gaging requirements. Our experience includes automatic, semi-automatic, and manual high accuracy systems for use in production and quality control departments. They measure precision components and are available with all these features:

GO-NO-GO SET POINTS

ACCEPT-REJECT LIGHTS

- DEVIATION INDICATORS

AUTOMATIC COMPUTING

OF: $\quad A+B$ for external diameter, out of round, thickness, etc.

A-B for internal diameter, concentricity, inclination, taper, etc.

$\triangle A$ or $\Delta(A+B)$ for runout, parallelism, runout of face, etc.

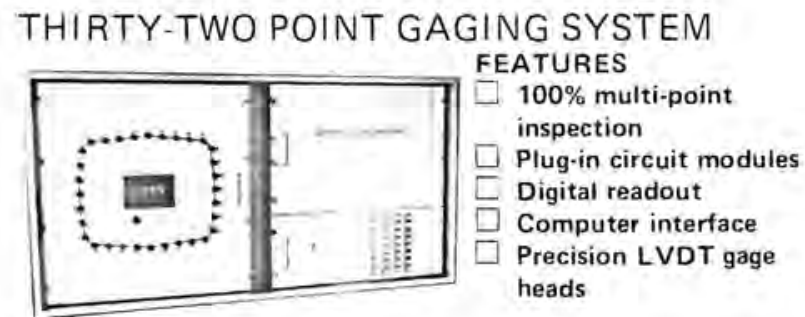

This semi-automated system is designed to gage the contour of television picture-tube face plates. It provides $100 \%$ precision inspection at less than the cost of sampling, and can be systematized to permit computer analysis of the entire quality-control operation.
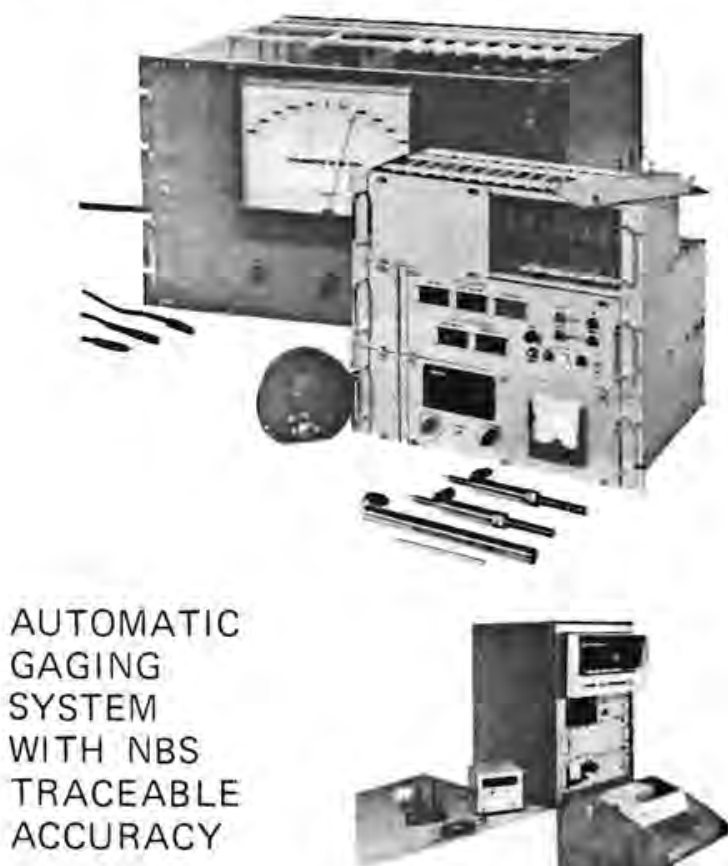

Designed for a large nuclear components manufacturer, this multi-channel system automatically reads and prints out the displacement of 48 individual gage heads with a system accuracy of $\pm 0.075 \%$ (traceable to NBS) over the range of $\pm 0.100^{\prime \prime}$. The system's scanning speed is 200 channels/second. 
- DISPLACEMENT

- acceleration

- pRESSURE

- FORCE/WEIGHT

- DIMENSION

- SLOPE/ANGLE

\section{DISPLACEMENT}

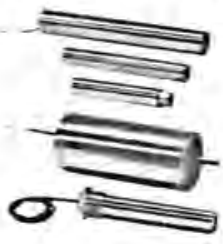

- ac or dC-OPERATED

- RANGES TO 20" STANDARD

- Linearity to $\pm 0.05 \%$

- models available for LINEAR OR ANGULAR DISPLACEMENT, VELOCITY, OR PROXIMITY

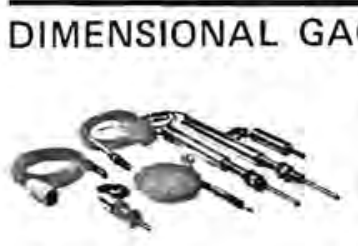

- repeatabillity to 0.000004 INCH

- RESOlution TOO 0.0000003 INCH

- LINEARITY TO $\pm 0.2 \%$ STANDARD, $\pm 0.05 \%$ SPECIAL

$\begin{array}{ll}\text { SLOPE/ANGLE } & \text { MEASURES CHANGE OF } \\ & \text { SLOPE OR ANGLE TO O.1 } \\ & \text { SECOND OF ARC } \\ & \text { LINEARITY TO } \pm 0.02 \%\end{array}$

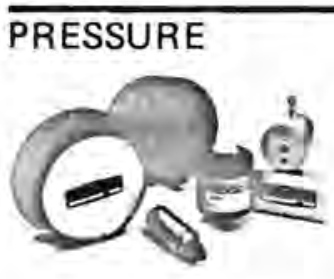

- gage, differential. ABSOLUTE AND BAROMETRIC

- RANGES FROM 10" $\mathrm{H}_{2} \mathrm{O}$ TO 10,000 PSI

- AC or DC-OPERATED

- hermetically SeALed

\section{FORCE/WEIGHT}

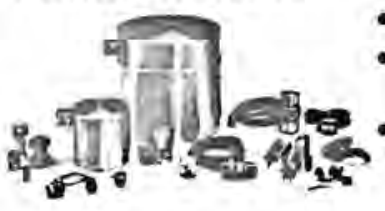

- ac or DC-OPERATED

- RANGES FROM 10 GRAMS TO 10,000 LBS

- TARE-TO-LIVE-LOAD RATIOS TO 10:1

\section{ACCELERATION}

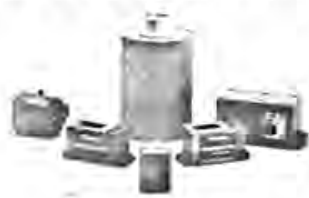

- DC INPUT - DC OUTPUT

- SMALl SIZE - LIGHT WEIGHT

- RANGes aVAILABLE FROM $\pm 0.25 \mathrm{~g}$ TO $\pm 50 \mathrm{~g} ' \mathrm{~s}$

- linearity TO $\pm 0.05 \%$
Schaevitz inclinometers measure horizontal angle or vertical deviation with exceptionally high accuracy and virtually infinite resolution. These DC operated transducers are entirely self-contained in hermetically sealed housings and require no external electronics or amplifier. Their $\pm 5 \mathrm{~V} \mathrm{DC}$ analog output (proportional to tilt) can be used for automatically setting slope of road grading and paving machines, in geophysics for tilt and strong-motion studies, for ship and barge leveling, and other applications where high-accuracy measurement of tilt is required.

For more information, request Series 46 Technical Bulletins.

Schaevitz LVDT and Bonded Strain Gage pressure transducers and transmitters constitute a broad family of sturdily-constructed yet laboratoryprecise sensors to satisfy the most stringent pressure measurement requirements. These units represent the widest selection of pressure ranges from any manufacturer (from 0.5 inches of water to $0.10,000 \mathrm{psi}$ ), and are available with combined error down to $\pm 0.1 \%$.

For more intormation, request:

Series 30 Technical Bulletins for LVDT Types

Series 35 Technical Bulletins for Strain Gage Types

High output, infinite resolution, excellent signal-to-noise ratio, and all stainless-steel construction are some of the outstanding characteristics of Schaevitz LVDT load cells. Typical applications are measurement of force in structures, and tank and hopper weighing.

For more information, request Series 50 Technical Bulletins.

Schaevitz servo accelerometers are closed-loop, force-balance transducers that provide an analog DC output signal proportional to acceleration. These DC-operated miniature devices are entirely self-contained within light-weight, hermetically sealed housings and require no additional amplifier or other electronics. They are suited for use in guidance and closed-loop control systems and for measurement of vibration or performance studies of vehicles and other moving systems. For more information, request Series 45 Technical Bulletins.

SIGNAL CONDITIONING

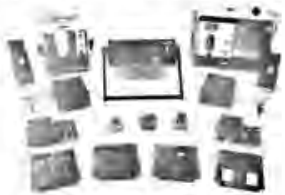

- Fully SELF-CONTAINED

- SINGLE-CHANNEL AND MULTIPLE-CHANNEL PLUG-IN CARDS

- displays available to 5-PLACE DIGITAL READOUT
These Schaevitz signal conditioners operate from standard AC power sources, and typically deliver an output of $\pm 10 \mathrm{~V} D C$ from a low impedance. Modular units are ready to hard-wire into your equipment: only external power is needed to produce an operating system.

For more information, request Series 70 Technical Bulletins. 


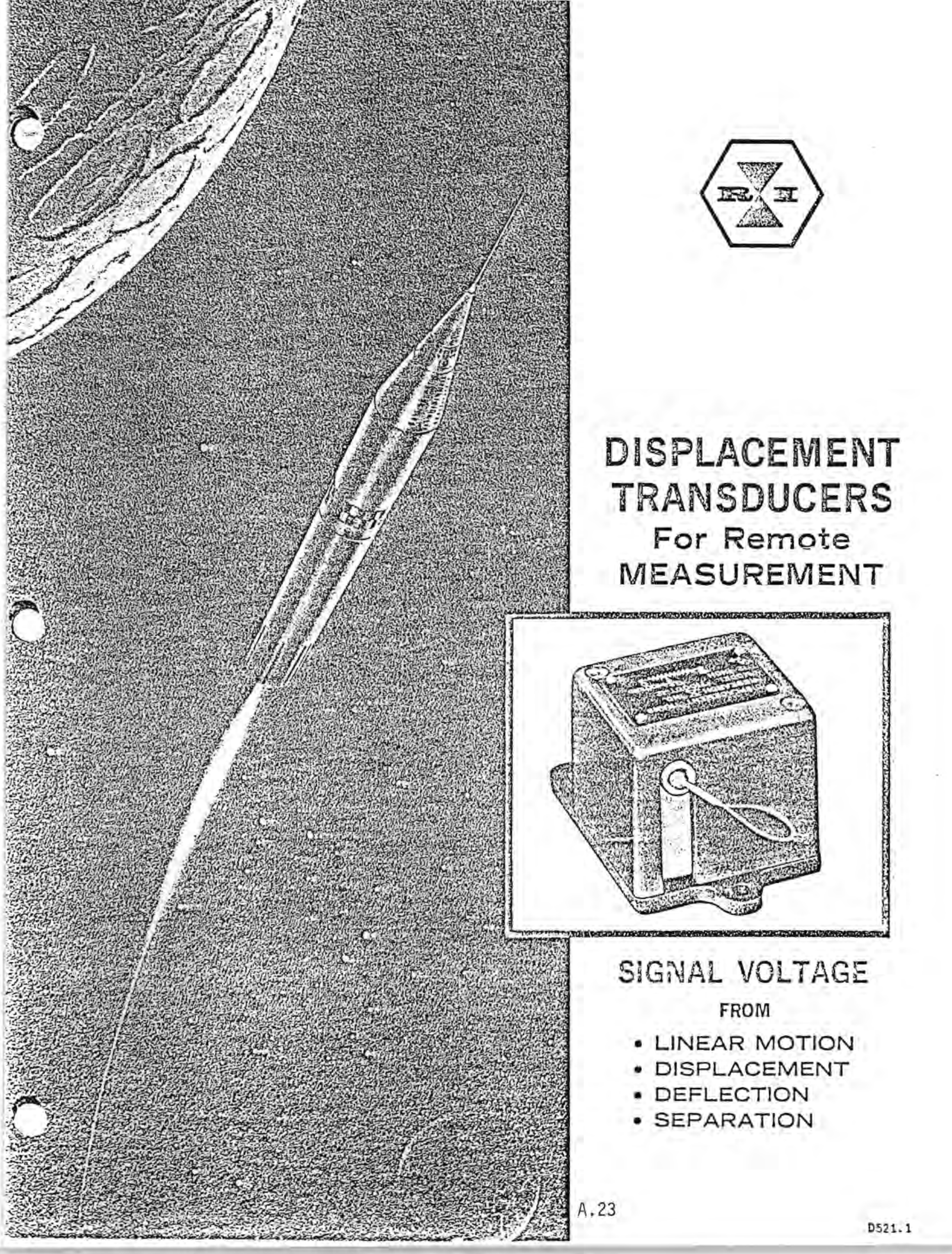




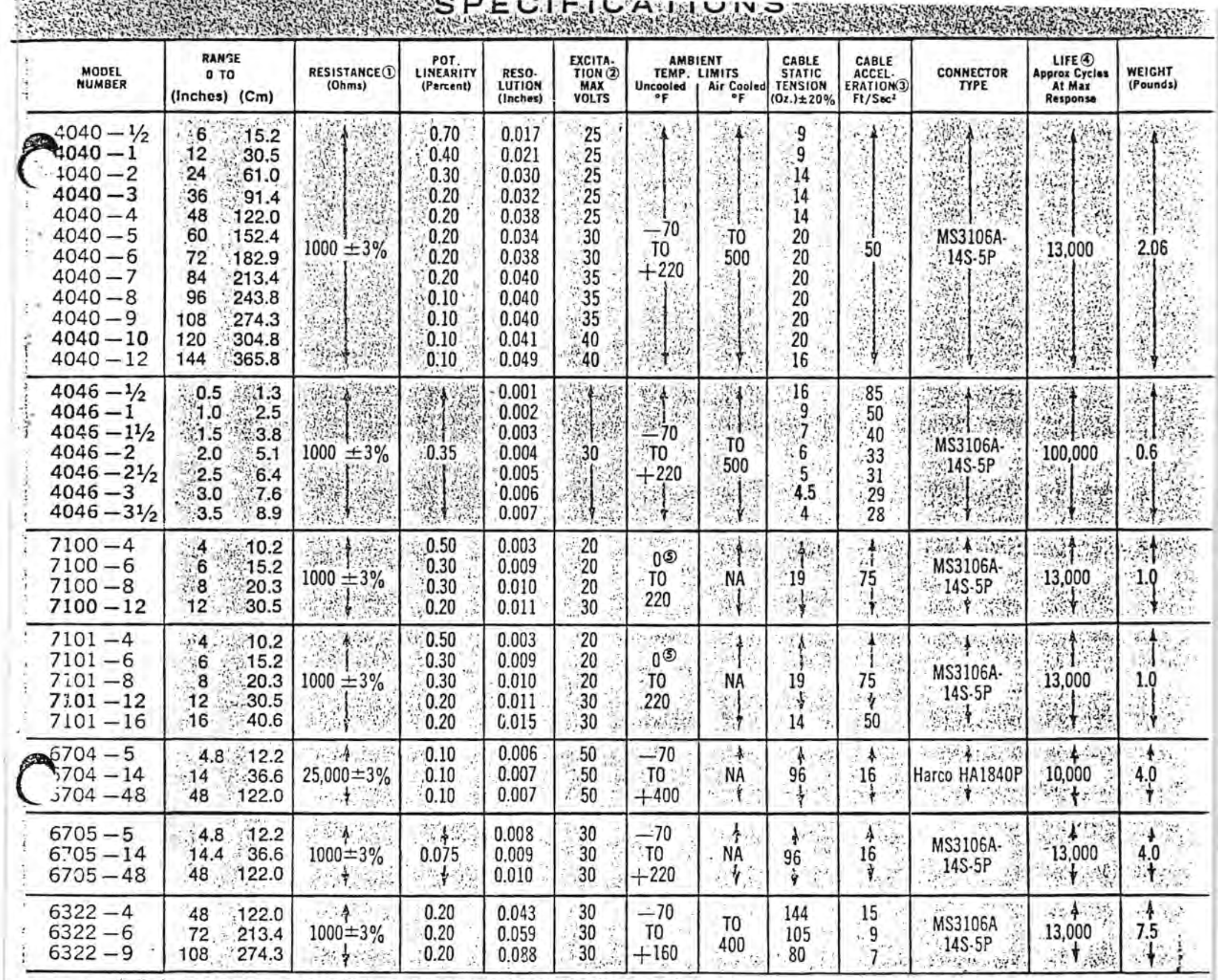

Models shown in bold type are generally available from stock:

(1) Other values and tolerances available.

(2) At operating temperatures up to $104^{\circ} \mathrm{F}$.

(3) Acceleration of cable during retraction by the internal spring motor. Extending acceleration can be greater. (4) Life based on minimum useful life of spring motor in continuou
operation at maximum rate over maximum range. Useful life c: remaining components is 250.000 cycles.

(5) Furnished with special lubricant for operation from $-70^{\circ} \mathrm{F}$ i $+100^{\circ} \mathrm{F}$ when so ordered.

\begin{tabular}{|c|c|c|c|c|c|c|c|c|c|c|c|c|c|c|c|c|c|c|c|c|c|c|c|c|c|}
\hline \multicolumn{2}{|c|}{$\begin{array}{c}\text { RANGE (Inches) } \\
0 \text { to } \rightarrow\end{array}$} & 0.5 & 1.0 & 1.5 & 2.0 & 2.5 & 3.0 & 3.5 & 4.0 & 4.8 & 6 & 8 & 12 & 14.4 & 16 & 24 & 36 & 48 & 60 & 72 & 84 & 96 & 108 & 120 & 144 \\
\hline & 4040 & & & & & & & & & & $-1 / 2$ & & -1 & & & -2 & -3 & -4 & -5 & -6 & -7 & -8 & -9 & -10 & -12 \\
\hline$M$ & 4046 & $-1 / 2$ & -1 & $-11 / 2$ & -2 & $-21 / 2$ & -3 & $-31 / 2$ & & & & & & & & & & & & & & & & & \\
\hline 0 & 7100 & & & & & & & & -4 & & -6 & -8 & -12 & & & & & & & & & & & & \\
\hline D & 7101 & & & & & & & & -4 & & -6 & -8 & -12 & & -16 & & & & & & & & & & \\
\hline$E$ & 6704 & & & & & & & & & -5 & & & & -14 & & & & -48 & & & & & & & \\
\hline L & 6705 & & & & & & & - & & -5 & & & & -14 & & & & -48 & & & & & & & \\
\hline & 6322 & & & & & & & & & & & & & & & & & -4 & & -6 & & & -9 & & \\
\hline
\end{tabular}


The Model PT-101 is a position or displacement transducer designed for measurements from 0-2 inches to 0.500 inches.

It provides an electrical signal proportional to the linear extension of a stainless steel cable. It can utilize either AC or DC as an excitation source and will provide a stepless output by means of a potentiometer with effectively infinite resolution. Non-linearity errors are less than $0.1 \%$ of full range.

Displacement is measured by attaching the cable to the moving part and the body of the transducer to any fixed convenient surface. Retraction is effected by means of a constant tension spring motor which maintains uniform tension on the cable. Response acceleration rates to $100 \mathrm{G}^{\prime}$ s may be provided.

A ruggedized version of the transducer designated Model PT-101RX is available for use in extreme environments. This instrument will endure shock of 2,000 G's for 6 milliseconds, and vibration of $50 \mathrm{G}$ 's over the $100-2,000 \mathrm{~Hz}$ spectrum without changes in calibration or damage.

\section{SPECIFICATIONS FOR THE PT101 POSITION/DISPLACEMENT TRANSDUCER}

Performance:

Range $^{1}$

Resolution

Accuracy ${ }^{2}$

Thermal Effects ${ }^{3}$
Sipan
Zero
Fiequency Response 4
Sensitivity

\section{$0.01 \% / O F$}
$0.01 \% / O F$
$0-60 \mathrm{~Hz}$ depending on amplitude (d)
See Specification Table

\section{$0-2$ to $0-500$ inches Infinite \\ $0.1 \%$ FS}

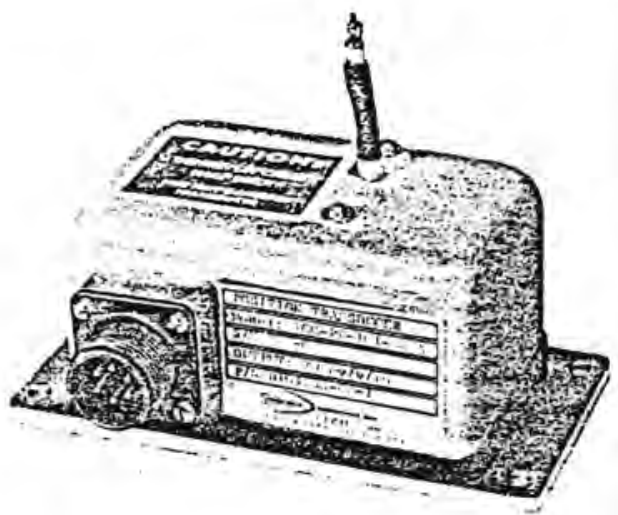

Notes

1. Standard ranges are $2,5,10,20,25$, $50,100,200,250,500$.

2. Repeatability and non-linearity errors includea.

3. Over temperature range from $0^{\circ} \mathrm{F}$ to $200^{\circ} \mathrm{F}$.

4. Using the approximation $d=\frac{g}{.05 f^{2}}$ value of " $\mathrm{g}$ " not to exceed lower acceleration value shown.

\section{FEATURES:}

\begin{tabular}{|c|l|l|c|cc|}
\hline $\begin{array}{c}\text { MEASUREMENT } \\
\text { RANGE }\end{array}$ & $\begin{array}{l}\text { POSITION TRANSOUCER } \\
\text { "A." Circuit } \\
\text { Output }\end{array}$ & $\begin{array}{c}\text { CABLE } \\
\text { Output }\end{array}$ & \multicolumn{2}{|c|}{$\begin{array}{c}\text { CABLE } \\
\text { TENSION }\end{array}$} & \multicolumn{2}{|c|}{ ACCELERATION } \\
\hline INCHES & MV/V/Inch & MV/V/Inch & OUNCES & EXT. & RET. \\
\hline & & & & \multicolumn{2}{|c|}{ G'S } \\
2 & 500 & 1.165 & 28 & 37 & 25 \\
5 & 200 & 530 & 12 & 17 & 5 \\
10 & 100 & 215 & 28 & 37 & 25 \\
15 & 65 & 147 & 21 & 18 & 12 \\
20 & 50 & .109 & 28 & 37 & 25 \\
30 & 32 & .073 & 21 & 15 & 10 \\
40 & 25 & .055 & 14 & 12 & 8 \\
50 & 20 & 044 & 12 & 7 & 5 \\
60 & 16 & 037 & 10 & 6 & 4 \\
75 & 13 & 031 & 8 & 5 & 3 \\
100 & 10 & .022 & 18 & 7 & 5 \\
150 & 6.5 & 01487 & 16 & 6 & 4 \\
200 & 5 & 011875 & 14 & 5 & 3 \\
250 & 4 & 007765 & 12 & 5 & -3 \\
300 & 3.2 & N.A & 14 & 5 & 3 \\
350 & 2.8 & N.A & 10 & 5 & 3 \\
500 & 2.0 & N.A & 10 & 5 & 3 \\
\hline
\end{tabular}

- $0.1 \%$ Accuracy Standard

- Resolution of 0.001 inch

- Ranges from $0-2$ to $0-500$ inches full scale

- Digital output available (optional)

- Frequency response up to $60 \mathrm{~Hz}$ (see Note 4)

- " $A$ " circuit full scale output approximates input

- "B" circuit simulates full wheatstone bridge with zero at midpoint

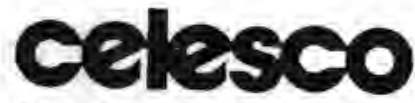

Transducer Products, inc.

P.O. Box 1457 • Canoga Park • California 91304 


\section{SPECIFICATIONS}
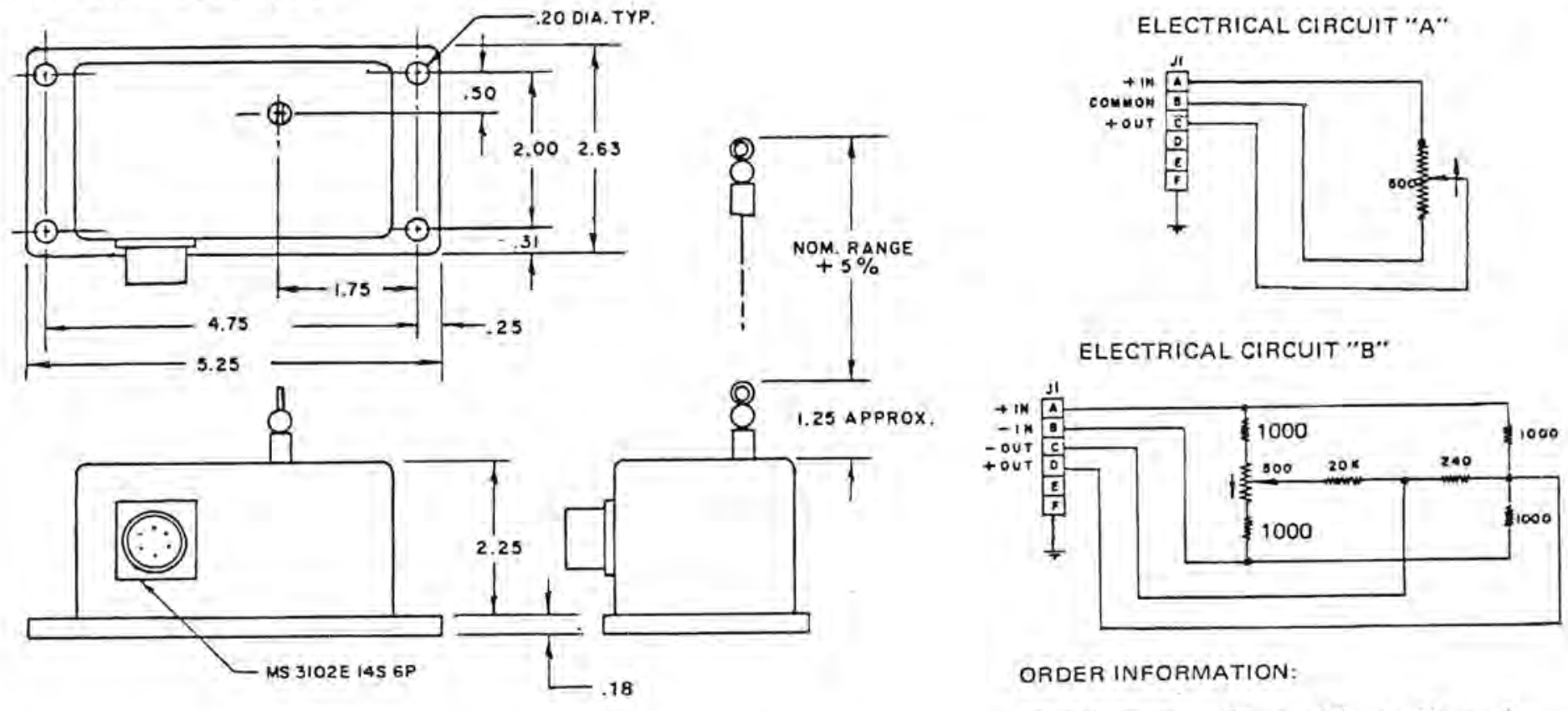

ORDER INFORMATION:

DIMENSIONS TYPICAL FOR RANGES TO 50 INCHES. OVFR $5 O$ INCHES, CONSULT FACTORY.

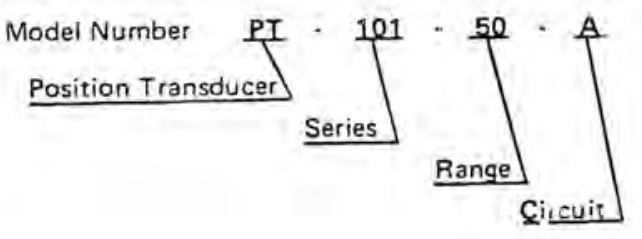

Electrical Characteristics Input Impedance

$$
\text { "A" Circuit }
$$

Output Impedance

$$
\text { "A" Circuit }
$$

"B" Circuit

Excitation Voltage

Physical

Weight

Case Material

Electrical Connection

Environmental

Temperature

Humidity

Shock

Vibration $\left.\begin{array}{l}500 \text { ohms } \\ 1100 \text { ohms }\end{array}\right\}$ Std. Other options available

$\left.\begin{array}{l}\text { 0-500 ohms } \\ 240 \text { ohms }\end{array}\right\}$ Std. Other options available

$5 / 25$ volts $A C$ or $D C$

20 ounces (to 50 inch range)

Aluminum

MS3102E 14S 6P (Other connectors optional)

$00 \mathrm{~F}$ to $+200^{\circ} \mathrm{F}$ (- $650 \mathrm{~F}$ to $+250^{\circ} \mathrm{F}$ available)

$100 \% \mathrm{RH}$ at $90^{\circ} \mathrm{F}$

$50 \mathrm{G}$ 's for 6 milliseconds

Per MIL-E-5272C

Reliability: Celesco maintains a program of constant surveillance over all products to ensure a high level of reliability. This program includes attention to reliability considerations during product design, the support of stringent quality control procedures, and continuing product support. These measures and conservative specifications provide an extremely reliable product.

Continuing product improvement necessitates that Celesco reserve the right to modify these specifications without notice. 


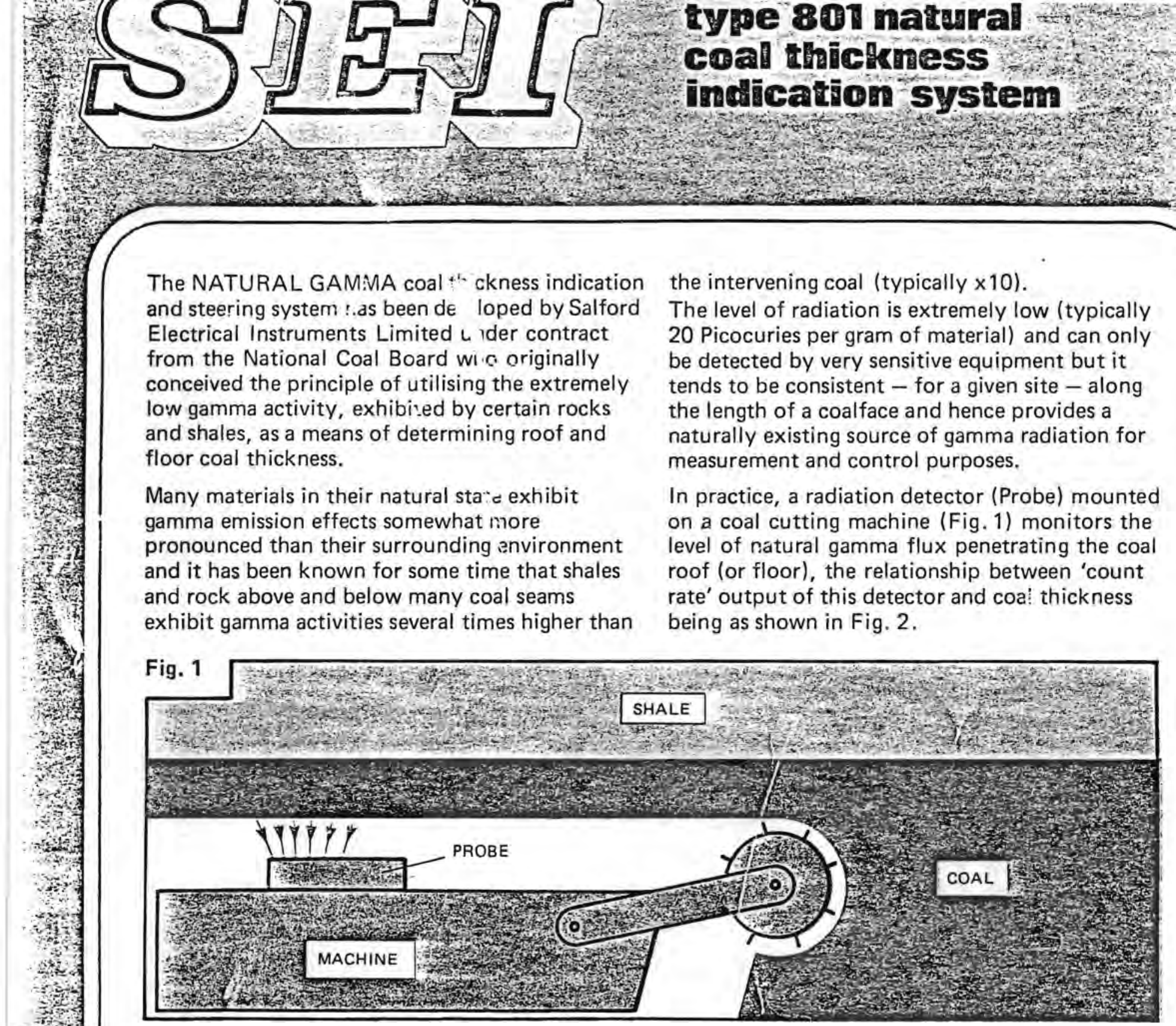

The NATURAL GAM:VA coal"' ckness indication pronounced than their surrounding anvironment and it has been known for some time that shales and rock above and below many coal seams the intervening coal (typically $\times 10$ ). be detected by very sensitive equipment but it tends to be consistent - for a given site - along the length of a coalface and hence provides a naturally existing source of gamma radiation for

In practice, a radiation detector (Probe) mounted on a coal cutting machine (Fig. 1) monitors the level of natural gamma flux penetrating the coal roof (or floor), the relationship between 'count rate' output of this detector and coa! thickness being as shown in Fig. 2 .
The system now available comprises a Type 801 NATURAL GAMMA Probe (radiation detector), a microprocessor based Indicator Unit, Remote Indicator and Power Supply.

\section{type 8ำ ตละเ probe (IS 1934)}

This probe is capable of monitoring coal thickness up to 20 inches $(50 \mathrm{~cm})$, where overlying or underlying shale etc. exhibits a gamma activity of nominally $20 \mathrm{PCi} / \mathrm{gm}$ in the energy band $30 \mathrm{KeV}$ to $2 \mathrm{MeV}$ and machine speeds of at least $20 \mathrm{ft} / \mathrm{min}$ can be accommodated.

Both pulsed and analogue outputs are provided and the unit is ruggedly constructed for a mining environment, being designed to withstand mechanical shocks up to $50 \mathrm{G}$.
OUTPUT CHARACTERISTIC NATURAL GAMMA PROBE

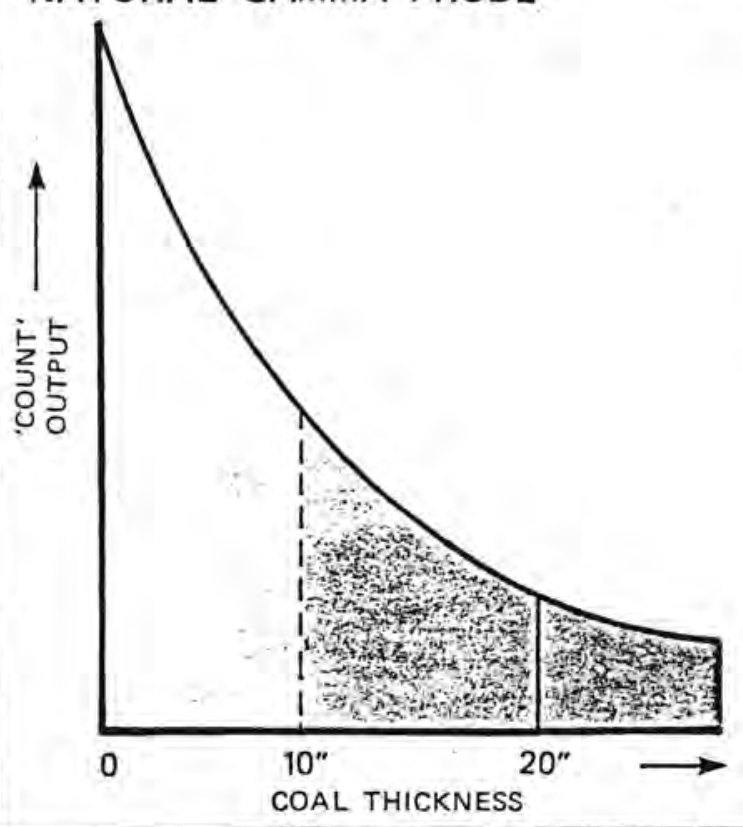




\section{INGOFLEX DTT}

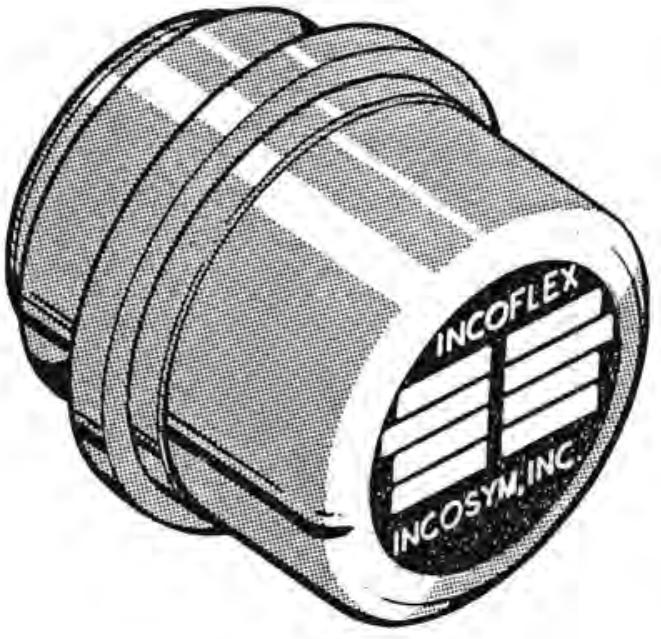

\section{Dynamically Tuned Gyro}

The gyroscopic element is coupled to the spin axis by a spring suspended universal joint whose rotational dynamics cancel out the spring constant of the suspension system resulting in excellent isolation of the gyroscopic element from disturbance torques.

This mature technology, extensively used in gimballed platforms, is now available for STRAPDOWN applications.

Each gyro provides two axes. Digital and analog torquing loops available.

The INCOFLEX DTG is characterized by:

- LOW COST

- HIGH ACCURACY

- HIGH TORQUING RATES

- AVAILABILITY at UNIT LEVEL IN EIGHT STANDARD CONFIGURATIONS WHOSE CHARACTERISTICS ARE LISTED IN THE TABLE BELOW

\begin{tabular}{|c|c|c|c|c|c|c|c|c|}
\hline \multirow{2}{*}{ PERFORMANCE PARAMETER } & \multicolumn{8}{|c|}{ STANDARD GYRO CONFIGURATIONS } \\
\hline & 1 & 2 & 3 & 4 & 5 & 6 & 7 & 8 \\
\hline $\begin{array}{l}\text { ACCURACY IN deg/hr } 1 \text { sigma } \\
\text { LONG TERM REPEATABILITY } \\
\text { SHUTDOWN REPEATABILITY } \\
\text { TWO HOUR DRIFT } \\
\text { ANISOELASTICITY IN } \mathrm{deg} / \mathrm{hr} / \mathrm{g}^{2}\end{array}$ & $\begin{array}{l}0.02 \\
0.01 \\
0.01 \\
0.02\end{array}$ & $\begin{array}{l}0.02 \\
0.01 \\
0.01 \\
0.02\end{array}$ & $\begin{array}{l}0.05 \\
0.02 \\
0.02 \\
0.02\end{array}$ & $\begin{array}{l}0.05 \\
0.02 \\
0.02 \\
0.02\end{array}$ & $\begin{array}{l}0.15 \\
0.05 \\
0.05 \\
0.05\end{array}$ & $\begin{array}{l}0.75 \\
0.25 \\
0.25 \\
0.05\end{array}$ & $\begin{array}{l}3.0 \\
1.0 \\
0.3 \\
0.1\end{array}$ & $\begin{array}{l}0.05 \\
0.02 \\
0.02 \\
0.02\end{array}$ \\
\hline $\begin{array}{l}\text { TORQUING RATES IN deg/sec @ } \\
165^{\circ} \mathrm{F} \text { ambient } \\
\text { STEADY STATE } \\
\text { TRANSIENT ( } 1 \text { second) } \\
\% \text { DUTY CYCLE @ } 400 \mathrm{deg} / \mathrm{sec} \\
\text { TORQUING ACCURACY IN PPM }\end{array}$ & $\begin{array}{l}75 \\
140 \\
0.25 \\
50\end{array}$ & $\begin{array}{r}110 \\
220 \\
1 \\
50\end{array}$ & $\begin{array}{l}75 \\
140 \\
0.25 \\
50\end{array}$ & $\begin{array}{r}110 \\
220 \\
1 \\
50\end{array}$ & $\begin{array}{r}165 \\
540 \\
15 \\
50\end{array}$ & $\begin{array}{r}165 \\
540 \\
15 \\
50\end{array}$ & $\begin{array}{r}400 \\
1200 \\
100 \\
100\end{array}$ & $\frac{15}{100}$ \\
\hline $\begin{array}{l}\text { PHYSICAL CHARACTERISTICS } \\
\text { SIZE DIA x LENGTH } \\
\text { WEIGHT IN POUNDS } \\
\text { SPIN SPEED IN RPM }\end{array}$ & $\begin{array}{l}2.0 \times 1.8 \\
0.75 \\
12,000\end{array}$ & $\begin{array}{c}2.0 \times 1.8 \\
0.75 \\
12,000\end{array}$ & $\begin{array}{c}2.0 \times 1.8 \\
0.75 \\
12,000\end{array}$ & $\begin{array}{c}2.0 \times 1.8 \\
0.75 \\
12,000\end{array}$ & $\begin{array}{c}2.0 \times 1.8^{\circ} \\
b .65 \\
12,000\end{array}$ & $\begin{array}{c}2.0 \times 1.8^{*} \\
0.65 \\
12,000\end{array}$ & $\begin{array}{c}1.0 \times 1.5 \\
0.2 \\
9,600\end{array}$ & $\begin{array}{l}2.1 \times 1.8 \\
0.6 \\
14,400\end{array}$ \\
\hline $\begin{array}{l}\text { POWER REQUIREMENTS IN waits } \\
\text { SPIN MOTOR } \\
\text { TORQUER @ } 1 \mathrm{rad} / \mathrm{sec} \\
\text { PICKOFF }\end{array}$ & $\begin{array}{l}2.0 \\
4.0 \\
0.2\end{array}$ & $\begin{array}{l}2.0 \\
2.0 \\
0.2\end{array}$ & $\begin{array}{l}2.0 \\
4.0 \\
0.2\end{array}$ & $\begin{array}{r}2.0 \\
2.0 \\
0.2\end{array}$ & $\begin{array}{l}2.0 \\
1.0 \\
0.2\end{array}$ & $\begin{array}{l}2.0 \\
1.0 \\
0.2\end{array}$ & $\begin{array}{l}1.5 \\
0.15 \\
0.2\end{array}$ & $\frac{3.0}{0.2}$ \\
\hline
\end{tabular}




\section{Measuring Coal Deposits by Radar}

Thickness is measured directly as a frequency

difference, eliminating the need for a local oscillator.

\section{Marshall Space Flight Center, Alabama}

A recently tested system determines the thickness of coal deposits by measuring the frequency difference between microwave signals reflected from the face and back of the deposit. The system has gaged deposits 2 to 24 inches (5 to 61 centimeters) in thickness, distinguishing them from underlying shale.

Unlike conventional radio-frequency coal-thickness monitors, the new system does not compare both reflected signal frequencies with the source frequency Instead it uses the reflection from the front of the deposit as a reference for the back-surface signal.

In the new system (see Figure 1), a $100-\mathrm{Hz}$ triangular wave modulates the frequency of a 2 - to $4-\mathrm{GHz}$ oscillator. and the resultant signal is beamed by an antenna to the coal deposit. A separate antenna receives both the signal reflected from the front surface and the signal reflected from the coal/shale interface.

Although the front- and backreflected signals arrive at the antenna simultaneously, the back-reflected signal traveled a longer distance and therefore originated earlier in time than the front reflection. The back reflection therefore has a lower frequency than the front-surface signal (see Figure 2), and the frequency difference is a measure of the extra travel time. The two signals are combined in a mixer diode to generate the difference frequency. and this signal is used to give a readout of the thickness of the coal layer.

The new system avoids several difficulties inherent in previous radar coal-thickness monitors. In a conventional system, the two received reflections are mixed with the local oscillator signal, and the composite

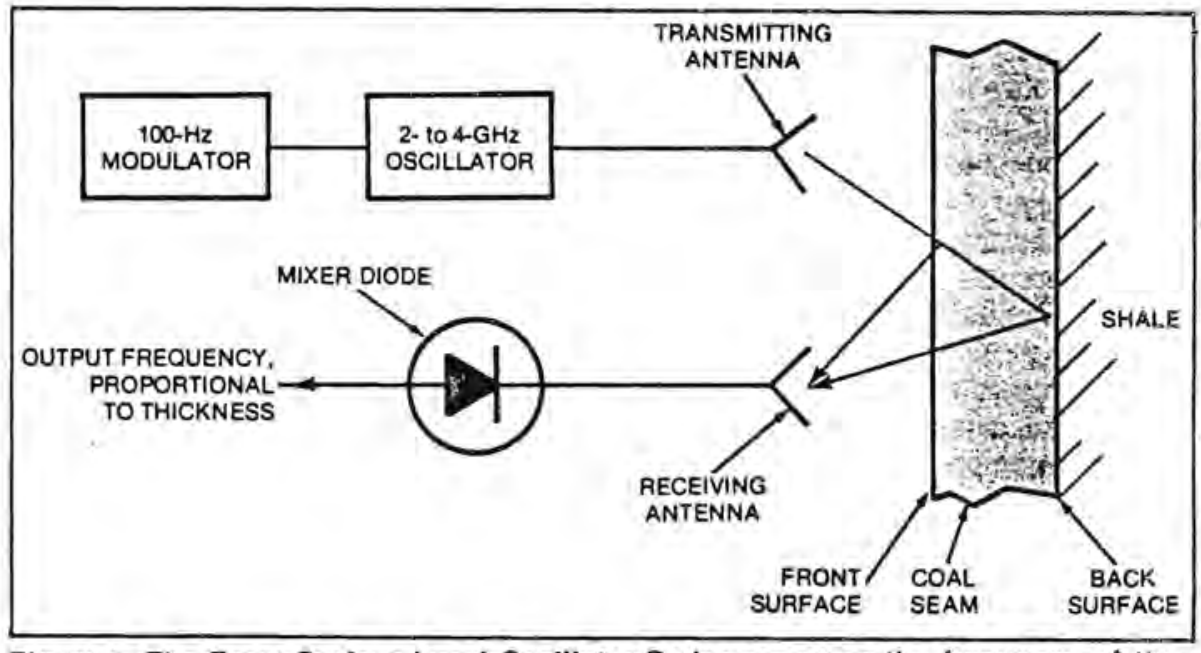

Figure 1. The Front-Surface Local-Oscillator Radar compares the frequency of the signal reflected from the back surface of a coal deposit with that reflected from the front surface. Previous systems compared both signals to a separate local-oscillator signal.

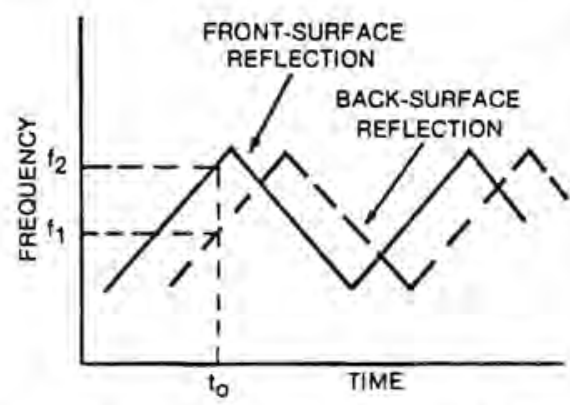

Figure 2. Reflections From the Front and Back of a coal deposit, received at time $t_{0}$, have different frequencies $\left(f_{1}\right.$ and $f_{2}$ ) because they originate at different times from the frequencymodulated transmitter. The frequency difference represents the travel time through the coal and hence its thickness. The displacement between the curves is exaggerated in this figure. signal is processed to determine the range to the front and the range to the back of the deposit. The thickness is then found by subtraction.

In contrast, the mixer output in the new radar is a direct measure of thickness; only a frequency-to-thickness conversion is needed. Moreover, masking of the weak back reflection by the strong front reflection is greatly reduced, since the two reflections are not detected separately but in combination. Another benefit of the new system is that it is not sensitive to extraneous reflections from targets between the transmitting antenna and the coal surface, since no target information is genterated until the front-surface reflection arrives at the mixer.

This work was done by Thomas $A$. Barr of Marshall Space Flight Center. No further documentation is available.

MFS-23922 


\title{
Detecting a Coal/Shale Interface
}

\author{
The depth of cut is determined by combining
}

penetrometer and reflectometer measurements.

\section{Marshall Space Flight Center, Alabama}

A prototype coal/shale interface detector combines the outputs of two optical reflectometers with that of a penetrometer. Eventually, it will be used on a longwall shearer to determine when the cut has pierced through the coal layer. Tests on the prototype in a mine show that the basic design is workable.

In the prototype, an accelerometer measures the hardness of the material struck by the penetrometer ram, while the reflectometers measure the reflectivity of the surface on both sides of the penetrometer. The signals are then combined in a voting circuit that indicates "coal" or "shale" depending on the information supplied by the three sensors.

As shown in Figure 1, one end of the penetrometer ram is hardened for striking the mine wall. The accelerometer is attached to the opposite end of the ram. The ram shaft is reciprocally driven by a spring attached to a supporting collar, and the collar is moved by linked, pivoted arms driven by a motor. As the ram strikes the mine wall, the spring compresses, preventing the impact head from damaging the surface.

The penetrometer distinguishes between coal and shale by the differences in the accelerometer waveforms for the two materials. As shown in the inset to Figure 1, the spike corresponding to shale is taller and sharper than that for coal, because shale is usually harder than coal. (There can be exceptions to this qualitative result, which is why the penetrometer output is compared to the reflectometer signals.) Discriminating circuitry can distinguish between the two signal characteristics.

The reflectometers are standard commercial units. Each includes a light source and a light-sensitive switch that trips when the reflected light exceeds a preset threshold.

The detection circuitry is shown in Figure 2. One threshold detector is

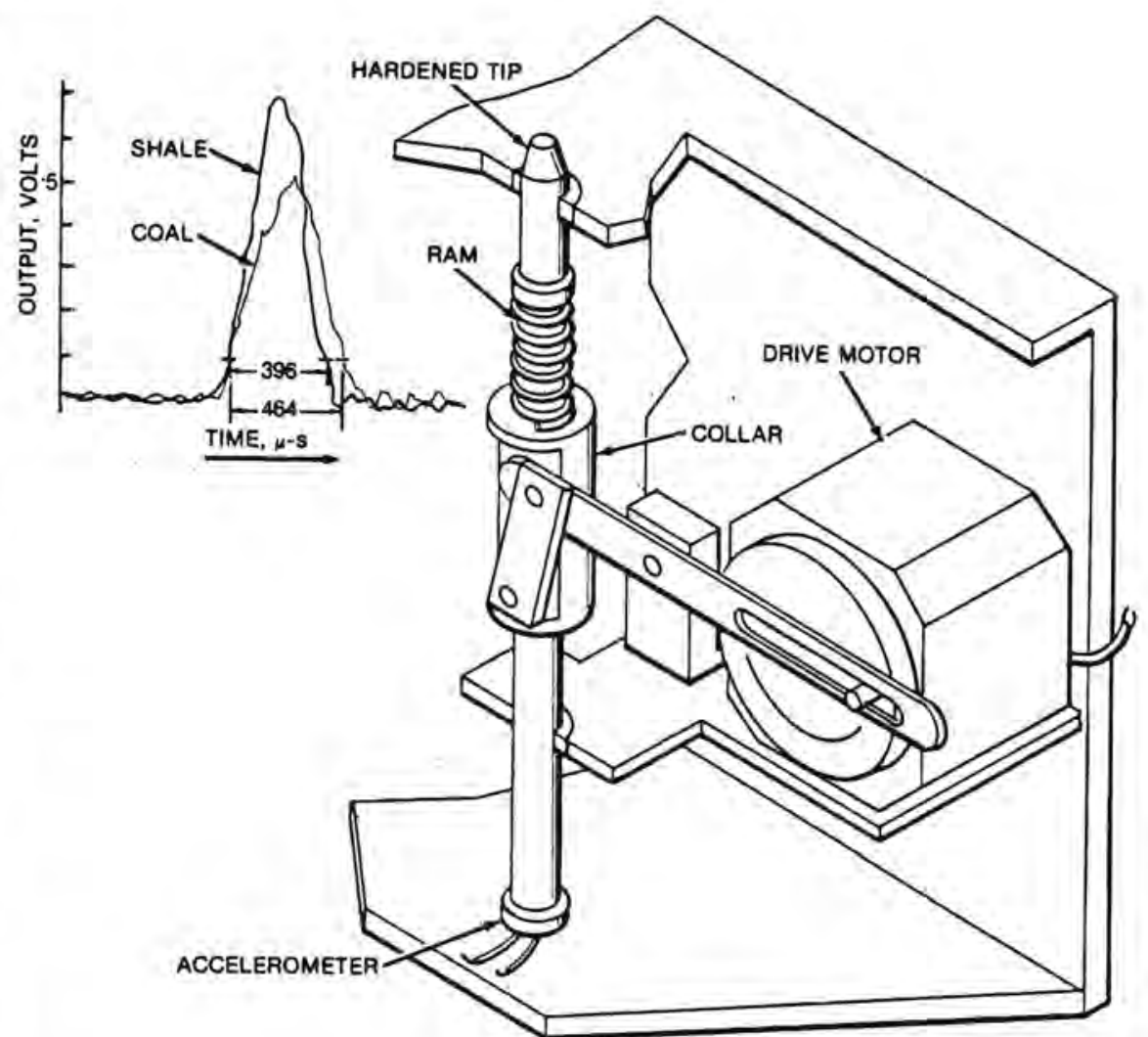

Figure 1. The Penetrometer Portion of the coal/shale interface detector includes a motor-driven ram with an accelerometer at the back end. Representative accelerometer outputs for coal and for shale are shown in the inset. The coal signal is identified by its broader width and lower height as compared to the shale-signal.

biased at 6 volts, which for the prototype is the maximum accelerometer output when the ram is impacted against coal. The triggered one shot that follows the threshold detector is normally in its high state, but it goes low when the 6-volt level is exceeded (i.e., when shale is encountered).

The accelerometer output is also applied to a threshold detector that puts out a high state when the input exceeds 1 volt. At the 1-volt level (see Figure 1), the signal width is 464 microseconds for coal and 396 microseconds for shale.

A cutoff of 450 seconds is selected to distinguish a coal pulse from a shale pulse. A 450-microsecond one shot that triggers on the leading edge of the pulse is applied to the disable input of a one shot that triggers on the pulse trailing edge. Thus, the second one shot fires only if the initial pulse width exceeds 450 microseconds. Uitimately, the AND gate output of the penetrometer is enabled only if the accelerometer pulse amplitude is between 1 and 6 volts and the pulse width exceeds 450 microseconds. Of course, these values are unique to the particular penetrometer selected and would vary with impact frequency and amplitude.

The penetrometer AND gate output is supplied to the voting circuit along

(continued on next page) 
with the reflectometer outputs, which are at logical " 1 " for low-light conditions (for coal). The voting circuit output is high only if two of the three inputs indicate the presence of coal. In this case, the coal indicating light is turned on. If the voting circuit output is low, the "shale" light is activated.

This work was done by Peter $H$. Broussard, John L. Burch, Richard A. Campbell, Edward J. Drost, Jerry L. Hudgins, Paul W. Morris, Harry Reid, Jr., Richard J. Stein, and Joe E. Zimmerman of Marshall Space Flight Center. For further information, Circle 52 on the TSP Request Card.

This invention is owned by NASA, and a patent application has been filed. Inquiries concerning nonexclusive or exclusive license for its commercial development should be addressed to the Patent Counsel, Marshall Space Flight Center [see page A5]. Refer to MFS-23720.

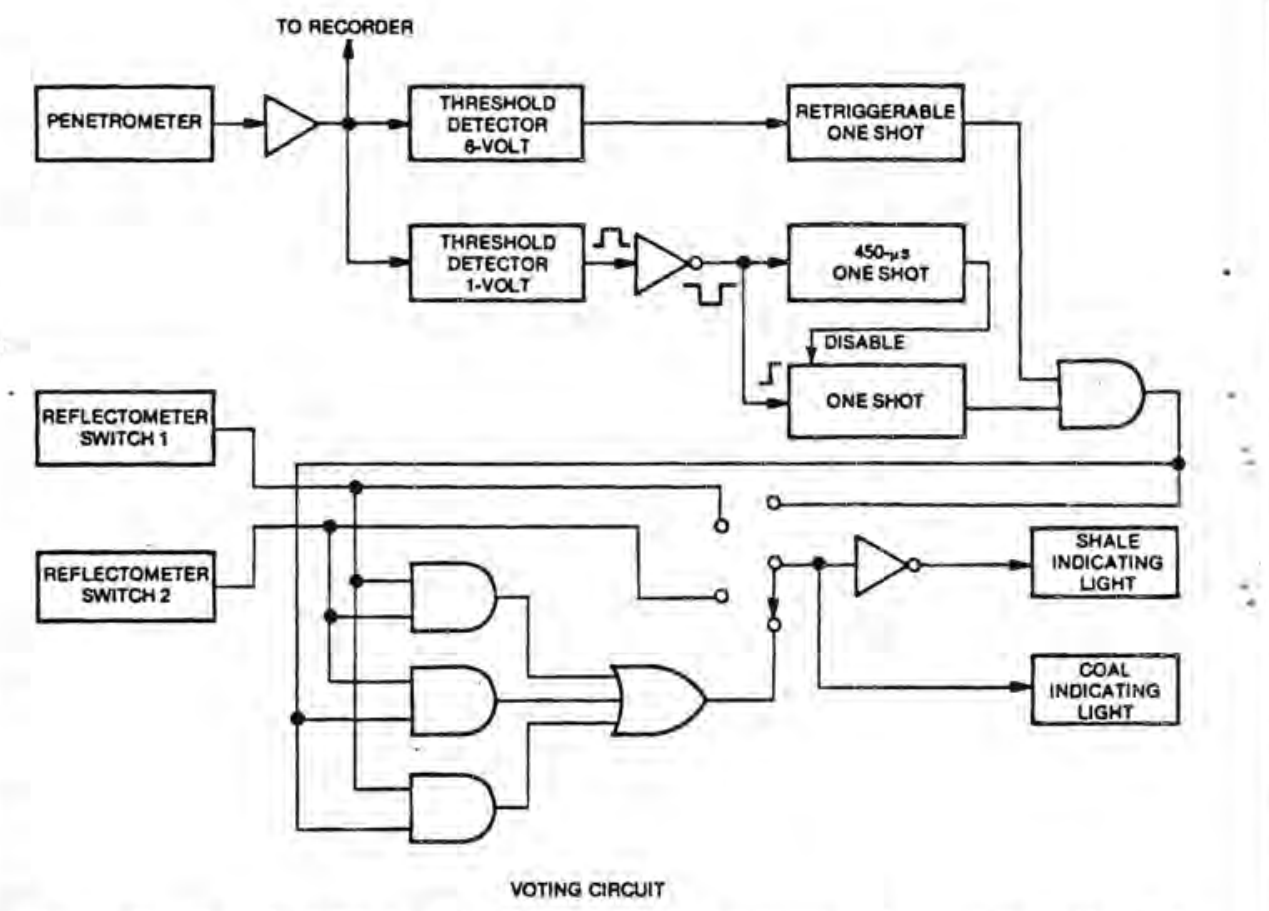

Figure 2. The Coal/Shale Detection Circuit processes the penetrometer and reflectometer signals. A voting circuit indicates "coal" or "shale" according to the consensus of two of the three inputs. 


\section{APPENDIX B}

DATA SHEETS FOR THE SURFACE ELECTRONICS PROCESSOR (SEC) 


\section{APPENDIX B \\ DATA SHEETS FOR THE SURFACE ELECTRONICS PROCESSOR (SEC)}

See Figures 13, 14 and 15 for references to the data sheets in this appendix.

Data sheets reprinted by permission of the respective companies.

B.1 


\section{ThP) HEWLETT}

\section{B/T \\ Desktop Computer Speciifications}

TECHNICAL DATA* MAY 1980

The $9825 \mathrm{~B} / \mathrm{T}$ is HP's fastest desktop computer for data acquisition, instrument control and computation. It maintains the same high-speed performance as its predecessor, the $9825 \mathrm{~A} / \mathrm{S}$.

The $9825 B$ has 22918 bytes of read/write memory and built-in String, Advanced Programming, Plotter, General 1/O and Extended 1/O ROMs (read-only memories).

The $9825 \mathrm{~T}$ is a desktop computer system consisting of:

- a 9825B Desktop Computer,

- 61670 bytes of read/write memory,

- a built-in Systems Programming ROM.

Whichever model you choose, you get a 32-character LED display, 16-character thermal strip printer, a typewriter keyboard that lets you use both uppercase and lowercase alphanumerics, three $\mathrm{I} / \mathrm{O}$ ports, four option-ROM slots, a $250 \mathrm{~K}$-byte tape cartridge drive and powerful interfacing features such as buffered $\mathrm{I} / \mathrm{O}$, direct memory access and internupt

Using DMA, the 9825 can acquire data at speeds up to $400 \mathrm{k}$ transfers per second. Each transfer can be either eight or 16 bits wide. Interrupt allows the 9825 to perform useful computation and other tasks between communications with devices that require attention at irregular intervals.

The 9825 allows flexible interfacing with more than a hundred HP-IB instruments for stimulus and measurement, as well as with plotters, printers, digitizers, flexible disc drives and paper-tape and card input and output devices.

HPL, the 9825's high-level programming language, offers power and efficiency for handling equations and input/output operations, yet is easy to learn and use.

The live keyboard allows you to perform calculations, execute subroutines, list the current program and examine or change variables while a program is running.

\section{Features}

- Up to $62 \mathrm{~K}$ bytes user read/write memory

- Alphanumeric keyboard

- 32-character LED display

- Built-in tape cartridge drive

- High-level programming language (HPL)

- Interrupt capability

- Plug-in read-only memories (ROMs)

- 12 Special Function Keys (24 with shift)

- 12 significant digits

- Live keyboard

- Direct memory access

- Trigonometric capability

- Boolean algebraic capability

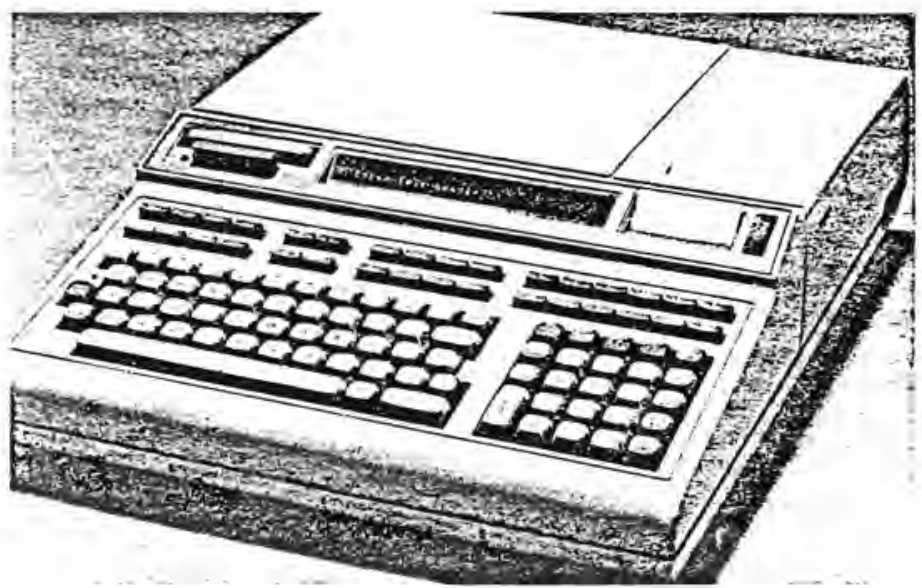

Index

General Information ........................

Optional ROMs . ........................... 4

Interfaces $\ldots \ldots, \ldots, \ldots, \ldots, \ldots, \ldots, \ldots, 4$

Ordering Information $\ldots \ldots \ldots \ldots \ldots \ldots \ldots \ldots \ldots$

\section{General Information}

$$
\begin{aligned}
& \text { Range } \\
& \text { Dynamic range: } \\
& 10^{99} \text { to } 10^{-99}, 0,-10^{-99} \text { to }-10^{99} \\
& \text { Intemal calculation range: } \\
& 10^{511} \text { to } 10^{-511}, 0,-10^{-511} \text { to }-10^{511}
\end{aligned}
$$

-Data subject to change. 


\section{Tape Cartridge}

Memory capacity ..........250 000 bytes

Read/write speed ......... $559 \mathrm{~mm} / \mathrm{s}$ (22 in./s)

Search speed (bidirectional) . . $2286 \mathrm{~mm} / \mathrm{s}$ (90 in. $/ \mathrm{s}$ )

Transfer rate ............2 750 bytes/s

Typical rewind time .........19 s (end-to-end)

Typical erase time ........40 s (one track)

Tape length ............. $42.67 \mathrm{~m}(140 \mathrm{ft})$

Size .................. $63.5 \times 82.5 \times 12.7 \mathrm{~mm}$

$(2.5 \times 3.25 \times 0.5$ in.)

Verification automatic on recording

Tape cartridges are intended for nominal program or data storage; the typical life cycle is $50-100$ hours, depending on the application. Environmental conditions of $25^{\circ} \mathrm{C}\left(77^{\circ} \mathrm{F}\right)$ and 20 to $50 \%$ relative humidity are most favorable for a long tape life. Tape life is decreased by a high duty cycle (percent of of time the tape is accessed during the total time the 9825 is in use), high tuming resistance and continuous use for long periods of time (longer than one-half hour). It is suggested that tape transports be regularly cleaned and cartridges removed from drives after use.

For heavy usage of mass storage files, such as in consecutive file sorts or data base management applications, flexible disc drives are recommended for optimum performance and reliability.

\section{Printer}

Paper width ............ $57.15 \mathrm{~mm}$ (2.25 in.)

Speed ................ 180 lines $/$ min

Font ............... $5 \times 7$ dot matrix; prints all the following characters in upper-and lowercase; up to 16 characters/line
Maximum $(\max ) \ldots \ldots \ldots \ldots \ldots \ldots \ldots \ldots$ variable

Minimum (min) . . . . . . . . . . . . . . . . . . . variable

Modulus (mod) . . . . . . . . . . . . . . . . . . . $3.1 \mathrm{~ms}$

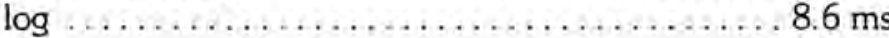

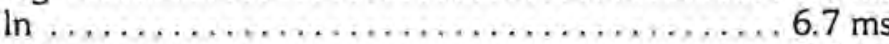

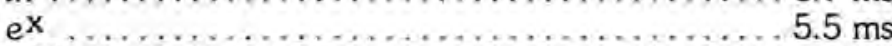

$10^{\mathrm{x}} \ldots \ldots \ldots \ldots \ldots \ldots \ldots \ldots \ldots \ldots \ldots \ldots, 7.6 \mathrm{~ms}$

Raise to power ...................... $15 \mathrm{~ms}$

Random number (rnd) . . . . . . . . . . . . . $1.8 \mathrm{~ms}$

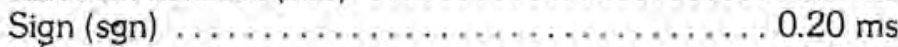

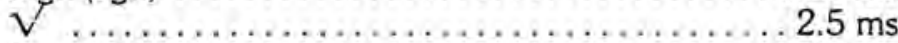

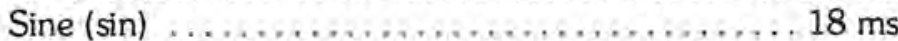

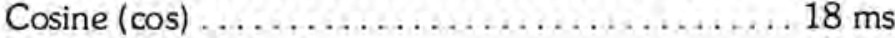

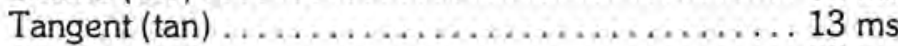

Arcsine (asn) ......................... $22 \mathrm{~ms}$

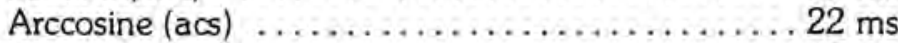

Arctangent (atn) .................................. 15

+ ...................................... 0.32

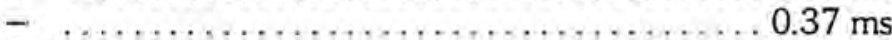

* ..................................... $0.88 \mathrm{~ms}$

I ................................ $2.5 \mathrm{~ms}$

Power of ten round (pmd) . . . . . . . . . . . . $0.74 \mathrm{~ms}$

Digit round ........................ $0.53 \mathrm{~ms}$

Logic operators

AND, NOT, OR, XOR (exclusive or)

Relational operators

$=$ equal to

$>=$ or $=>$ greater than or equal to

$>$ greater than

$<=$ or $=<$ less than or equal to

$<$ less than

\# or $<>$ not equal to

\section{Environmental Range}

Operating temperatures $\ldots 5^{\circ} \mathrm{C}$ to $40^{\circ} \mathrm{C}$ ambient Storage temperature...... $-40^{\circ} \mathrm{C}$ to $65^{\circ} \mathrm{C}$ Ambient humidity ........<80\%

\section{Size/Weight}

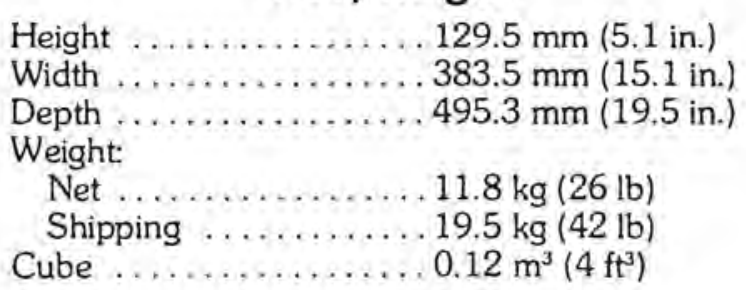

\section{Power Requirements}

$\begin{array}{rl}\text { Source } \ldots \ldots \ldots \ldots \ldots & 110 \mathrm{~V}+5 \%,-10 \% \\ 120 \mathrm{~V}+5 \%,-10 \% & 220 \mathrm{~V}+5 \%,-10 \% \\ & 240 \mathrm{~V}+5 \%,-10 \%\end{array}$

Note: Voltage is switch-selectable.

\section{Built-in Functions}

Mathematical and trigonometric functions and operations are included in the following with average execution times.

Absolute (abs) ....................... $0.19 \mathrm{~ms}$

Fraction (frc) ....................... $0.37 \mathrm{~ms}$

Integer (int) $\ldots \ldots \ldots \ldots \ldots \ldots \ldots \ldots \ldots \ldots \ldots \ldots \ldots \ldots \ldots \ldots . .47 \mathrm{~ms}$

\section{$C$}

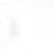




\section{MULTIPROGRAMMER AND EXTENDER MAINFRAMES}

6942A

\section{MULTIPROGRAMMER}

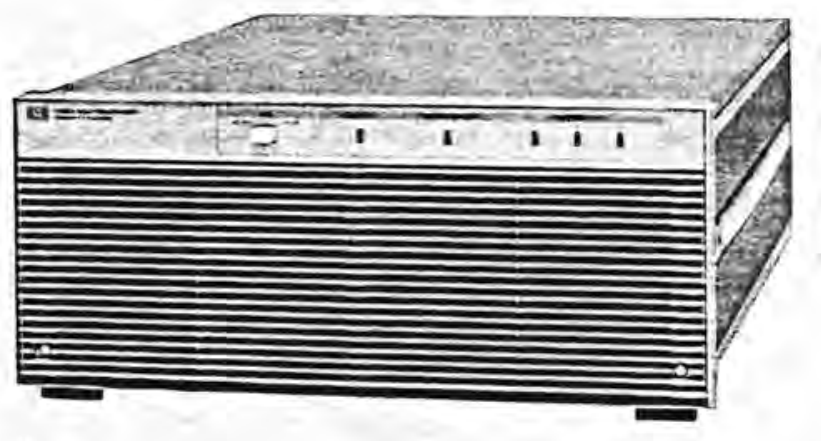

6943A

EXTENDER

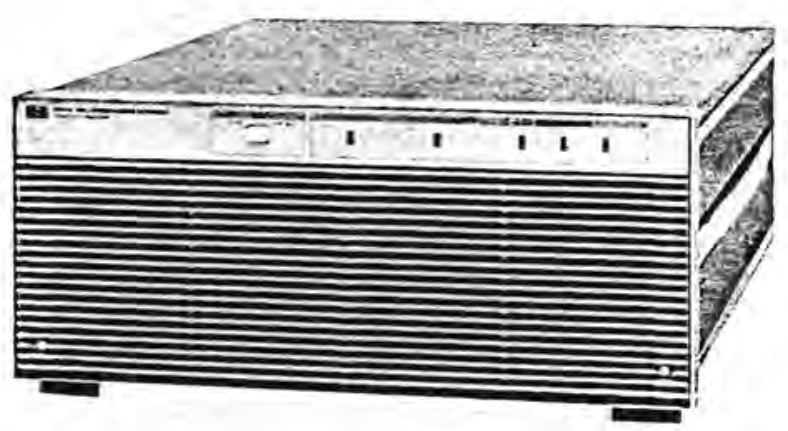

\section{A and 6943A Specifications}

Plug-in I/O Card Positions: Maximum of 16 plug-in output or input cards per mainframe. Removable rear cover provides access to card slots.

Computer Interface (6942A only): The Multiprogrammer is connected to a controller via the Hewlett-Packard Interface Bus (HP-IB), a versatile interconnect system for instruments and controllers. This is Hewlett-Packard's implementation of IEEE Std, 488-1975 "Standard Digital Interface for Programmable Instrumentation."

Real Time Clock (6942A only): The built-in real time clock is automatically synchronized with the $50 / 60 \mathrm{~Hz}$ ac power line frequency. Long-term accuracy is the same as the frequency accuracy of the ac power line input. The clock is read and set with data in the form of days, hours, minutes and seconds with resolution of 0.1 seconds. The clock resets to zero when power is applied to the 6942A. Maximum clock data value is 65,000 days.

Extender Interface Kits (6943A only):

Each 6943A Extender requires one $14700 \mathrm{~A}$ or $14701 \mathrm{~A}$ Interface kit and one 14702A Chaining Cable for operation with the 6942A. The 14700A is ordered with the first 6943A Multiprogrammer Extender added to a 6942A Multiprogrammer. The 14701A Interface Kit is ordered with the second through seventh $6943 \mathrm{~A}$ Multiprogrammer Extender added to a chain of mainframes.

Accessories Furnished: PC Board Extender Card (HP Part No. 5060-2792).
Maximum Number of Mainframes per Chain: Up to seven 6943A Multiprogrammer Extenders may be placed in a chain with one 6942A Multiprogrammer.

Maximum Chain Length:

A chain of mainframes can be up to 152 meters (500 feet) long. This maximum length is the sum of the lengths of all 14702A Chaining Cables used in one chain.

Power Supplies: All power supplies for up to $161 / 0$ cards are built-in including three $\pm 18 \mathrm{~V}$ supplies isolated from each other and from ground.

Cooling: Built-in forced air cooling draws air in through the front panel and exhausts air through the ventilated rear cover.

Front Panel Indicators: Five light emitting diodes on the front panel indicate power supply and self-test status.

Operating Temperature Range: $0^{\circ} \mathrm{C}$ to $55^{\circ} \mathrm{C}$.

Power: 100/120/220/240Vac (selectable), $+5 \%,-10 \%, 47$ to $63 \mathrm{~Hz}, 600 \mathrm{VA}$.

Dimensions: $177.0 \mathrm{~mm}$ high $\times 425.5 \mathrm{~mm}$ wide $\times 597.0 \mathrm{~mm}$ deep. (6.969in. high $\times 16.750 \mathrm{in}$. wide $\times 23.500 \mathrm{in}$. deep).

Weight (without I/O cards):

Net 20kg. (45 lbs).

Shipping, 27kg. (60 lbs).

Options Available:

Option 908 Rack mounting kit

Option 910 Extra operating and service manual 


\section{A Cartridge Tape Unit}

*TECHNICAL DATA NOVEMBER 1979

The Hewlett-Packard Model 9875A Cartridge Tape Unit is a peripheral mass storage device that provides a standard for data interchange among the HP Series 9800 Desktop Computers as well as other HP-IB devices. The 9875 can also perform certain data acquisition operations on its own, without the help of a computer or controller.

\section{HP-IB and SIF Compatible}

Compatible data interchange among the various desktop computers is made possible two ways.

First, the tape unit interfaces to the HP Series 9800 Desktop Computer via the Hewlett-Packard Interface Bus (HP-IB - conforms to IEEE Standard 488-1978). Any desktop computer with HP-IB capability can store data on the 9875 tape unit, which can then be read by any other desktop computer in the series.

Second, the 9875 tape unit stores data in HP's Standard Interchange Format (SIF). While HP-IB compatibility requires that the tape unit be interfaced to the desktop computer receiving the data, a SIF-compatible machine can read a 9875 tape on its own internal tape drive without being connected to the 9875 .

Similarly, tapes produced by SIF machines can be read by the 9875 . SIF tapes can be used with HP's graphics desktop computer, the System 45 , and also the System 35 , using existing binary programs. Many future HP products will also be SIF-compatible. This will allow older data files to be used on newer computers without manually reentering the data.

\section{K Byte Capacity}

The 9875 is available as either a single or double tape drive unit, and each cartridge has up to $225 \mathrm{~K}$ byte capacity, providing large mass storage.

\section{TALK-only and LISTEN-only Modes}

An internal microprocessor enables the 9875 to perform some operations independently, without an external computer or controller. The LISTEN-only mode makes it possible to log data from another HP-IB device without a controller, and the TALK-only mode permits driving a LISTEN-only device, such as a printer, without a controller.

\section{Commands}

Twenty-three built-in commands provide exceptional flexibility in formatting the tape cartridge. The tape is partitioned into files and records, much like the structure of many disc memories. Two physical tracks on the tape are treated as a single logical track. Data can be organized in a serial access format (access by file) or in a random access format (access by record). Logical record sizes

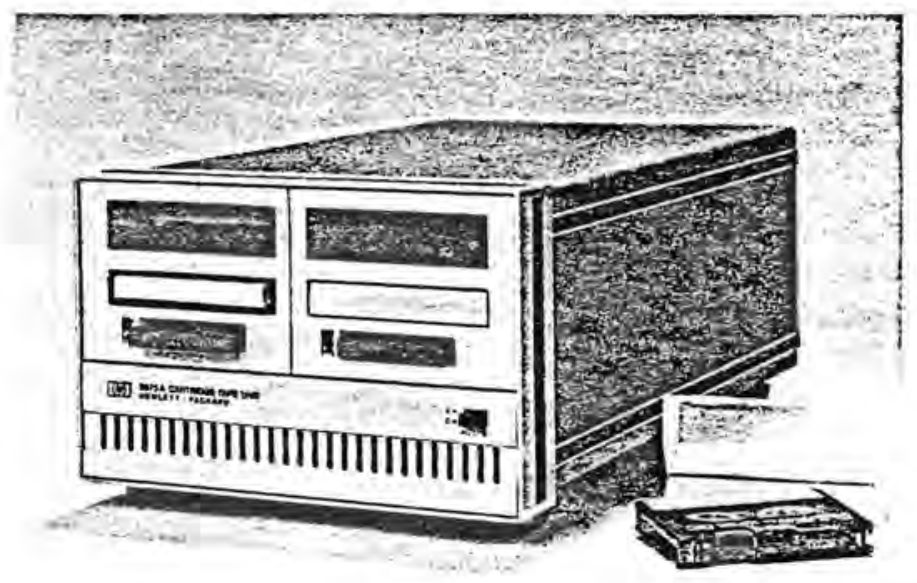

from 2 to 256 bytes can be selected. Different files can have different record sizes. Records and files can ve marked on the tape before any data are written, or they can be created automatically as the data are stored.

\section{Added Features}

The 9875 is equipped with a self-test feature that can be activated under software control or by a switch on the rear panel.

A programmable delay ( 1 second to 18 hours) allows automatic delays between successive inputs and outputs.

The 9875 responds to both serial and parallel poll. Serial poll response is status information about the 9875 . The 9875 can be configured to respond affirmatively to parallel poll or to activate the service request line (SRQ) under various status conditions. Extensive status and error information is available under software control.

\section{Specifications}

\section{TAPE DRIVE}

Read/Write Speed , . . . . . . . . .. $559 \mathrm{~mm} / \mathrm{s}(22 \mathrm{in.} / \mathrm{s})$

Search Speed ..................22286mm/s (90 in./s)

End to Search Time ........... 19/s

Average Transfer Rate

btwn controller/tape .......... 1500 bytes/s

Maximum Transfer Rate

btwn controller and 9875

data buffer .................8 8000 bytes/s

Error Rates ................. $<1$ error in $10^{s}$

bits read

Number of Tracks .............. 2 (implemented as

1 logical track) 


\section{CARTRIDGE}

Type

98200A (also used on 9815,9825 , 9831, 9835, 9845)

Usable Tape Length

$43.4 \mathrm{~m} \pm .76 \mathrm{~m}$

$(142.5 \mathrm{ft} . \pm 2.5 \mathrm{ft}$.)

Bit Density

1. 600 flux

reversals/in.

Formatted Data Capacity

$225 \mathrm{~K}$ bytes

maximum

Coding

Delta-distance

\section{POWER REQUIREMENTS}

$\begin{aligned} \text { Source }(+5 \%,-10 \%) & 100 \mathrm{Vac} \\ \text { (switch selectable) } & 120 \mathrm{Vac} \\ & 220 \mathrm{Vac} \\ & 240 \mathrm{Vac}\end{aligned}$

Frequency .............., 48 $\mathrm{Hz}$ to $66 \mathrm{~Hz}$

Consumption ................800 ma @100 Vac

680 ma@120 Vac

$380 \mathrm{ma} @ 220 \mathrm{Vac}$

345 ma @240Vac

\section{ENVIRONMENTAL RANGE}

Temperature ................. $5^{\circ} \mathrm{C}$ to $40^{\circ} \mathrm{C}$

Relative Humidity ............... 20\% to $80 \%$

non condensing

\section{SIZE/WEIGHT}

Height ..............., ., 132.6mm (5.22 in.)

Width . ................. 212.3mm (8.35 in.)

Depth ...................... 345.4mm (13.60 in.)

Net Weight

One Drive ................ $6.5 \mathrm{~kg}(14.3 \mathrm{lb})$

Two Drives .............. $6.9 \mathrm{~kg}(15.2 \mathrm{lb})$

Shipping Weight

One Drive ............... $10.5 \mathrm{~kg}(23.1 \mathrm{lb})$

Two Drives $10.9 \mathrm{~kg}(24 \mathrm{lb})$

\section{Options}

Opt. n01: Second tape drive.

Opt. 002: Rack mounts.

Opt. 015: Manual 98135-90011 for use with 9815A.

HP-IB card 98135A not supplied.

Opt. 025: Manual 09825-90075 for use with 9825A.

HP-IB card 98034A not supplied.

Opt. 030: Manual 09830-90075 for use with $9830 \mathrm{~A} / \mathrm{B}$.

HP-IB card 59405A not supplied.

Opt. 130: HP-IB card 59405A (without I/O ROM) and the manual 09830-90075 for use with $9830 \mathrm{~A} / \mathrm{B}$.

Opt. 035: Manual 09845-90675 for use with $9835 \mathrm{~A} / \mathrm{B}$. HP-IB card 98034A not supplied.

Opt. 045: Manual 09845-90675 for use with System 45. HP-IB card 98034A not supplied.

\section{Accessories Required}

98135A HP-IB Card for use with the 9815A.

59405A HP-IB Card for use with the $9830 \mathrm{~A} / \mathrm{B}$, includes I/O ROM 11272. If you already have the ROM, order a 9875 Opt. 130.

98034A HP-IB Card for use with the $9825 \mathrm{~A}, 9835 \mathrm{~A} / \mathrm{B}$, System 45. A General I/O ROM is required for use with 9825. The 98432A I/O ROM is required for use with the 9845. The 9835 requires 98332 I/O ROM.

(If using multiple HP-IB instruments, one of the cables listed under Accessories Available is required to connect the 9875 to the bus.)

\section{Accessories Supplied}

Item

HP Part No.

Operating Manual .............. 09875-90000

Service Manual ............... 09875-90030

Tape Cartridge ................. 9162-0061.

Tape Head Cleaner ............ 8500-1251

Spare Fuses

$1.0 \mathrm{~A} \ldots \ldots \ldots \ldots \ldots \ldots . \ldots 2110-0007$

$0.5 A \ldots \ldots \ldots \ldots \ldots \ldots . \ldots . \ldots . . .2110-0202$

Power Cord (Appropriate cord supplied, based on origin of sale.)

\section{Accessories Available}

Item HP Part No.

Additional Tape Cartridges

(5/carton) ................98200A

HP-IB Cable $1 \mathrm{~m}(3 \mathrm{ft}) \ldots \ldots \ldots \ldots 10631 \mathrm{~A}$

HP-IB Cable $2 \mathrm{~m}(6 \mathrm{ft}) \ldots \ldots \ldots \ldots$ 10631B

HP-IB Cable $4 \mathrm{~m}(12 \mathrm{ft}) \ldots \ldots \ldots$..... 10631C

Rack Mounting Kit ............ 5061-0057

\section{Purchase Plans}

Contact one of the Hewlett-Packard worldwide Sales and Service offices for specific prices and plans in your area.

\section{Maintenance Agreements}

Maintenance agreements are available for all desktop computer products. Current U.S. rates can be determined by contacting your local HP sales office.

These agreements represent HP's best level of support. Major advantages to the customer include: fixed annual cost, priority service response, on-site service.

*Data subject to change

For assistance call the HP regional office nearest you: Eastern 301/258-2000, Western 213/877-1282. Midwest 312/255-9800, Southern 404/955-1500. Canadian 416,678-9430. Ask for an HP Desktop Computer representative. Or write to Hewlent-Packard, 3404 East Harmony Road, Fort Collins, Colorado 80525 . 


\section{HIGH RESOLUTION \\ Model GRAPHIC TRANSLATOR 1350A}

TECHNICAL DATA 15 OCT 80

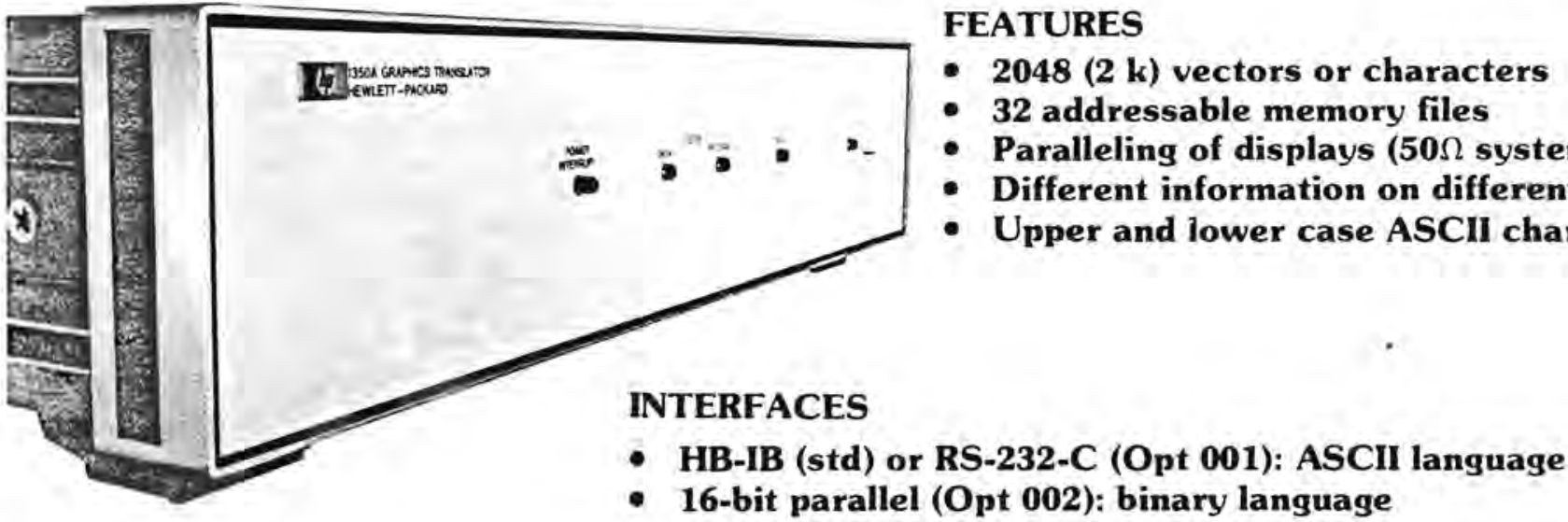

\section{DESCRIPTION}

Hewlett-Packard's Model 1350A Graphics. Translator converts inputs from digital systems to analog outputs capable of driving HP high resolution CRT displays. Digital information, from the Hewlett-Packard Interface Bus (HP-IB) or an optional RS-232-C or 16-bit parallel interface bus, is stored in a digital memory. Vectors and /or characters are generated, and the display is continually refreshed by the $1350 \mathrm{~A}$, freeing the host computer to collect or process other data.

The combination of the 1350A and HP large screen displays provides bright, high-resolution graphics for minicomputer or desktop computer systems. The Graphics Translator can address and display 1023 x 1024 points on the CRT display with alphanumeric listings and vector presentations.

The Graphics Translator has a significant advantage in system applications with its ability to drive up to four CRT displays, each with different information. Presenting different information to multiple displays is accomplished with 32 independent files.

These 32 files also provide selective erase to change some or all of the data on any display without altering the information on all the displays. For added operating flexibility, the 32 files are selectable in size, separately addressable and eraseable, and can be directed to flash information on and off to highlight areas of interest on any display.

Each digital word in the $1350 \mathrm{~A}$ can be a vector co. ordinate or an upper or lower case ASCIl character. A character ROM generates each ASCII character, using only one word of RAM, making more words of RAM available for other display information. Each character can be programmed to be displayed in four different sizes with two degrees of rotation. The translator is designed to accept an additional ROM for user definable vectors for graticules and/or other special symbols.

Because of the high-speed vector generating capability of the Graphics Translator, it is recommended for use with directed-beam displays with at least $2 \mathrm{MHz}$ bandwidth. Hewlett-Packard Models 1310, 1311, 1317, and 1321 large screen displays all produce bright, sharp vectors with the $1350 \mathrm{~A}$.

\section{APPLICATIONS}

The $1350 \mathrm{~A}$ is designed for use in statistical, medical, numerical control, production test, real-time process control, radar/simulation, and engineering applicationsanywhere high resolution, high speed presentation of computer generated information is needed. A wide variety of computers are compatible with the Graphics Translator, including the HP85, HP9825/35/45, HP1000, DEC PDP 11, and other minicomputers or microcomputers that have HP-IB, RS-232-C, or 16-bit parallel interfacing capability. The HP.IB interface is standard with the $1350 \mathrm{~A}$ and is ideal for instrumentation systems because of the wide spectrum of HP.IB compatible measurement instruments now available. For remote operation or computers that don't support HP.IB, the RS.232. C interface option is available. And for real time simulation, modeling, and radar type applications, the 16 . bit parallel interface option allows the $1350 \mathrm{~A}$ to accept up to $200 \mathrm{k}$ vectors per second. 


\section{A SPECIFICATIONS}

INPUT INTERFACE: HP.IB listener only that conforms to IEEE 488.1978. Data acceptance rate is $2 \mu$ s per character.

X, Y, ANALOG OUTPUT: $+0.2 \mathrm{Vdc}$ to $+1.2 \mathrm{Vdc}$ into $50 \Omega, \mathrm{X}, \mathrm{Y}$ analog vectors, between addressable points. Positive up and to right.

Z ANALOG OUTPUT: 0 to $1 \mathrm{~V}$ unblanked, $-1 \mathrm{~V}$ blanked, into $50 \Omega$. REFRESH RATE: dependent on total length of vectors displayed, Contact your HP Field Engineer for exact refresh rate for a given application.

ADDRESSABLE RESOLUTION: 1023 x 1024 points.

\section{MEMORY}

2048 Vectors and/or characters.

32 ADDRESSABLE FILES: files can be erased or blanked. Files may be of any length that does not exceed memory size.

ADDRESSABLE WRITE POINTER: allows new data to be written from that address forward.

\section{CHARACTER GENERATOR}

$8 \times 12$ Resolution stroke characters. Modified full ASCIl set (compatible with HP 9825A/B keyboard). Character strokes are stored in plug-in ROM's.

4 PROGRAMMABLE SIZES: $1 \mathrm{X}, 2 \mathrm{X}, 4 \mathrm{X}, 8 \mathrm{X}, 80$ Characters per line and 51 lines (not to exceed memory size) at $1 X$ character size. 2 PROGRAMMABLE ORIENTATIONS: $0^{\circ}$ and $90^{\circ}$

\section{GENERAL}

AUXILIARY OUTPUTS: 4 TTL outputs are available for presenting information from different memory files to different displays.

INPUT CONNECTOR: rear panel, conforms to IEEE 488-1978.

OUTPUT CONNECTORS: three rear panel BNC's for X, Y, and $Z$ axes with shields grounded. Four rear panel BNC auxiliary outputs for TTL blanking of displays.

\section{FRONT PANEL}

Indicator Lights: power interrupt, listen data, listen program, power on.

On/Off Switch

OPERATING ENVIRONMENT

Temperature: (operating) $0^{\circ} \mathrm{C}$ to $+55^{\circ} \mathrm{C}\left(+32^{\circ} \mathrm{F}\right.$ to $\left.+130^{\circ} \mathrm{F}\right)$; (nonoperating) $-40^{\circ} \mathrm{C}$ to $+70^{\circ} \mathrm{C}\left(-40^{\circ} \mathrm{F}\right.$ to $\left.+158^{\circ} \mathrm{F}\right)$.

Humidity: to $95 \%$ relative humidity at $+40^{\circ} \mathrm{C}\left(+104^{\circ} \mathrm{F}\right)$.

Altitude: (operating) to $4600 \mathrm{~m}$ (15000 ft); (non-operating) to $7600 \mathrm{~m}$ $(25000 \mathrm{ft})$.

Shock: $30 \mathrm{~g}$ level with $11 \mathrm{~ms}$ duration and $1 / 2$ sine wave shape.

Vibration: vibrated in three planes for $15 \mathrm{~min}$. each with $0.25 \mathrm{~mm}$ (0.010 in.) excursion, 10 to $55 \mathrm{~Hz}$.

POWER: selectable $100,120,220$ or $240 \mathrm{Vac},+5 \%,-10 \%, 48 \mathrm{~Hz}$ to $440 \mathrm{~Hz}$, max power $100 \mathrm{VA}$ (approx $80 \mathrm{~W}$ ). Average power dissipation at $60 \mathrm{~Hz}$ and $120 \mathrm{~V}$ without options is approx $74 \mathrm{~W}$.

SIZE: see outline drawing.

WEIGHT: net, $9.5 \mathrm{~kg}(21 \mathrm{lb})$; shipping, $11.8 \mathrm{~kg}(26 \mathrm{lb})$.

ACCESSORIES SUPPLIED: one $2.3 \mathrm{~m}(7.5 \mathrm{ft})$ line cord $\left(90^{\circ}\right.$ IEC to NEMA 5-15P, 3-conductor for use in Canada, Mexico, Japan, and U.S.), one Operating Guide.

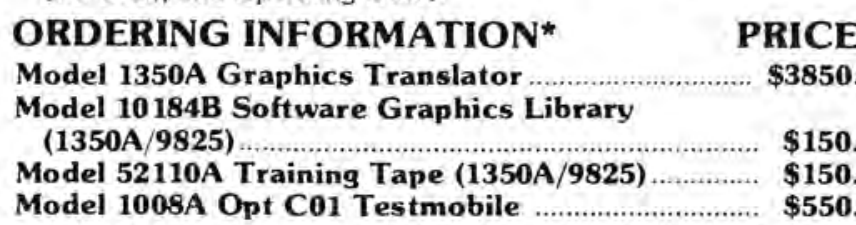

* Refer to the 1350 S data sheet for a complete Computer Graphics Display System,

\section{OPTIONS}

001: RS-232.C interface with selectable baud rates, replaces HP.IB interface Add $\$ 175$.

002: 16. Bit parallel interface instead of std HP-IB $\mathbf{N} / \mathbf{C}$.

908: Rack Mount Flange Kit Add \$20.

909: Rack Mount Flange Kit with Handles Add \$41. Prices apply only to domestic U.S. customers.

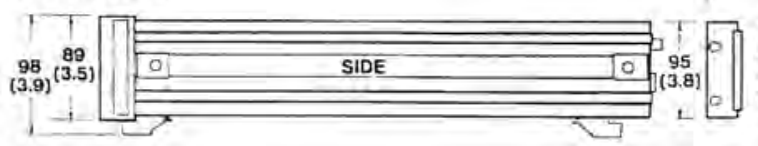

HP-IB (std), RS-232-C

(Opt 001)

(ASCII character sequence, similar to HP.GL)

16-Bit Parallel (Op' 002)

(16-Bit binary words) plot absolute to $X=510, Y=1001$ pa 510, 1001;

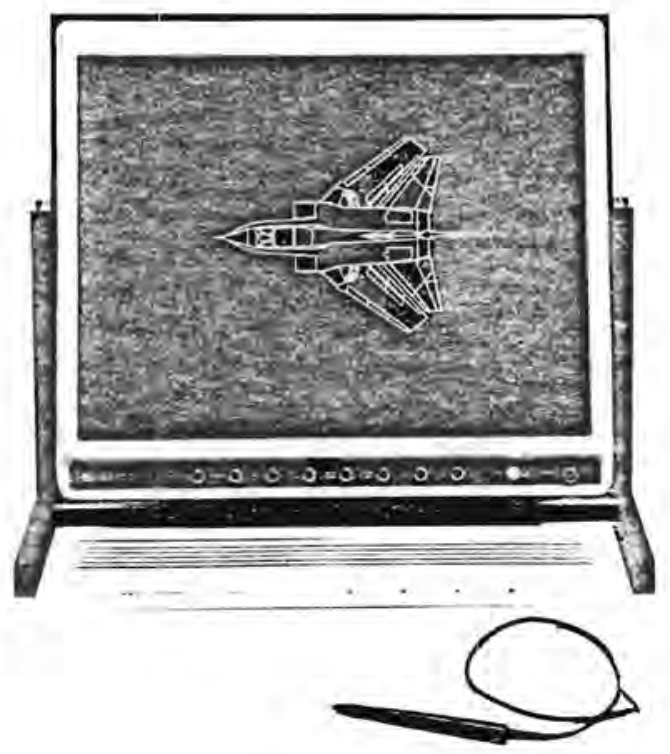
word $1000000111111110(510)$ word 2000001111101001 (1001)

A high speed, high resolution interactive graphics system can be configured using the $1350 \mathrm{~A}$ with an HP large screen display and a 9111 T Graphics Tablet.

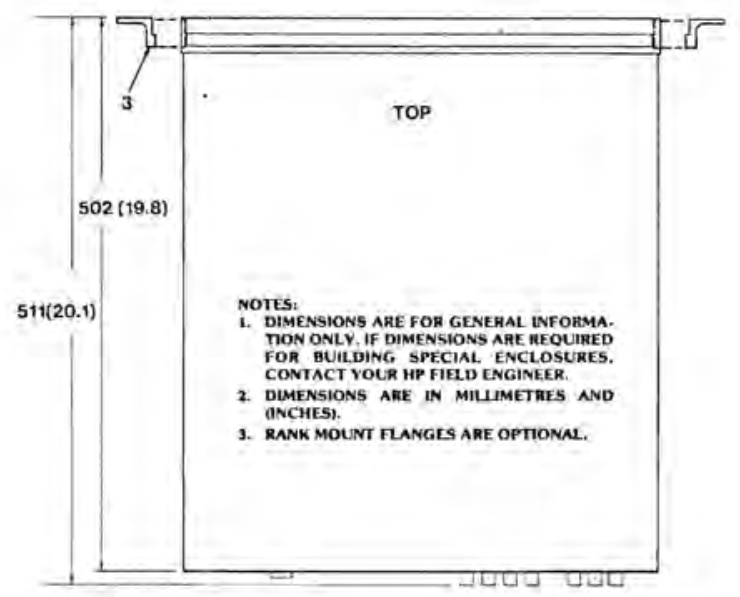




\section{INTRODUCTION}

Hewlett Packard's Model 1311: B offers highs writing speed, fast'settling times and: the brightnesstand contrast needed for the display of high density graphicinformation. This display is ideal as a computer peripherals with its: resolution of 24 lines/ $\mathrm{cm}$ (60) lines/in) in center screen with minimum corner defocusing.

This 14 in (diagonal-measurement) large screen display contains highspeed X and Y deflection circuits; a fast rise time $Z$ axis amplifier and regulated power supplies. An attractively styled"enclosure withratile: stand makes this display idealfortable? top applications suchi as remote? monifors:

\section{PIGTURE CEARITY}

Spot resolutions of the $1311 \mathrm{~B} \mathrm{CRT}$. Display is $0.43 \mathrm{~mm}$ ( $0.0 .17 \mathrm{~m}$ in $)$ and remainst exceptionallys wellkfocusedtin all parts of the screen which solves: such difficult display problems as writing many characters around the picture edges while showing great. detailzin curves graphs or diagrams: Using an aluminized screent and $28: 5 \mathrm{kV}$ accelerating potentia allows brightness, greatenough to assule a crisp. presentation of complex computer graphics pictures. Excellentsmage quality is assured with a contra st control. circuit which offers constant intensity with variable contrast A flat optical quality glass contrastifiler whichieliminates trace diffusion and minimizes glare provides excellent trace qualify=and contrast:

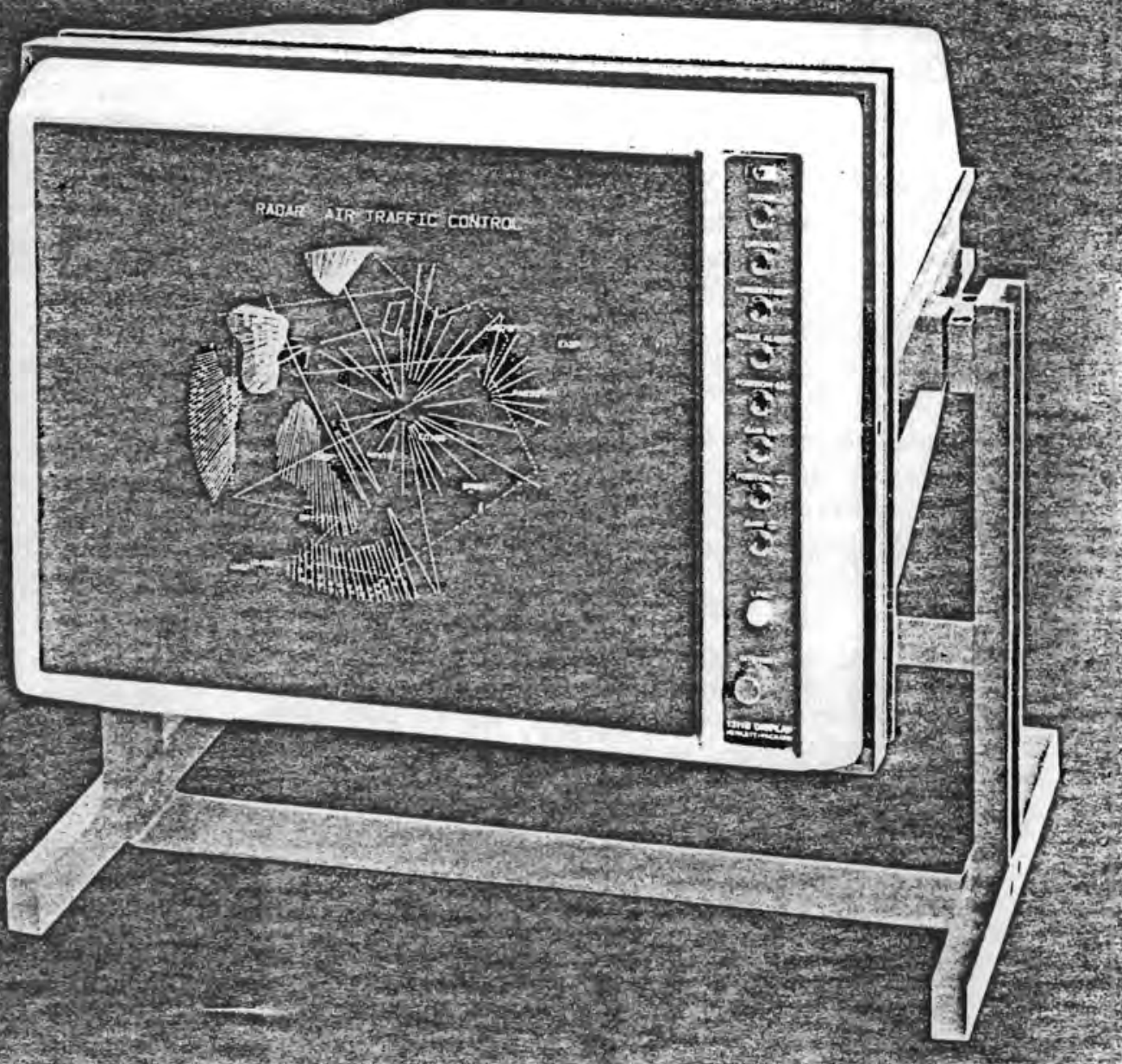

उets 


\section{HIGH-SPEED AMPLIFIERS}

Maximum picture detail with minimum flicker is obtained using the extremely fast writing speed of the display. The 1311B can make any size on-screen movement in less than $500 \mathrm{~ns}$ including settling time. Rise times for both $X$ and $Y$ amplifiers are less than $75 \mathrm{~ns}$ and the Z-axis amplifier has a rise time of less than $25 \mathrm{~ns}$.

\section{LOW POWER}

This large screen display uses an electrostatically deflected CRT that requires very little power (only 115 Va maximum) with fast writing speeds. The yokeless, electrostatic deflection also simplifies operation by eliminating geometric correction circuits and unnecessary delay lines while reducing power requirements and weight.

\section{COMPUTER INTERFACING}

The increasing use of mini- and microcomputers for data bases and data reduction as well as design aids has resulted in a need for very high quality CRT displays along with easy interfacing to a computer. A costeffective solution to a wide spectrum of demanding graphics applications includes HP's Model 1350A Graphics Translator which is an ideal interface between a computer and the 1311B. The Graphics Translator has the ability to store data in memory and continually refresh the display, reducing the load on your computer.

For more information about Hewlett-Packard displays refer to the Large Screen CRT Display Data Sheet (\#5953-3842D) or call your local HP Field Engineer.

\section{SPECIFICATIONS, 1311B}

\section{VERTICAL AND HORIZONTAL AMPLIFIERS}

RISE TIME: $<75 \mathrm{~ns}, 10 \%$ to $90 \%$ points for full screen deflection.

BANDWIDTH: do to $5 \mathrm{MHz}$ ( $3 \mathrm{~dB}$ down at $5 \mathrm{MHz}$ ) with $8.9 \mathrm{~cm}$ (3.5 in.) deflection.

LINEAR WRITING SPEED: $>25.4 \mathrm{~cm} / \mu \mathrm{S}(>10 \mathrm{in} / \mu \mathrm{S})$.

SETTLING TIME: signal settles to within 1 spot diameter of final value in $<500 \mathrm{~ns}$ for any on screen movements.

REPEATABILITY: $<0.15 \%$ of full screen error in readdressing any point on screen trom any point an screen.

CROSSTALK: $<0.38 \mathrm{~mm}(<0.015 \mathrm{in}$.) with one input terminated in $50 \Omega$ and the other input driven by $1 \mathrm{~V}, 500 \mathrm{kHz}$ signal.

DEFLECTION FACTOR: front panel adjustable through the indicated range.

\begin{tabular}{|c|c|}
\hline Vertical & Horizontal \\
\hline from approx $46.3 \mathrm{mV} / \mathrm{cm}$ & from approx $35.8 \mathrm{mV} / \mathrm{cm}$ \\
$(118 \mathrm{mV} / \mathrm{in})$ to & $(90 \mathrm{mV} / \mathrm{in}$ to \\
$81 \mathrm{mV} / \mathrm{cm}(207 \mathrm{mV} / \mathrm{in})$ & $60.9 \mathrm{mV} / \mathrm{cm}(153 \mathrm{mV} / \mathrm{in})$. \\
\hline
\end{tabular}

SPOT JITTER AND MOTION: $0.13 \mathrm{~mm}(0.005$ in.) with $X$ INPUT and Y INPUT disconnected

POSITION: zero input can be set to any on-screen position.

POLARITY: positive vertical input moves beam up; positive horizonta input moves beam right. Polarity can be changed by changing internal lead connections.

$\mathbf{X}-\mathbf{Y}$ INPUT: rear panel BNC female connectors with floating shield.

$X-Y$ INPUT IMPEDANCE: $50 \Omega$, switchable to $10 \mathrm{k} \Omega$ shunted by $40 \mathrm{pF}$

MAXIMUM INPUT: $\pm 50 \mathrm{~V}$ (dc + peak ac) with $10 \mathrm{k} \Omega$ internal lermination. $\pm 5 \mathrm{~V}(\mathrm{dc}+$ peak ac) with $50 \Omega$ internal termination.

LINEARITY: $1 \%$ of full scale display (along major axes).

DRIFT: $1.27 \mathrm{~mm} / \mathrm{hr}(0.05 \mathrm{in} / \mathrm{hr})$ and $2.54 \mathrm{~mm} / \mathrm{hr}(0.10 \mathrm{in} / \mathrm{hr})$ in 24 hours with covers installed.

\section{Z-AXIS AMPLIFIER}

RISE TIME: $<25$ nS.

SENSITIVITY: $-1 \vee$ signal blanks trace; $+1 \mathrm{~V}$ signal (Intensity at maximum) provides maximum intensity. Polarity may be reversed by changing internal lead connections.

GAIN ADJUST: adjustable over $5: 1$ attenuation ratio.

BALANCE: $\pm 1 \mathrm{~V}$ offset, internal adjustment.

Z-INPUT: rear panel BNC female connector with grounded shield.

Z-INPUT IMPEDANCE: $50 \Omega$, or $10 \mathrm{k} \Omega$ shunled by $60 \mathrm{pF}$.

TTL BLANKING: high slate blanks CRT (polarity reversible).

MAXIMUM INPUT: $\pm 50 \mathrm{~V}(\mathrm{dc}+$ peak ac) with $10 \mathrm{k} \Omega$ internaltermination. $\pm 5 \mathrm{~V}(\mathrm{dc}+$ peak ac) with $50 \Omega$ internal termination.

\section{CATHODE-RAY TUBE}

VIEWING AREA: $36.5 \mathrm{~cm}$ (14 in.) diagonal; $20.3 \mathrm{~cm}$ high, $25.4 \mathrm{~cm}$ wide ( 8 in. high by 10 in. wide).

TYPE: post-accelerator, approx $28.5 \mathrm{kV}$ accelerating potential. P31 aluminized phosphor is standard. Electrostatic focus and deflection.

SPOT SIZE: $\leq 0.43 \mathrm{~mm}(0.017 \mathrm{in})$ center screen and $\leq 0.51 \mathrm{~mm}$ $\leq(0.020$ in.) in the corners.

RESOLUTION: $\leq 24$ lines/cm (60 lines/in.) center screen and $\leq 20$ lines/ $\mathrm{cm}$ ( 50 lines/in.) in the corners over a $20.3 \times 24.4 \mathrm{~cm}$ ( $8 \times 10$ in.) viewing area.

BRIGHTNESS: at least $84 \mathrm{~cd} / \mathrm{m}^{2}(50 \mathrm{fl})$ measured at $2.54 \mathrm{~mm} / \mu \mathrm{S}$ ( $0.1 \mathrm{in} . / \mu \mathrm{s}), 60 \mathrm{~Hz}$ rate. with spot size of $0.5 \mathrm{~mm}(0.020 \mathrm{in}$.).

CONTRAST RATIO: $4: 1$ or greater.

X-RAY EMISSION: CRT emission $<0.2 \mathrm{mR} / \mathrm{hr}$; not measurable in background noise using Victoreen Model 440RF/C.

IMPLOSION PROTECTION: rim and tension banding prevents implosive devacuation (UL/IEC348).

PHOSPHOR PROTECTION: circuit detects absence of deflection signals and limits beam current.

\section{GENERAL}

POWER: selectable to $100 \mathrm{Vac}, 120 \mathrm{Vac}, 220 \mathrm{Vac}$, and $240 \mathrm{Vac}$ $+5 \%-10 \%, 48 \mathrm{~Hz}$ to $440 \mathrm{~Hz}, 115 \mathrm{Va}$ max.

\section{OPERATING ENVIRONMENT}

Altitude: $4600 \mathrm{~m}$ (15 $000 \mathrm{ft}$ ) at $25^{\circ} \mathrm{C} ; 7600 \mathrm{~m}(25000 \mathrm{ft}$ ) non-operating. Temperature: $0^{\circ} \mathrm{C}$ to $+55^{\circ} \mathrm{C} ;-40^{\circ} \mathrm{C}$ to $+70^{\circ} \mathrm{C}$ non-operating

Humidity: up to $95 \%$ at $40^{\circ} \mathrm{C}$

Vibration: $10.55 \mathrm{~Hz}$ at $0.38 \mathrm{~mm}$ ( $0.015 \mathrm{in}$.) peak to peak excursion

Shock: level $30 \mathrm{~g}$; duration $11 \mathrm{~ms}$; shape $1 / 2$ sine wave

$X, Y$, and $Z$ INPUT CONNECTORS: BNC on rear.

WEIGHT: net, $24.7 \mathrm{~kg}(54.5 \mathrm{lb})$; with covers, $30.8 \mathrm{~kg}$ (68 lb); shipping $28 \mathrm{~kg}(62 \mathrm{lb})$.

DIMENSIONS: refer to outline drawings on the Large Screen Displays Data Sheet. The only difference between the 1311A and 1311B is overall height because of the higher tit stand.

\section{OPTIONS \& ACCESSORIES}

ACCESSORIES SUPPLIED: one tilt stand, top and bottom covers, one flat, glass contrast filter, one power cord, and one Operating and Service Manual.

ORDERING INFORMATION

Model $1311836 \mathrm{~cm}$ (14 in.) Display ............... $\$ 5300$. OEM discounts are available.

\section{OPTIONS}

001: deletes tilt stano and adds rackmount hardware... Less $\$ 250$.

002: deletes high tilt stand and adds low tilt stand .... No Charge.

003: replaces contrast control with brightness control .. Less \$125.

004: deletes glass contrast filter and tilt stand and adds a

plastic form-litting neutral density filter.............. Less $\$ \mathbf{4 0 0}$.

ACCESSORIES

RACKMOUNT KIT: HP P/N 01311-68701 .............\$\$77. INPUT SIGNAL CABLES: Model 52125A (1 m) and 52124A(10 m) input cables offer convenient connection between a signal source and the display. These cables contain four color-coded $50 \mathrm{ohm}$ coaxial cables with male BNC connectors on each end for $X, Y, Z$, and TTL blanking inputs.

Model 52125A 1 metre cable .....................\$150.

Model 52124A 10 metre cable....................... \$175.

Data subject to change.

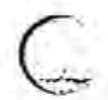

$\cdot$

.

$$
s
$$

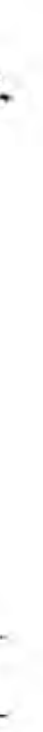




\section{Hewlett-Packard 98034A HP-IB Interface Installation and Service Manual}

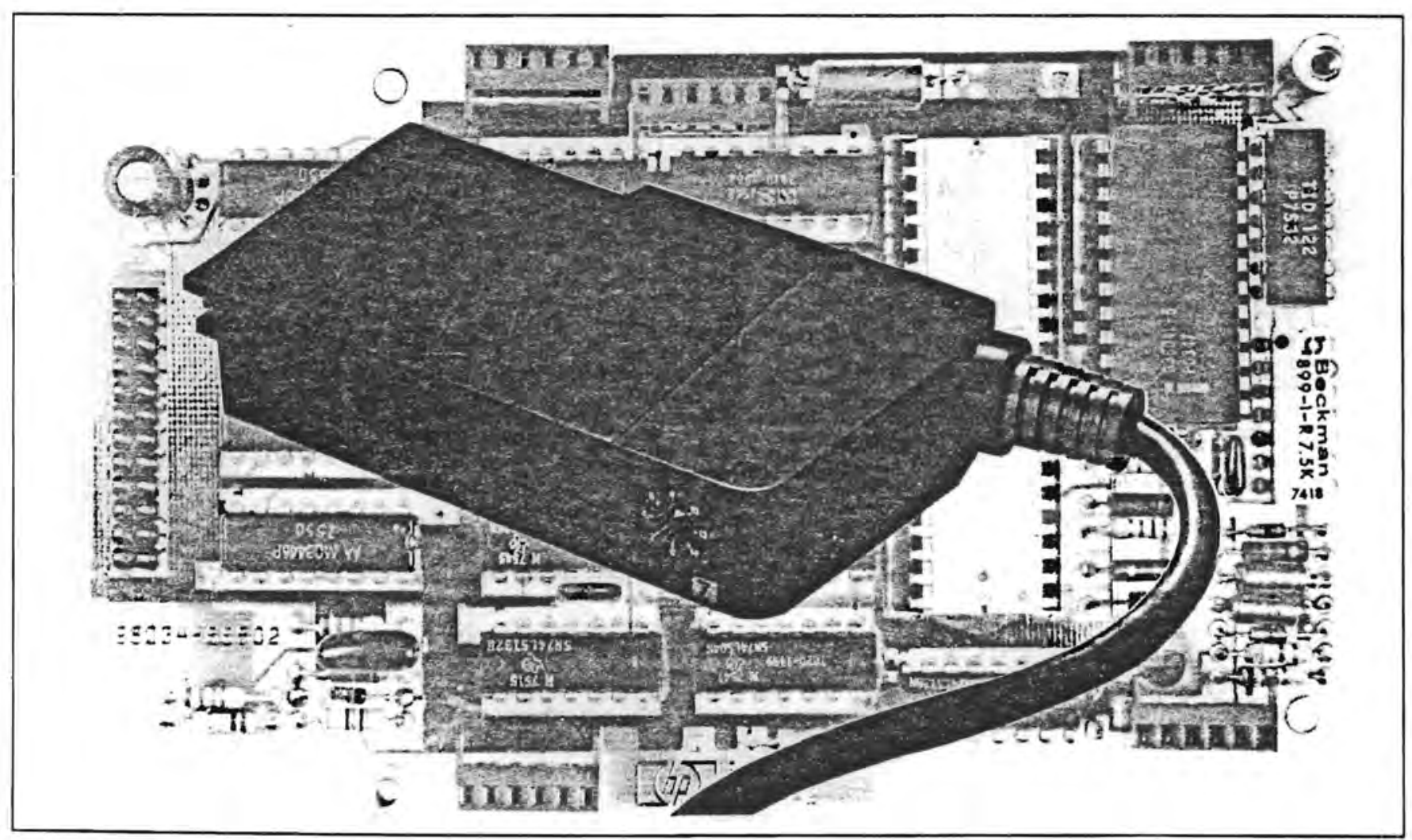


Recommended for use where an analog signal is required for nulling, peaking or for indicating trends or reference points.

Applications include ship board, process control, audio consoles, engine monitors. Accepts DC current or voltages. Input impedance $(100 \mathrm{~K})$ is well in excess of needle-type meters. A red LED bargraph display provides measurements from zero to full $3^{\prime \prime}$ scale. Features green overand-under-range indicators. Control (or alarm) signals can be set with calibrated dial potentiometer. Options include high impedance input, center zero, differential inputs, autopolarity, brightness control, and single or dual setpoints.

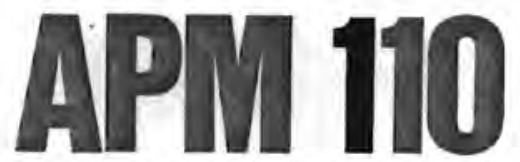

Accepts 7 -bit binary signals - TTL or 5-V C-MOS - and is directly compatible with microprocessors. Designed for use in process monitoring, medical instrumentation, portable test equipment. Can replace oscilloscope displays in some applications.

Options available are single and dual setpoints and increased damping.
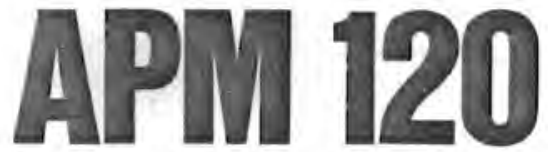

An $A C$ meter for applications where $A C$ voltage or current is available and analog representation is required. LED display includes red bargraph, green over-and-under-range indicator. 40 $\mathrm{Hz}$ to $1000 \mathrm{~Hz}$ response characteristic with $1 \%$ accuracy and $2 \%$ at 5000 $\mathrm{Hz}$. Options include single and dual setpoints.
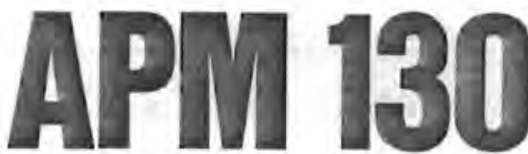

A VU/audio meter for display of either RMS (APM 131) or RMS and Peak simultaneously (APM 132). Used in recording studio equipment to indicate volume units and in broadcast studios for indication of \% modulation. Scales comply with ANSI 16.5 standards. Frequency response: $25 \mathrm{~Hz}-16$ $\mathrm{KHz}$.
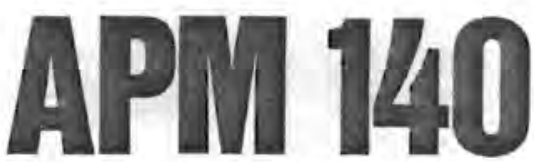

Features simultaneous display of process variables and setpoints on a single LED bargraph indicator. Shows how a system is operating in comparison with its control points. Can be made to flash when control point is exceeded, and provides a control output for each setpoint. All circuitry for either one or two setpoints is included.

Options for the APM 141

Control Meter (single visual setpoint) and the APM 142 Control Meter (dual visual setpoint) include differential input, high input impedance, damping, and flashing bargraph.

The bar flashes when bargraph is outside the two setpoints or a switch may be used to display either the setpoints or the bargraph.
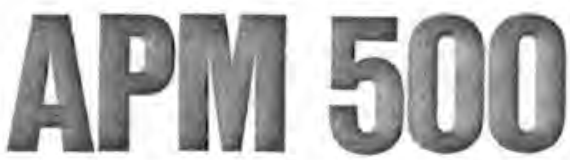

Designed with a larger (5") 53 segment LED display for installations calling for greater visibility and readability, particularly at a distance. Applications include oil drilling equipment, automotive, ship control panels, power distribution control systems, large machinery. process control, military, instrumentation and a variety of other installations. Accepts all standard APM 100, APM 110, APM 120, APM 130 , and APM 140 inputs. The Model 500 is also available with a bright orange display.

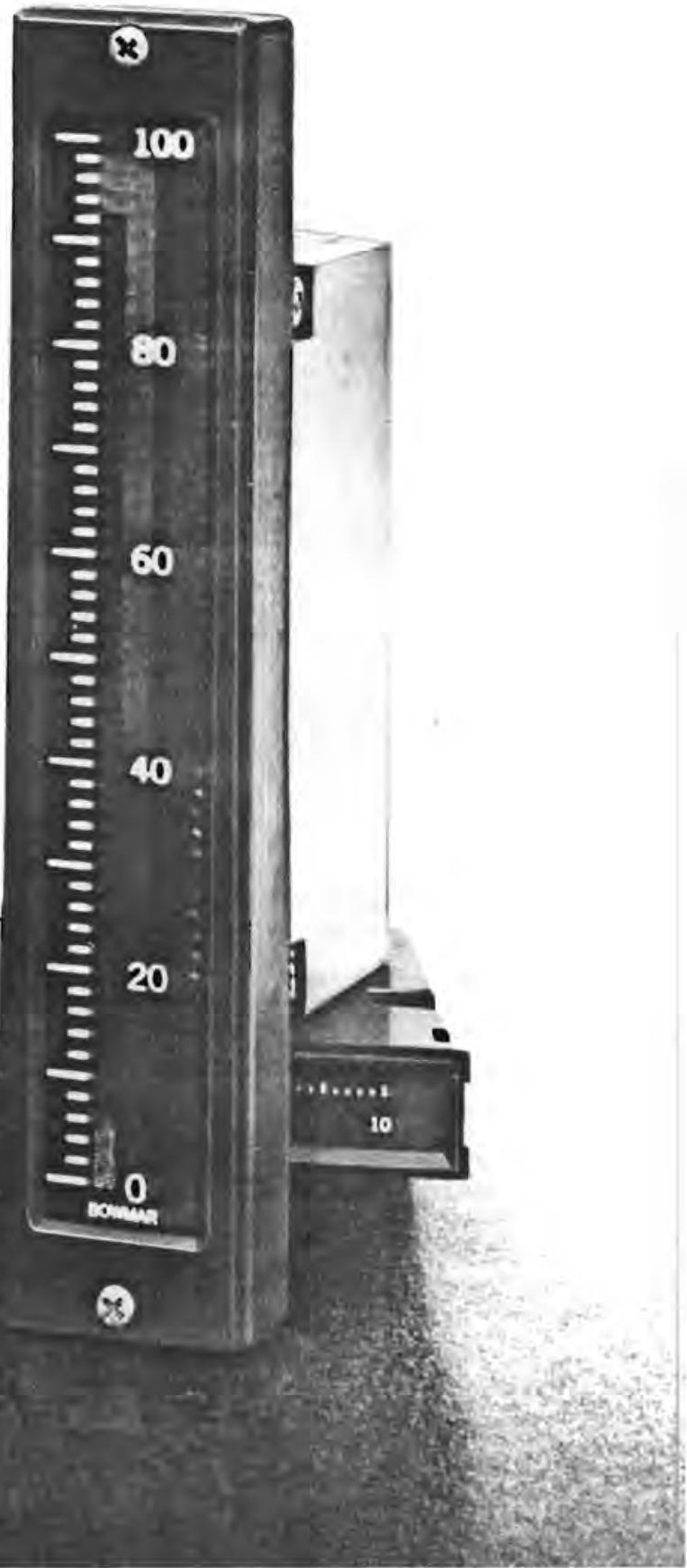




\section{Specifications}

\begin{tabular}{|c|c|c|c|c|c|c|c|c|}
\hline & APM 100 & APM 110 & APM 120 & \multicolumn{2}{|c|}{ APM 130} & \multicolumn{2}{|c|}{ APM 140} & APM 500 \\
\hline $\begin{array}{l}\text { Signal } \\
\text { Ranges }\end{array}$ & $\begin{array}{l}50 M V \text { to } 100 V D C \\
\text { IOUA to } 10 A D C\end{array}$ & $\begin{array}{l}7 \text { bit binary } \\
\text { TIL CMOS } \\
\text { Offset binary }\end{array}$ & $\begin{array}{l}50 M V-250 V A C \\
\text { IMA- } 5 A A C\end{array}$ & $\begin{array}{l}\text { Odd }=1.23 \\
\text { VRMS }\end{array}$ & $\begin{array}{l}\text { Odb }=1.23 \\
\text { VRMS }\end{array}$ & $\begin{array}{l}\text { Same as } \\
\text { APM } 100\end{array}$ & $\begin{array}{l}\text { Same as } \\
\text { APM } 100\end{array}$ & $\begin{array}{l}\text { Same as } \\
\text { APM } 100,110,120, \\
130,140\end{array}$ \\
\hline $\begin{array}{l}\text { Power } \\
\text { Supply }\end{array}$ & $\begin{array}{l}+5 \pm .25 \mathrm{~V} \mathrm{DC} \\
370 \mathrm{MA} T Y P\end{array}$ & $\begin{array}{l}+15 V \text { DC 3MA TYP } \\
-5 \pm 25 V \text { DC } \\
\text { 380MA TYP }\end{array}$ & $\begin{array}{l}+5 \pm 25 \mathrm{~V} \mathrm{DC} \\
380 \mathrm{MA} \text { TYP }\end{array}$ & $\begin{array}{l}+5 \pm .25 \mathrm{~V} \mathrm{DC} \\
300 \mathrm{MA} \\
-5 \mathrm{~V} \mathrm{DC} \text { 10MA }\end{array}$ & $\begin{array}{l}+5 \pm 25 \mathrm{~V} D C \\
300 \mathrm{MA} \\
-5 \mathrm{~V} \text { DC 1OMA }\end{array}$ & $\begin{array}{l}+5 \pm 25 V \mathrm{DC} \\
300 \mathrm{MA} \\
\text { TYP }\end{array}$ & $\begin{array}{l}+5 \pm 25 \mathrm{~V} \mathrm{DC} \\
300 \mathrm{MA} \\
\text { TYP }\end{array}$ & $\begin{array}{l}\text { Same as APM } 100 \\
110,120,130,140\end{array}$ \\
\hline $\begin{array}{l}\text { Input } \\
\text { Impedance } \\
\text { (ohms) }\end{array}$ & $100 \mathrm{~K}$ & $\begin{array}{l}100 \mathrm{~K} \text { to } \\
\text { ground }\end{array}$ & $100 \mathrm{~K}$ & $20 \mathrm{~K}$ & $20 K$ & & $100 \mathrm{~K}$ & $\begin{array}{l}\text { Same } 25 \text { APM } 100, \\
110,120,130,140\end{array}$ \\
\hline Linearity & $\pm 0.5 \%$ & $\pm 0.5 \%$ & $\pm 0.5 \%$ & $\pm 0.5 \%$ & $\pm 0.5 \%$ & $\pm 0.5 \%$ & $\pm 0.5 \%$ & $\pm 0.5 \%$ \\
\hline
\end{tabular}

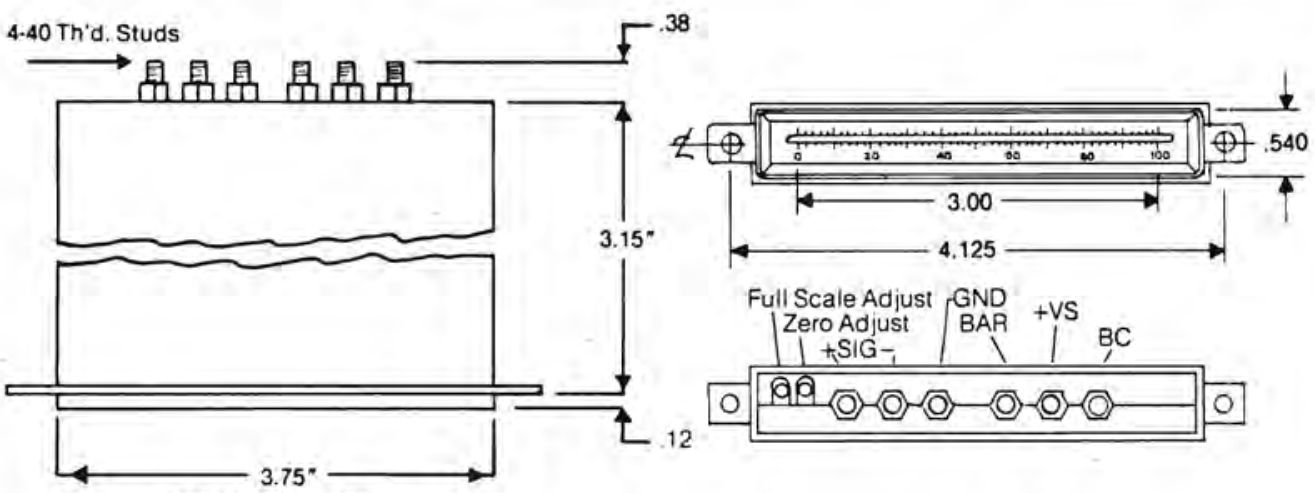

APM 100, APM 120
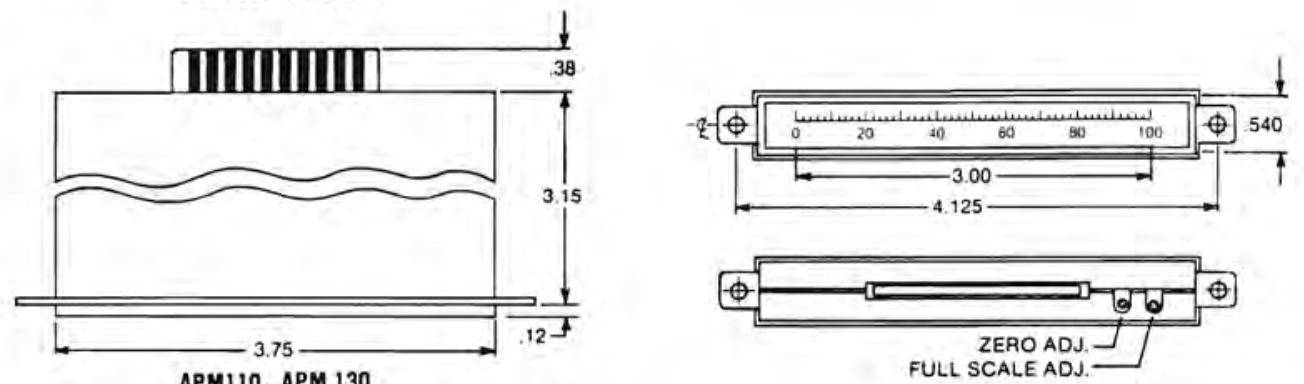

APMI10, APM 130
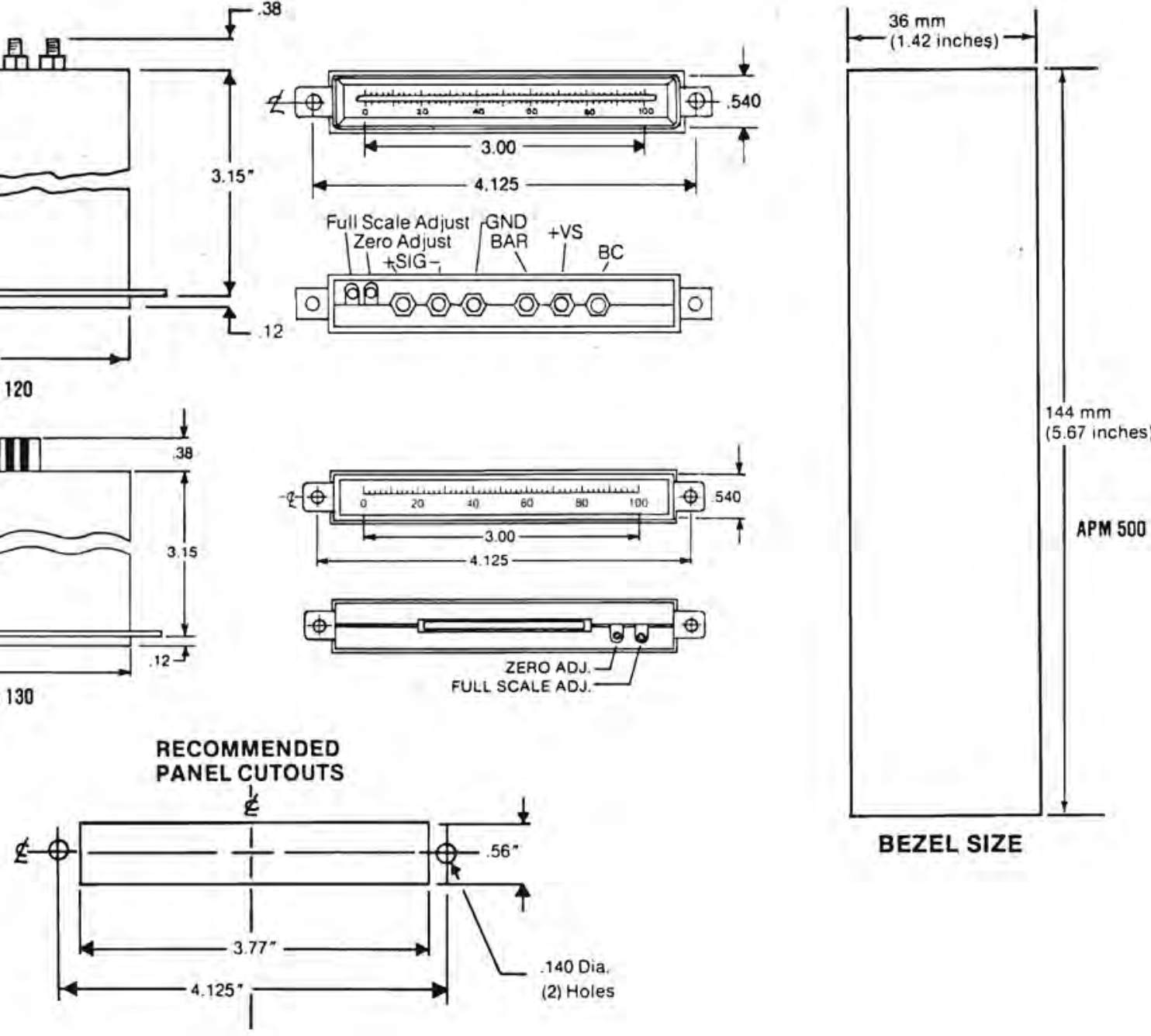

BEZEL SIZE

Bowmar/ALI, Inc., 531 Main Street, Acton, MA 01720

TEL: (617) 263-8365/TWX: (710) 347-1441

FOR FAST SERVICE DIAL

800-343-5202

EXCEPT MASS.

B. 14 


\section{APPENDIX C}

GUIDANCE PROGRAM FOR HP9825T 
APPENDIX $C$

GUIDANCE PROGRAM FOR HP9825T

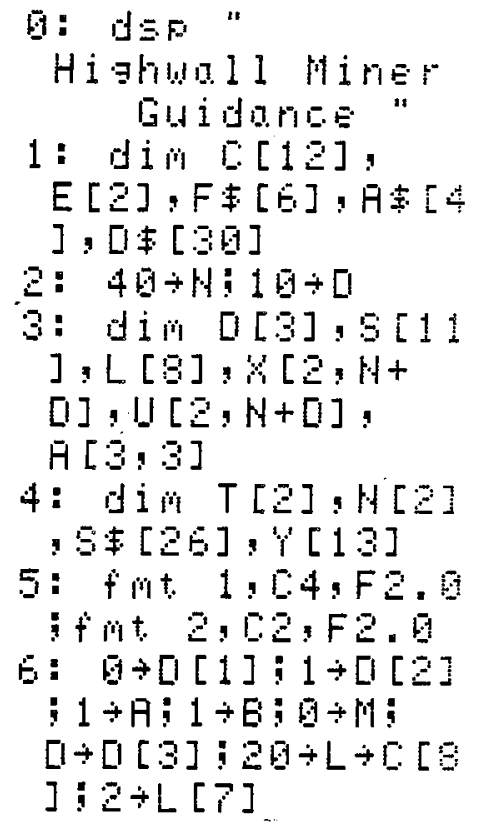

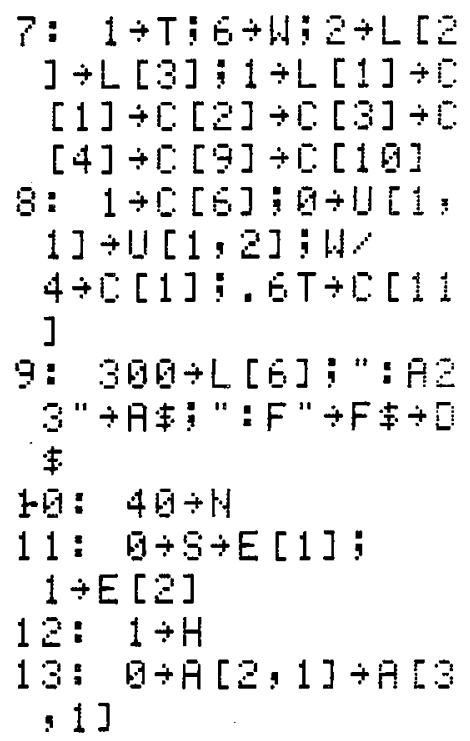

Comment

Statement
Identifies the program and its location.

See 3 and 4 below.

See 5-12 below.

Gives dimensions of array used in the program.

Format statements.

Establishes initial values. 


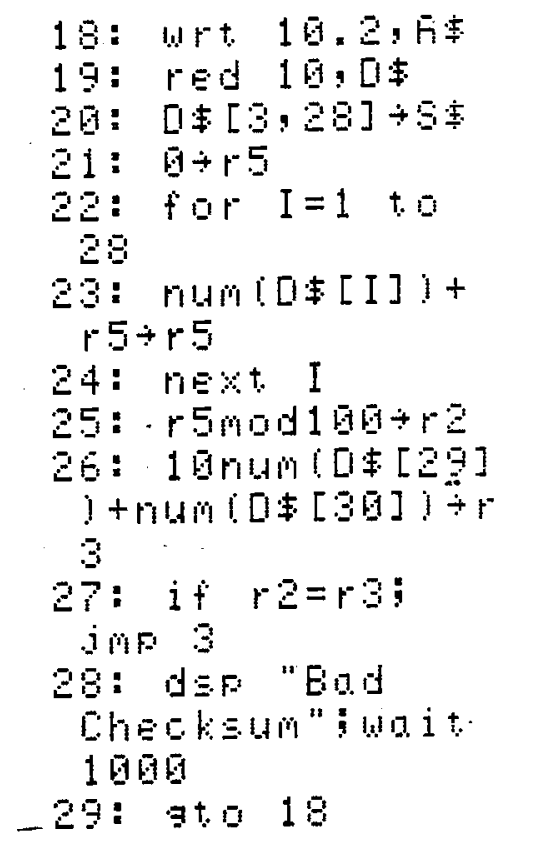

Statement

18

19

20

21-24

25

26

27-29

Comment

:A23 This message to the REP instructs the REP to read a11 the sensors and send back a message in the for :FS\$CC where $S \$$ is a string of 26 ASCII characters.

Instructs the $9825 \mathrm{~T}$ to read the REP message.

String $\$ \$$ is extracted from $D \$$.

This forms a decimal sum interpreting the $D \$[I]$ as ASCII

characters but does not include the checksum elements $D \$[29]$ and $D \$[30]$ in the sum.

Finds the last two digits of the sum and stores them as $r l$.

Expresses the checksum $C C$ as a two digit number and stores it in $r 3$.

If the transmitted checksum agrees with the received checksum the data is assumed to be valid. If it does not agree, the message "Bad Checksum" is displayed and the SEC (9825T) asks for another data aquisition operation. 


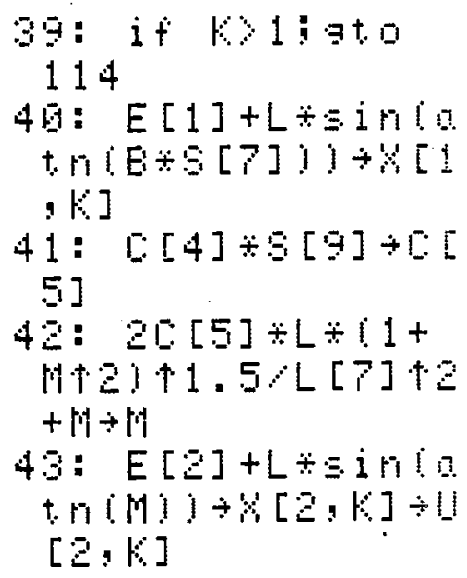

Statement and 'atn' means 'arctan'. slope). Statement 55 upon return. the best vertical trajectory.

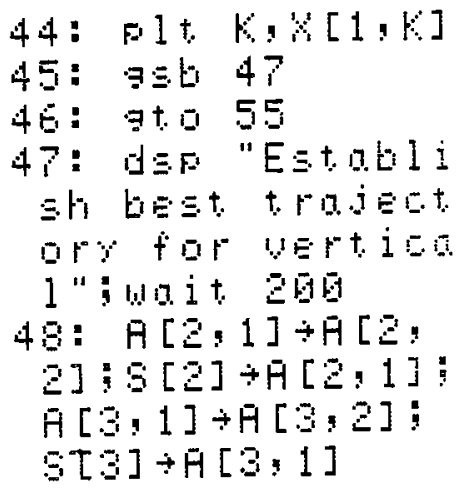

\section{Comment}

If $K$ is greater than 1 goto 114 .

$X[1, K]$ is the vertical coordinate at the depth LK. This equation cooresponds to Eq. $6-2$ with $V_{1}=X[1,1], V_{0}=E[1]$ and $\theta_{1}=\operatorname{atn}(B S[7])$ where $S$ is the initial vertical slope

$C[4]$ is the calibration constant which converts the LR-LVDT sensor voltage to a curvature value $C[5]$.

Corresponds to Eq. 6-18 for calculating the yaw (horizontal

Corresponds to Eq. 6-19 with $E[2]=X[2,0]$. $U[2, K]$ will be stored in the previous hole memory at the end of the run.

In the final program this plot instruction will be replaced with an appropriate instruction to the CRT display.

Go to subroutine beginning at Statement 47 and then to to

A comment statement stating that Statements $47-52$ calculate

$A[2,1]$ and $A[2,2]$ designate memory spaces for previous values of the roof thickness $S[2]$.

$A[3,1]$ and $A[3,2]$ designate memory spaces for previous values of the floor thickness $S[3]$. 
55: if $\{[2,1] \geqslant E[$ 2] "L" $+F$

BE: if $Y[2,16]$ CE 2]: "F"

$57:$ if $G[1]) L[1]$ at口 8

5: if $[$ : $[B]<0$;

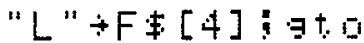

$E$

$59: " F "+F+[4]$

El: if $5[2]<5[8]$

$-[[1]: \exists t 0 \quad 51:$

if $S[4] 2[1[2]$

"E"广F⿻[弓]:

70

Statement

$55-68$

$5.5-56$

$57-59$

$60-68$

69

$67-72$

73

74
61: if $6[2] \measuredangle[8]$

$-[1] ; " \mathrm{E} "+\mathrm{F}+[3]$

if $5[4]<-[2]$

"[:" $\div F$

62 if $5[2]<[3]$

$+[[1]: \exists \operatorname{tg} 70$

63 if $5[2] 9[3]$

$+[[1]: \exists t 0 \quad 54$

if $5[4] \geqslant[[2]$ :

"H"广F⿻[弓]: 70

$54:$ if $5[2] 98[3]$

$+[1]=" A " \div F \neq[3]$

if $5[4]<-[[2]$ :

"[G"+F [S]
$65:$ if $5[2]>5[3]$

$+[[1] \div 9 t 070$

E: if $5[4] 2[0]$

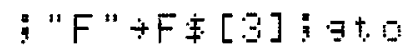

70

67: if $5[4]-$

[ $[2] ; "\left[{ }^{\prime}+F \neq[3] ;\right.$

ㅂ. 070

68: "I"+F干[3]

69: $0 \div 0$

7E: for $I=1$ to

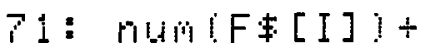
$5 \div 0$

7E: nExt I

$73:$ Dod $100 \div 0$

74: wrt $16,1, F=$

Comment 


$$
\begin{aligned}
& 91: k+1 \div k+100 \\
& 723 \cdot r 1 \\
& 9: \quad 1-1-i n t+1 \\
& 61+r 4 \\
& \text { 93: if } r 4<\text { i juF } \\
& -2 \\
& \text { 94: wrt 18.2, } \\
& \text { 95: red 10! [1: } \\
& 96: \quad[1 \neq[3,20] \div 5 \text { 市 } \\
& 97: 0+r 5 \\
& \text { 98: for } I=1 \text { t. } \\
& 28 \\
& \text { 99: मUm![聿[I]!+ } \\
& r .5+r .5 \\
& \text { 160: मEQ I } \\
& 101: \quad 5 \text { mod } 100 \div 2
\end{aligned}
$$

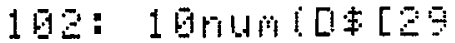

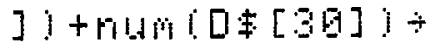

$$
\begin{aligned}
& \text { - } 3 \\
& 103 \text { if } r 2=r 3 \text { : } \\
& \text { IIIF } 3
\end{aligned}
$$

Statement

$91-93$

95-96

$97-100$

$101-105$

$106-113$ depth $r 4$ equals $L$. $D \$[29,30]$ is the checksum.
164: d 0 " "Eod

EhEcksul" ond

1060

195: 9 t. 94

$160:+0 r \cdot I=1$ t.

20

167: if numist [I

:I] j 58 and

I. I] $1-48 \div Y[I]$

in $F$

169: num St: [I:

I ] $j-5.5 \div \%[I]$

1.9: next I

110: +or $I=2$ t.

18

111: if Inod $=1$ : $\exists+0113$

$112: 16 \%[I-1]+$

$Y[I]+5[I] 2]$

$113: n E s t$ I

\section{Comment}

Read the depth indicator until the depth $r 1$ increases by the cutterhead length $L$ : i.e., until the increase in

SEC instructs REP to read and transmit sensor data.

SEC reads sensor data which is included in $D \$$ as an ASCII string $S \$[1,26]=D \$[3,28]$. D $\$[1,2] \rightarrow ": F "$ and

Sums the ASCII decimal values in the message.

Uses the last two digits, $r 2$, in the sum as a checksum to compare with the transmitted checksum $r 3$ to verify the accuracy of the transmitted message. If $r 2 \neq r 3$ the message "Bad Checksum" is displayed and a new reading of sensor data is attempted.

If $r 2=r 3$ this routine interprets the ASCII string $S \$$ as decimal sensor outputs $S[1], S[2], \ldots, S[13]$. 


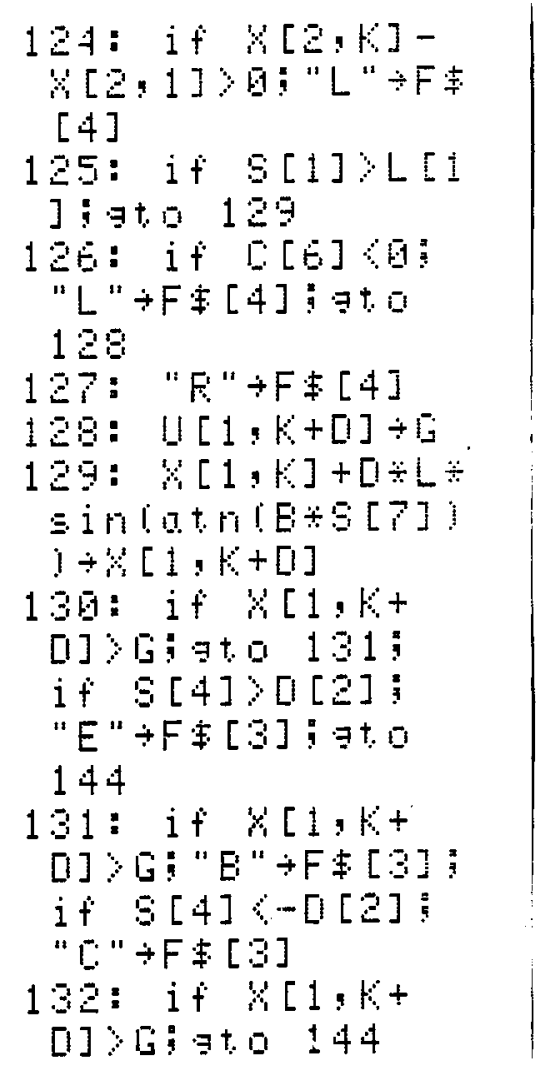

Statement

124

Guidance instructions generated in the form of a two
letter ASCII code identified in Table 2 and Table 3.

Guidance instructions generated in the form of a two
letter ASCII code identified in Table 2 and Table 3.

139-143 Generates a checksum to be used by the REP to verify the accuracy of the data received.

144 Sends the guidance instructions to the REP.

135 if $x[1,1+$ [1] [3:0 134 if $S[4] 2[12]$ :

"H"广F⿻[弓]: 144

$134:$ if $8[1, k+$ [1] [G "A" $\div F \div[3]$ if $S[4]-[12]$ "[ं" $+F \neq[3]$

$135:$ if $8[1, k+$ [1] [1:?to 144 $135: " I "+F+[3]$ " if $S[4] 2[[2]$ ! "F"广F⿻[3]: 144

137: if $5[4]-$ [I $[2]: "[" \div F \neq[3]$ ำ 144

$138: " I "+F+[3]$

$199: 0 \div 0$

14⿴囗: $\quad \mathrm{ar} \quad I=1$ t. 4

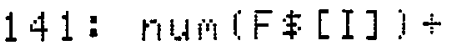
$5 \div 0$

$142:$ next I

$143: 0 m 0196 \div 0$

144 : w5 10.1 ?

F丰，日

Comment

If this is not the first hole being augered (i.e., $\mathrm{H}>1$ ) to this depth there will be an anticipation target and guidance instructions will be generated in accordance with Statements 124-138. 


\section{APPENDIX D}

PROGRAM FOR SIMULATED RUNS-VERTICAL PLOT 
APPENDIX D

\section{PROGRAM FOR SIMULATED RUNS-VERTICAL PLOT}

The program included in this appendix is designed to facilitate studies of the expected trajectory of the auger machine for diffent coal seam profiles. Calculations follow those of the Guidance Program discussed in Appendix C. Statements 27 through 41 are identical to Statements 40 through 54 in the Guidance Program. Similarly Statements 72 through 81 parallel Statements 114 through 123 in the Guidance Program.

As a result of Statement 3 the user specifies the maximum depth to be augered in terms of $\mathrm{N}$, the number of measurement intervals. The auger moves a distance $L$ between measurements so the total depth is NL. The user also specifies anticipation target distance $D$.

The program calls for a description of the coal seam in terms of its vertical centerline and its thickness. Statement 103 specifies the centerline geometry in terms of a starting position $E[1]$, a vertical displacement amplitude $\mathrm{C}[7]$ and a wavelength $L[4]$. Statement 104 expresses the thickness variation in terms of an amplitude $C[9]$ and a wavelength $L[5]$.

After these values have been entered as requested by the enter-print (enp) statements in the program, the program procedes to plot the roof and floor interfaces as instructed by Statements 119 and 126 . The program stops at Statement 129 to allow change of pen if desired. When the "continue" keyboard instruction is given the centerline of the coal seam is plotted. The program stops again at Statement 134 to allow a change in pen clolor for plotting the course of the auger through the coal seam.

Sensor inputs are generated in Statements 93 through 102 and Statements 109, 110, 115 and 116. Course correction instructions are given in Statements 42 through 91.

Previous hole data is stored in accordance with the instructions of Statement 54. 
9: Higrigl l Winet GUI dance "yEFT"

1: $f x+1$

$2:$ in $[:[12]$ ? $E[2]$

3: ERF H: [

$4: 501$ 日, $4:-2$. 26

$5: \quad 0 \times 50,0,5,10$

6: $d i$ m $[3], 5[9]$

, L[G], $\mathrm{x}[2, \mathrm{H}+[1]$

$\|[2, H+[1], \bar{H}[3, \Xi]$

$7:$ 向 $T[2], H[2]$

8: $6 \div 0[1] \div 1 \div[1[2]$

I $1+\mathrm{H}+\mathrm{I}+\mathrm{E}+\mathrm{Q}+\mathrm{N}$

$[1+[][3] 16 \div L \div C[B$

] $: \div 4[7]$

$9: 1+T \div 6+4 \div 2+L[2$ ]$+L[3]: 1 \div L[1]+1:$ $[1] \div[:[2]+[[3] \div[$ $[4]+[[9]+[:[19]$

16: $1+[$ [6]:日+U[1

, $11 \div U[1,2] ; \omega$

$4 \div[[1] ; .6 T \div[:[1]$ ]

11: $306 \div L[E]$

$12: 1+2$

13: ERF" "y [IEF

AHF $[[7] ",[[\bar{Y}]$

14: Frt "Thl:

yar Fafo, [9]"

1:"Ft. 1 " 1 ?

"Fudil L L int"; 360

15: EnF" "HQUEleh 马t. thert" L $[4]$

1E: EHF "HOUElEn

$\exists$ t.

$17: 0 \div 5+E[1] ;$

$1 \div E[2]$

$1 B: 1$ LLE]-IL [E]

$+2-L[7]+2 !+, 51 \div$

$L[B]: L[7]+2 \div E$

[4]

19: 1+F木 FEn

20: if $z=1: 9 t 0$

163

1: $Z+1+Z$

$2: \quad 1 \div \mathrm{H}$

$23: G \div \mathrm{B} \div \mathrm{A}[2,1] \div \mathrm{A}$

[?;1]

$2 \div \quad 6+1 \div 6$

25: $6 \div 1$
ZE: ZT+E[1];L[Z]

$+5[2]+5[5] \div 0[$

$4]+5[5]+5[0]+5[$

$7]+5[8]+5[9]$

27: $E[1]+L \because \Xi i n ! E$

$\because$ ath $\mathrm{G} !+\mathrm{Q}[1: \mathrm{K}]$

$28:[4] \div 5[9] \div[[$

5]

$29:[5] \div L \div 11+$

$1+2]+1,5+14+1$

36: $E[2]+L \div \equiv$ in 6

t. n $11 ! 1+8[2: k]$

3: Flt $k, \because 1,6]$

3: $: 3 \mathrm{~b} \quad 34$

3: 9 t. 42

34: 日EF" $E \equiv t a b l i$

sh best trojegt

ary for yertica

I" $\log$ it 200

35: $\mathrm{A}[2,1] \div \overline{\mathrm{A}}[\mathrm{Z}:$

$2]: S[2] \div A[2,1] \div$

$A[3,1]+A[S, 2]:$

$G[3]+A[3,1]$

6: if $G[2]-H[2$ :

$2]\rangle$ L $[2] ; A[2,2]+$

$L[2] \div 5[2]$

37: if $5[3]-\bar{H}[3$

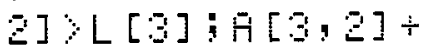

$L[3]+5[3]$

$38: \%[1,1]+5[2]+$ $[Z[Z]+F$

$39: 2[1,6]-5[9]-$ $[\mathrm{C}]+\mathrm{F}$

4E: $[F+F] Z+1][1:$ เ]

41: ret

$42:$ if $[2: 1]-$

$E[2] 9: a b \quad 101$

$43:$ if $[2: 1]-$

$E[2]<0: \exists=6 \quad 102$

$44: \quad i+5[2]<[3]$

$-[1[1]: \exists t 045:$

if $s[4])[[2]$

$\exists \equiv 6 \quad 98$

$45:$ if $5[2]<5]$

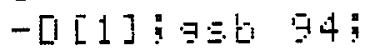

if $5[4]-[12]$ !

$\exists \equiv \mathrm{b} \quad 1 \mathrm{G}$

46 if $5[2] 35[3$

$+[1]]: \exists t 047$ i

it $s[4]>[1[2] ;$

$\exists \Xi \mathrm{b} \quad 97$ 


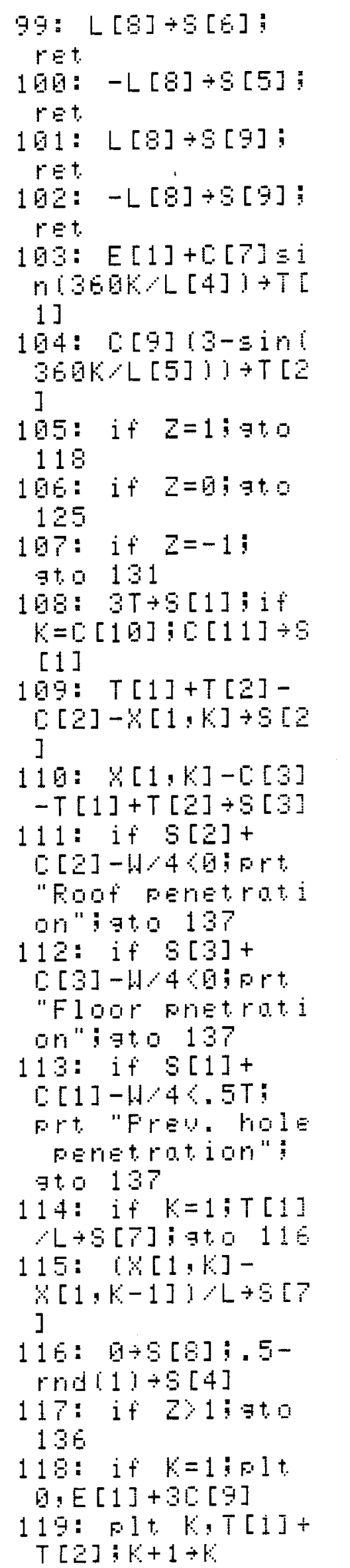
126: if $k=14$
gt. 0163
$121: 1 \div 6$
$122: 6 \div 2$
$123:$ FEn
$124: \quad 9 t 0163$
$125:$ if $k=1 ; \mathrm{F} i$
a. $E[1]-3[[9]$
$12 E: F]$ F $F[1]-$
$T[z]: k+1 \div k$
$127:$ if $<=4$ :
ㅋ․ 1 日3
$128: 1 \div<$
$129:-1+2 ;$ Fen:
日 3 " $[0]$ or T [1]
$" \equiv$ t. F
130: 9 t. 103
131 : Flt KaT[1];
$1+1 \div 16$
132 : if $16=H$ :
ㅋ. 100
$133: 1 \div 2$
134: FEn
"Fen Color";
$\Xi t . F$
$135:$ at. 21
$135:$ if KCH:
7 回
$137: K+H[1]$ ifEn
$130: 6+1$
139: F]t $0, E[1]-$
H. 4
14⿴: $k+1 \div k$

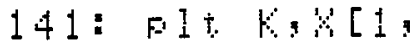 (6] $-\mathrm{H} 4$
$142:$ if $64[1]$ :
ํ. 140
$148: F 1+$ F : $[1$ :
F] $+\mathrm{H} 4$
$144: \quad 6 \div k$
$145: k+1+k$
$145: \quad[1]-4+1$
147: Flt. I, $[1]$
.1] $+\mathrm{H} 4$
$148:$ if
$1: 9 \operatorname{tg} 145$
$149: F 1$ t $0, E[1] \div$ 1.14
15日: FEn' $\% 165$




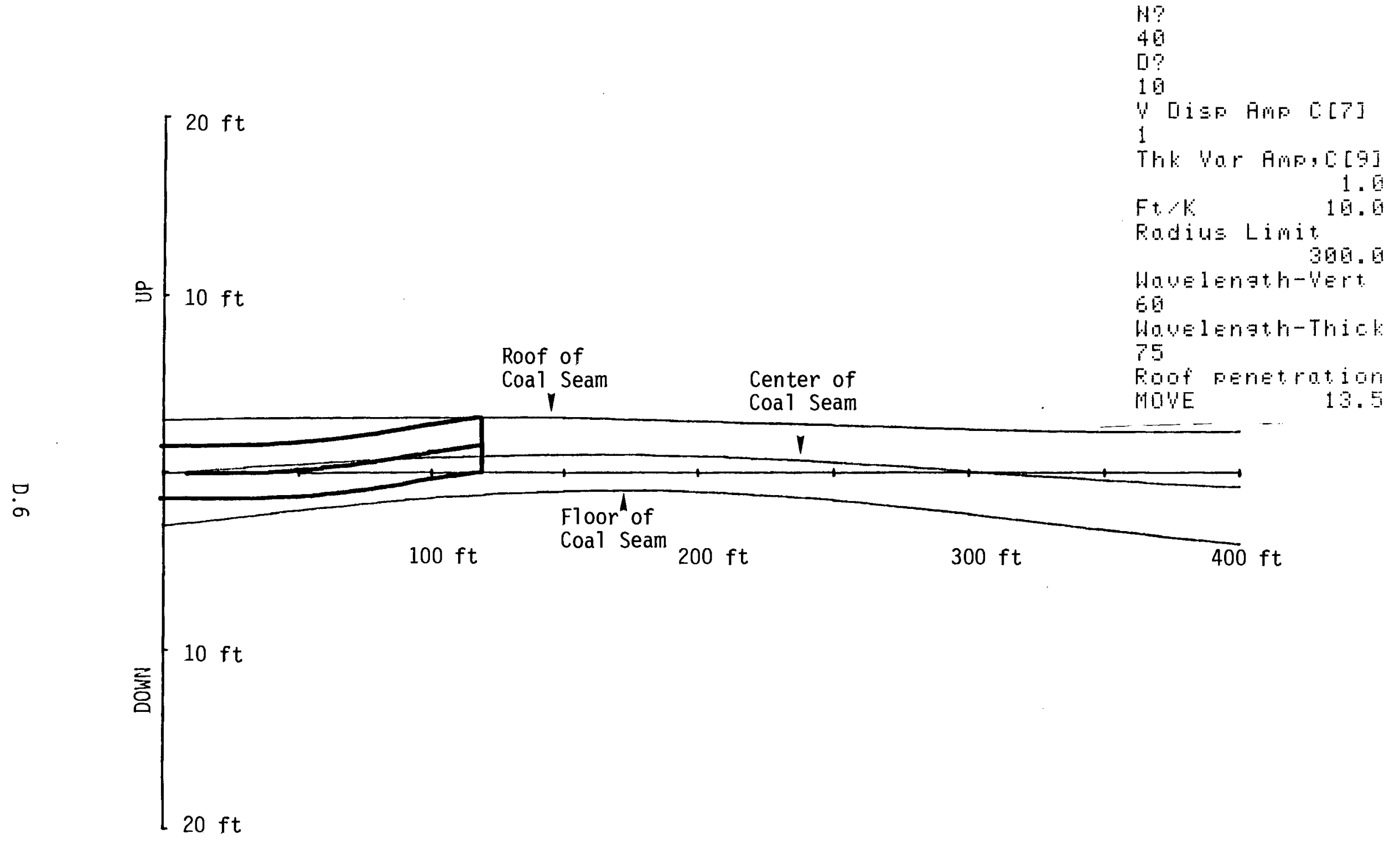

FIGURE D.1. Simulation Run-First Hole-Vertical 


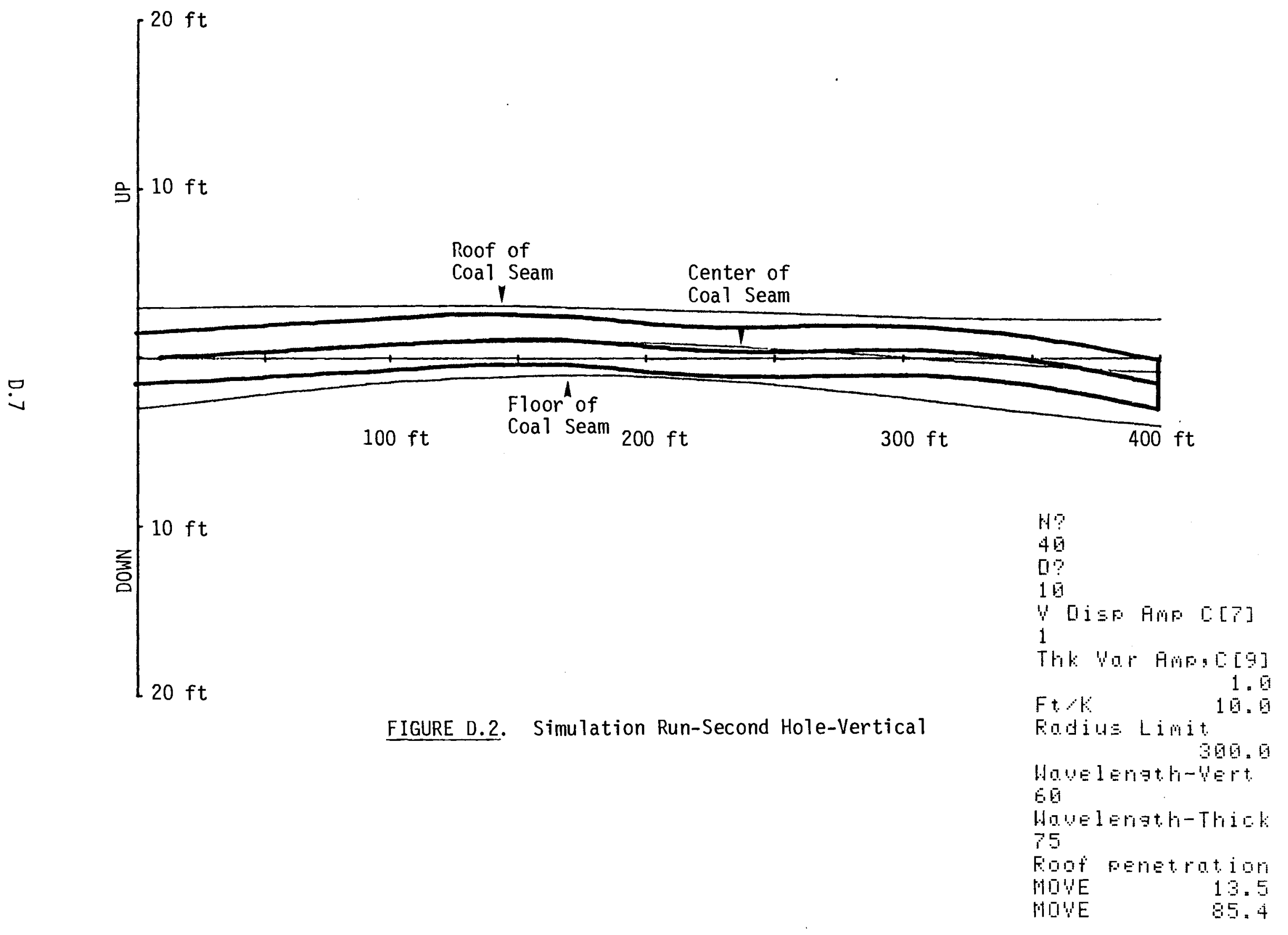




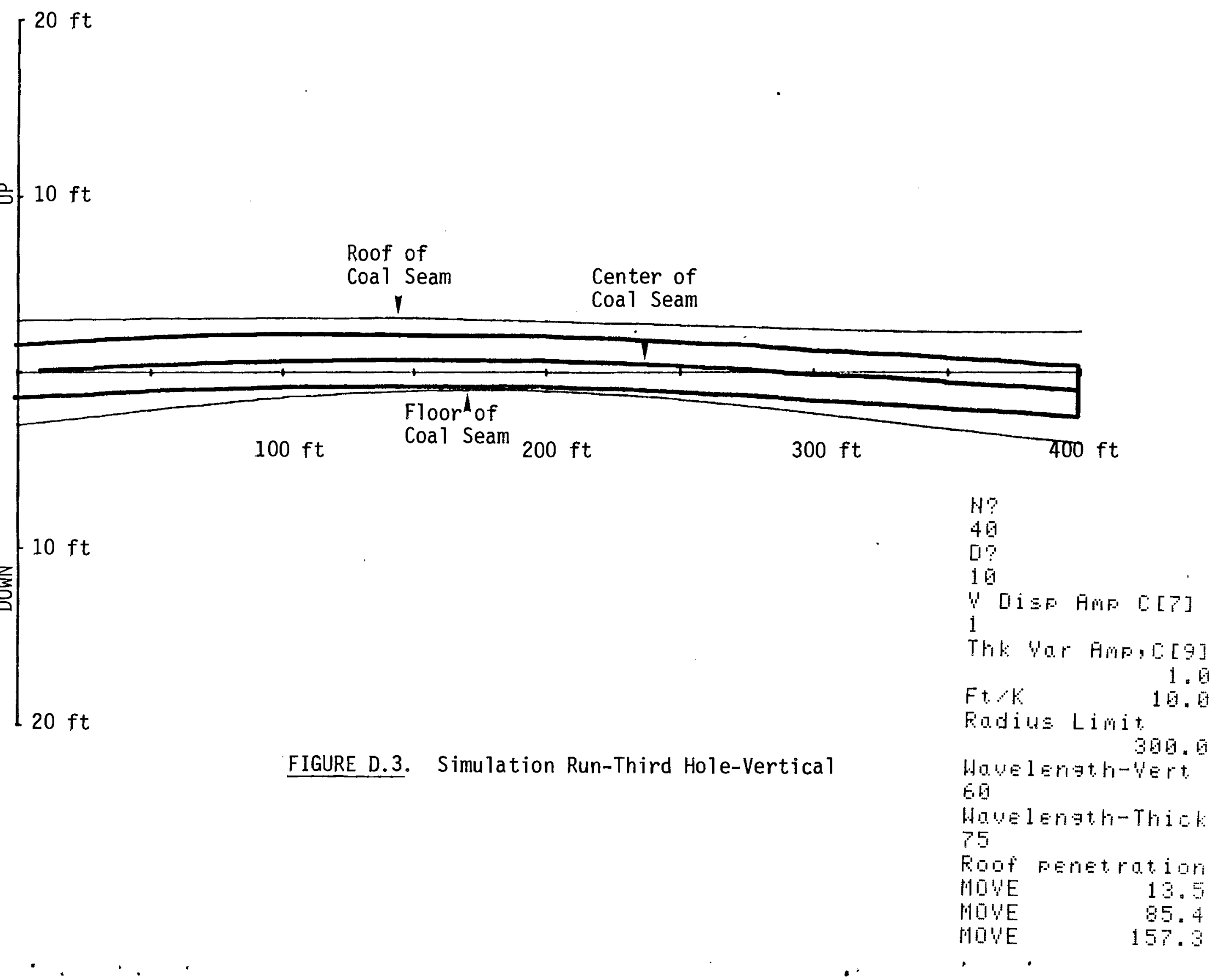


APPENDIX E

PROGRAM FOR SIMULATED RUNS-HORIZONTAL PLOT 


\section{PROGRAM FOR SIMULATED RUNS-HORIZONTAL PLOT}

The program listed in this appendix is almost identical to that given in Appendix D. The chief difference lies in the plot instructions which in this case deal with the horizontal plane coordinate $x[2, K]$. There are other changes in the program. Statement 11 has been added to identify the direction of movement from one hole to the next. The initial horizontal slope $M$ is input in Statement 14 . This input is useful in illustrating the manner in which the guidance program selects the starting position to avoid intercepting the previous hole. This feature is illustrated in Figure E.1 in which the horizontal entry slope $M$ as set to 0.2 for the first hole and to zero for the second hole. The guidance program started the second hole 15.9 feet to the left of the starting point of the first hole to avoid interception. It is assumed that in normal operation the horizontal entry slope will always be zero. However, deviations from a straight horizontal path will develop because of accumulated navigational error. In order that the succeeding hole may be planned as a straight course, the guidance program calculates the appropriate entry point to avoid intercepting the previous hole. If the stump thickness sensor detects impending interception (stump thickness below limit) this message will have priority and cause the auger to change its course to avoid the undesired condition. When the sensor indicates adequate stump thickness the program directs the course back to a straight trajectory with $M=0$.

Provision is made for entering a "Warn Position" in Statement 15. This statement together with Statement 107 simulates a 'stump thickness below limit' signal at the depth posiition $K=C[10]$. Since it occurs at only one position it has practically no effect on the trajectory. In a real mining situation the 'stump thickness below limit' signal would be seen over a range of $K$ values and would appreciably affect the trajectory. Figure D.1 uses the same input parameters for describing the coal seam contour as were used for the vertical plots in Figures D.1 through D.3. 
a

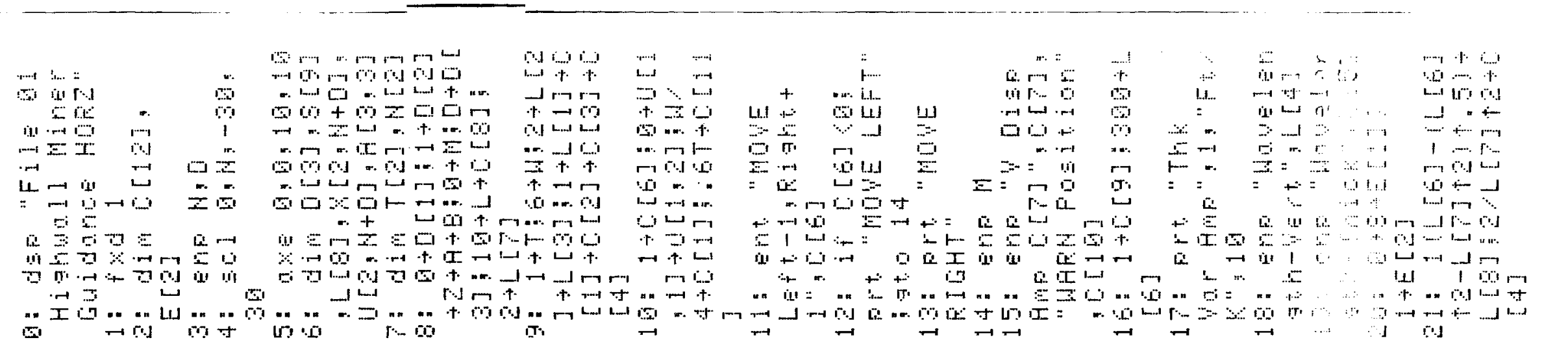




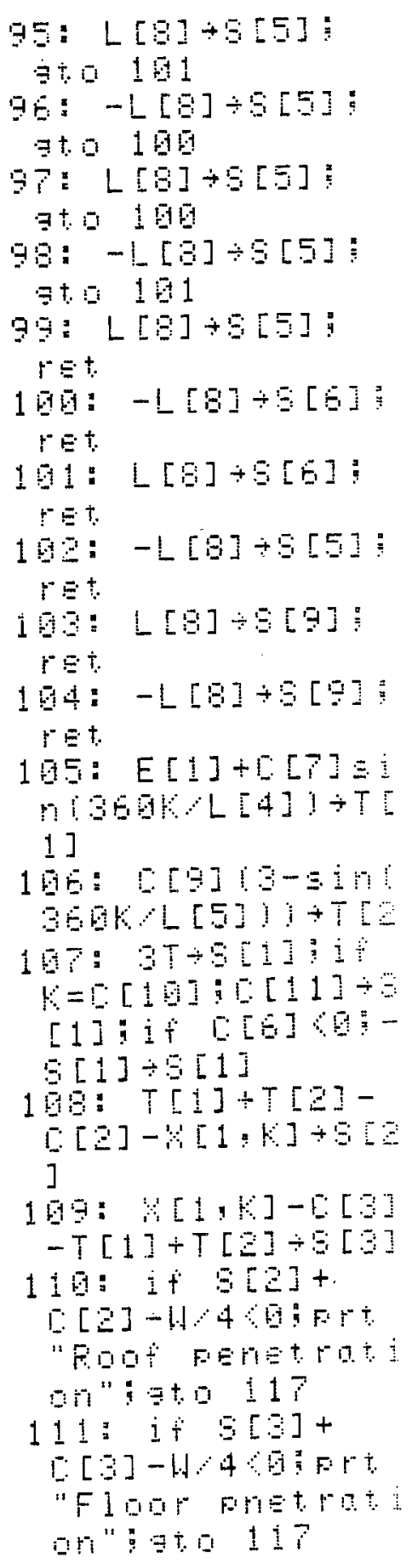

$112: \quad$ if $0 \mathrm{~b}=15[1]$

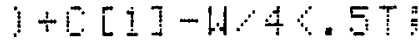
Fit. "Freu= hoI

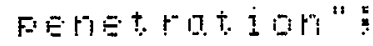
=ti 117

$113:$ if $k=1 ; T[1]$ $L \div g[7]=0115$ 114: [. [1, $]-$ $x[1,[-1], 1 \div 5$ 1

$115: 9+5[6]: 5-$ ridil $1+5[4]$

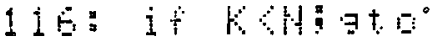
78

117 : $+\mathrm{H}[1]: F$

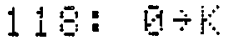

$119: F 1$ t. $690[2]-$ 42

120: $\quad C+1+6$

$121:$ : ․] $-H$

$129: 1514[1]$ 3t. 120

129 : $14[1$

$4[2,1]+1 \cdot 2$

$12 \div \quad 9 \div 6$

$125: K+1+K$

$126: H[1]-k+1$

$127: 01 \mathrm{t} \quad \mathrm{I}:[2$ $11+1.12$

128 if

199 to 125

$129:$ Fit. 42

130 FEn $6+19$

$19: \quad$ it $2=390$ 57

$12:$ an: $2+2$

ํ. 51

42946 


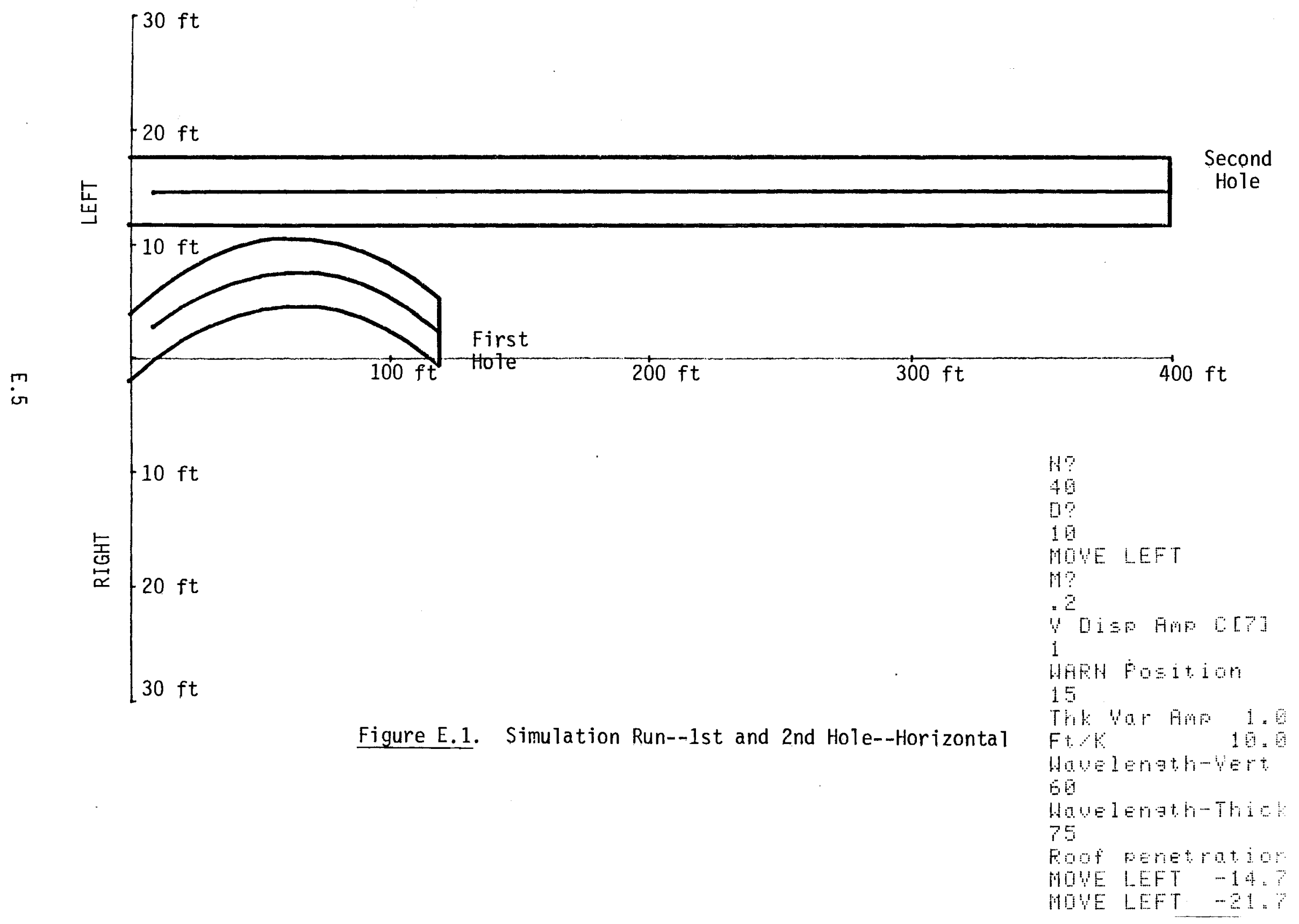




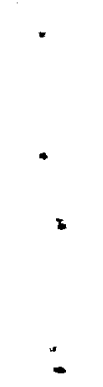

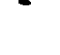


APPENDIX F

LIST OF SYMBOLS USED IN THE GUIDANCE SOFTWARE 


\section{APPENDIX $F$}

\section{LIST OF SYMBOLS USED IN THE}

GUIDANCE SOFTWARE

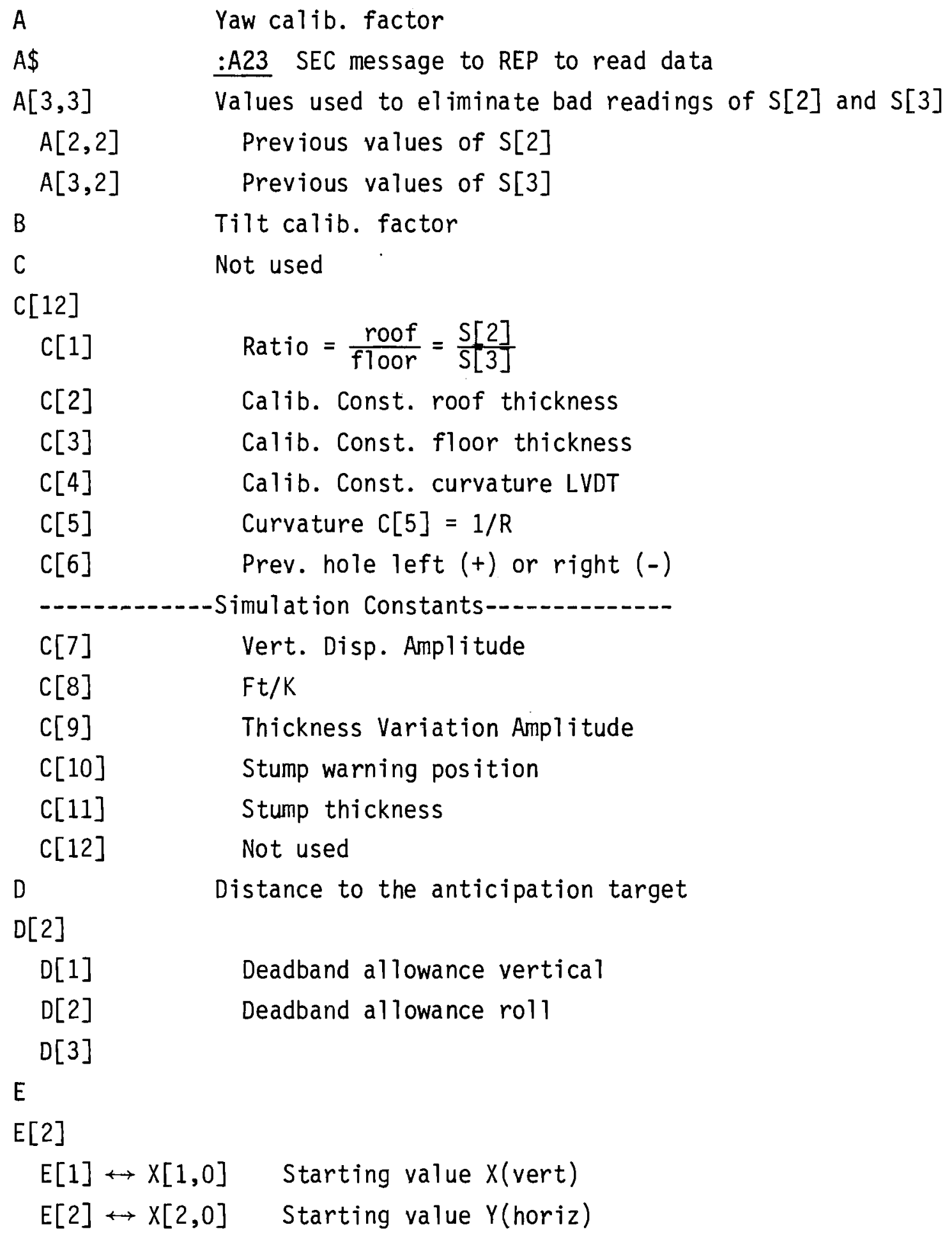




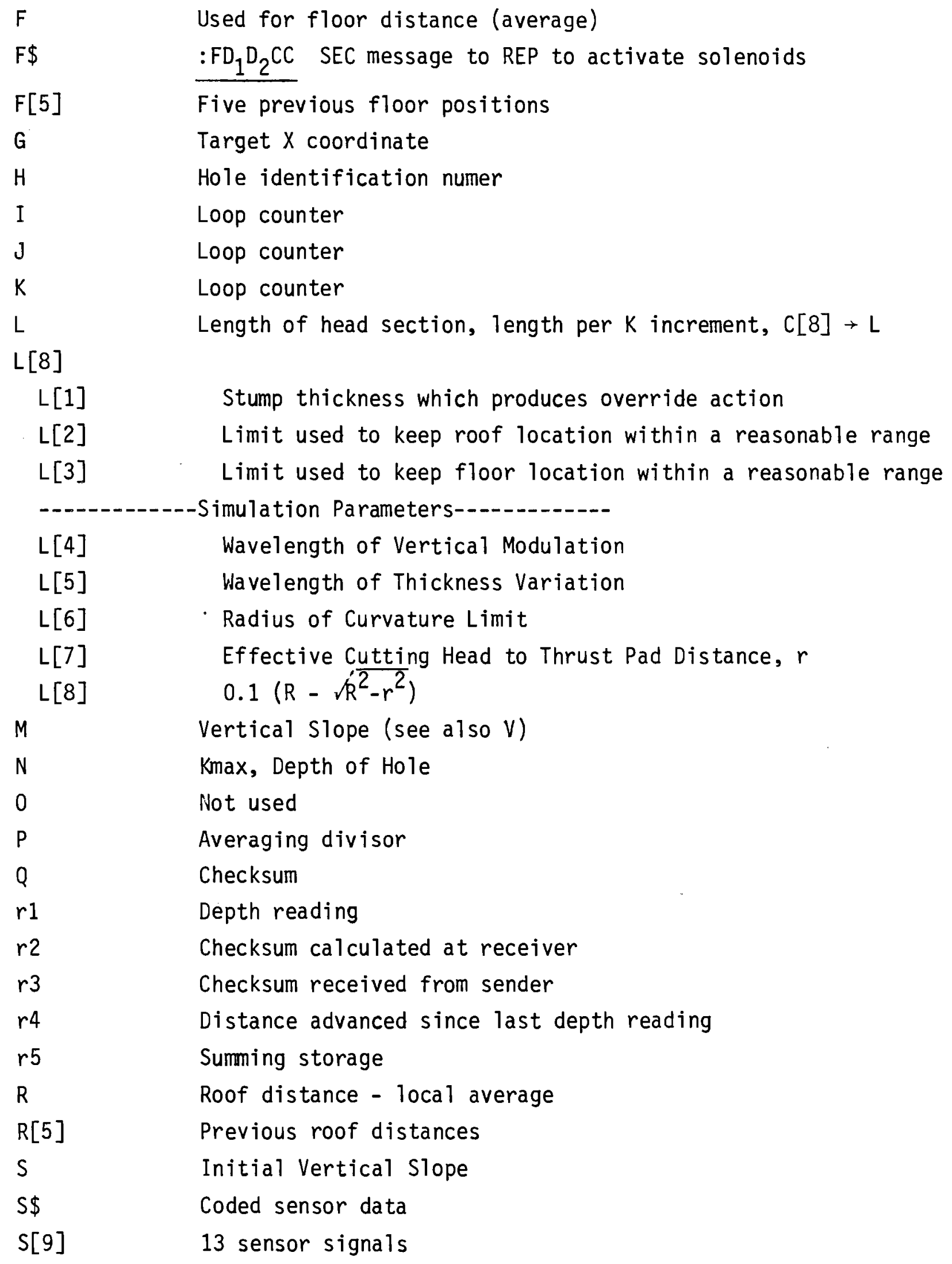

Used for floor distance (average) $: \mathrm{FD}_{1} \mathrm{D}_{2} \mathrm{CC}$ SEC message to REP to activate solenoids

Five previous floor positions

Target $X$ coordinate

Hole identification numer

Loop counter

Loop counter

Loop counter

Length of head section, length per $K$ increment, $C[8] \rightarrow L$

Stump thickness which produces override action

Limit used to keep roof location within a reasonable range

Limit used to keep floor location within a reasonable range

Wavelength of Vertical Modulation

Wavelength of Thickness Variation

- Radius of Curvature Limit

Effective Cutting Head to Thrust Pad Distance, $r$

$$
0.1\left(R-\sqrt{R^{2}-r^{2}}\right)
$$

Vertical Slope (see also $V$ )

Kmax, Depth of Hole

Not used

Averaging divisor

Checksum

Depth reading

Checksum calculated at receiver

Checksum received from sender

Distance advanced since last depth reading

Summing storage

Roof distance - local average

Previous roof distances

Initial Vertical Slope

Coded sensor data

13 sensor signals 


\begin{tabular}{|c|c|}
\hline$S[1]$ & Stump thickness \\
\hline$S[2]$ & Roof thickness \\
\hline$S[3]$ & Floor thickness \\
\hline$S[4]$ & Roll inclinometer reading \\
\hline$S[5]$ & Left LVDT - Up Down \\
\hline$S[6]$ & Right LVDT - Up Down \\
\hline$S[7]$ & Tilt inclinometer \\
\hline$S[8]$ & Yaw measurement - Gyro output \\
\hline$S[9]$ & $\begin{array}{l}\text { LVDT - Left-Right - Relates to curvature and calculation } \\
\text { of position in the horizontal plane }\end{array}$ \\
\hline$S[10]$ & Torque - Left \\
\hline$S[11]$ & Thrust - Left \\
\hline$S[12]$ & Torque - Right \\
\hline$S[13]$ & Thrust - Right \\
\hline$T$ & Desired Stump thickness \\
\hline \multicolumn{2}{|l|}{$T[2]$} \\
\hline$T[1]$ & Simulated value of $X[1, K]$ \\
\hline$T[2]$ & Simulated seam thickness \\
\hline$U$ & Extreme value of $U[2, K]$ \\
\hline V & Not used \\
\hline W & Auger width \\
\hline \multicolumn{2}{|l|}{$x$} \\
\hline \multicolumn{2}{|l|}{$x[2,600]$} \\
\hline$x[1, \mathrm{~K}]$ & Vertical trajectory \\
\hline$x[2, k]$ & Horizontal trajectory \\
\hline \multicolumn{2}{|r|}{ 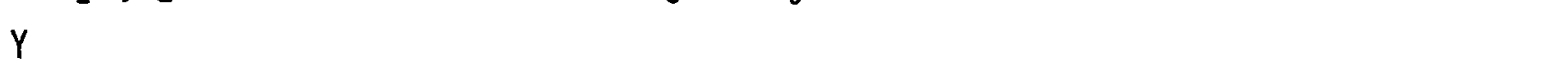 } \\
\hline$Y[26]$ & Decimal value of hexidecimal symbol \\
\hline$z$ & Counter $-z=1$ generates plot of simulated coal seam \\
\hline
\end{tabular}


APPENDIX G

FLOW CHART FOR GUIDANCE PROGRAM

(APPENDIX C) 


\section{APPENDIX G}

\section{FLOW CHART FOR GUIDANCE PROGRAM}

(APPENDIX C)

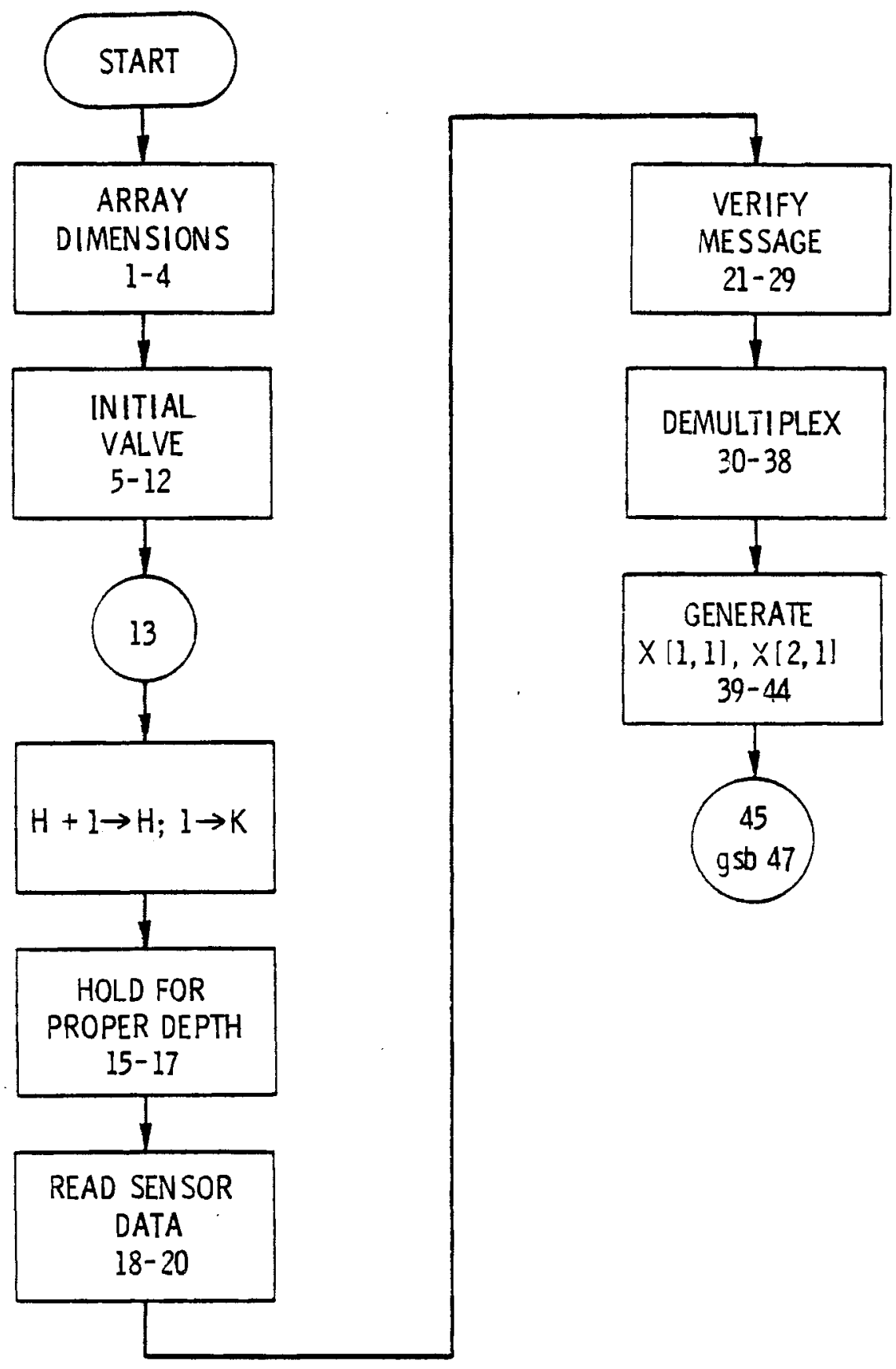

G.1 


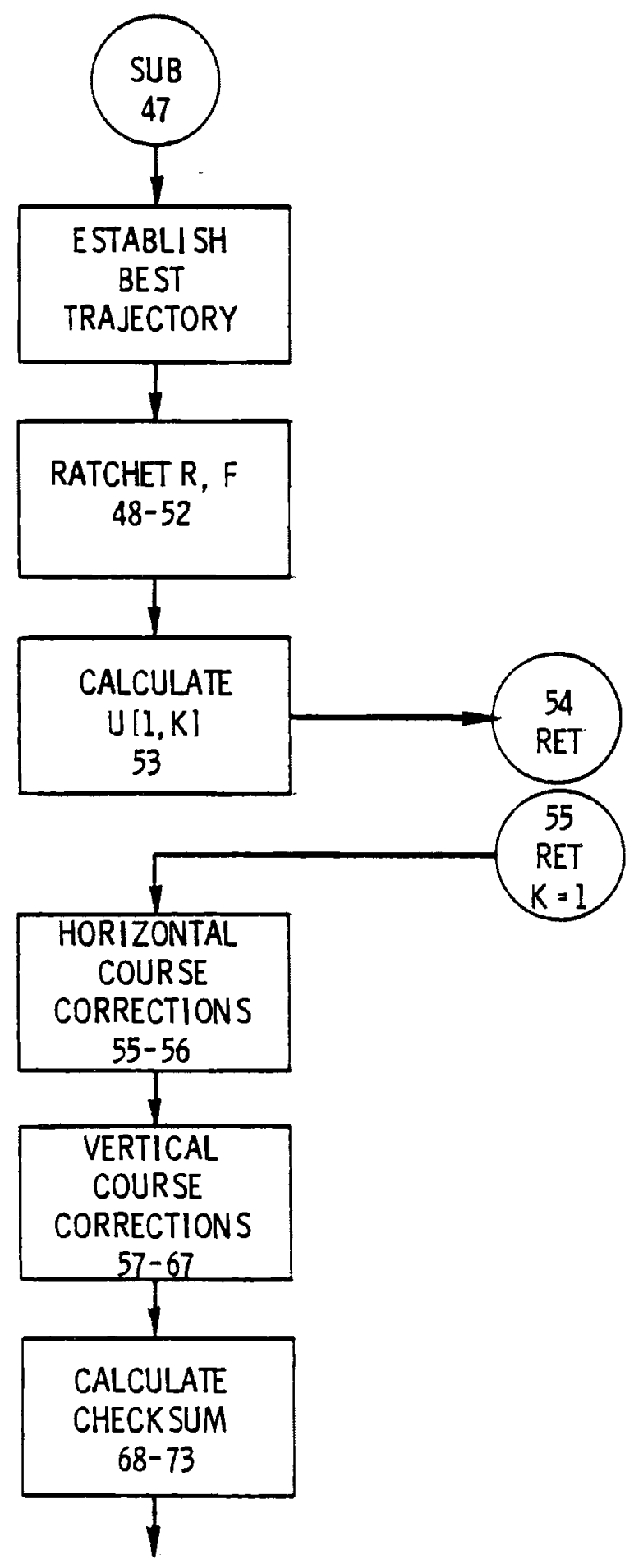

G.2 


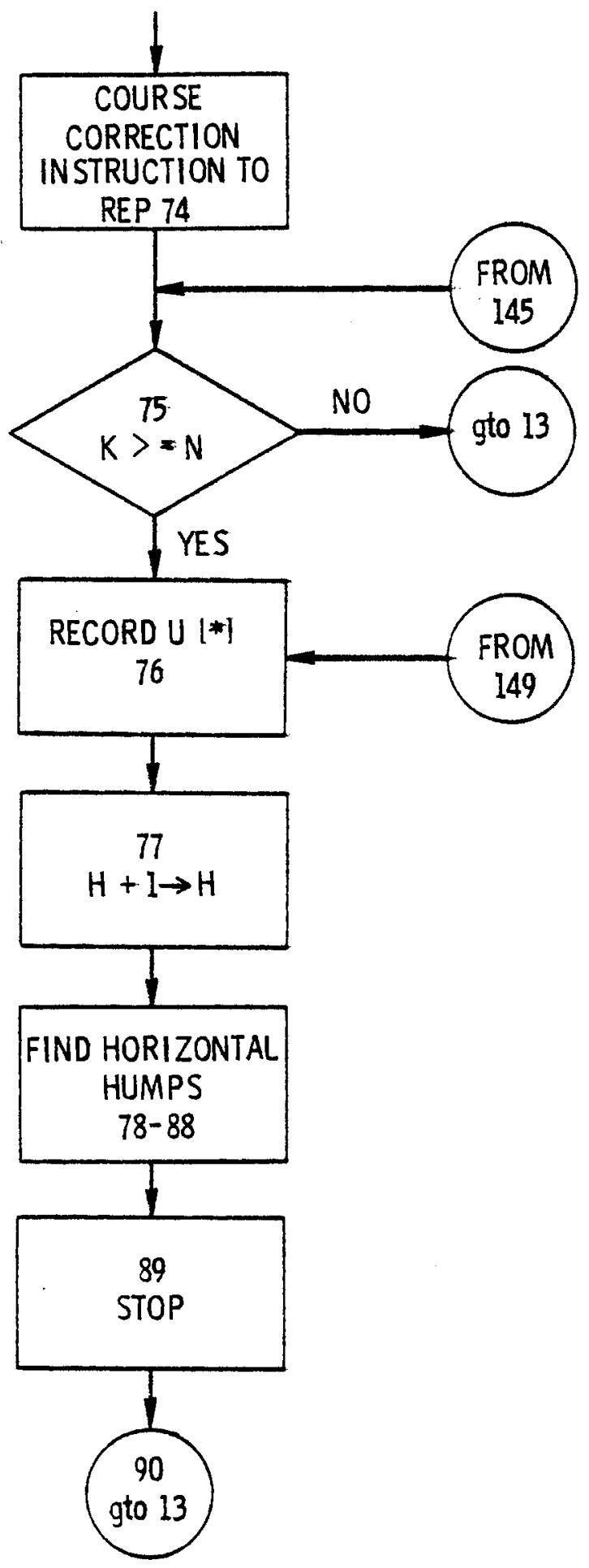

G. 3 


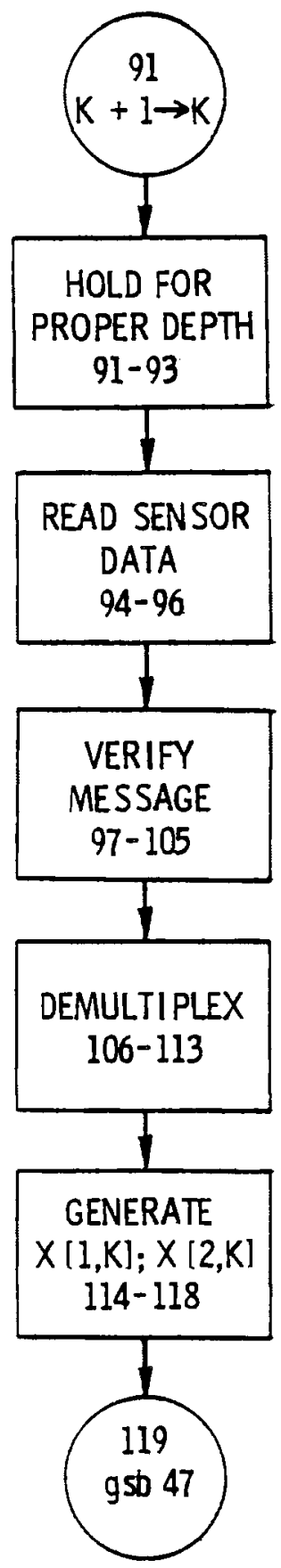

G. 4 


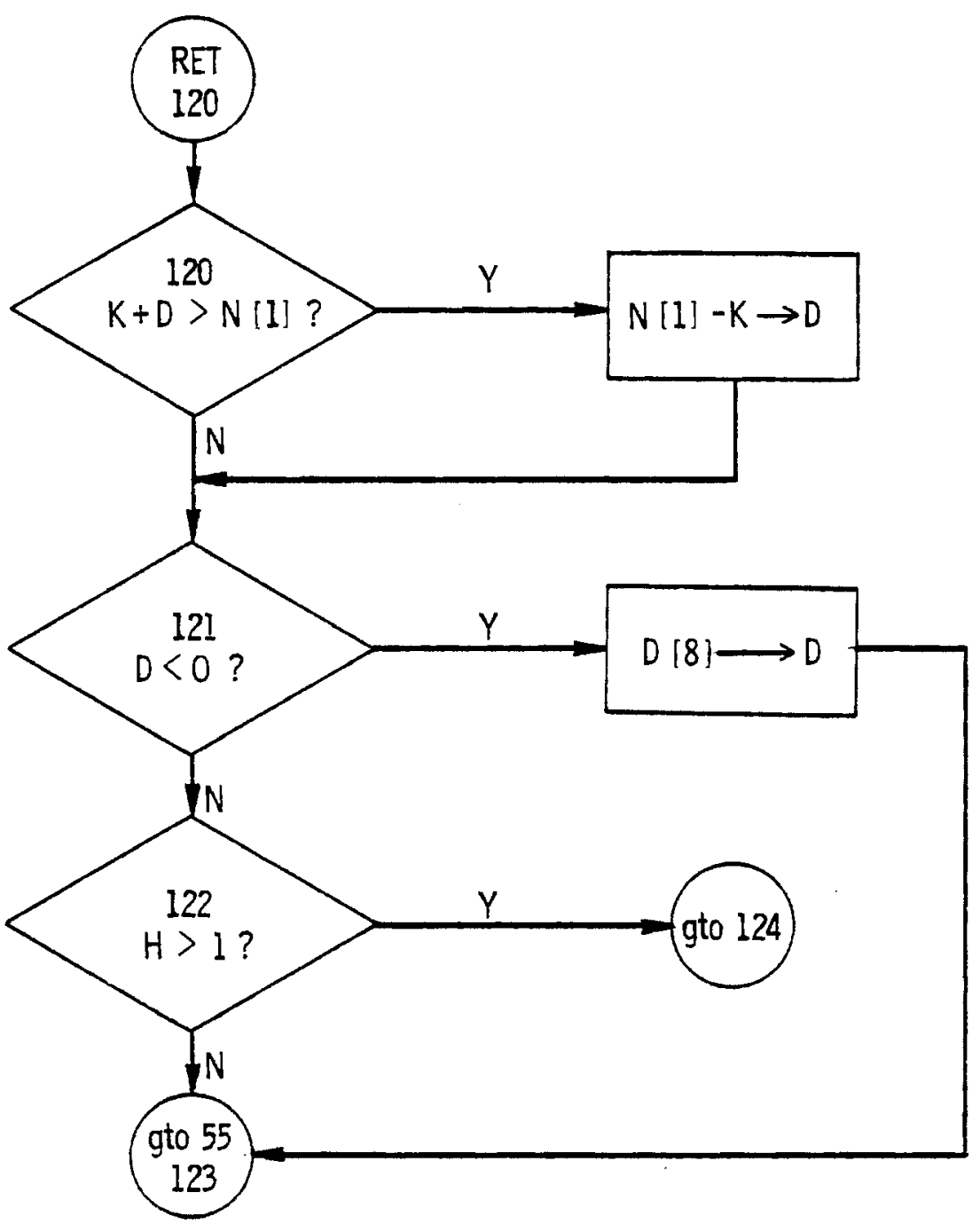




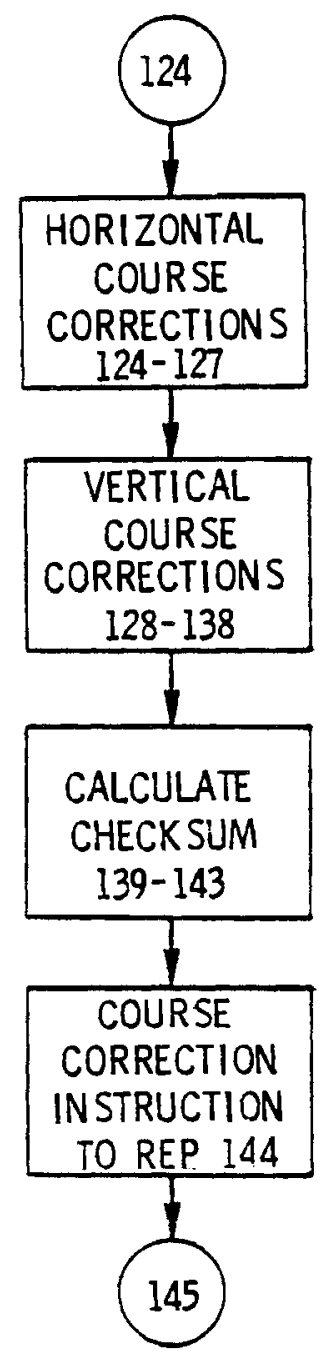

G. 6 


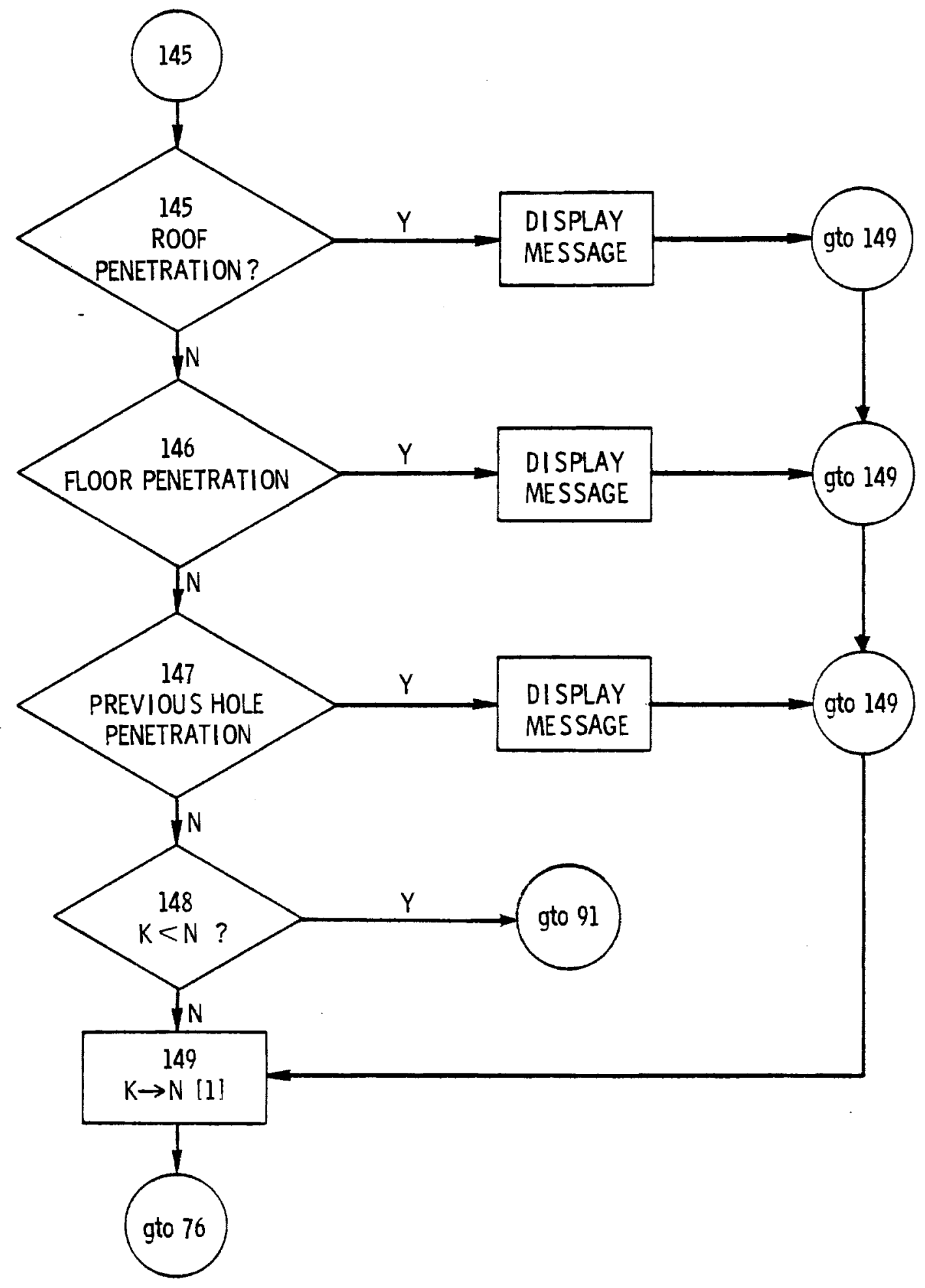

G.7 



\section{DISTRIBUTION}

No of

Copies

\section{OFFSITE}
A.A. Churm
DOE Patent Division
9800 S. Cass Avenue
Argonne, IL 60439

Eugene Palowitch

U.S. Department of Energy

Pittsburg Mining Technical Center

4800 Forbes Avenue

Pittsburg, PA 15213

William Schmidt

Director, Office of Coal Mining

Division of Fossil Fuel Extraction

U.S. Department of Energy, D-107

Wa shington, D.C. 20545

27 DOE Technical Information Center

Richard Farrar

Carbondale Mining Research Center

P.0. Box 2587

Carbondale, IL 62901

D.E. Rasmussen

Battel le-Northwest

North 9508 Division

Suite E

Spokane, WA 99218

ONSITE

DOE Richland Operations Office

H.E. Ransom

17 Pacific Northwest Laboratory

B.B. Brenden (5)

W.I. Enderlin

M.A. Lind

G.P. Morgen

J.R. Skorpic

A.M. Sutey

Publ ishing Coordination (2)

Technical Information (5) 
: . 